University of Louisville

ThinkIR: The University of Louisville's Institutional Repository

Electronic Theses and Dissertations

$5-2010$

\title{
Evaluation of the field application of the Air Void Analyzer in quality control.
}

David Todd Kessinger 1971-

University of Louisville

Follow this and additional works at: https://ir.library.louisville.edu/etd

\section{Recommended Citation}

Kessinger, David Todd 1971-, "Evaluation of the field application of the Air Void Analyzer in quality control." (2010). Electronic Theses and Dissertations. Paper 739.

https://doi.org/10.18297/etd/739

This Master's Thesis is brought to you for free and open access by ThinkIR: The University of Louisville's Institutional Repository. It has been accepted for inclusion in Electronic Theses and Dissertations by an authorized administrator of ThinkIR: The University of Louisville's Institutional Repository. This title appears here courtesy of the author, who has retained all other copyrights. For more information, please contact thinkir@louisville.edu. 
EVALUATION OF THE FIELD APPLICATION OF THE AIR VOID ANALYZER IN QUALITY CONTROL

\author{
By \\ David Todd Kessinger \\ B.S., University of Louisville, 2007
}

\begin{abstract}
A Thesis
Submitted to the Faculty of the

University of Louisville

J.B. Speed School of Engineering

In Partial Fulfillment of the Requirements

For the Professional Degree
\end{abstract}

MASTER OF ENGINEERING

Department of Civil and Environmental Engineering

May 2010 

EVALUATION OF THE APPLICATION OF THE AIR VOID ANALYZER IN QUALITY CONTROL

Submitted by:

David Todd Kessinger

A Thesis Approved on

(Date)

by the Following Reading and Examination Committee:

Dr. Zhihui Sun, Thesis Director

Dr. J.P. Mohsen

Dr. James Lewis 


\section{ACKNOWLEDGEMENTS}

The author would like to first and foremost thank God for allowing him the time and energy and support to obtain the standing to be a part of the research and writing of this paper. The author would like to thank Dr. Zhihui Sun for her interest and support during this research and guidance while writing this thesis. The author would also like to thank Dr. J.P. Mohsen for his insight and input into the research and thesis. The author would like to thank Dr. James Lewis for his insight and service on the thesis committee; Dr. Moran, Bernard Roach P.E. and Carl B. Jenkins P.E. for seeing in me what he didn't see himself. The author would also like to thank Mom and Dad for their love and support. The author would also like to thank his wife, Shannon, and children Riley, Kaden, Leah, and Dylan. Financial support from Kentucky Transportation Cabinet through University of Kentucky Research Foundation is also appreciated. 


\begin{abstract}
Three lab concrete mixes and one field concrete mix were evaluated to establish the Air Void Analyzer (AVA) as a means of real-time, "In-the-Field", Quality Control testing method. In this study, both the Air Void Analyzer and conventional test methods were used to examine each concrete mix. Each mix was evaluated three times to record a total of twelve tests. Experimental data were organized to allow direct comparison of different testing methods. The air volume, the spacing factor, and the specific surface area that were obtained from the Air Void Analyzer tests were correlated to the durability index and total air volume that were measured with traditional methods. The research shows that the durability of concrete is governed by the structure of air void system, which is represented by the spacing factor and the specific surface area. To use AVA as a field quality control method, one should pay attention to leveling, power supply, and especially the temperature of testing liquids.
\end{abstract}




\section{TABLE OF CONTENTS}

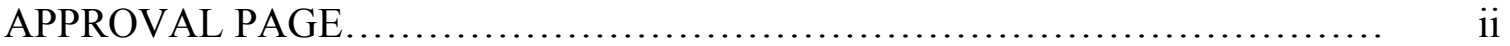

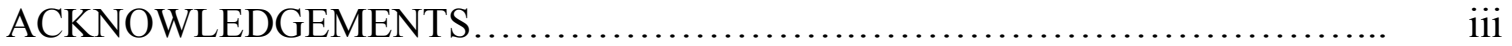

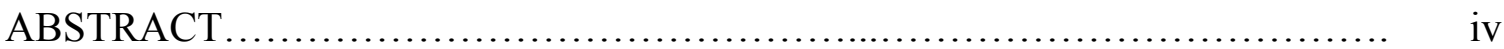

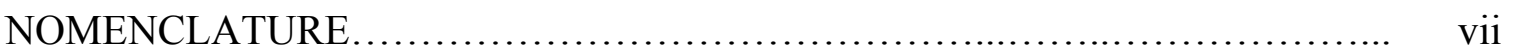

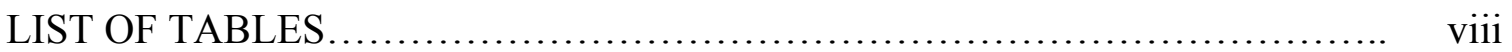

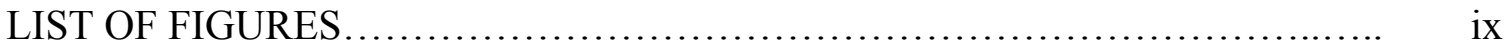

I. INTRODUCTION ................................................. 1

A. Background Information.................................. 1

B. Purpose of Research....................................... 3

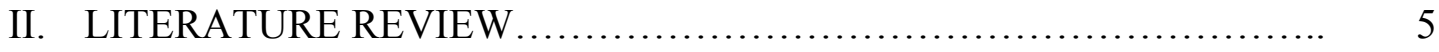

III. EQUIPMENT .................................................. 9

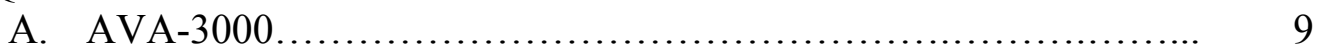

B. AVA-3000 PC Software ...................................... 9

C. Computer and Printer.......................................... 10

D. Sampling Equipment....................................... 10

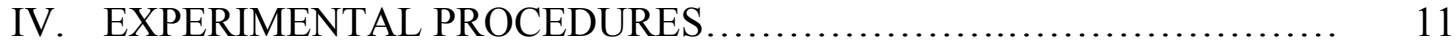

A. Setting up the Air Void Analyzer............................... 11

B. Preparing to Obtain Sample.................................. 14

C. Obtaining Samples......................................... 15

D. Preparing Samples.......................................... 15

E. Operating Air Void Analyzer.................................... 16

F. Exporting Information from AVA 3000 Software................. 18

G. Compiling Data......................................... 18

H. Analyzing Data........................................... 19

I. Complementary Tests......................................... 19

J. Complementary Experiments - Resistance of Concrete to freeze-thaw............................................... 20

V. RESULTS AND DISCUSSION.................................... 21

A. Raw Material and Sample Preparation.......................... 21

B. Mix Designs............................................... 26

1. Presentation of Mix Designs and Test Values.............. 27

a. Lab Mix Design Proportions..................... 27

b. Field Mix Design Proportions.................... 28

c. Mortar and Paste Volume....................... 29

C. Test Results and Discussion.................................. 31

1. Presentation of Results.............................. 31

2. Evaluation of Results................................. 34

a. Durability Factor versus Various Material
Parameters........................................................... 34

b. Compressive Strength versus Various Material

c. Total Air Pressure versus the AVA \% of Air....... 43 
D. Conclusions.............................................. 45

VI. OBSERVATIONS................................................. 47

VII. RECOMMENDATIONS ........................................... 50

REFERENCES ....................................................... 53

APPENDIX 1 - CALCULATION EXAMPLES .............................. 56

APPENDIX 2 - AVA-3000 DATA SHEETS ................................ 60

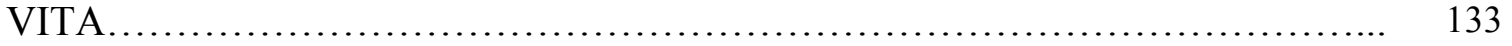




\title{
NOMENCLATURE
}

\author{
${ }^{\circ} \mathrm{F} \quad$ Degrees Fahrenheit \\ ${ }^{\circ} \mathrm{C}$ Degrees Celsius
}




\section{LIST OF TABLES}

TABLE I COARSE AGGREGATE PROPERTIES ....................... 22

TABLE II COARSE AGGREGATE GRADATION.......................... 23

TABLE III FINE AGGREGATE PROPERTIES......................... 23

TABLE IV FINE AGGREGATE GRADATION............................... 24

TABLE V LAB MIX PROPORTIONS .................................. 28

TABLE VI $\quad$ FIELD MIX DESIGN........................................ 29

TABLE VII MORTAR \& PASTE VOLUMES ............................. 30

TABLE VIII LAB TEST RESULTS OF CONCRETE WITH SYNTHETIC

ENTRAINER ........................................... 32

TABLE IX FIELD TEST RESULTS..................................... 33

TABLE $X \quad$ LAB TEST RESULTS OF NON-ENTRAINED CONCRETE........ 33

TABLE XI LAB TEST RESULTS OF CONCRETE WITH VINSOL RESIN.. 34 


\section{LIST OF FIGURES}

FIGURE 1 - Durability Factor versus AVA Spacing Factor.................. 35

FIGURE 2 - $\quad$ Durability Factor versus AVA Specific Surface Area............. 36

FIGURE 3 - $\quad$ Durability Factor versus Total Air, Pressure Method.............. 37

FIGURE 4 - $\quad$ Durability Factor versus AVA \% of Air......................... 38

FIGURE 5 - Compressive Strength versus Specific Surface Area............. 39

FIGURE 6 - Compressive Strength versus Spacing Factor................... 41

FIGURE 7 - Compressive Strength versus Total Air, Pressure Method......... 42

FIGURE 8 - Compressive Strength versus AVA \% of Air................... 43

FIGURE 9 - $\quad$ AVA \% of Air versus Total Air, Pressure Method............... 42

FIGURE 10 - Total Air, Pressure Method versus AVA \% of Air................. 45 


\section{INTRODUCTION}

\section{A. Background Information}

Concrete is a mixture of water, cement, sand, and coarse aggregates, which after mixing, it slowly changes from a liquid to a solid due to the hydration of cement. The cement-bound microstructure provides the concrete with strength and durability. Research has shown that concrete does not become completely solid during its service life; it always remains, to some degree, porous, which greatly affects its performance when it is subjected to freeze-thaw cycles. Across the United States, most Departments of Transportation require certain porosity ranges when casting different classes of concrete. For example, Kentucky Transportation Cabinet requires jointed concrete pavement (JPC) and other commonly used concretes (Class A, AA, Class M), to have a porosity within the range of $6 \pm 2 \%$ (KYTC 2008). Researchers have found that the durability of concrete is not only related to the total volume of air voids, but more importantly, the structure of the air voids. The two main parameters in describing air

void structure are: spacing factor and specific surface area. Spacing factors are used to describe the distance between air voids and specific surface area describes the size distribution (Tanesi 2006).

The expansion of water during freezing (volume change) is what causes damage to a concrete's structure, by damaging the aggregate and/or the cement bonds within the paste. The ability to withstand the freeze and thawing effects caused by temperature 
changes, will leave concrete more durable and will provide a longer lasting life cycle for any application. Durability is achieved by building an air void system that does not allow the internal pore pressure (osmotic pressure) to build beyond the internal strength of the mix structure during volume change, as this is what cracks concrete (Powers 1975). Along with total air content, the specific surface and spacing factor make up the definition of an "air void system", but what they control is of the same importance, pore pressure. Porosity is important in determining the strength and stability of hardened concrete. Capillary pores, which are channels between two pores, between pores and air bubbles, or between two air bubbles, allow movement of water during freezing. The fewer pore spaces that exist in concrete, the stronger it will become; however, the more pore spaces that exist in concrete, the more durable it may become. Therefore, when designing a concrete mixture, it is important to optimize its internal pore structure to have both strength and durability in consideration (Cordon 1966).

To create the desired air void system, entrained air is needed to supplement entrapped air, which is created in a concrete mix during mixing and placement. Entrained air is added during mixing to increase the total air content while attempting to "build" the spacing factor and specific surface areas to their desired values. When entrained air is introduced in the mix, the aggregate is incased by a cement paste consisting of air voids, which allow space for volume change to occur during freezing. These voids additionally allow any excess water contained in the aggregate, to have a place to expand or to be forced into (Powers 1975). 
Currently the Commonwealth of Kentucky uses slump tests and air volume measurements for field quality control. The air content of concrete is normally determined by the pressure method described by Kentucky Method 64-303-08 AIR CONTENT OF FRESHLY MIXED CONCRETE BY THE PRESSURE METHOD, which is a modification of ASTM C-231- 08. As this method only measures the total volume of air voids, the details of the air void structure in the concrete cannot be determined in the field.

To evaluate the air void structure that is represented by spacing factor and specific surface area, one can use the linear traverse method. Currently, this is the only standardized method listed in the ASTM, however it can only be applied to hardened concrete (ASTM C-457-08). To obtain consistent test results from C-457-08, it takes extensive time, possibly weeks, and must be performed by a highly trained technician. Therefore, a method that allows for additional mix parameters to be quantified during a concrete's plastic stage is desired.

Recent work with the Air Void Analyzer (AVA) by the Federal Highway Administration (FHWA) and other entities has shown promise with regards to being able to effectively measure and record values for the entrained air content, spacing factor, and specific surface area within concrete.

\section{B. Purpose of Research}

The air void system of concrete consists of three parameters; air content, spacing factor, specific surface area. Standard testing method currently used on the field only 
measures air content, which leaves the other two parameters unknown. However, researches found that the spacing factor and the specific surface area are the two parameters that govern the freeze-thaw durability of concrete. Thus, it is necessary to have a field-testing method that can provide information about these two parameters. This leads to the objective of this research, which is to evaluate the field application of AVA as a tool to assist the field quality control of concrete. Applying such a field testing method to detect the quality of concrete in terms of durability would allow civil engineers to identify the problem during the construction process and then remix, replace, or recast concrete if needed. This would allow for addressing durability as preventive measures rather than corrective and replacement work after completion of a project. 


\section{LITERATURE REVIEW}

The use of entrained air in concrete began in the early 1930's and has been used, since then, to increase the durability of Portland Cement Concrete. The ability to produce a desired air void system in concrete has been the study of an industry, while trying to develop an admixture that would create a stable air void system during production, delivery, and various forms of placement (Mielenz 1958). To determine what air voids are in concrete, physical tests must be performed on the mixture in question. The most commonly used test methods for determining the percent of air, in a concrete mixture, determines the percent of the total air content. The total air content consists of both entrapped air and entrained air. The four most commonly used methods are:

- $\quad$ ASTM C231-08 - Standard Test Method for Air Content of Freshly Mixed Concrete by the Pressure Method.

- $\quad$ ASTM C138-07 - Standard Test Method for Density (Unit Weight), Yield, and Air Content (Gravimetric) of Concrete.

- $\quad$ ASTM C 173-09 - Standard Test Method for Air Content of Freshly Mixed Concrete by the Volumetric Method.

- $\quad$ AASHTO T199-00 - Air Content of Freshly Mixed Concrete by the Chase Indicator.

In order to determine the actual air void system, including both entrapped and entrained air, the current standard test method must be performed on the concrete in the hardened state. The most commonly used test method for determining the air void system in hardened concrete is: ASTM C-457-08 - Standard Test Method for 
Microscopical Determination of Parameters of the Air-Void System in Hardened Concrete.

ASTM C-457-08 consists of two procedures, which both require taking physical measurements of a prepared hardened concrete specimen. Research continues on the use of different technologies for making the required physical measurement, including the use of flatbed scanners and computer digital modeling.

With the increased pace of industry and construction practices in various parts of the country today, there is a need to have a real time quality control test that is both accurate and dependable. In 1986, Dansk Beton Teknik of Copenhagen, Denmark released the Air Void Analyzer (AVA), which was designed to perform real time air void system analysis. The first AVA, later named the AVA-1000, was fragile during transportation and also had problems with computer compatibility, often requiring a special piece of computer hardware, a driver card, to be installed prior to using the AVA. In the late 1990's the AVA-2000, which was more resistant to transportation, and more technologically advanced, was released from development. To bypass the computer problems, the AVA-2000 came with a laptop computer with the required hardware and AVA software preinstalled, ready for attachment to the AVA equipment, via USB, for testing. The AVA-2000 has been used commercially in a number of European countries, from 1995 to 2006, when it was replaced by the AVA-3000 (Vanikar 2004).

The AVA-3000, which took nearly 10 years to develop, is unaffected by transportation as it is fitted with an encased miniature precision balance. Although rugged, the balance is unaffected by minor vibrations from the equipments immediate 
surroundings, while performing a test. To remove any affects from wind movement, a riser column top or "windshield", has been placed around the tip of the precision balance. Additionally, the need for a hardware driver installation was eliminated by modern microprocessor technology and computer software, while still allowing connectivity between the AVA and the computer via USB (Germann 2006).

The Federal Highway Administration (FHWA) began experimenting with the AVA in 1999, and by 2006, had extended its experimentation to nine states in a variety of applications, including pavements, bridge decks, reinforced slabs, and precast sheet piling. By 2007, the FHWA had extended experimentation into 21 states, listed here in alphabetical order: Arkansas, California, Delaware, Illinois, Iowa, Kansas, Maryland, Michigan, Minnesota, Missouri, Nebraska, Nevada, New York, North Carolina, North Dakota, Oklahoma, Pennsylvania, Texas, Utah, Virginia, and Wisconsin (Disltehorst 2006). In the United States, Kansas has led the nation in developing specifications for specific surface area and spacing factor for concrete pavements. New Jersey has developed a specification for a minimal total air content of $5.5 \%$ for precast piles based on the maximum spacing factor of $0.200 \mathrm{~mm}$ (0.008 in). Iowa State University incorporated the AVA into their mobile concrete lab and has performed extensive testing on concrete pavements and reinforced bridge slabs. Others have experimented or used the technology in limited applications, but have not fully implemented the AVA into their specifications to the extent of Kansas (Magura 1996).

The Kansas Department of Transportation (KDOT) purchased an AVA-2000 in 2001 for the evaluation of fresh concrete samples on select projects. KDOT was trying to 
deal with premature pavement joint deterioration in 10-year-old pavement. In 2002, the AVA-2000 was used for monitoring the placement of pavement and allowed the contractors to make mix changes in real time based on the results. KDOT compiled data from extensive work with the AVA and ASTM C-457-08 equipment and obtained an acceptable offset correlation for the spacing factor and the specific surface area, but not the total air content. The inability to correlate the total air of an ASTM C-457-08 test to another test method is not a main concern. Multiple C-457-08 tests on the same specimen, even by the same technician, can produce conflicting results. The conclusion by KDOT and the FHWA after much research, demonstrated that the AVA technology can produce beneficial information about concrete's air void system characteristics. KDOT performed a case study and determined that the AVA can be used for quality control and real time assessment of concrete mixes, thus providing the contractor with information valuable to making mix modifications during concrete production. By the end of 2002 KDOT had used the AVA on three projects and used it on all applicable projects in 2003. KDOT continues to use of the AVA technology to develop its quality control and acceptance specifications. The current KDOT specifications for specific surface area and spacing factor for concrete pavements is 401 - Concrete, part "g)", Design Air Content; for Portland Concrete Cement Pavements. The specification establishes a minimum total air content of $5.5 \%$ based on the maximum spacing factor of $0.25 \mathrm{~mm}$ (0.010 in) (Magura; KDOT 2007). 


\section{EQUIPMENT}

\section{A. $\quad$ AVA-3000}

The test apparatus for this study was the AVA-3000, which was first introduced in September 2006 following the AVA-2000 from the 1990's and AVA-1000 from the late 1980's. The AVA was developed and manufactured by Dansk Beton Teknik in Copenhagen, Denmark. The AVA-3000 is the most durable of the AVA series, including a miniature precision balance designed to withstand irregular handling as well as being unaffected by vibrations from the immediate surroundings during testing. The AVA3000 consists of a 35-liter (9.2-gallon) water tank base, which serves as a ballast during testing and an upper section consists of the riser column, stirrer, mini precision balance, and windshield. The base tank controls the temperature of the water and the of the release liquid, while allowing the water to de-aerate. The release liquid is stored in two 2-liter (0.528-gallon) bottles that enter through either of two holes in the top of the tank. The water tank uses either $110 \mathrm{~V}$ or $220 \mathrm{~V}$ to calibrate and display the tanks internal temperature.

\section{B. AVA-3000 PC Software}

The included AVA-3000 PC Software, which is compatible only with the Microsoft XP operating system, was installed on a university laptop for testing and recording. The software includes a setup wizard that was used to install the software and setup file folders for the storage of test data. A key component for software and 
equipment compatibility is the need to NOT have a PCMCIA card installed, as the AVA3000 connects via a USB cable. In order for the USB driver to be installed, the included USB cable needs to be plugged into the laptop, as well as the AVA-3000, connecting the devices for data transmission.

\section{Computer and Printer}

The computer used was a Dell laptop running Microsoft XP as its operating system. Different printers can be used for documenting test results, as the printer is not controlled by the AVA-3000 or the AVA-3000 software.

\section{Sampling Equipment}

The sampling equipment used for this research:

- $\quad$ Cordless Percussion Drill - Used to vibrate the wire cage into the concrete mass.

- $\quad$ Three $20 \mathrm{cc}(0.68 \mathrm{oz})$ Syringes - Used to gather the paste sample

- Vibration Isolation Assembly - Attached to the cordless percussion drill and holds the $20 \mathrm{cc}(0.68 \mathrm{oz})$ syringes one at a time.

- Wire Cage - Is attached to the vibration isolation assembly. Prevent coarse aggregate from entering the sample.

- $\quad$ Template with Center Hole - Used to guide the wire cage perpendicular to the concrete mass and to stop the forward motion of the wire cage to prevent over insertion while obtaining the sample.

- $\quad$ Sample Holding Rack and Cooler - Used to contain and protect the three $20 \mathrm{cc}(0.68 \mathrm{oz})$ syringes after obtaining the samples and prior to inserting them into the AVA-3000. 


\section{EXPERIMENTAL PROCEDURES}

\section{A. Setting up the Air Void Analyzer}

A step-by-step procedure was followed by the author for the setup of the AVA with the intent to apply consistency and reliability to the research. The following procedures can be duplicated for setting up the AVA-3000 for the first test and for additional tests.

The AVA-3000 is stored and transported in two aluminum cases. One case contains the laptop, base unit, sample syringes, wire cage and other accessories. The second case houses the water tank used for de-aerating and tempering the water and release liquid, along with other accessories. A description of the AVA components can be found in the Equipment Chapter of this text.

Prior to testing, the AVA needs to be completely set-up and prepared. When testing in the "Lab", one day for preparation was sufficient. To begin set-up, the operator needs to remove the water tank, release agent bottles and accessories from the second case, placing the water tank on a smooth, level, and sturdy table. The water tank should be positioned so that the drain valve is allowed to hang over the front edge of the table, thus allowing the operator to have access to obtain the de-aerated and tempered water during testing. 
With the water tank in position, the set-up process is continued by adding the required liquids. To access the inside of the water tank, the lids need to be removed to expose two openings in the top of the tank. Next, the operator removes the two 2-liter (0.528-gallon) containers, which will be used to contain and temper the release liquid. The tank should now be filled with water, up to at least the \#10 line, which is marked on the fill tube on the front of the water tank. This level of water allows for the heating elements inside the tank to be covered during testing and to remain covered after six individual tests are completed, which equals the water needed for a total of two samples.

Recognizing that multiple tests are going to be performed, the 2-liter ( 0.528 gallon) containers need to be sufficiently filled to provide a minimum of $200 \mathrm{ml}(6.8 \mathrm{oz})$ of release liquid for each test. Once filled, the containers should be placed into the tank allowing for tempering. With the release agent in place, the lids should be replaced to prevent contamination of the contents of the tank. Finally, with the controls of the water tank plugged in to an electrical outlet, the tempering process can begin. The tank is now ready to have the riser unit attached.

The riser unit is placed on top of the water tank and held in position by two 8-mm (0.32 inch) screws. Prior to running the AVA-3000 software, place the laptop near the AVA, and connect the two using the included USB cable. The laptop will recognize that the AVA is ready for testing, once the base unit is connected to an electrical outlet and activated. Before starting a test, sample information and mix design information need to be entered into the AVA software by the operator to aid in the calculation of the test data. 
To prepare the rising column, inspect the o-rings that hold seal to the piston by turning the o-rings with a dry cloth, removing any excess water or mortar from prior tests. Next, place the stirrer rod in the bottom of the riser column. Prior to inserting the piston, place a small amount of the silicone gel on the surface of the piston to assist with maintaining the required seal. After the riser column is assembled, place it on the base unit and fasten it firmly using two 6-mm (0.24 inch) screws. Fill the riser column with water to just above the top of the piston assembly, and use the long handled brush to remove air bubbles created from filling the column.

Once the bubbles have been removed, the next step is to fill the riser column with the tempered, de-aired water and release liquid. Start by placing the funnel into the riser column, letting the tip of the funnel rest just above the bottom of the riser column base. Next, remove a 2-liter (0.528-gallon) container of release agent and slowly add the release liquid into the riser column through the funnel, allowing the liquid to remain unmixed in the bottom. After $200 \mathrm{ml}(6.8 \mathrm{oz})$ of the release liquid is deposited in the riser column base, slowly remove the funnel so that movement of the release liquid is minimal.

Ensure that the water level is 2 to $3 \mathrm{~mm}$ ( 0.08 to $0.12 \mathrm{inch}$ ) above the top edge of the riser column; if not, remove or add accordingly. Place the buoyancy dish into the top of the riser column at an angle allowing no air to remain trapped under the dish. Use the opening in the side of the dish to remove any remaining air bubbles. With the buoyancy dish free of trapped air, hang the dish on the balance in the top of the AVA and place the 
windshield on the top of the riser column. Set-up of the AVA is now complete, and the device is ready to receive a sample.

\section{B. Preparing to Obtain Sample}

In preparation for testing a sample, the technician needs to ensure the device is prepared for operation. Once the AVA has been prepared for testing and the computer is ready to record data, the remaining steps are to prepare for actual sample extraction. In the lab, the use of a corded electric percussion drill is desirable; however, in the field, a cordless percussion drill is required due to the necessity of mobility. Once the percussion drill type is chosen, attach the vibration isolation assembly to the percussion drill, with the wire cage attached on the end as an extension. The cage is made of brass and is held in place by friction between the assembly and the base of the cage. At this point, the first $20-\mathrm{cc}(0.68-\mathrm{oz})$ syringe can be prepared for insertion into the core of the vibration assembly prior to placing the syringe in the drill apparatus, pull the plunger to the base of the syringe, fully opening the tube, to allow for concrete paste to completely fill the entire volume of the syringe; this allows for excess paste, which can be later removed. Once the syringe is inserted into the vibration isolation assembly, the base of the plunger is held in place while still allowing the movement of the clear section of the syringe into which the sample will be drawn. Depending on the physical proximity of the sample area to the testing area, a cooler may be used to gather and transport the samples, as it was in all situations during this research. The cooler and the clear Plexiglas template with center hole, need to be ready for use prior to approaching the freshly placed concrete to be sampled. 


\section{Obtaining Samples}

After the placement process is complete and the concrete to be tested is in the desired condition, the center hole template is gently placed on the concrete's surface. This is after the concrete has been mixed, transported, placed, and finished. Once the template has good contact with the concrete's surface, the percussion drill is used to vibrate the wire cage into the concrete mass through the center hole of the template. The rate of speed at which the sample is taken is heavily dependant on the slump and aggregate size of the concrete. While lowering the cage, ensure that the surface elevation of the concrete is the same inside of the cage as it is surrounding the cage, as this will prevent any lateral movement of the paste inside of the cage. Lateral movement reduces the integrity of a sample.

Once the wire cage is completely inserted into the concrete mass, the collar of the cage should be resting against the center hole template. At this time, extend the clear syringe body into the concrete mass with a smooth and consistent movement, lasting 3 to 4 seconds. Once the syringe movement is complete, discontinue the operation of the percussion drill. To remove the sample from the concrete mass, lift the percussion drill, vibration assembly and wire cage from the concrete mass in one consistent movement, while holding the syringe in place.

\section{Preparing Samples}

Preparation of the syringe is the next step after the samples are obtained. In order to ensure that the sample is exactly $20-\mathrm{cc}(0.68-\mathrm{oz})$, the operator must remove any excess paste gathered by extruding it from the end of the syringe and removing it with a small 
knife, while at the same time keeping the end of the sample smooth, and without creating entrapped air voids. After the paste volume is correct and the open end of the syringe is correctly prepared, completely clean the outer surface including the plunger shaft to ensure that excess paste is not allowed to build up, as this will weaken the syringe and will cause loss of movement that is required for obtaining future samples. Additionally, removing the excess paste from the outer surface of the syringe increases the number of tests that can be run prior to having to inspect the o-rings that hold seal to the piston. When the sample syringe is completely cleaned off and prepared, pull the plunger back to create a gap at the top of the syringe that is equal to the extended length of the plunger; this area allows for the syringe to be later joined to the end of the piston without causing damage to the sample. The process also creates a large air bubble that will be seen during positioning the sample into the base of the riser column, which will be released prior to beginning the test and is not recorded as air in the sample.

\section{E. Operating Air Void Analyzer}

Some of the steps required for setting up the AVA are repeated in this section for the purpose of illustrating which steps are required for setting up the equipment 24 hours prior to testing, and which steps are repeated for performing multiple tests in series.

Between tests, inspect the o-rings that create the seal for the piston. Turn the orings using a dry cloth, removing any excess water or mortar from prior tests. Next, place the stirrer rod in the bottom of the riser column. Prior to inserting the piston, place a small amount of silicone gel on the surface of the piston to assist with maintaining the required seal. Place the riser column on the base unit after it is assembled, and fasten it 
down firmly using two 6-mm (0.24-inch) screws. Fill the riser column with water to just above the top of the piston assembly, and use the long handled brush to remove air bubbles created from filling the column.

Once the bubbles have been removed, the next step is to fill the riser column with the tempered, de-aired water and release liquid. Start by placing the funnel into the riser column, letting the tip of the funnel rest just above the bottom of the riser column base. Next, remove a 2-liter (0.528-gallon) container of release agent and slowly add the release liquid into the riser column through the funnel, allowing the liquid to remain unmixed in the bottom. After 200-ml (6.8-oz) of the release liquid is deposited in the riser column base, slowly remove the funnel so that movement of the release liquid is minimal.

Ensure that the water level is 2 to $3 \mathrm{~mm}$ ( 0.08 to 0.12 inches) above the top edge of the riser column; if not, remove or add accordingly. Place the buoyancy dish into the top of the riser column at an angle allowing no air to remain trapped under the dish. Use the opening in the side of the dish to remove any remaining air bubbles. With the buoyancy dish free of trapped air, hang the dish on the balance in the top of the AVA; and place the windshield on the top of the riser column. Set-up of the AVA is now complete and the device is ready to receive a sample.

Part of the process of receiving a sample into the AVA is positioning the sample syringe into the base of the riser column and backing out the piston to a position that retains the integrity of the sample and at the same time is out of the way of the path of the sample being injected. Once this is completed the test is ready to begin. With the laptop 
connected to the AVA and the AVA ready to receive a sample, advance the software to begin testing. Once the stir rod begins to rotate, inject the $20-\mathrm{cc}(0.68-\mathrm{oz})$ sample into the column and protect the system from any accidental movement. Within 25 minutes, the test will be complete and the results will be accessible on the computer screen or by computer file used for export.

\section{F. Exporting Information from AVA 3000 Software}

In order to export the data, the author decided to use the method of printing the reports generated by the AVA software as *.pdf files. Exporting the data into a spreadsheet is possible with the AVA-3000 software, but the formatting steps involved made the spreadsheet method less desirable and more time consuming. Once the reports are generated and printed, values for the spacing factor, specific surface area, and AVA \% of air can be easily compiled into a spreadsheet for data analysis.

\section{G. Compiling Data}

Following the data export, the AVA data has to be manually entered into spreadsheet software which has the capability to compare strings of data, as well as provide the ability to present the data values in visual formats such as charts and graphs. This approach was also chosen as a quick and efficient platform to present and compare data from this and other research projects. The values of the AVA data are shown in Appendix 2 with the lab tests grouped first and the field tests grouped second. In addition to the Appendix 2, the data from all complementary tests and complementary experiments are found in the body of this text in Chapter V. 


\section{H. Analyzing Data}

The AVA software uses the data from the device to generate reports that include the AVA \% of air, the spacing factor and the specific surface area, which are indications of the durability of hardened concrete. The measurement of the AVA \% of air, spacing factor, and specific surface area during placement of concrete can be used as real-time Quality Control by the industry. For the AVA to be accepted by the industry and eventually become considered a conventional test, a sense of comfortability must be achieved. This text compares and verifies AVA results to those of current conventional test methods.

\section{Complementary Tests}

The author performed complementary tests in conjunction with the AVA tests. For these and the AVA tests, the concrete was sampled per (Kentucky Method) KM 64301-08 (ASTM C-172). The conventional tests that were run included the slump, unit weight, total air content, temperature, and cylinder compressive strength. The slump test was performed according to KM 64-302-08 (ASTM C-143), while the unit weight was measured per KM 64-324-08 (ASTM C-138-07). The total air content was tested using the pressure method per KM 64-303-08, which is a modification of ASTM C-231-08; and the temperature of the concrete was tested according to KM 64-318-08 (ASTM C-1064). The concrete cylinder specimens were made per KM 64-305-08, which is a modification of ASTM C-31-09, and were capped per ASTM C-617. Finally, the cylinders were tested per ASTM C-39 which is different from KM 64-317-08 (ASTM C-1231), and the cylinder compressive strength results were evaluated per KM 64-314-08. 
J. Complementary Experiment - Resistance of Concrete to freeze-thaw

To perform the additional experiments for volume change per ASTM C-666-03, additional specimens were required. In addition to the AVA samples taken during placement of the concrete mix, prism specimens for freeze and thaw resistance testing were cast per ASTM C-31-09 for use by another student who performed the freeze-thaw experiment per ASTM C-666-03. 


\section{RESULTS AND DISCUSSION}

\section{A. Raw Material and Sample Preparation}

The concrete mixes used in laboratory testing were completely controlled. To ensure the ability for repetition, all ingredients included were kept inside, in the basement of the University. The lab environment allowed for consistent ambient air temperature control as well as consistent humidity control. After the first two sessions of testing, all ingredients became normal from session to session. Prior to beginning any testing, the following ingredients were delivered to the university: Type I Portland cement, air entrainment, coarse aggregate, fine aggregate, with the water being available by municipal tap. Type I Portland cement (ASTM C-150, AASHTO M85), river sand, limestones, and various types of air-entraining agents were used in this study.

Air entrainment is used to purposely introduce and stabilize microscopic air voids in the concrete mix. A local manufacturer provided the air entrainments used for the lab mixes; and coincidently, the same manufacturer's air entrainment was used in the field applications that were tested, which allowed for closer comparison of test methods due to having nearly identical mixes in the lab and the field. Both Vinsol resin and synthetic air entrainment were used in the lab, while only synthetic air entrainment was used for the field mixes (Kosmarka 1988). 
Aggregate used in concrete for transportation applications needs to conform to specific standards including hard, durable, strong, clean, and free of chemicals. The Kentucky Department of Transportation performs in-depth inspections of local quarries at a minimum of every two years, with periodic checks yearly, to ensure consistency of the materials being produced. The coarse aggregates used in all concrete mixes sampled for this research were $100 \%$ limestone and originated from quarries that are on the Department's List of Approved Materials. This list, with respect to quarries, is composed of all approved aggregate sources that produce aggregate for the state, conforming to the required specific standards. While the coarse aggregate did not come from the same quarry location, the sources of all coarse aggregate used in the lab and in the field were locally crushed. The properties that affect the concrete mix design are shown in TABLE I for comparison. The coarse aggregate gradation is also included for reference, shown in

\section{TABLE II.}

TABLE I

COARSE AGGREGATE PROPERTIES

\begin{tabular}{c|c|c}
\hline Properties & Field & Lab \\
Quarry & Quarry \\
\hline Specific Gravity & 2.69 & 2.72 \\
Absorption (\%) & 0.9 & 1.7 \\
Size & 67 & 67 \\
\hline
\end{tabular}

As with the coarse aggregate, the fine aggregate used in all concrete mixes sampled for this research originates from suppliers that are on the Departments List of Approved Materials. The fine aggregate used in all concrete mixes sampled for this 
research was $100 \%$ natural sand dredged from the Ohio River. The fine aggregate came from the same supplier location, while the source stock piles could not be confirmed, all

TABLE II

COARSE AGGREGATE GRADATION

\begin{tabular}{c|c|c}
\hline \multirow{2}{*}{ Sieve Size } & Field & Lab \\
Quarry & Quarry \\
\hline 1 inch & Percent Passing & Percent Passing \\
$3 / 4$ inch & 100 & 100 \\
$1 / 2$ inch & 95 & 93 \\
$3 / 8$ inch & 62 & 64 \\
$\# 4$ & 31 & 38 \\
$\# 8$ & 9 & 10 \\
PAN & 5 & 2 \\
\hline
\end{tabular}

fine aggregates were dredged and prepared for use identically. The fine aggregate properties that affect the concrete mix design are shown in TABLE III for comparison.

TABLE III

FINE AGGREGATE PROPERTIES

\begin{tabular}{c|c|c}
\hline Properties & $\begin{array}{c}\text { Field } \\
\text { Same Supplier }\end{array}$ & $\begin{array}{c}\text { Lab }^{(1)} \\
\text { Same Supplier }\end{array}$ \\
\hline Specific Gravity & 2.63 & 2.636 \\
Absorption (\%) & 1.9 & 1.9 \\
Size & Concrete Sand & Concrete Sand \\
\hline
\end{tabular}

${ }^{(1)}$ Fine aggregate properties tested by university staff 
Like the coarse aggregate, the fine aggregate gradation is also included for reference, shown in TABLE IV. The fineness modulus should be in the range of 2.3 to 3.1 for Portland cement concrete mix designs.

TABLE IV

FINE AGGREGATE GRADATION

\begin{tabular}{c|c|c}
\hline Sieve Size & $\begin{array}{c}\text { Field } \\
\text { Supplier }\end{array}$ & $\begin{array}{c}\text { Lab } \\
\text { Supplier }\end{array}$ \\
\hline & Percent Passing & Percent Passing \\
\hline $3 / 8$ inch & 100 & 100 \\
$\# 4$ & 96 & 98 \\
$\# 8$ & N/A & 88 \\
$\# 16$ & 71 & 71 \\
$\# 30$ & N/A & 57.6 \\
$\# 50$ & 24.1 & 24.8 \\
$\# 100$ & 4.9 & 4.7 \\
PAN & 0 & 0.1 \\
\hline
\end{tabular}

A larger value of the fineness modulus results in a coarser fine aggregate (Mamlouk 2006). The fineness modulus for the lab mix designs was 2.561, while for the field mix designs it was 2.873. Detailed calculations for the fineness modulus is found in Appendix 1 .

The water used in all concrete mixes sampled for this research came from a municipal source via a standard tap. The lab mixes utilized water from a tap in the University's concrete lab that was directly introduced into the concrete mixer, while the 
water for the field mixes came from the tap at the concrete producer's plant location. For the AVA testing, the water was taken straight from the tap and placed in the AVA water tank for de-airing and tempering to within a range of 21 to $25^{\circ} \mathrm{C}\left(70\right.$ to $\left.77^{\circ} \mathrm{F}\right)$.

Before taking the AVA to a job site, it was first used in the lab to detect air void systems in the three lab mixtures. Three batches of each mix were made with the ingredients previously described for a total of nine separate tests. The first lab mix was the control sample, which had no air entrainment added; while the second lab mix was made with vinsol resin as the air entrainment, and the third was with a synthetic air entrainment. Table I displays the ingredient proportions used for all three lab mixes, respectivley. Note, the only difference between each mix is the air entrainment.

When mixing concrete, after buttering the inner surface of the mixer, coarse aggregates together with a little amount of water were added followed by fine aggregates with additional water. After approximately one minute of mixing, cement powder was added along with the proportioned air entrainer and the remaining mixing water. The mixer remained running for about four minutes after all ingredients were introduced to the drum. Following a two-minute rest, the concrete was remixed for another three minutes. All nine batches of concrete were mixed by the same procedures; and for each batch, slump test, total air with pressure meter, unit weight and temperature were conducted immediately after mixing was complete. Three samples obtained from each mix were prepared for the AVA test. Concrete cylinders and prism beams were made for the compressive strength and freeze-thaw durability tests, respectively. The testing results are listed in Tables V, VI and VII for each mix separately. All ingredients and 
processes for mixing the lab samples in this study were prepared per ASTM C192-07, while all the ingredients and mixing processes for the field mixes in this study were prepared per the 2008 Kentucky Standard Specifications for Road and Bridge Construction.

The prism and cylinder specimens cast during sampling of the lab mixes were made and cured per ASTM C-192-07, while the specimens cast during sampling in the field were made and transported per ASTM C-31-09. After the initial cure in the field (24 hours), the field sample specimens were delivered to the University to cure for 28 days along with the lab samples in a $23{ }^{\circ} \mathrm{C}\left(73^{\circ} \mathrm{F}\right)$ water bath in accordance with ASTM C-192-07.

\section{B. Mix Designs}

There are many factors that control what type of concrete mix designs are used for different applications. To this, there are a variety of chemical and mineral admixtures that may produce similar desired air void system values; and at different doses, the admixtures may affect the air system differently. In addition, different aggregate shapes, sizes, and mineral content may also affect the properties in a concrete mix. For this research, the type of concrete mix was controlled by the Kentucky Transportation Cabinet construction project's application in which the comparative samples were to be taken. The Kentucky 2008 Standard Specifications for Road and Bridge Construction (KYTC 2008 specification book), provided by the transportation cabinet, included all of the needed information to develop the lab mixes, and in doing so, ensured a close comparison to the field mix to be used by the contractor. 
To begin, the construction project's application for the concrete mix, was used for constructing reinforced bridge slabs (bridge decks). With this information the KYTC 2008 specification book directs the concrete mix to be a Class AA, which is required to have the maximum free water by water to cement ratio $(\mathrm{w} / \mathrm{c})$ of pounds to pounds to be 0.42 , as well as obtain a compressive strength of 4000 psi with 28 days of cure. Additionally, during placement, the Class AA is to meet a slump measurement within the range of 2 to 4 inches while containing a total air content percentage within the range of 4 to $8 \%$. The Class AA mix also does not allow a cement factor to be below 620 pounds per cubic yard. As for the coarse aggregate and fine aggregate percentages, they are controlled by an approximate percentage of fine to total aggregate, based on the mineral make up of the coarse aggregate. If the coarse aggregate is river gravel, the percentage of fine aggregate is $36 \%$. With the coarse aggregate being crushed limestone, the approximate percentage of fine aggregate should be $40 \%$.

\section{Presentation of Mix Designs and Test Values}

a. Lab Mix Design Proportions. To have a credible comparison between lab and field results, there is a need to have similar mixes. As shown in Table V, the lab mixes used in this research follow the "receipt" provided by the KYTC 2008 specification book, with exception to the air entrainment, which is not directed by KYTC specification. With the total air content being a pass or fail test for the KYTC, the chemical air admixture is determined by the producer to provide the desired air content on the project after mixing, travel time, and being placed with a concrete pump. With this concern, the dosage of air entrainment used in the lab mixes was determined to be 7 oz per hundredweight through discussions with the air entrainment producer and the 


\section{TABLE V}

\section{LAB MIX PROPORTIONS}

\begin{tabular}{c|c|c|c}
\hline & Control 2 & Vinsol Resin & Synthetic \\
\hline Type I Cement (lbs) & 620 & 620 & 620 \\
Type F - Fly Ash (lbs) & 0 & 0 & 0 \\
Coarse Aggregates (lbs) & 1839 & 1839 & 1839 \\
Fine Aggregates (lbs) & 1188 & 1188 & 1188 \\
Water (lbs) & 260 & 260 & 260 \\
w/c - ratio & 0.42 & 0.42 & 0.42 \\
Air entrainment (oz/100 lbs) & 0 & 7 & 7 \\
\hline
\end{tabular}

construction project's concrete producer. The decision was made to not use fly ash in any of the lab mixes based on a few factors. Fly ash is known to affect the workability, setting time, heat of hydration, and incompatibility with some cements and chemical admixtures. Fly ash was not used in the lab, since a more controlled mixture was desired. The masses of each ingredient shown in Table $\mathrm{V}$ are based on designing of $1 \mathrm{yd}^{3}$ of concrete.

b. Field Mix Design Proportions. In developing the field mix designs, the producer who provided the concrete mix to the construction project also used the KYTC 2008 specification book. Knowing these requirements originally allowed for the lab mix designs to be created. As shown in Table VI, the field mix design is very similar to the lab mixes, with minor exceptions. Instead of containing straight cement, the field mix contains a cement-fly ash mixture with the fly ash replacing the cement pound for pound at $18 \%$. The coarse aggregate is virtually the same, limestone coming from nearby quarries, and the fine aggregate being identical from the same producer/supplier. For 
field modification, placement and workability, the field mix was delivered to the construction project with a w/c ratio of 0.40 and contained $4 \mathrm{oz}$ per hundredweight of a retarding chemical admixture. Due the retarding admixture being added, the air entrainment was reduced to $1 \mathrm{oz}$ per hundredweight. The main reasons for the addition of retarder was to delay the set time of the mix to allow for the time required to transport the mix from the producers site to the project location, in addition to providing a more uniform set of the bridge deck slab during cure. The air entrainment and retarder dosages were set under the expectation that the two chemical admixtures would work together to increase the air void system in a way that if the air entrainment was not reduced, the total air content would be excessively high and not desirable.

TABLE VI

FIELD MIX DESIGN

\begin{tabular}{c|c}
\hline Cement Type I (lbs) & 508 \\
Flyash (lbs) & 112 \\
Coarse Aggregate (lbs) & 1826 \\
Fine Aggregate (lbs) & 1190 \\
Water (lbs) & 248 \\
w/c - ratio & 0.40 \\
Retarder (oz/100 lbs) & 4 \\
Air Entrainment (oz/100 lbs) & 1 \\
\hline
\end{tabular}

c. Mortar and Paste Volume. The AVA test method requires the input of three mix parameters; volume $\%$ of mortar, volume $\%$ of paste, and volume $\%$ of air. The volume $\%$ of mortar is defined as the percent of concrete minus the percent of total 
measured air, minus volume percent of coarse aggregate greater than $8 / 16 \mathrm{~mm}$ (1/4 inch). The volume percent of paste is defined as the volume percent of cement plus the volume percent of water, plus the volume percent of all liquid air entrainer and/or other liquid admixtures. The calculated volume percents of mortar and paste are provided in Table VII for all lab and field mixes included in this research. The volume percent of air is defined and obtained by the total pressure method or ASTM C-231-08; however, the volume percent of air is not shown in this section, as it is included with the test results and discussion section. Detailed calculations for the volume $\%$ of mortar and volume $\%$ of paste can be found in Appendix 1.

TABLE VII

MORTAR AND PASTE VOLUMES

\begin{tabular}{c|c|c}
\hline Mix Identification & $\begin{array}{c}\text { Volume \% } \\
\text { of Mortar }\end{array}$ & $\begin{array}{c}\text { Volume \% of } \\
\text { Paste }\end{array}$ \\
\hline Control 2A & 56.91 & 22.52 \\
Control 2B & 57.71 & 22.52 \\
Control 2C & 57.51 & 22.52 \\
RVR-15 A & 52.51 & 22.52 \\
RVR-15 B & 53.90 & 22.52 \\
RVR-15 C & 53.61 & 22.52 \\
RSA-10 A & 55.01 & 22.52 \\
RSA-10 B & 55.41 & 22.52 \\
RSA-10 C & 55.31 & 22.52 \\
Jeptha Creek & 55.54 & 22.35 \\
R-R Bridge & 52.54 & 22.35 \\
KY 395 & 55.54 & 22.35 \\
\hline
\end{tabular}




\section{Test Results and Discussion}

\section{Presentation of Results}

This research is to determine the feasibility of the use of the AVA technology in the field. This is not intended to perform an in-depth statistical analysis review of the AVA, but to determine if field use of the AVA can be correlated to conventional field tests. The first two parameters to be compared are the AVA \% of air and the Total percent air (Pressure Method). To have a more direct comparison between mixes, the author has picked a lab mix, which contains a synthetic air entrainer, which as described previously, closely resembles the field mix. The total air percentages for the synthetic lab mix are $4.9 \%, 4.5 \%$, and $4.6 \%$ for an average of $4.7 \%$, while the AVA percentages of air for the same synthetic lab mix are $2.1 \%, 1.9 \%$, and $1.2 \%$ for an average of $1.7 \%$. The average difference between the two test methods is 3.0\%, with the AVA percent of air being lower than the total air for the conventional method, as shown in Table VIII. The total air percentages for the field mix are $4.2 \%, 7.2 \%$, and $4.2 \%$ for an average of 5.2\%; however, not using the $7.2 \%$ will produce an average of $4.2 \%$. (Note: The value of $7.2 \%$ was read off a pressure gauge mounted to a different air meter than all other additional field testing. Uncontrolled by the technician, the State field crew left the original meter at the opposite end of the bridge deck; however, due to the requirements to complete the conventional test methods within a set time limit, the crew elected to use a different meter for that test.) The AVA percentages of air are $1.9 \%, 1.3 \%$, and $1.7 \%$ for an average of $1.63 \%$. The average difference between the two test methods including the $7.2 \%$ in the calculations is $3.5 \%$; however, if one excludes the $7.2 \%$ in the calculations, the average is $2.57 \%$. These values calculate a median value of $3.04 \%$ between the field results shown 
in Table IX. It can be assumed that a more precise correlation, from additional, more extensive testing, may provide a value around 3\% as an offset between the AVA and conventional tests. For additional comparisons, the author has provided the test values from the lab Control, non-entrained, samples in Table $\mathrm{X}$ and the values from the lab samples containing Vinsol resin in Table XI.

The consistent correlation between the AVA value and conventional tests, with respect to air voids, is a predominant factor for the future use of the AVA, but should not be the only test value reviewed. Past research shows that there is a correlation between the spacing factor of concrete and its durability. Ensured or increased durability of hardened concrete is a main desire of the industry and the owners of the placed product.

TABLE VIII

LAB TESTING RESULTS OF CONCRETE WITH SYNTHETIC ENTRAINER

\begin{tabular}{c|c|c|c|c}
\hline Tested Properties & $\begin{array}{c}\text { Synthetic } \\
\text { A }\end{array}$ & $\begin{array}{c}\text { Synthetic } \\
\text { B }\end{array}$ & $\begin{array}{c}\text { Synthetic } \\
\text { C }\end{array}$ & Average \\
\hline Slump (in) & 2.50 & 2.25 & 3.00 & 2.58 \\
Air Volume (AVA, \%) & 2.1 & 1.9 & 1.2 & 1.7 \\
Total Air (pressure meter, \%) & 4.9 & 4.5 & 4.6 & 4.7 \\
Temperature ( $\left.{ }^{\circ} \mathrm{F}\right)$ & 74 & 74 & 76 & 75 \\
Unit Weight $\left(\mathrm{lbs} / \mathrm{yd}^{3}\right.$ ) & 147.320 & 148.760 & 147.328 & 147.803 \\
Specific surface $\left(\mathrm{mm}^{-1}\right)$ & 22.5 & 20.5 & 28.3 & 23.8 \\
Spacing factor $(\mathrm{mm})$ & 0.291 & 0.312 & 0.283 & 0.295 \\
Durability factor & 0.92 & 0.94 & 0.97 & 0.94 \\
Strength (psi) & 6501 & 6592 & 6273 & 6455 \\
\hline
\end{tabular}


TABLE IX

\section{FIELD TESTING RESULTS}

$\begin{array}{cccc}\text { Tested Properties } & \text { Jeptha Creek } & \mathrm{R} / \mathrm{R} & 395 \text { Overpass } \\ \text { Slump (in) } & 5.50 & 4.75 & 4.50 \\ \text { Air Volume (AVA, \%) } & 1.90 & 1.30 & 1.70 \\ \text { Total Air (pressure meter, \%) } & 4.2 & 7.2 & 4.2 \\ \text { Temperature }\left({ }^{\circ} \mathrm{F}\right) & 77 & 77 & 78 \\ \text { Unit Weight }\left(\mathrm{lbs} / \mathrm{yd}^{3}\right) & 147.91 & 140.92 & 146.99 \\ \text { Specific Surface }\left(\mathrm{mm}^{-1}\right) & 30.2 & 37.7 & 25.3 \\ \text { Spacing Factor }\left(\mathrm{mm}^{3}\right) & 0.23 & 0.17 & 0.300 \\ \text { Durability Index } & 1.00 & 0.97 & 0.96 \\ \text { Strength (psi) } & 5265 & 4841 & 6433\end{array}$

TABLE X

LAB TEST RESULTS OF NON-ENTRAINED CONCRETE

$\begin{array}{ccccc}\text { Tested Properties } & \text { Control } & \text { Control } & \text { Control } & \text { Average } \\ \text { Slump (in) } & 2 \mathrm{~A} & 2 \mathrm{~B} & 2 \mathrm{C} & \\ \text { Air volume (AVA, \%) } & 1.00 & 1.25 & 2.00 & 1.42 \\ \text { Total Air (pressure meter, \%) } & 3.8 & 1.8 & 0.9 & 1.8 \\ \text { Temperature }\left({ }^{\circ} \mathrm{F}\right) & 74 & 2.2 & 2.4 & 2.5 \\ \text { Unit Weight }\left(\mathrm{lbs} / \mathrm{yd}^{3}\right) & 151.336 & 152.576 & 150.976 & 151.629 \\ \text { Specific surface }\left(\mathrm{mm}^{-1}\right) & 4.5 & 6.7 & 6.1 & 6.2 \\ \text { Spacing factor }\left(\mathrm{mm}^{3}\right) & 1.277 & 1.123 & 1.198 & 1.214 \\ \text { Durability factor } & 0.00 & 0.00 & 0.00 & 0.00 \\ \text { Strength (psi) } & 6714 & 7138 & 7053 & 6968\end{array}$


TABLE XI

LAB TEST RESULTS OF CONCRETE WITH VINSOL RESIN

\begin{tabular}{c|c|c|c|c}
\hline Tested Properties & $\begin{array}{c}\text { Vinsol } \\
\text { Resin A }\end{array}$ & $\begin{array}{c}\text { Vinsol } \\
\text { Resin B }\end{array}$ & $\begin{array}{c}\text { Vinsol } \\
\text { Resin C }\end{array}$ & Average \\
\hline Slump (in) & 5.50 & 2.50 & 2.75 & 3.58 \\
Air volume (AVA, \%) & 4.6 & 3.8 & 3.3 & 3.9 \\
Total Air (pressure meter, \%) & 7.4 & 6.0 & 6.3 & 6.6 \\
Temperature ( $\left.{ }^{\circ} \mathrm{F}\right)$ & 74 & 75 & 74 & 74 \\
Unit Weight (lbs/yd $\left.{ }^{3}\right)$ & 142.128 & 146.456 & 145.904 & 144.829 \\
Specific surface (mm $\left.{ }^{-1}\right)$ & 31.1 & 24.1 & 28.3 & 27.9 \\
Spacing factor (mm) & 0.152 & 0.208 & 0.196 & 0.185 \\
Durability factor & 0.99 & 0.92 & 1.00 & 0.97 \\
Strength (psi) & 4390 & 5711 & 5615 & 5239 \\
\hline
\end{tabular}

\section{Evaluation of Results}

a. Durability versus Various Material Parameters. The durability factor in concrete is a function of the air void spacing factor. The distance between two voids is required to be less than the critical maximum distance, which is the furthest distance in which expanding water can travel without causing excessive pore pressure. Excessive pore pressures will develop into internal stresses that will cause the concrete to fail. For desirable durability values, the air void spacing factor needs to be less than $0.30 \mathrm{~mm}$ (0.012 in). When the spacing factor is increased, the durability of a mix decreases as was shown in prior research by the U.S. Bureau of Reclamation (Backstrom 1956; Kansas DOT). 
As shown in Figure 1, this research produces a similar pattern from recorded values as seen in other reports. Spacing factor values that are associated to the range of durability between the lower and higher values were not included in this research. It can be clearly seen that the lower durability values are represented by spacing factors that are in excess of $1 \mathrm{~mm}$ (0.04 inches), and the higher durability values are represented by spacing factors that are equal to or less than $0.30 \mathrm{~mm}(0.012 \mathrm{in})$. The spacing factors from the lab and field mixes can also be reviewed in Tables VIII, IX, X, and XI.

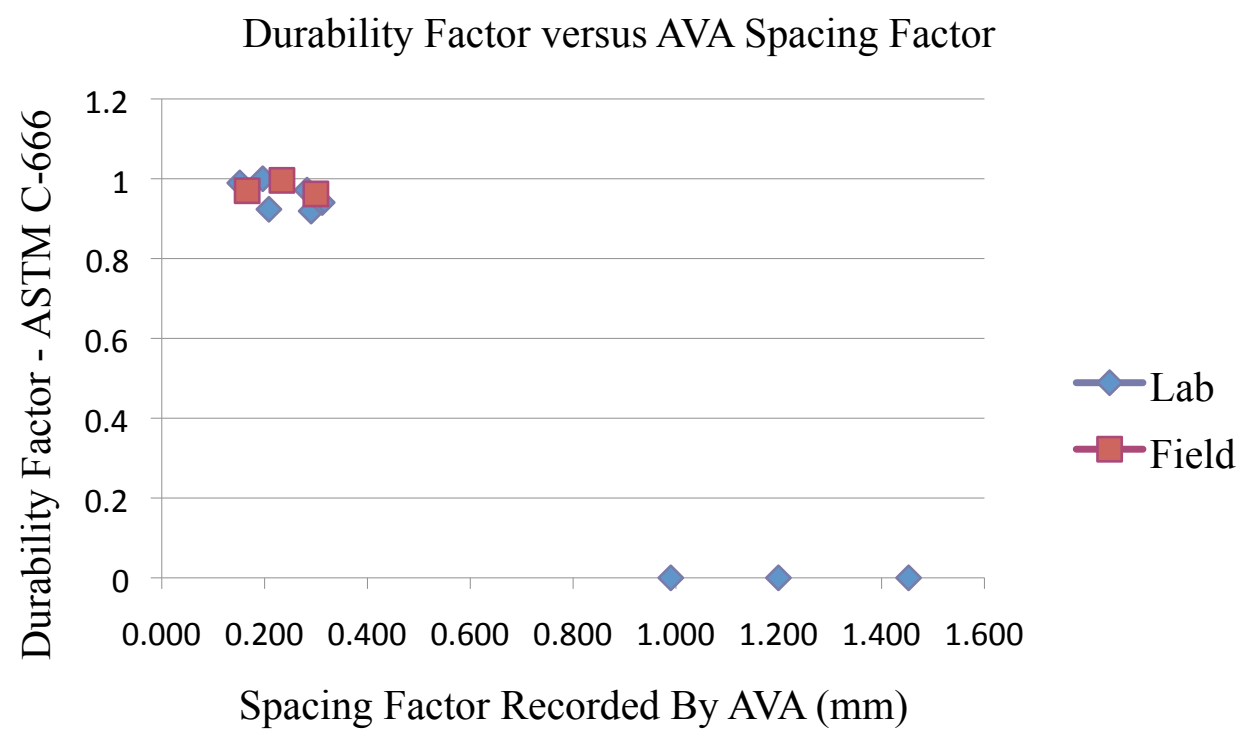

FIGURE 1 - Durability Factor versus AVA Spacing Factor

In addition to the spacing factor, the specific surface area is another parameter that can be used to determine the durability of concrete. For desirable durability values, the specific surface area needs to be above $20.4 \mathrm{~mm}^{-1}\left(0.804 \mathrm{inch}^{-1}\right)$. When the specific surface area approaches $20.4 \mathrm{~mm}^{-1}\left(0.804 \mathrm{inch}^{-1}\right)$ the durability is shown to be above 90 , and continues to be between 92 and 100 up to $37.7 \mathrm{~mm}^{-1}\left(1.49\right.$ inches $\left.^{-1}\right)$. As the specific 
surface area decreases from $20.4 \mathrm{~mm}^{-1}$ the durability of the concrete is greatly reduced. ASTM C-457-08 states that when air-entrained concrete is produced according to ACI 201.2R and ACI 211.1, the specific surface area ranges between $24^{-1} \mathrm{~mm}$ and $43 \mathrm{~mm}^{-1}$ $\left(0.95\right.$ inch $^{-1}$ to 1.69 inches $\left.^{-1}\right)$.

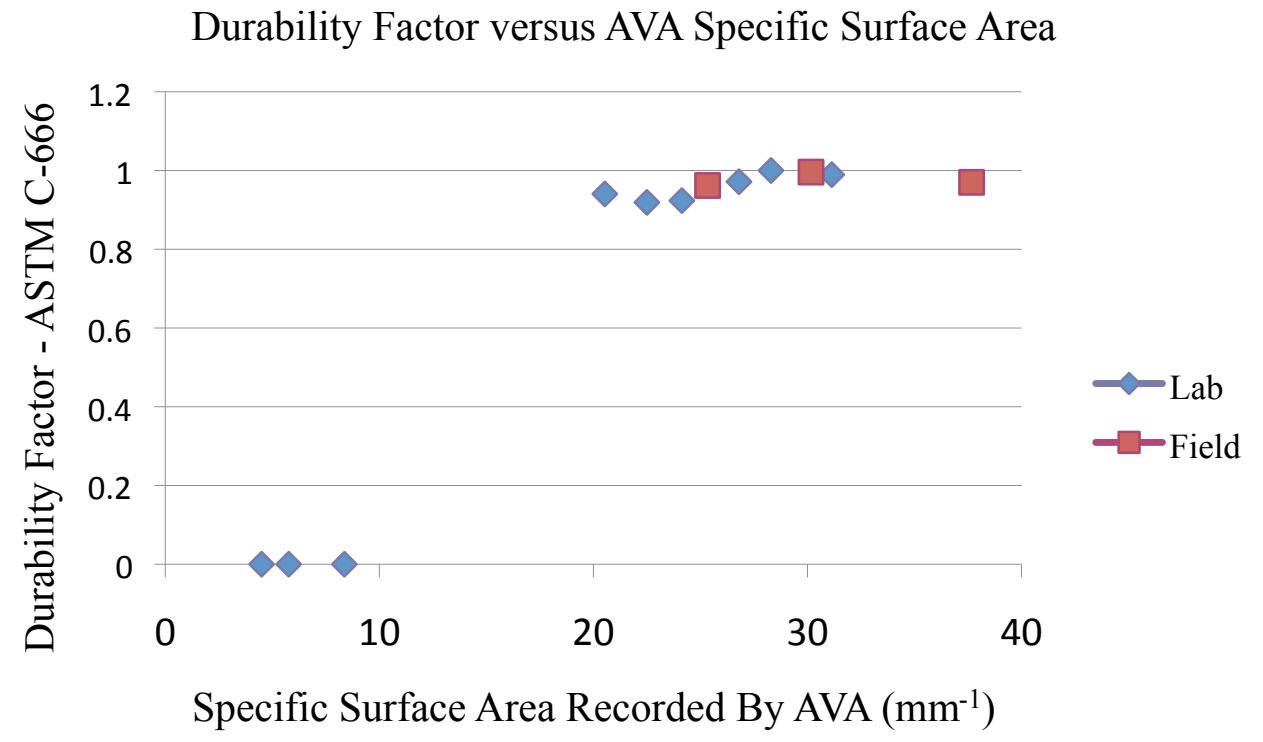

FIGURE 2 - Durability Factor versus AVA Specific Surface Area

Lower specific surface area values equate to durability that is less than desirable which is consistent with ACI literature and ASTM test methods (ASTM C-666-03 2008). The specific surface area values can be reviewed in Tables VIII, IX, X, and XI; and are shown in Figure 2. This research produces a similar pattern to those seen in other research (Wang 2008; Tanesi 2006).

The next parameters to compare are durability and the total air using the pressure method. The pressure method is the most common conventional test method used in the industry to determine the total air content. This research shows that the concrete tested 
has preferred durability values between 92 and 100, with total air content values above $4 \%$, and increasing to $8 \%$. Other research has shown that the total air parameter can be used to determine, with relative comfortablility, the durability of concrete. The values from this research are shown in Figure 3, and produce a similar pattern to prior research.

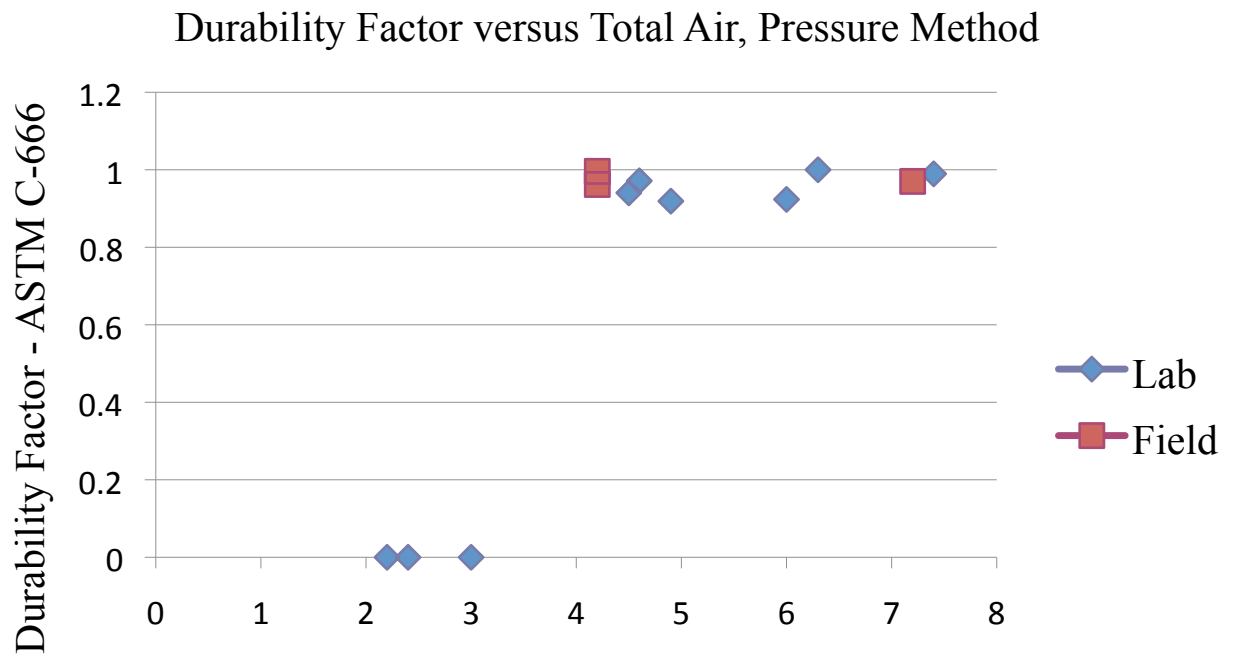

Total Air Content (\%) KM 64-303-08

FIGURE 3 - Durability Factor versus Total Air, Pressure Method

Research by the Iowa State University, Institute for Transportation, shows slightly different values with the exception that their research shows a distinctive change in durability at and above $6 \%$ instead of $4 \%$. This pattern is further confirmed in ASTM vol. 63, 1966, by W. A. Cordon.

Similar to the pressure method for air content, the AVA \% of air can be used to predict durability in concrete, but only when the AVA \% of air is above $2.8 \%$. Most research shows that the AVA \% of air can be used to predict durability by showing the 
durability as a function of the AVA \% of air, as can be shown from this research in Figure 4, with exception of a range between $1.3 \%$ and $2.8 \%$.

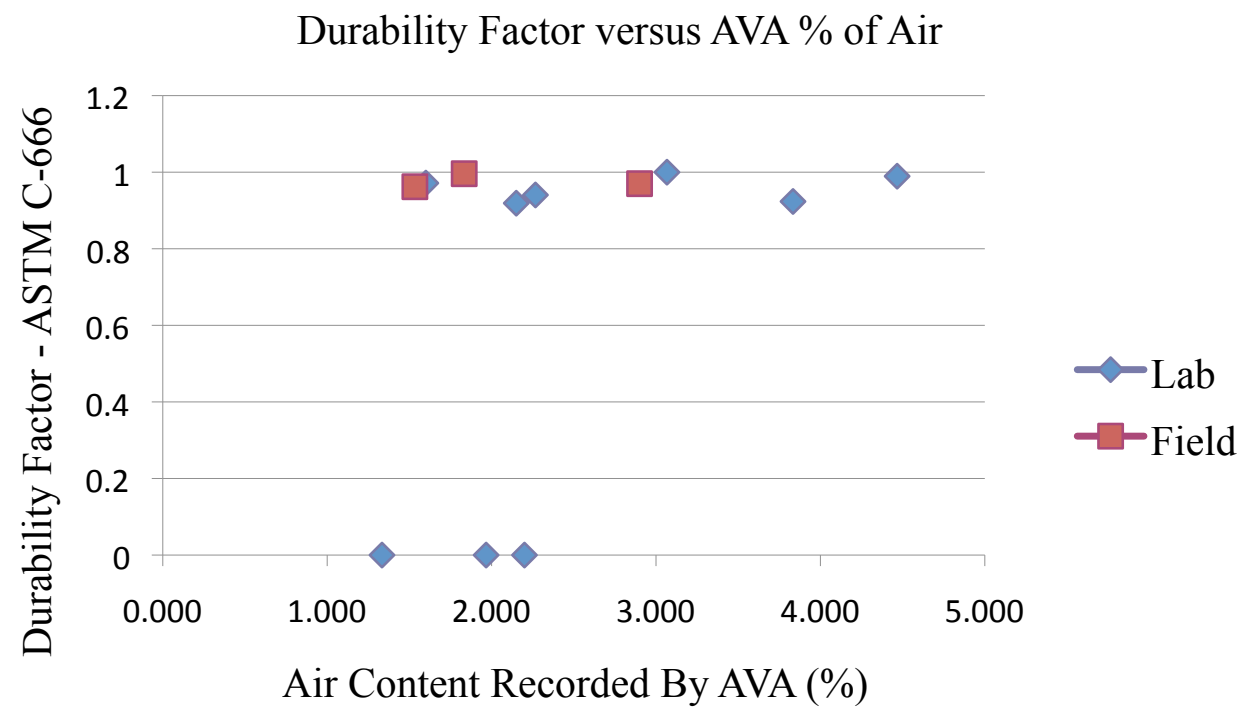

FIGURE 4 - Durability Factor versus AVA \% of Air

b. $\quad$ Compressive Strength versus Various Material Parameters. Unlike durability, previous researches have not reported the strength of concrete as a function of the specific surface area or the strength as a function of spacing factor. One journal did compare the strength of cement mortar to the specific surface area but not the spacing factor. What can be observed from the journal is that the effects of the spacing factor on the mortar strength are not that significant in value. The research outlined in the journal also indicates that the finer the cement or mineral admixture is ground, specific surface area increases; and this may affect the compressive values positively (Nacert 2006). 
This research does not agree with the prior mortar research with regards to increasing compressive strength with increased specific surface area, shown in Figure 5. Instead of increasing, this research indicates that as the specific surface area increased, the compressive strength decreases; keep in mind that this is comparing mortar to concrete (absence of coarse aggregate).

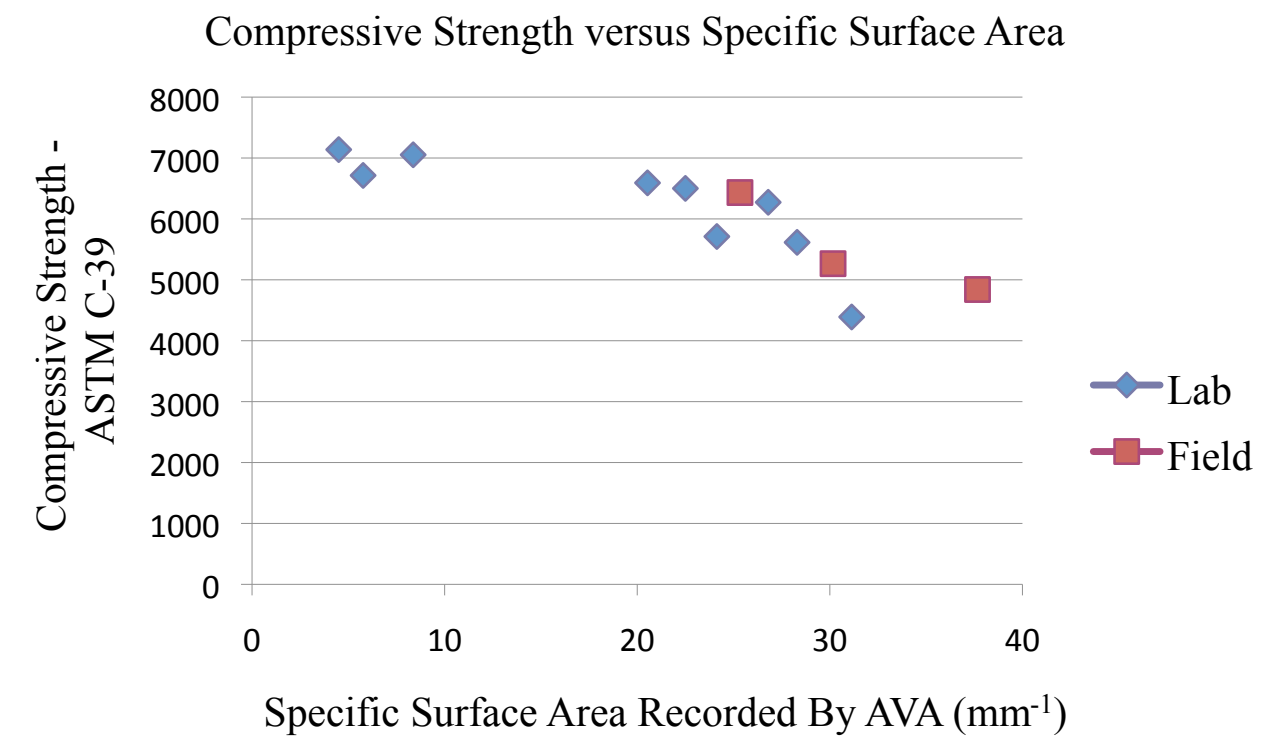

FIGURE 5 - Compressive Strength versus Specific Surface Area

Without prior research to confirm the findings shown in Figure 6, it can be assumed that other reports have not found significance in the compressive strength of concrete as a function of the spacing factor.

The negative effects of air entrainment in concrete are known, and this reduction in compressive strength is tolerable knowing that the increase of durability is the counter effect. The variables that can affect the strength of concrete are numerous. The data presented here cannot be used to determine the cause of the difference with respect to the 
specific surface area of this research and the specific surface area of other research (Nacert).

As shown in Figure 6, as the spacing factor increases, the strength does not decrease; however, as the spacing factor decreases, the compressive strength is decreased sharply. A review of the lab mixes to obtain more points of data shows that the spacing factors vary from $0.152 \mathrm{~mm}^{-1}$ to $1.277 \mathrm{~mm}^{-1}\left(0.006 \mathrm{inch}^{-1}\right.$ to $\left.0.05 \mathrm{inch}^{-1}\right)$ with a range of $1.125 \mathrm{~mm}^{-1}\left(0.044 \mathrm{inch}^{-1}\right)$. Over this range, the strength varies from $4390 \mathrm{psi}$ to $7138 \mathrm{psi}$ (30269 $\mathrm{kPa}$ to $49217 \mathrm{kPa}$ ) with a maximum variance of $2748 \mathrm{psi}(18947 \mathrm{kPa})$.

Determining the relationship between the compressive strength and the spacing factor shows that for every $0.1 \mathrm{~mm}^{-1}$, the strength change is $244 \mathrm{psi}(1682 \mathrm{kPa})$. Using the pressure method, the values of air volume are between $0.9 \%$ and $7.4 \%$ with a range of $6.5 \%$. Over a range of $2748 \mathrm{psi}(18947 \mathrm{kPa})$, that equates to $42.3 \mathrm{psi}(292 \mathrm{kPa})$ per $0.1 \%$. Comparing the different ranges, if one needed to use a plastic test to predict compressive strength, the pressure method may be more applicable. The author understands that this is not fully supported and that it cannot be confirmed solely by the data in this text. To be consistent in format, the discussion of the concrete compressive strength as a function of AVA $\%$ of air and the pressure method $\%$ of air is next. 


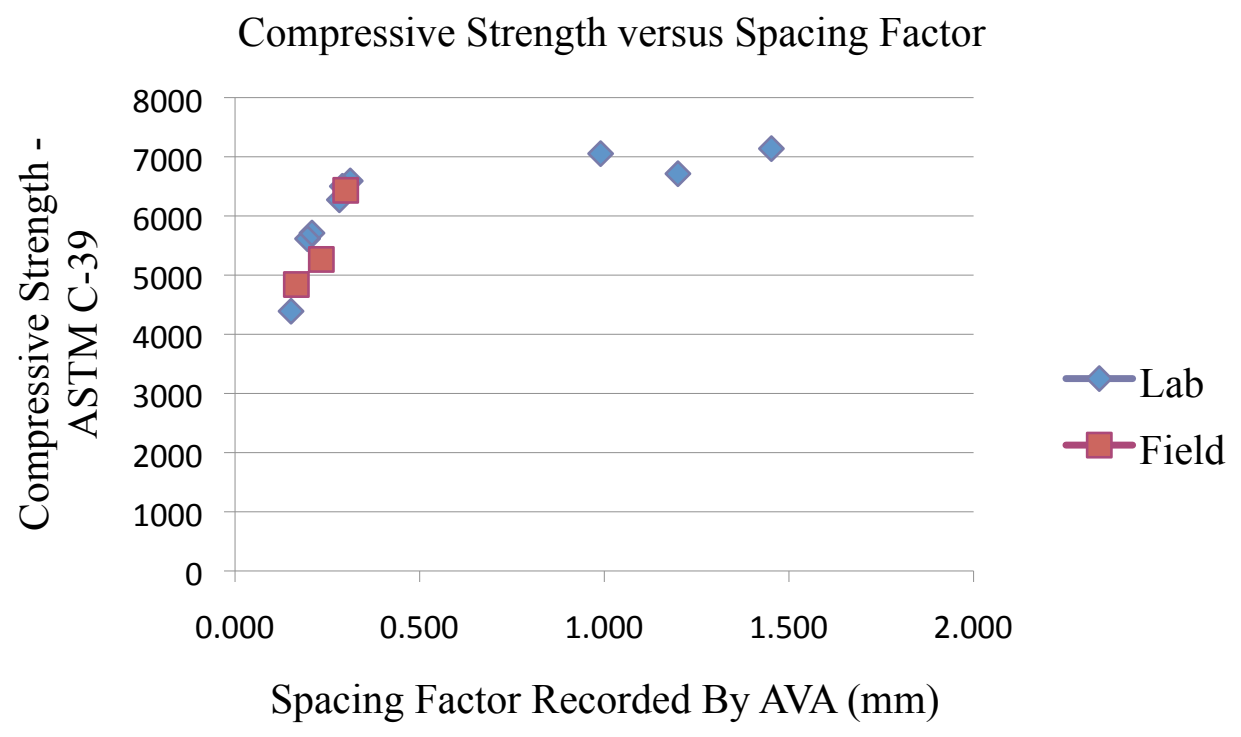

FIGURE 6 - Compressive Strength versus Spacing Factor

It is widely published that the presence of air in concrete may have a negative influence on the compressive strength of concrete. The relationship between air content and compressive strength in 28-day concrete shows a commonly known trend. While air entrainment increases the durability of a concrete, having mass removed and replaced with air will inherently create a lower compressive strength. Not to be confused, if a concrete mix has the air volume increased and at the same time the amount of cement is increased, this keeps the air void to cement ratio consistent; thus, a concrete mix that does not have any ingredient volume changes other than having the volume of air increase will show a decrease in compressive strength from a 28-day cylinder test. Figure 7 is produced from the values of this research, and the trend formed is very similar to the information shown by the Portland Cement Association (Kosmatka 1988). 
As stated previously, this thesis is to determine if the field application of the AVA in quality control should be further entertained. Instead of basing the use of the AVA solely on durability, a comparison will be made between the AVA \% of air and the Pressure Method, tested according to KM 64-303-08, which is used per specification for acceptance testing by the Kentucky Department of Transportation. Comfortability with the AVA in correlation to the currently used conventional test may be more acceptable rather than correlating it only to compressive strength. A review of the compressive strength of a mix versus the air volume content of the same mix from the KM-303-08 and the AVA shows a similar pattern. As seen in Figures 7 and 8, the only difference between the two graphs is the value for the volume of air; however, they both share a similar trend. Even though there are many variables that influence a concrete's compressive strength, correlation between compressive strength and air content has been

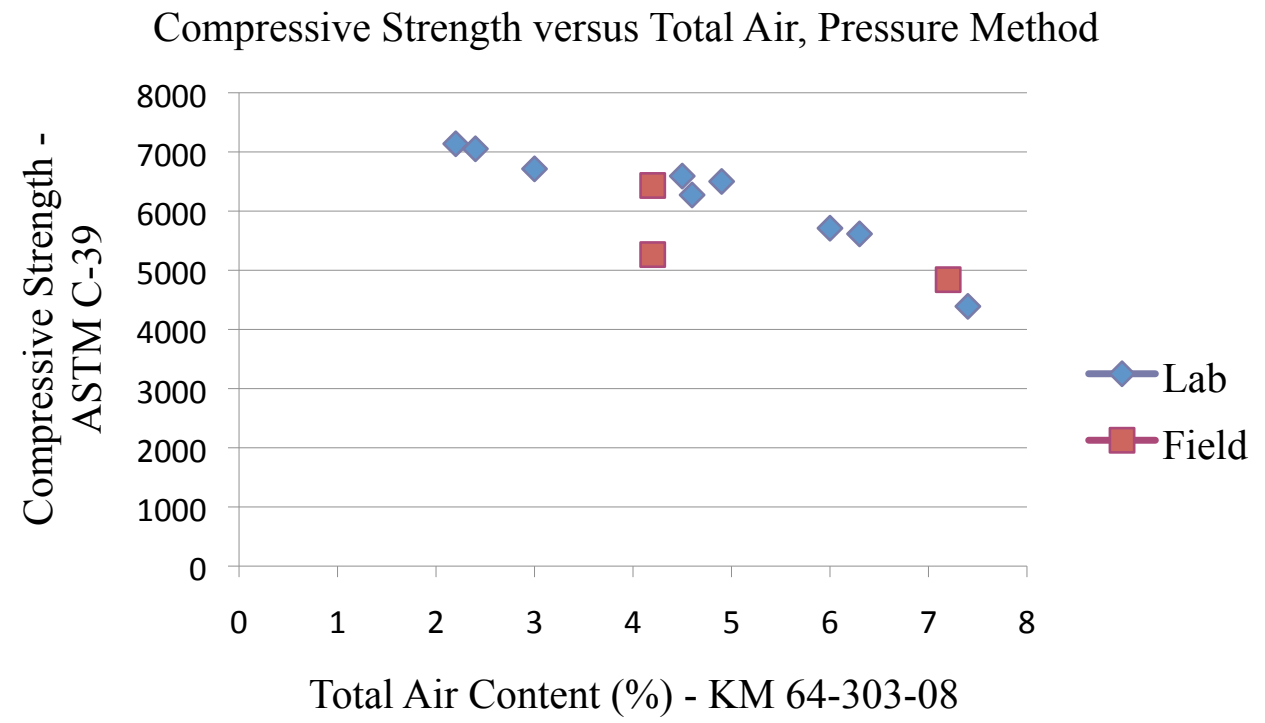

FIGURE 7 - Compressive Strength versus Total Air, Pressure Method 


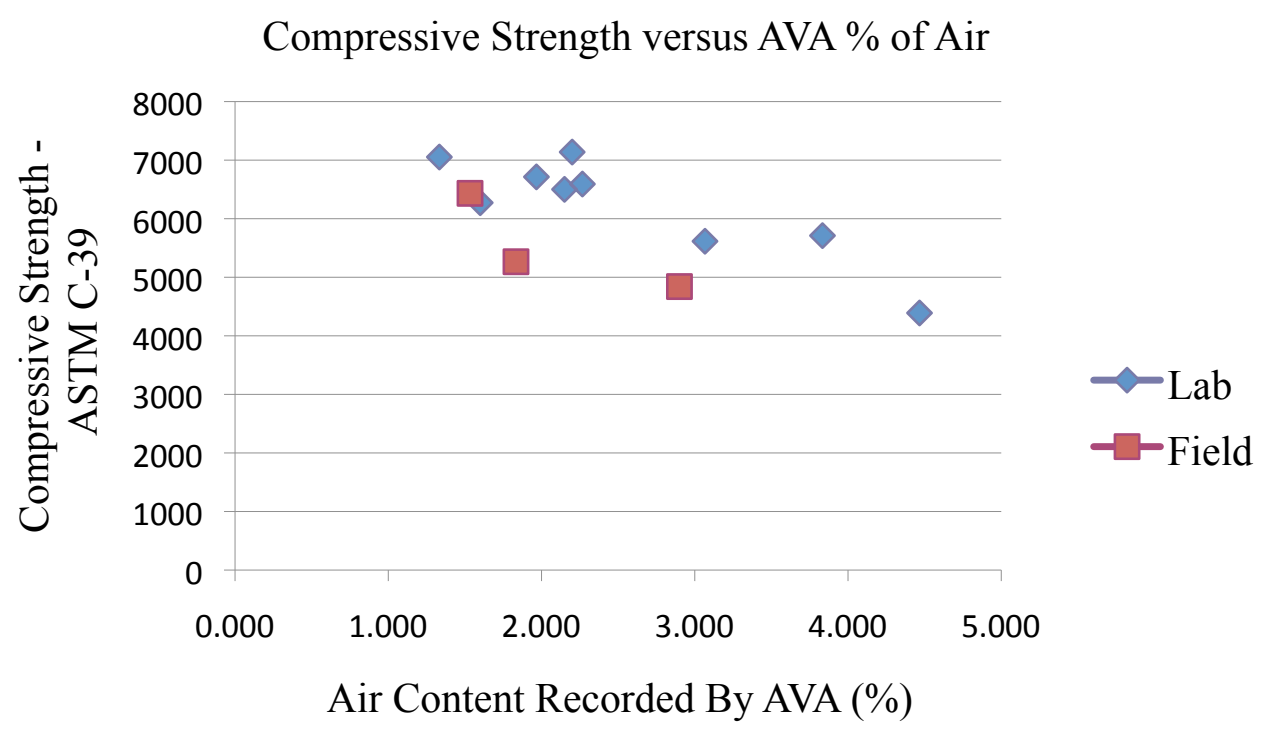

FIGURE 8 - Compressive Strength versus AVA \% of Air

shown in previous figures. This correlates the AVA \% of air to the KM-303-08 pressure method with respect to compressive strength, and in doing so, correlates the AVA \% of air with KM-303-08 pressure method with respect to in-field testing. The benefit to this correlation is that with the AVA also being correlated to durability, an in-field quality control test exists at real time.

c. Total Air Pressure versus the AVA \% of Air. The last step of this research is to compare the values of the AVA \% of air and those of the KM-303-08 pressure method. The same National Concrete Pavement Technology Center (NCPTC) study mentioned earlier during the durability section also compares the AVA to the ASTM C231-08 pressure method. This shows that the correlation between methods has a $R^{2}$ value of 0.5 . The $\mathrm{R}^{2}$ value for this research is only 0.1 higher than that of NCPTC, shown in Figure 9. Performing a simple average calculation for comparison, the NCPTC study 
shows the AVA \% of air to be 2.27 times lower than the ASTM pressure method, while the same simple average calculation on this research produces an AVA \% of air that is 2.71 times lower than the KM-303-08 pressure method. This comparison does not statistically prove anything more than that the AVA \% of air, as a majority, is lower than the current conventional test methods to measure total air content in the field.

Future study is required with regards to improving the use of the AVA in the field. Figure 10 shows the lab and field data plotted from this research together, as a beginning of a process to combine lab and field data as one body of information. This information will be used to further develop specifications to govern the use of the AVA technology for in-field concrete quality control.

\section{Total Air, pressure method versus AVA \% of Air}

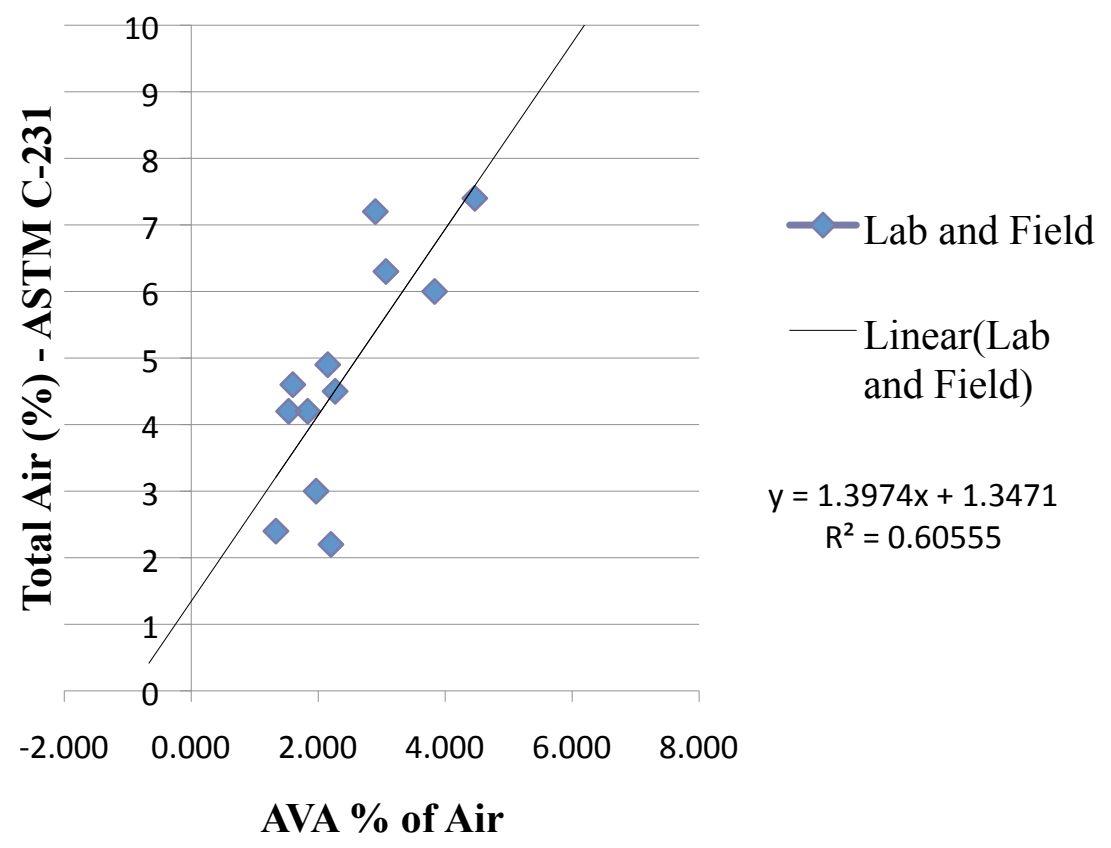

FIGURE 9 - AVA \% of Air versus Total Air, Pressure Method 
The equation shown for the data trend line is used to calculate an upper and a lower bound limits. The upper limit is the trend value plus 0.25 , while the lower limit is the trend value minus 0.25 . For example, if the AVA value is $2.5 \%$, then the actual range that the pressure method could produce may be between $2.0 \%$ and $2.75 \%$ with the most likely being above $2.5 \%$.

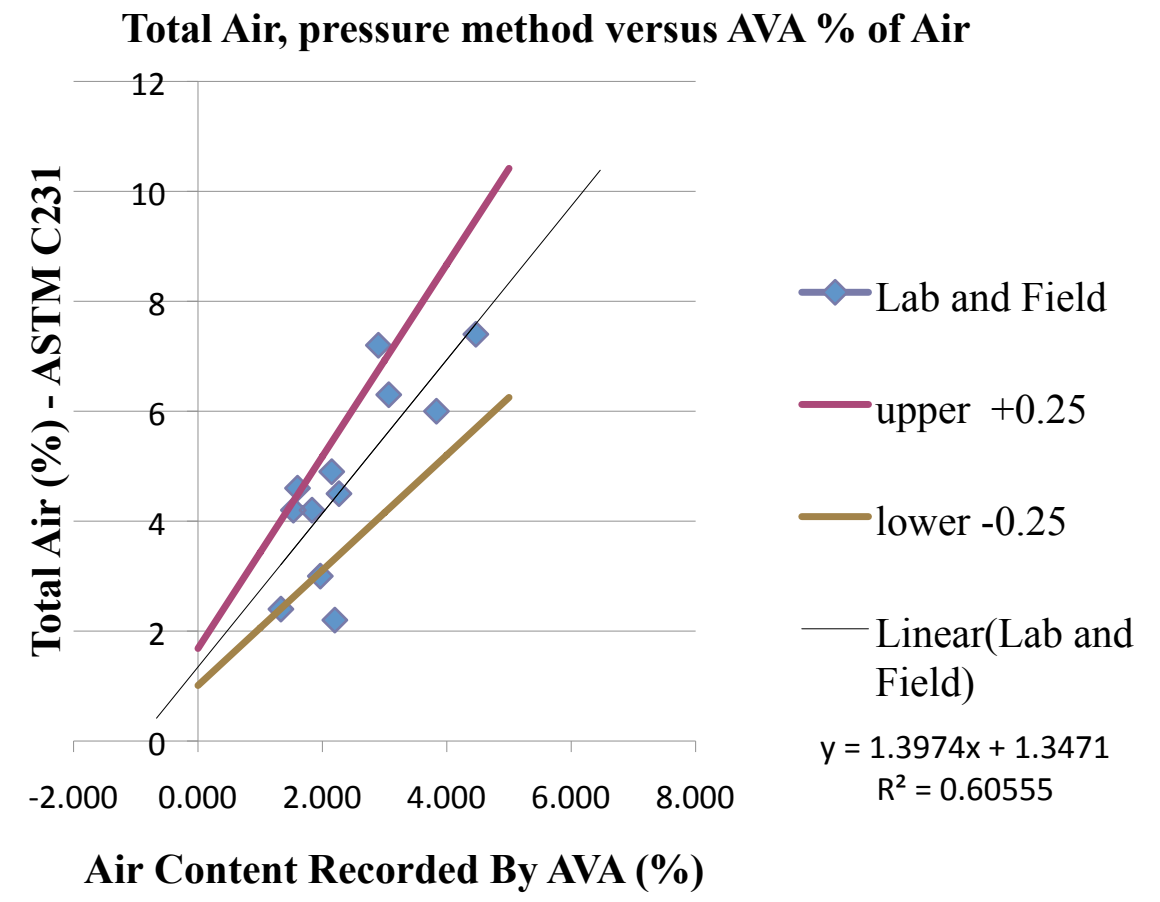

FIGURE 10 - Total Air, Pressure Method versus AVA \% of Air

\section{Conclusions}

This research shows the possibility of using the AVA as a field quality control method. The application of this method to detect the quality of fresh concrete in terms of durability will allow civil engineers the ability to identify durability issues during the 
construction process when placing fresh concrete. This can help to reduce the long-term cost of preserving an infrastructure.

Based on this research, the following conclusions with respect to the AVA equipment and positioning on a project can be drawn:

- $\quad$ For better accuracy in the field, the AVA equipment needs to have modifications to how temperature in the riser column is maintained. The current equipment will heat the liquid in the riser column but will not cool the liquid.

- $\quad$ The AVA is best used in a location where multiple tests are to be performed as the amount of effort that is required to transport and assemble the equipment is not a process that one would be able to perform numerous times a day while performing the test efficiently.

- $\quad$ The distance between the AVA equipment and where the sample is to be taken is not so important, as a walking distance of 1 to 2 minutes is allowable on most projects.

As a means to gain comfortability with the AVA technology, the following conclusions are with respect to the in-field AVA test results and how they are compared to the conventional field test results:

- $\quad$ AVA \% of air should not be used to predict compressive strength. If a test method that is used to test for the volume of air is to be used to predict compressive strength, the use of the pressure method has shown to be more precise. This is achieved through having a range of percentages that equate to closer movements between the strength values.

- The majority of the values recorded by the AVA are going to be less than that recorded by a pressure method and further testing is required to produce a more accurate correlation between the two.

- $\quad$ The AVA system can be used to determine durability through the spacing factor, which is a function of the air void system. This is also proven in previous research to be a factor in the durability of a concrete mix. 


\section{OBSERVATIONS}

The main information obtained from this research is that both lab and field-testing support at least three relationships: durability as a function of entrained air, durability as a function of the spacing factor, and durability as a function of the specific surface area. With any testing, duplication or reproduction is required to have a method accepted by the industry. The main concern voiced against the AVA is vibration and air movement; the cap on the riser column greatly reduces the concern of excess air movement, while a sturdy and level workstation greatly reduces the vibration. In addition to the equipment design, choosing a location that is away from active construction and live traffic also decreases the chance of vibration. The field locations of this research allowed for a buffer distance of 30 or more feet; however, the lab area at times seemed to not have a safe clear distance from lab technician movements.

Often times a piece of equipment can be used for more conditions than its original design; and in the case of multiple applications, a wider range of slump values were able to be tested than originally thought using the collection equipment. Obtaining a paste sample from concrete having of a slump less than 2 inches is rudimentary; however, fresh concrete having a slump less than 2 inches may take a few seconds longer, but is possible, while protected by the included collection cage. Obtaining a sample from a concrete mix having a slump measuring less than 1 inch is not desirable as the required effort of vibration may lead to the loss of entrained air. 
Other observations are more related to gaining familiarity with the equipment and its environmental limits. As the AVA was produced outside of the United States, the electrical connections are European, thus requiring electrical adapters to obtain power. In the lab, adapters are easy to use and keep track of; however, in the field, adapters are easy to forget or misplace. An additional concern is that there is no time buffer during which the AVA will run without a continuous electrical connection. A steady current is required for the test; and when using a generator, a time with low or no current will cause a "not connected" error between the collection equipment and the AVA, which will stop the collection equipment from recording, thus ruining the sample.

With the AVA based around Stoke's law, keeping the riser column's viscosity consistent during a test and consistent from test to test is very important. When putting the stopper in the base, cleaning of the o-rings need to be performed first, as a watertight seal is required to perform the AVA tests. When loading the $20 \mathrm{cc}(0.68 \mathrm{oz})$ syringe samples into the AVA, a small amount of silicone gel placed on the exterior surface of the syringe allows for easier specimen placement in the base of the apparatus. Although the silicone is an aid to control the movement of the syringe and stopper, ensure that no silicone from the exterior surface of syringe enters into the sample in the riser column, as it may interfere with the test. Once the AVA is assembled, filling the riser column with the test water and glycerin is the next step. Do not prepare the riser column until just prior to injecting the paste sample, experience from this research has shown that the temperature of the liquids in the riser column is most likely the most prominent source of error. The ambient air temperature can affect the temperature of test water and glycerin; and once $25^{\circ} \mathrm{C}\left(77^{\circ} \mathrm{F}\right)$ is exceeded, there is nothing else to do but to disassemble the 
apparatus and begin again. With the riser column being close to the upper temperature limit, by design, the sample needs to be chilled to keep the riser column liquid from exceeding the allowable temperature range. Once the riser column is prepared, double checking the level of the liquid is over the balanced collection dish will prevent any time from being wasted performing an invalid test. Consistency will determine accuracy. One of the last things observed with the AVA is that the time that is recorded for the start of a test is determined at the time "OK" is clicked on the input screen, not when the "Start" is clicked for the actual start of the test. This fact was exposed while preparing the apparatus for a subsequent test exposed (Trost 2009). 


\section{RECOMMENDATIONS}

The recommendations have been separated by three categories. The first category is modifications that could be made to the AVA hardware that would make the AVA3000 more in-field user friendly and more precise. The second category is modifications that could be made to the AVA software that would allow for increased use and easier to obtain test data in a useable format. The third category is for the future direction of research that would further assist the acceptability of the AVA technology for in-field use.

The following recommendations are for modifications of the AVA hardware to provide a more fault tolerant system:

- $\quad$ Provide more control of the temperature of the liquids in the riser column. After placing the two liquids in the riser column, the ambient air temperature affects the temperature of those liquids and therefore affecting the test temperature.

- Improve the o-ring seals in the base of the riser column. The o-rings contact the surface of the piston; and after a few tests, fines begin to propagate into the boundaries around the o-rings. When the piston is inserted into the base, the o-rings roll in their location and expose the fines to the area needing to hold seal, which could lead to volume change. A leak around the piston or syringe will allow the liquid from the riser column to leak out and therefore change the volume of liquid used for the air voids to rise according to Stoke's Law.

- Develop a stand-by, internal power storage, able to complete one test. The power supply is required to be constant. Using a generator in the field may cause a test to be lost due to running out of gas as the test stops immediately if the power supply is interrupted for even a second.

- Vibration device to assist removal of unwanted air bubbles created during set-up. Removing the air bubbles that find their way into the riser column during preparation of the test can be accomplished by using the brush 
included with the test equipment. This brush allows for the removal of the air bubbles, but a small vibration device could be included in the base that would assist and improve the removal of these air bubbles.

- $\quad$ Have a plastic buoyancy pan instead of glass. Having a glass buoyancy pan lends itself to damage. A plastic buoyancy pan would allow for minor impact without breaking and ending the ability to test, especially in the field, where spares may not be available.

- $\quad$ Connect the electrical adapters to the power cords, or include cords that do not require adapters. The AVA equipment was originally designed for European outlets; and the electrical cords included, require a $50-\mathrm{Hz}$ converter to work with $60-\mathrm{Hz}$ outlets. A delay or complete stoppage of infield testing will occur if the adaptors are not brought to the field with the AVA. Connecting the adapter to the actual power cord, or including power cords especially for each outlet design would eliminate this problem.

- Include a cordless percussion drill. The percussion drill included with the AVA is a standard hammer drill with electrical cord. To use in the field an electrical cord drill is not feasible due to mobility concerns, as a generator is required. The use of a cordless percussion drill is a necessity.

- Include a light source to illuminate the riser column to assist in monitoring the testing process during low light or nighttime conditions that exist outside of a lab.

The following recommendations are for modifications of the AVA software to provide a more fault tolerant system:

- Develop the test software for multiple computer operating platforms. Trying to find a laptop that could run the AVA-3000 software was difficult. It would be advantageous to the life of this technology to be compatible to different computer hardware set-ups and different operating systems and/or platforms.

- $\quad$ Provide a means of exporting the test data in a format that can be imported into spreadsheet software. The AVA-2000 could be exported to a file format that could be opened and modified by spreadsheet software. The AVA-3000 does not export to a spreadsheet file format, which can be seen as a move backwards in technology.

- $\quad$ Have the software set the beginning of test time based on the actual starting process and not the time in which the operator enters the test 
window. When setting up a test, mix information can be pre-entered into the software, and then advanced to the test window. Having the mix information already in the computer and having the computer advanced to the test window makes the final steps of beginning the test easier. Not having to complete these steps while preparing and entering the sample will prevent having to delay testing while entering the information. The software records the test time as the time in which the test window is opened, not the time that the test begins.

The following recommendations are for the future direction of research that would further assist the acceptability of the AVA technology for in-field use:

- Further concurrent in-field research with the AVA-3000 and conventional test methods is needed to develop more accurate correlations. Further congruent data will develop in to the comfortability needed for adoption of this newer technology.

- $\quad$ Further research needs to be performed to obtain a more precise correlation between the conventional test methods and the AVA for the volume of air. 


\section{REFERENCES}

AASHTO T-199-00 (2004). Air Content of Freshly Mixed Concrete by the Chase Indicator. (2004). American Association of State Highway Transportation Officials.

American Concrete Institute. "Concrete Terminology." American Concrete Institute Advancing concrete knowledge. 2009, available from http://www.concrete.org/Technical/CCT/FlashHelp/ACI_Terminology.htm; accessed 5 December 2009.

ASTM C-138-07. Standard Test Method for Density (Unit Weight), Yield, and Air Content (Gravimetric) of Concrete. (2007). A. International.

ASTM C-173-09. Standard Test Method for Air Content of Freshly Mixed Concrete by the Volumetric Method. (2009). A. International.

ASTM C-192 / C-192M-07. Standard Practice for Making and Curing Concrete Test Specimens in the Laboratory. (2007). A. International.

ASTM C-231-08. Standard Test Method for Air Content of Freshly Mixed Concrete by the Pressure Method. (2008). A. International.

ASTM C-31 / C-31M-09. Standard Practice for Making and Curing Concrete Test Specimens in the Field. (2009). A. International.

ASTM C-457-08. Standard Method for Microscopical Determination of Parameters of the Air-Void System in Hardened Concrete. (2008). A. International.

ASTM C-666 / C-666M-03(2008). Standard Test Method for Resistance of Concrete to Rapid Freezing and Thawing. (2008). A International.

Backstrom, J. E., The air-void systems of Highway Research Board cooperative concretes. U.S. Dept. of the Interior Bureau of Reclamation, Concrete Laboratory Report No. C- 824, April 6, 1956.

Cordon, William A. 1966. Freezing and Thawing of Concrete Mechanisms and Control. American Concrete Institute, Detroit. Iowa: The Iowa State University Press.

Disltehorst, Jennifer A., Kurgan, Gedoffery J. 2006. Development of Precision 
Statement for Determining Air Void Characteristics of Fresh Concrete with Use of Air Void Analyzer - 07-3479, Concrete Materials, TRB $86^{\text {th }}$ Annual Meeting, January 21-25, 2007.

Germann Insturments Inc. 2006. NDT Systems - Catalog NDT-2007. DK-2400

Copenhagen, Denmark; Evanston, Illinois. www.germann.org. 7 July 2008.

Kansas Department of Transportation (KDOT, 2007) Standard Specifications for State Road and Bridge Construction, Section 401 - Concrete. 2007.

Kentucky Standard Specifications for Road and Bridge Construction: Edition of 2008. Transportation Cabinet / Department of Highways. (KYTC, 2008). Approved for December 12, 2007. Office of Personnel Management, Policy Support Branch Frankfort, Kentucky.

KM 64-301-08. Sampling Fresh Concrete (ASTM C-172). (2008). Kentucky Department of Transportation, Kentucky Methods.

KM 64-302-08. Slump of Portland Cement Concrete (ASTM C-143). (2008). Kentucky Department of Transportation, Kentucky Methods.

KM 64-303-08. Air Content of Freshly Mixed Concrete by the Pressure Method (ASTM C-231-08). (2008). Kentucky Department of Transportation, Kentucky Methods.

KM 64-318-08. Temperature of Freshly Mixed Concrete (ASTM C-1064). (2008). Kentucky Department of Transportation, Kentucky Methods.

KM 64-324-08. Unit Weight of Concrete (ASTM C-138-07). (2008). Kentucky Department of Transportation, Kentucky Methods.

Kosmatka, S. H., Panarese, W.C. 1988. Design and Control of Concrete Mixtures; Thirteenth Edition. Portland Cement Association. Skokie, Illinois. 205 pp.

Magura, D. D., et al. Air Void Analyzer Evaluation, Report No. FHWA-SA-96-062. FHWA, U.S. Department of Transportation, Washington, D.C,. May 1996.

Mamlouk, M., Zaniewski, J., 2006. Materials for Civil and Construction Engineers Second Edition. Pearson Education Inc. Upper Saddle River, New Jersey: Pearson Prentice Hall

Mielenz, Richard C., Vladimir E. Wolkodoff, James E. Backstroms, and Richard W. Burrows. 1958. Origin, Evolution, and Effects of the Air Void System in Concrete: Part 4 The Air Void System in Job Concrete. Journal of the American Concrete Institute, vol. 55, no. 4, pp. 507-517. 
Nacert, Abdelghani. 2006. Effect of Specific Surface Area of Cements On the Mechanical Properties of Mortar. HBRC Journal Volume 2, No. 2: 6 pp.

Powers, T.C. 1975. "Freezing Effects in Concrete", Durability of Concrete. ACI SP 47, pp. 1-11. American Concrete Institute, Detroit.

Tanesi, Jussara; Meininger, Richard. Freeze-Thaw Resistance of Concrete With Marginal Air Content; Publication No. FHWA-HRT-06-117; December 2006; U.S. Department of Transportation; FHWA; Research, Development, and Technology, Turner-Fairbank Highway Research Center, 6300 Georgetown Pike, McLean, VA 221012296

Trost, Steve. Measuring Air Void Characteristics of Oklahoma Air- Entrained Concrete using the Air Void Analyzer (AVA) / Analyzing AVA Sources of Error, Report No. FHWA-OK-08-03. Oklahoma Department of Transportation, Stillwater, Oklahoma, January 2009.

Vanikar, Suneel N. 2004. The Advances and Barriers in Application of New Concrete Technology. Washington, D. C.: Federal Highway Administration, U.S. Department of Transportation, Washington, D. C., USA.

Wang, Kejin; Lomboy, Gilson; Steffes, Robert. Investigation into Freezing-Thawin Durability of Low-Permeability Concrete with and without AIr Entraining Agent. Iowa State University, National Concrete Pavement Technology Center ; Iowa Dept. of Transportation ; Ames \& Askey, IA : Iowa Concrete Paving Association, 2009-06, 48 pp. http://www.cptechcenter.org

Wang, Kejin; Mohamed-Metwally, Mohamed; Bektas, Fatih; Grove, Jim. Improving Variability and Precision of Air-Void Analyzer (AVA) Test Results and Developing Rational Specification Limits. Iowa State University, National Concrete Pavement Technology Center ; Iowa Dept. of Transportation ; Ames \& Askey, IA : Iowa Concrete Paving Association, 2008-06, 97 pp. http://www.cptechcenter.org 
APPENDIX 1 - CALCULATION EXAMPLES 


\section{VOLUME \% OF MORTAR CALCULATION}

Volume \% of Mortar Calculation

Given: $\%$ Volume of Concrete $=100.00 \%$

$\%$ Volume Air Measured $=5.0 \%$

$\%$ Volume Coarse Aggregate greater than $8 / 16 \mathrm{~mm}(1 / 4 \mathrm{inch})=40.00 \%$

Volume $\%$ of Mortar $=\%($ Concrete $)-\%$ (Air measured) $-\%($ Coarse Aggregate $>8 / 16$ $\mathrm{mm}(1 / 4$ inch $))=$

$\underline{\text { Volume } \% \text { of Mortar }}=100.00 \%-5.00 \%-40.00 \%=\underline{55.00 \%}$ 


\section{VOLUME \% OF PASTE CALCULATION}

Volume \% of Paste Calculation

Given: \% Volume of Cement $=11.00 \%$

$\%$ Volume of Water $=13.00 \%$

$\%$ Volume of Air Entrainer $=0.10 \%$

Volume $\%$ of Paste $=\%($ Cement $)+\%($ Water $)+\%($ Air Entrainer $)=$

$\underline{\text { Volume } \% \text { of Paste }}=11.00 \%+13.00 \%+0.10 \%=\underline{24.10 \%}$ 


\section{FINENESS MODULUS CALCULATION}

\begin{tabular}{c|c|c|c}
\hline Sieve Size & $\begin{array}{c}\text { Percentage of } \\
\text { individual fraction } \\
\text { retained by mass }\end{array}$ & $\begin{array}{c}\text { Cumulative percentage } \\
\text { passing, by mass }\end{array}$ & $\begin{array}{c}\text { Cumulative percentage } \\
\text { retained, by mass }\end{array}$ \\
\hline 3/8 inch & 0 & 100 & 0 \\
$\# 4$ & 1.8 & 98.2 & 1.8 \\
$\# 8$ & 10.6 & 87.6 & 12.4 \\
$\# 16$ & 16.6 & 71.0 & 29.0 \\
$\# 30$ & 13.4 & 57.6 & 42.4 \\
$\# 50$ & 32.8 & 24.8 & 75.2 \\
$\# 100$ & 20.1 & 4.7 & 95.3 \\
PAN & 4.7 & 0.1 & --- \\
Total & 100 & --- & 256.1 \\
\hline
\end{tabular}

Fineness Modulus $=$ Cumulative percentage retained, by mass divided by 100

Fineness Modulus $=256.1 / 100=2.56$ 
APPENDIX 2 - AVA-3000 DATA SHEETS 
Air Void Analyzer AVA-3000

Type Company name

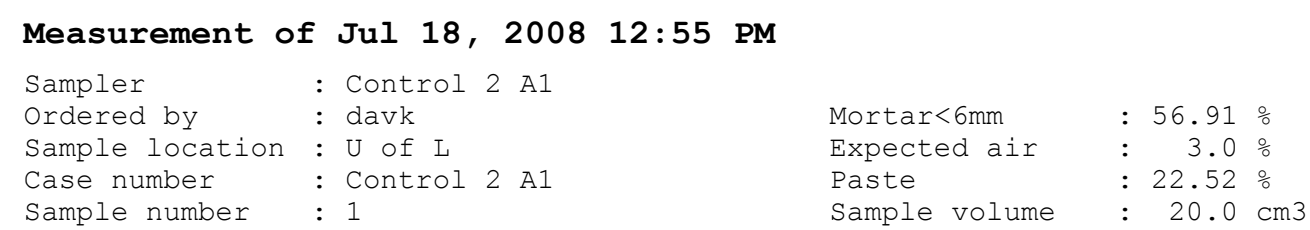

\section{Analysis}

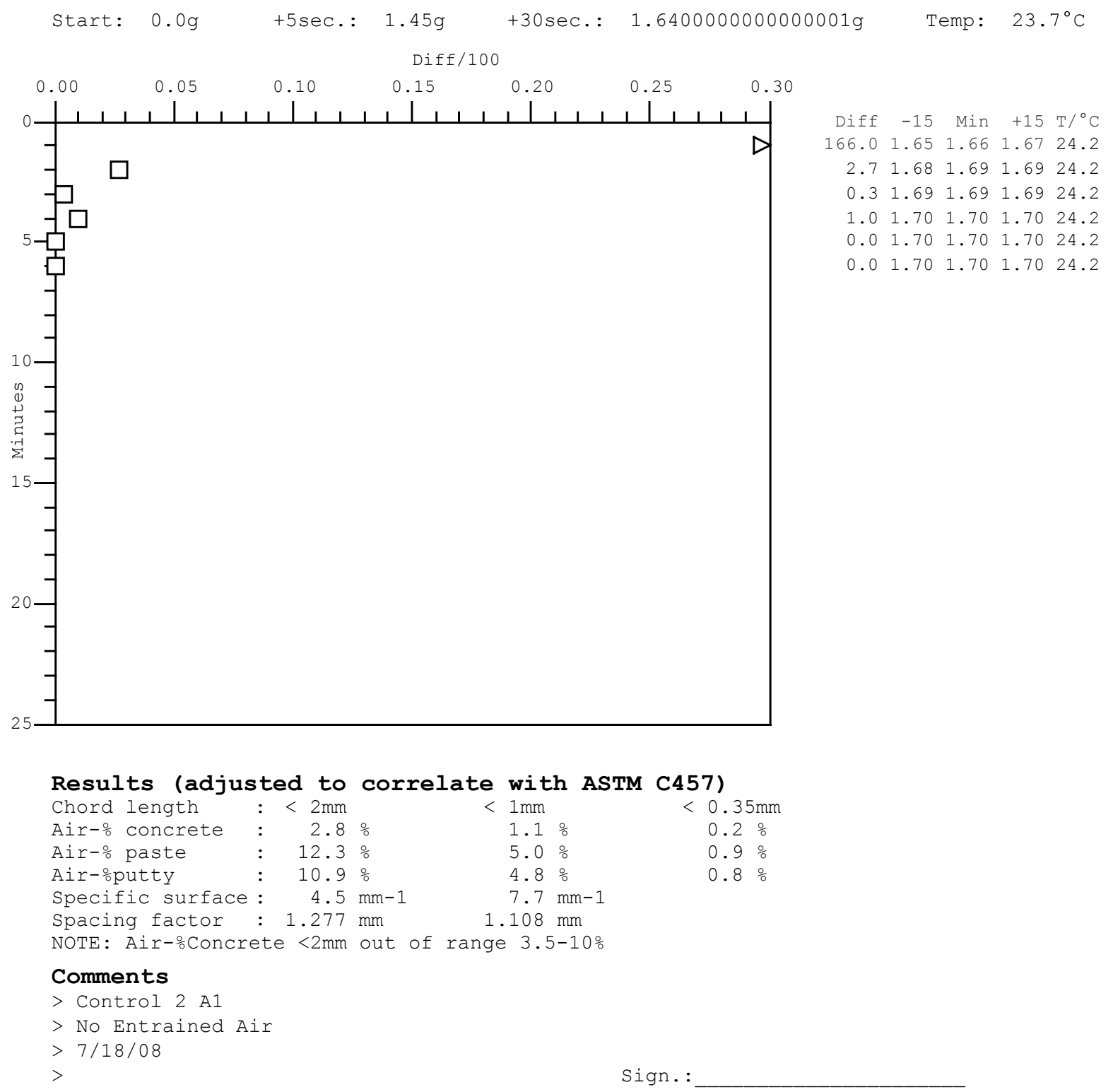


Air Void Analyzer AVA-3000

Type Company name

\section{Measurement of Jul 18, $200812: 55$ PM}

Case number : Control 2 Al

Sample number : 1

Distribution of air void content for voids $<2 \mathrm{~mm}$ (\%)

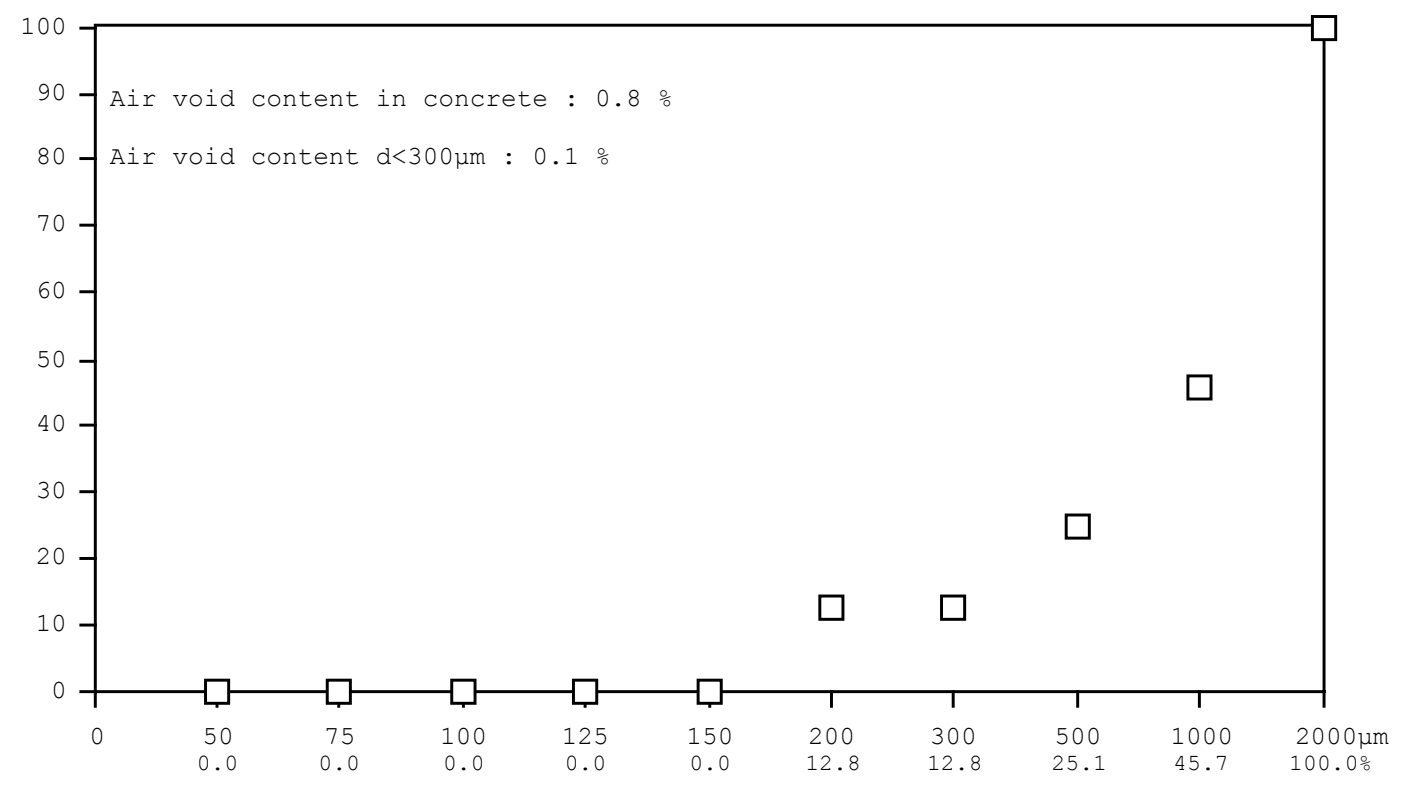

Distribution of air void content in cement paste for voids $2 \mathrm{~mm}$ ( $\%$ )

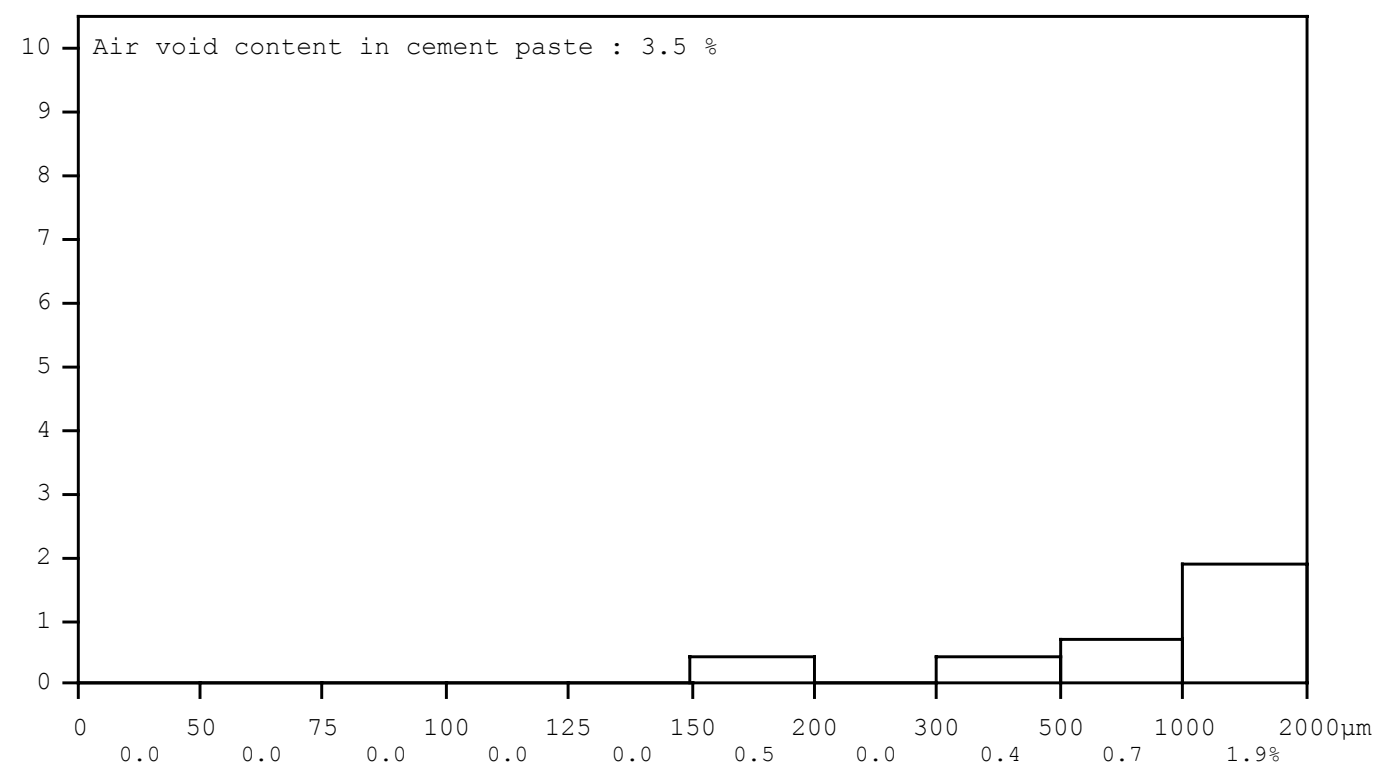


Air Void Analyzer AVA-3000

Type Company name

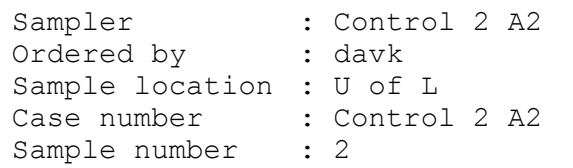

Sampler

Ordered by : davk

Sample location : U of L

Case number : Control 2 A2

Sample number : 2

\author{
A2
}

2

$\begin{array}{llrl}\text { Mortar<6mm } & : 56.91 \% \\ \text { Expected air } & : & 3.0 \% \\ \text { Paste } & : 22.52 \% \\ \text { Sample volume } & : & 20.0 \mathrm{~cm} 3\end{array}$

Analysis

+5 sec.: $0.37 \mathrm{~g} \quad+30 \mathrm{sec}: 0.65 \mathrm{~g} \quad$ Temp: $23.7^{\circ} \mathrm{C}$

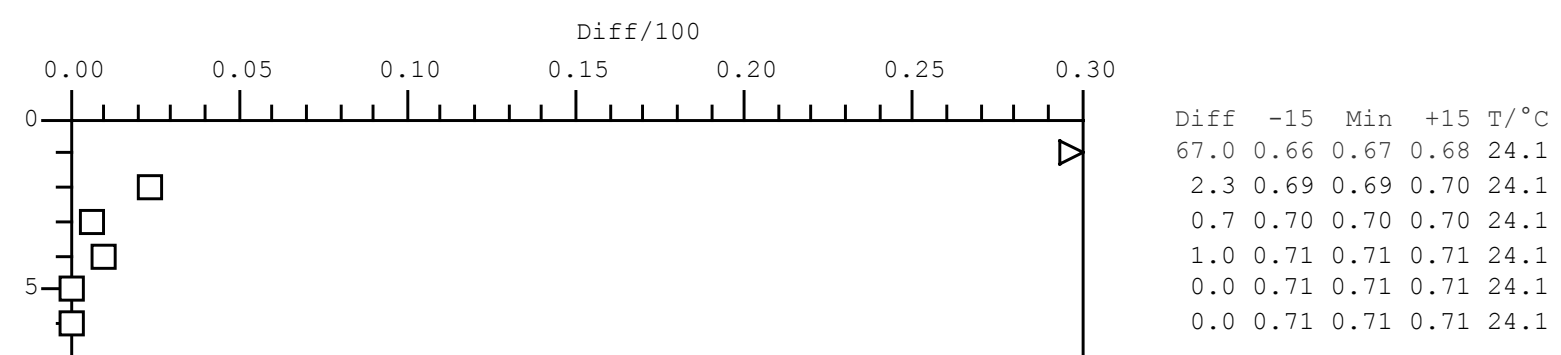

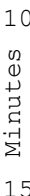

$15-1$

20

$-$

Results (adjusted to correlate with ASTM C457)

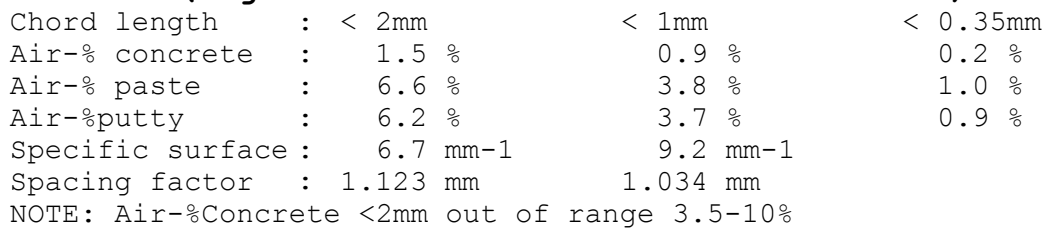

Air - Concrete $<2 \mathrm{~mm}$ out of range 3.5-10\%

\section{Comments}

$>$ Control 2A2

$>$ No Entrained Air

$>7 / 18 / 08$

$>$

Sign. : 
Air Void Analyzer AVA-3000

Type Company name

\section{Measurement of Jul 18, $20081: 24$ PM}

Case number : Control 2 A2

Sample number : 2

Distribution of air void content for voids $<2 \mathrm{~mm}$ (\%)

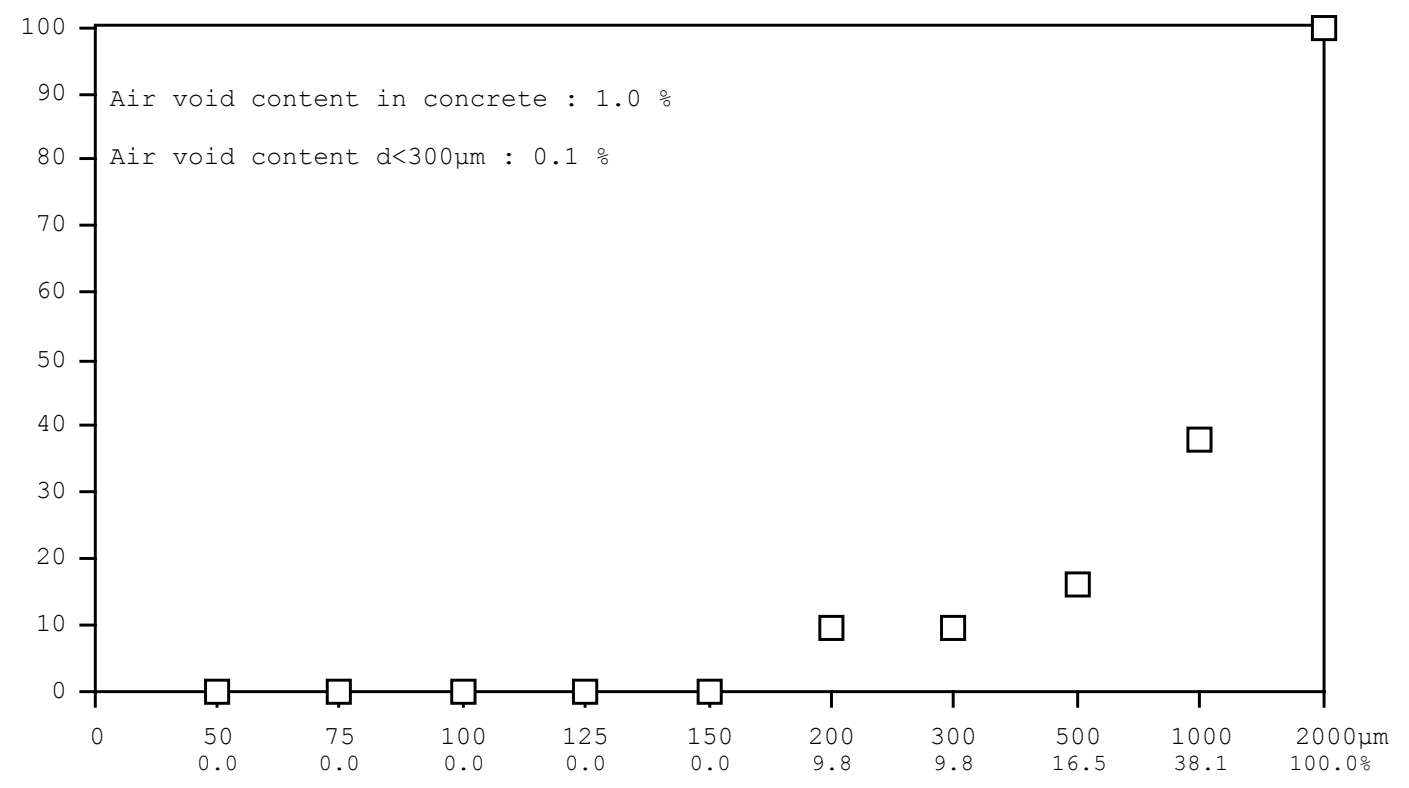

Distribution of air void content in cement paste for voids $<2 \mathrm{~mm}$ (\%)

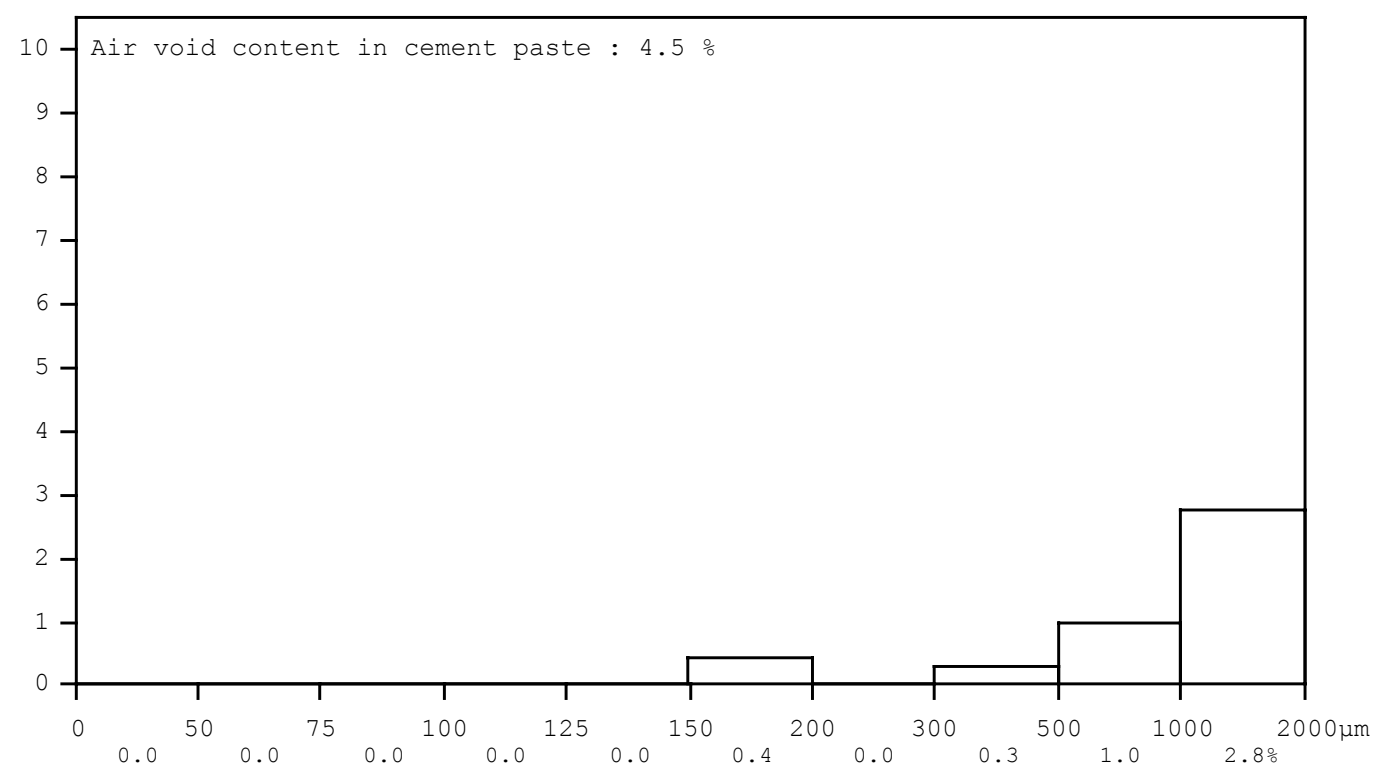


Air Void Analyzer AVA-3000

Type Company name

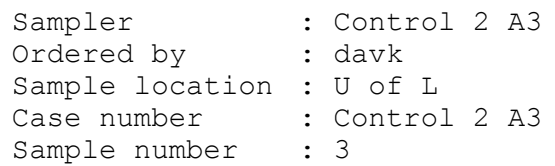

Sampler

Ordered by : davk

Sample location : U of L

Case number : Control 2 A3

Sample number : 3

\author{
A3
}

Mortar<6mm : $56.91 \%$

Expected air : $3.0 \%$

Paste : $22.52 \%$

Sample volume : $20.0 \mathrm{~cm} 3$

\section{Analysis}

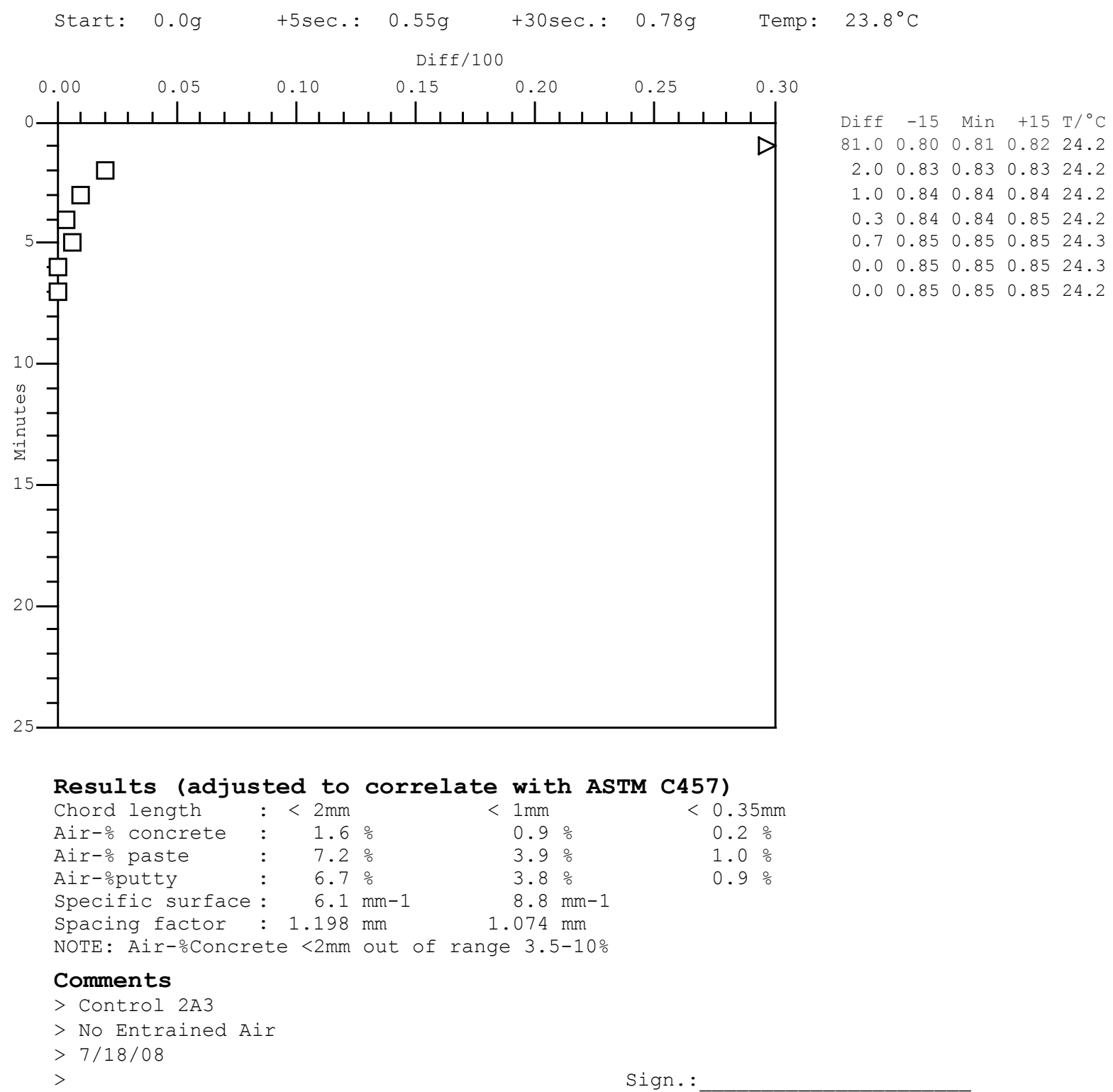


Air Void Analyzer AVA-3000

Type Company name

\section{Measurement of Jul 18, $20081: 54$ PM}

Case number : Control 2 A3

Sample number : 3

Distribution of air void content for voids $<2 \mathrm{~mm}$ (\%)

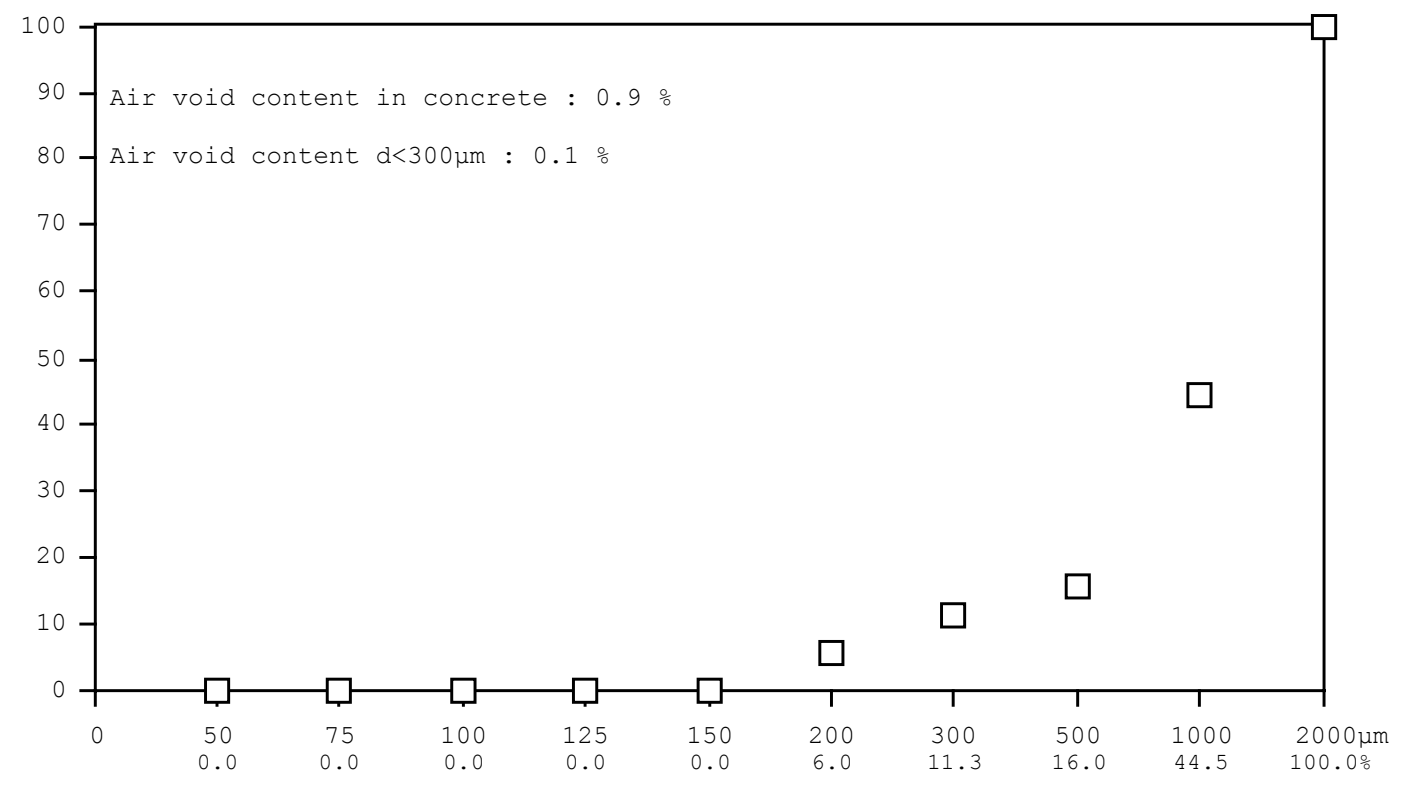

Distribution of air void content in cement paste for voids $2 \mathrm{~mm}$ ( $\%$ )

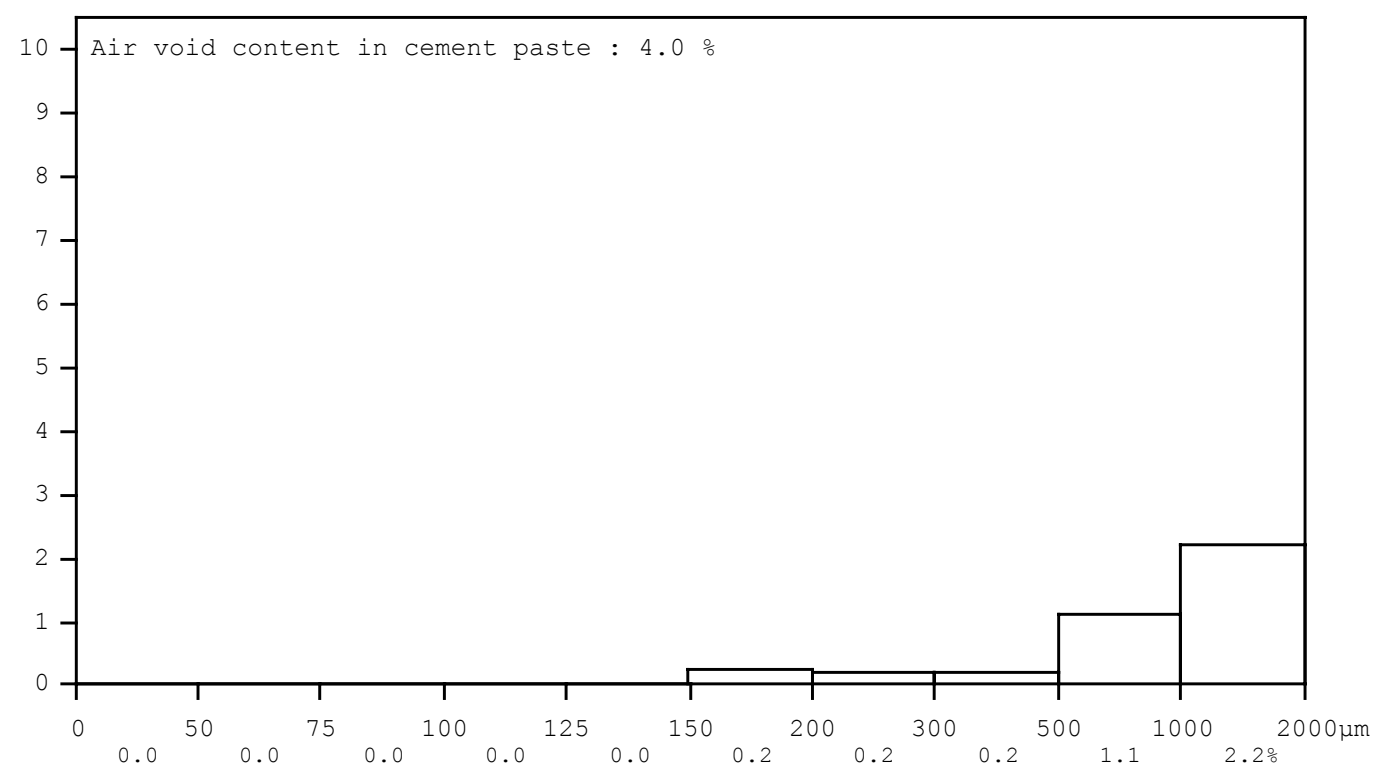


Air Void Analyzer AVA-3000

Type Company name

Measurement of Jul 18, 2008 2:10 PM

Sampler

: Control 2 B1

Ordered by : davk

Sample location : U of L

Case number : Control 2 B1

Sample number : 1

$\begin{array}{llrl}\text { Mortar<6mm } & : 57.71 \% \\ \text { Expected air } & : & 2.2 \% \\ \text { Paste } & : 22.52 \% \\ \text { Sample volume } & : 20.0 \mathrm{~cm} 3\end{array}$

Analysis

Start: $0.0 \mathrm{~g}$

+5 sec.: $\quad 0.66 \mathrm{~g}$

+30 sec.:

$0.89 \mathrm{~g}$

Temp:

$23.6^{\circ} \mathrm{C}$

Diff/100

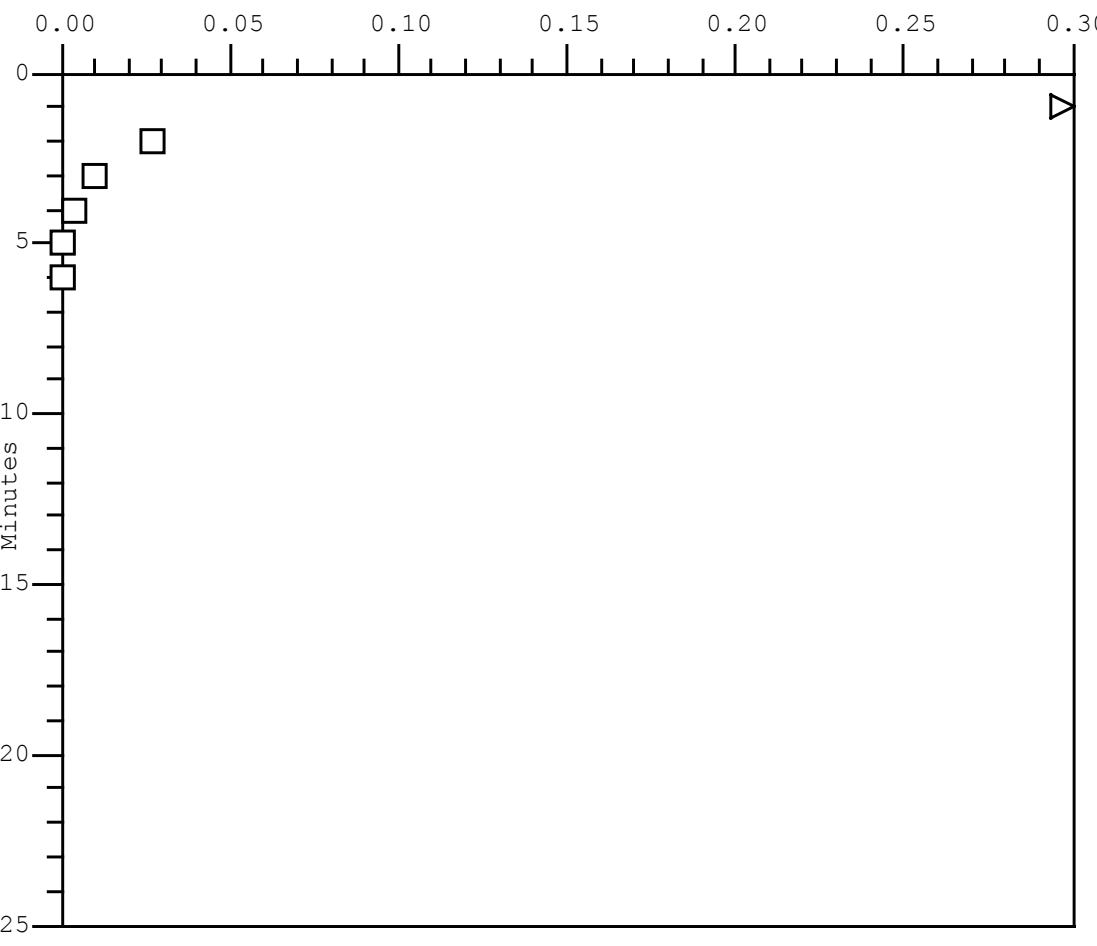

Diff $-15 \mathrm{Min}+15 \mathrm{~T} /{ }^{\circ} \mathrm{C}$

$\begin{array}{lllll}91.0 & 0.90 & 0.91 & 0.92 & 23.9\end{array}$

$\begin{array}{llllll}2.7 & 0.93 & 0.94 & 0.94 & 24.1\end{array}$

$\begin{array}{llllll}1.0 & 0.94 & 0.95 & 0.95 & 24.1\end{array}$

$\begin{array}{lllll}0.3 & 0.95 & 0.95 & 0.95 & 23.9\end{array}$

$\begin{array}{lllll}0.0 & 0.95 & 0.95 & 0.95 & 24.1\end{array}$

$\begin{array}{llllll}0.0 & 0.95 & 0.95 & 0.95 & 24.1\end{array}$

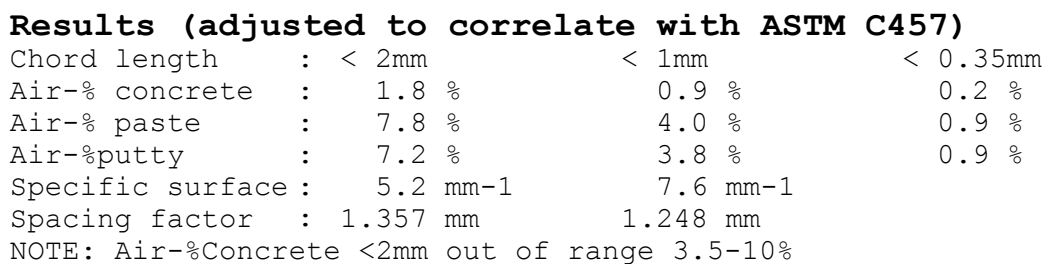

NOTE: Air-\%Concrete $<2 \mathrm{~mm}$ out of range $3.5-10 \%$

\section{Comments}

$>$ Control 2B1

$>$ No Entrained Air

$>7 / 18 / 08$

$>$

Sign. : 
Air Void Analyzer AVA-3000

Type Company name

\section{Measurement of Jul 18, $20082: 10$ PM}

Case number : Control 2 B1

Sample number : 1

Distribution of air void content for voids $<2 \mathrm{~mm}$ ( $\left.\frac{\circ}{0}\right)$

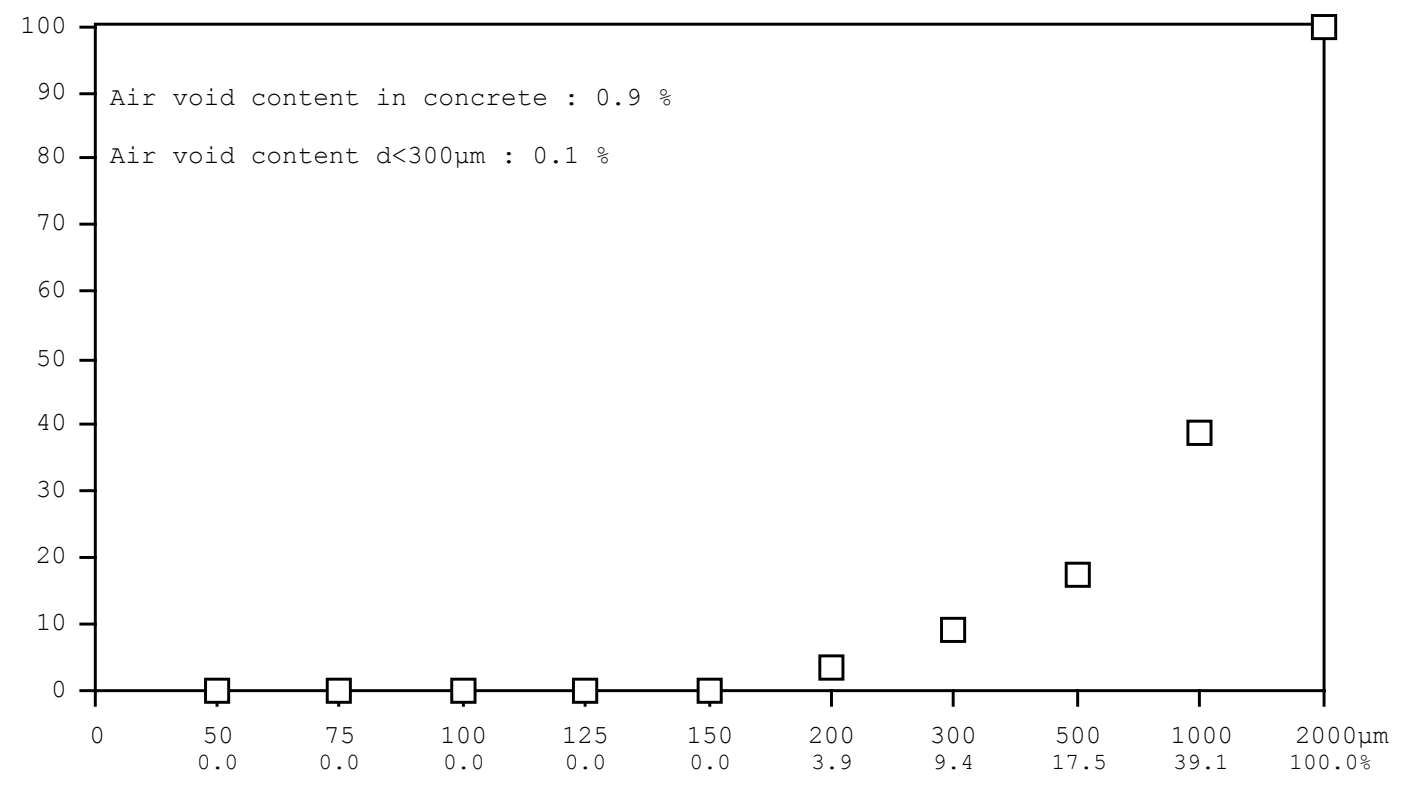

Distribution of air void content in cement paste for voids $<2 \mathrm{~mm}$ (\%)

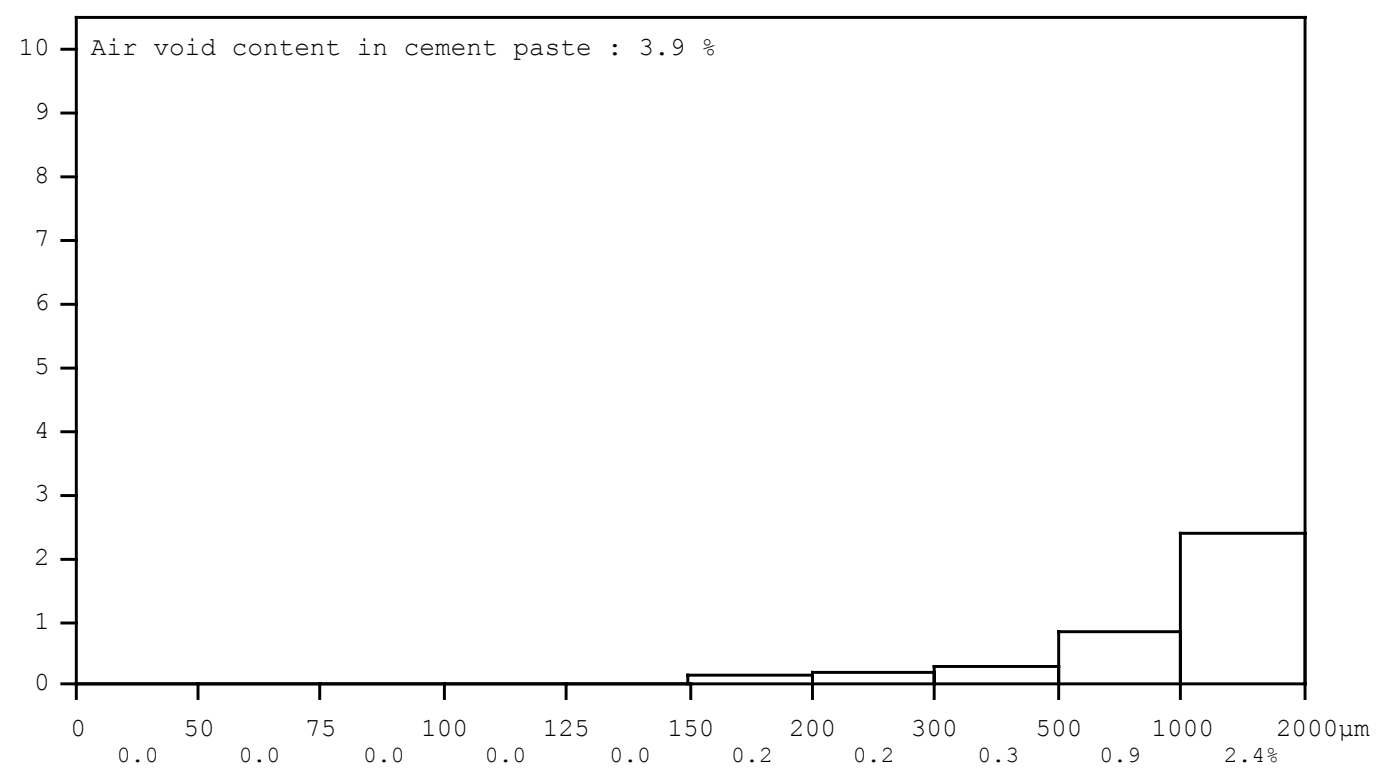


Air Void Analyzer AVA-3000

Type Company name

\section{Measurement of Jul 18, 2008 2:47 PM}

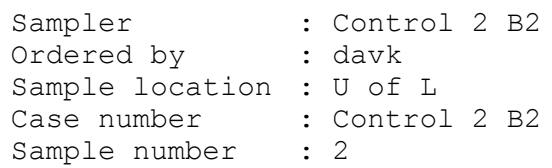

Mortar $<6 \mathrm{~mm} \quad: 57.71 \%$

Expected air : $2.2 \%$

Paste : $22.52 \%$

Sample volume : $20.0 \mathrm{~cm} 3$

\section{Analysis}

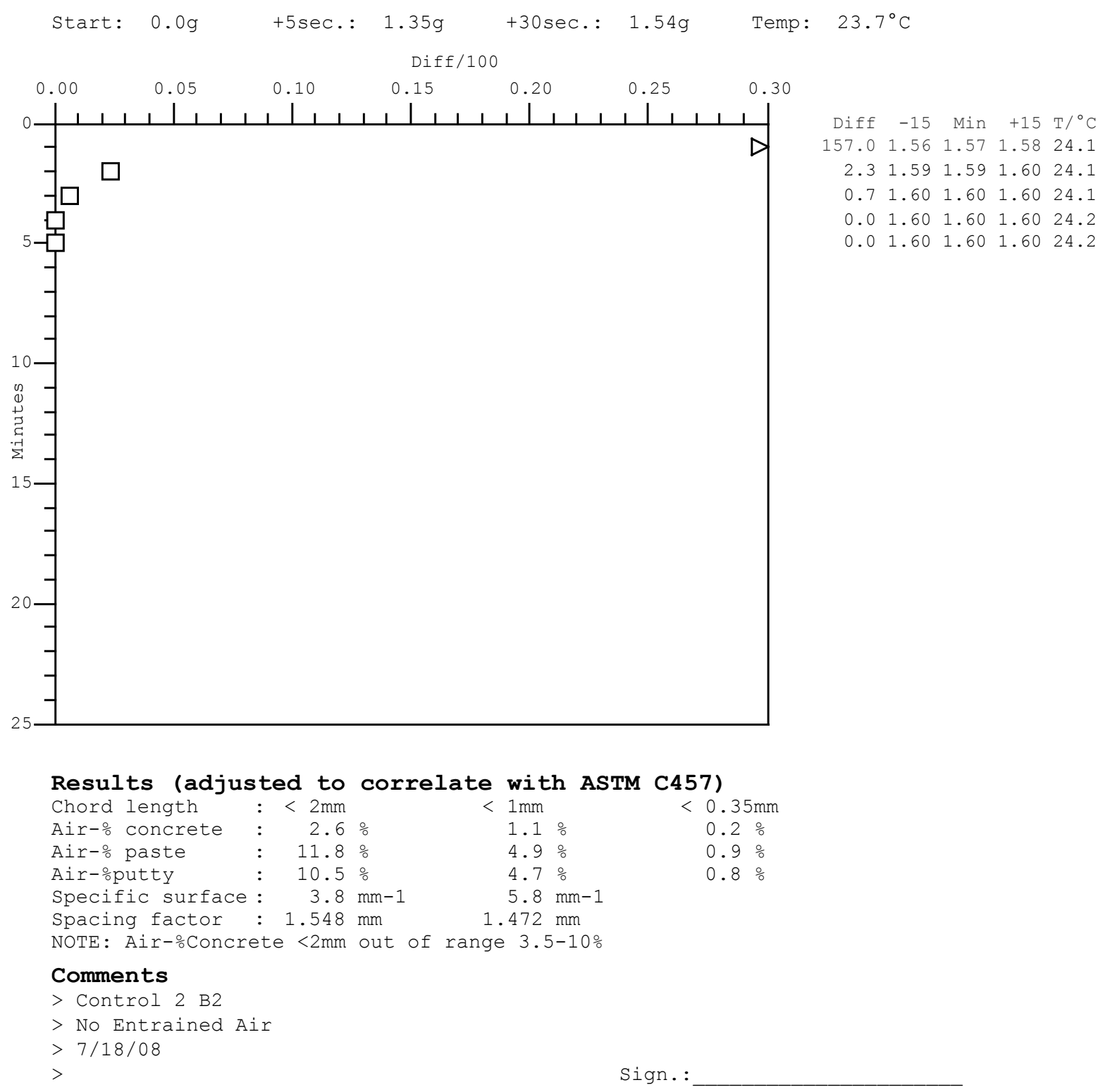


Air Void Analyzer AVA-3000

Type Company name

\section{Measurement of Jul 18, $20082: 47$ PM}

Case number : Control 2 B2

Sample number : 2

Distribution of air void content for voids $<2 \mathrm{~mm}$ (\%)

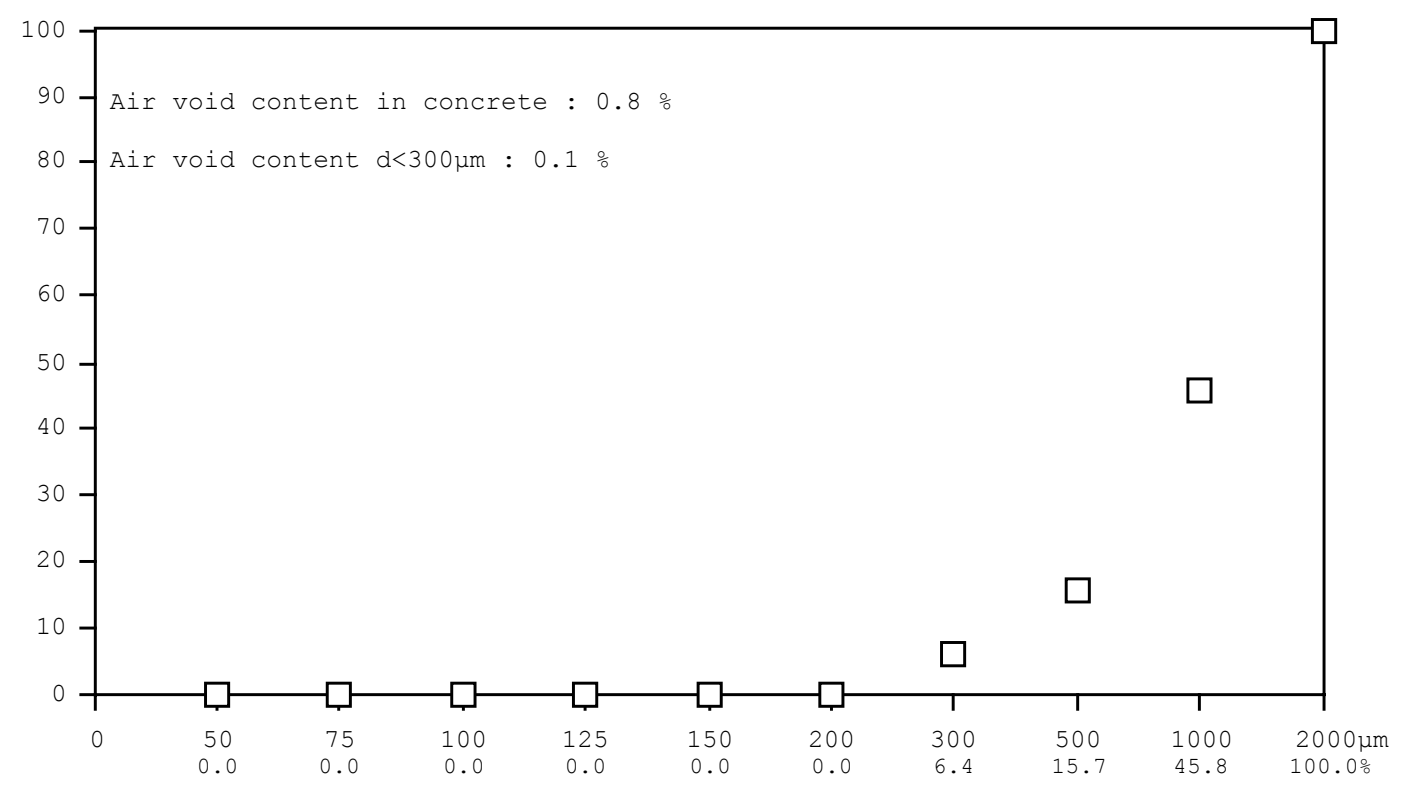

Distribution of air void content in cement paste for voids $<2 \mathrm{~mm}$ (\%)

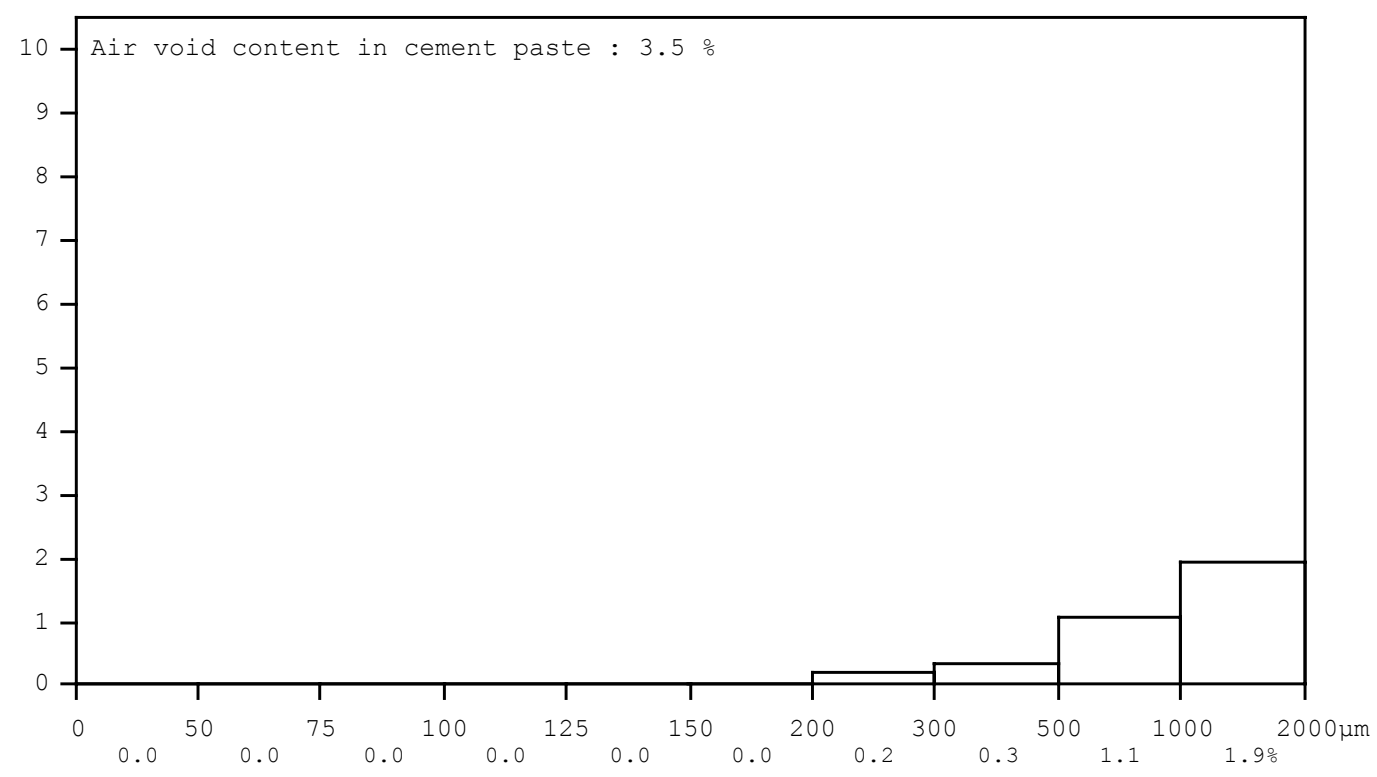


Air Void Analyzer AVA-3000

Type Company name

Measurement of Jul 18, 2008 3:15 PM

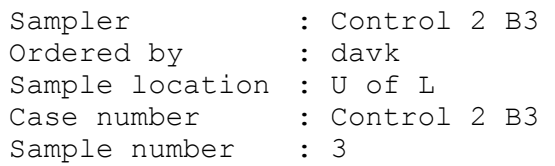

Sample number : 3

$\begin{array}{llr}\text { Mortar } 6 \mathrm{~mm} & : & 57.71 \% \\ \text { Expected air } & : & 2.2 \% \\ \text { Paste } & : & 22.52 \% \\ \text { Sample volume } & : & 20.0 \mathrm{~cm} 3\end{array}$

Analysis

+5 sec.: $0.32 g$

+30 sec.: $0.52 \mathrm{~g}$

Temp: $\quad 23.7^{\circ} \mathrm{C}$

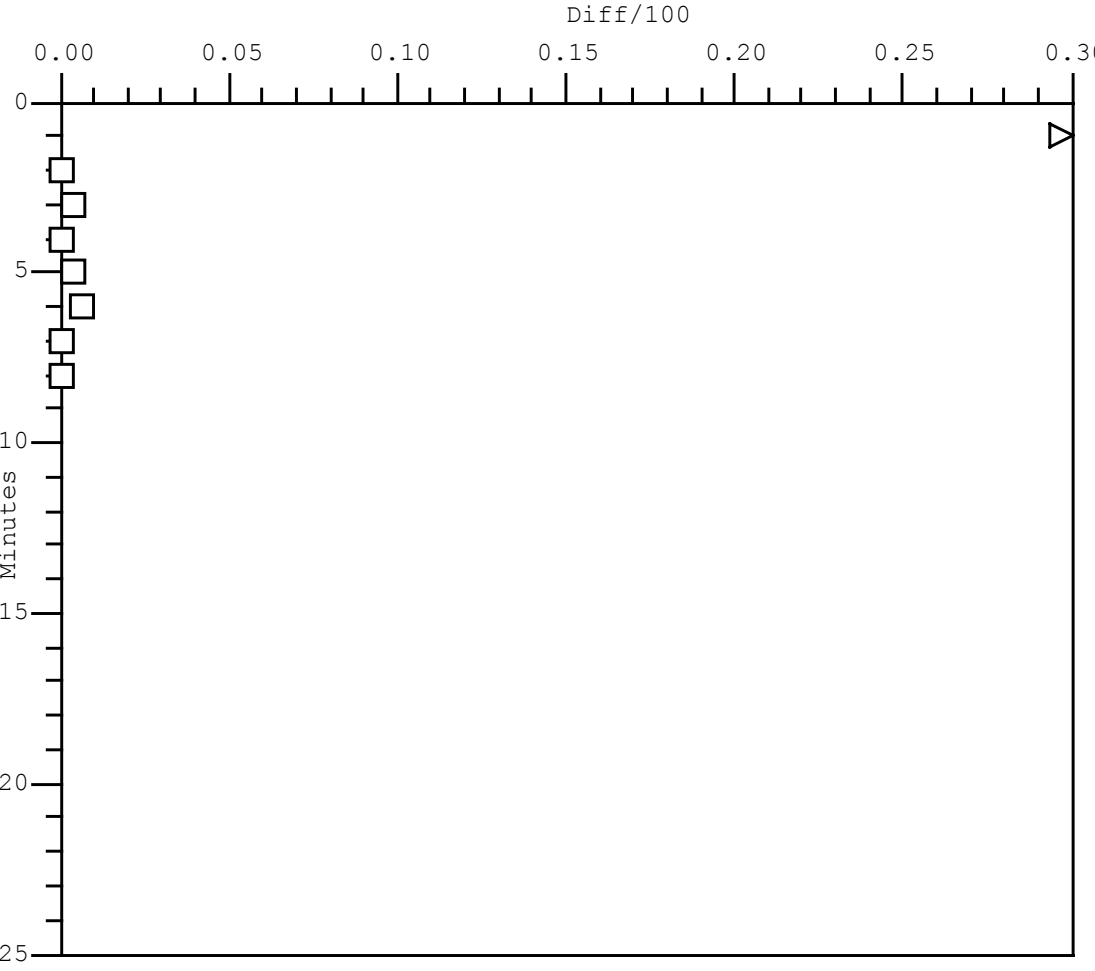

$$
\begin{array}{rrrrr}
\text { Diff } & -15 & \text { Min } & +15 & \mathrm{~T} /{ }^{\circ} \mathrm{C} \\
53.0 & 0.53 & 0.53 & 0.53 & 24.1 \\
0.0 & 0.18 & 0.19 & 0.19 & 24.1 \\
0.3 & 0.19 & 0.19 & 0.19 & 24.1 \\
0.0 & 0.19 & 0.19 & 0.19 & 24.1 \\
0.3 & 0.19 & 0.19 & 0.20 & 24.1 \\
0.7 & 0.20 & 0.20 & 0.20 & 24.2 \\
0.0 & 0.20 & 0.20 & 0.20 & 24.2 \\
0.0 & 0.20 & 0.20 & 0.20 & 24.1
\end{array}
$$

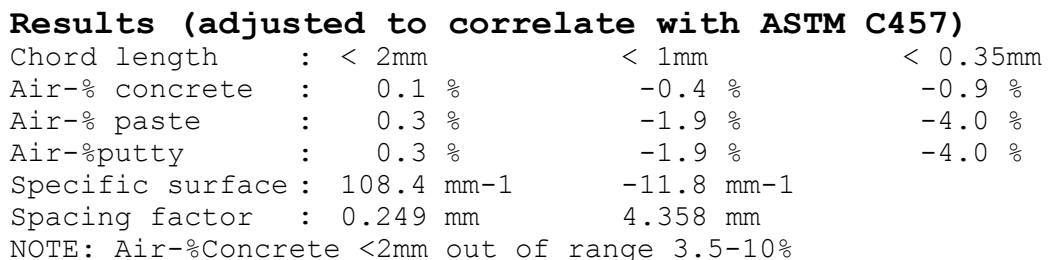

\section{Comments}

\footnotetext{
$>$ Control 2B3

$>$ No Entrained Air

$>7 / 18 / 08$
}

Sign. : 
Air Void Analyzer AVA-3000

Type Company name

Measurement of Jul 18, $20083: 15$ PM

Case number : Control 2 B3

Sample number : 3

Distribution of air void content for voids $<2 \mathrm{~mm}$ (\%)

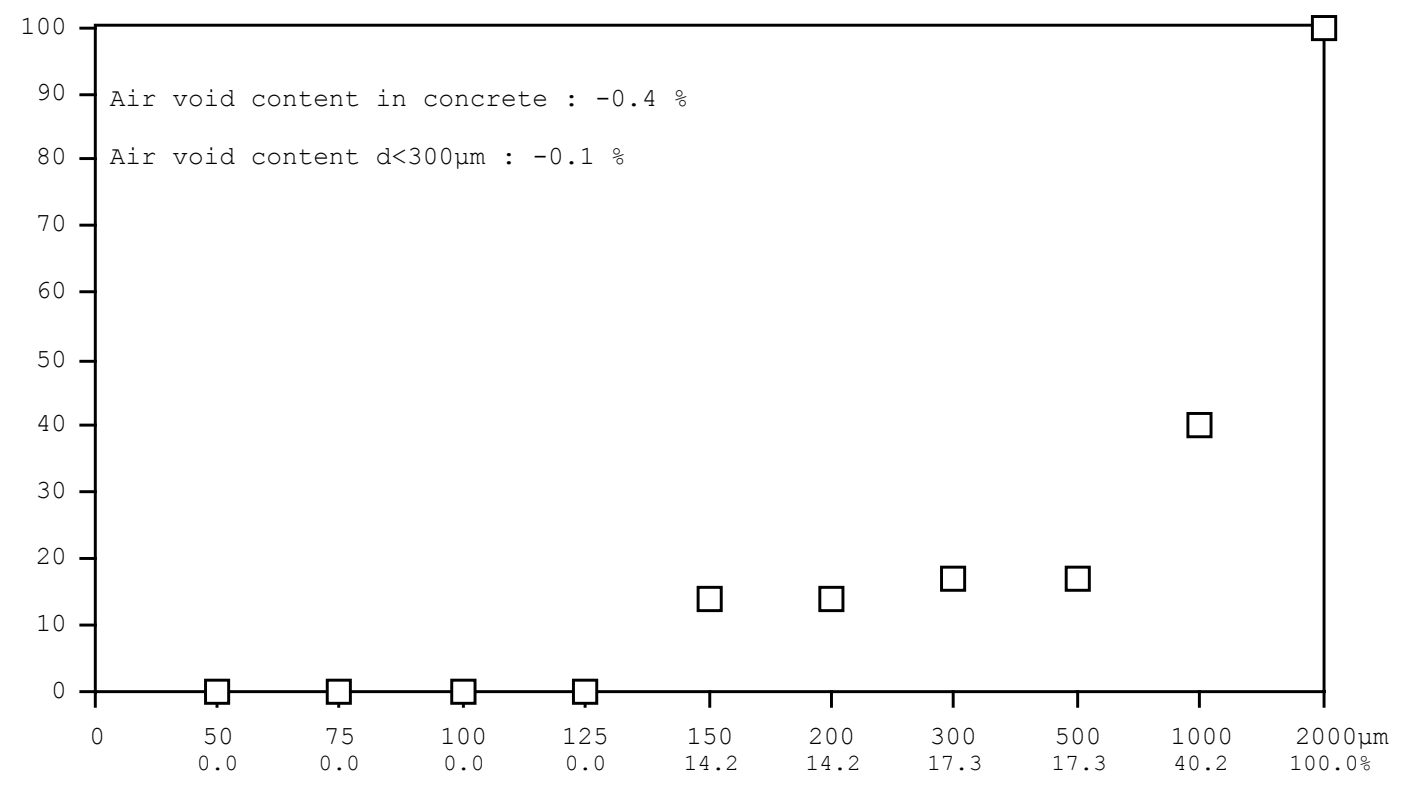

Distribution of air void content in cement paste for voids $<2 \mathrm{~mm}$ (\%)

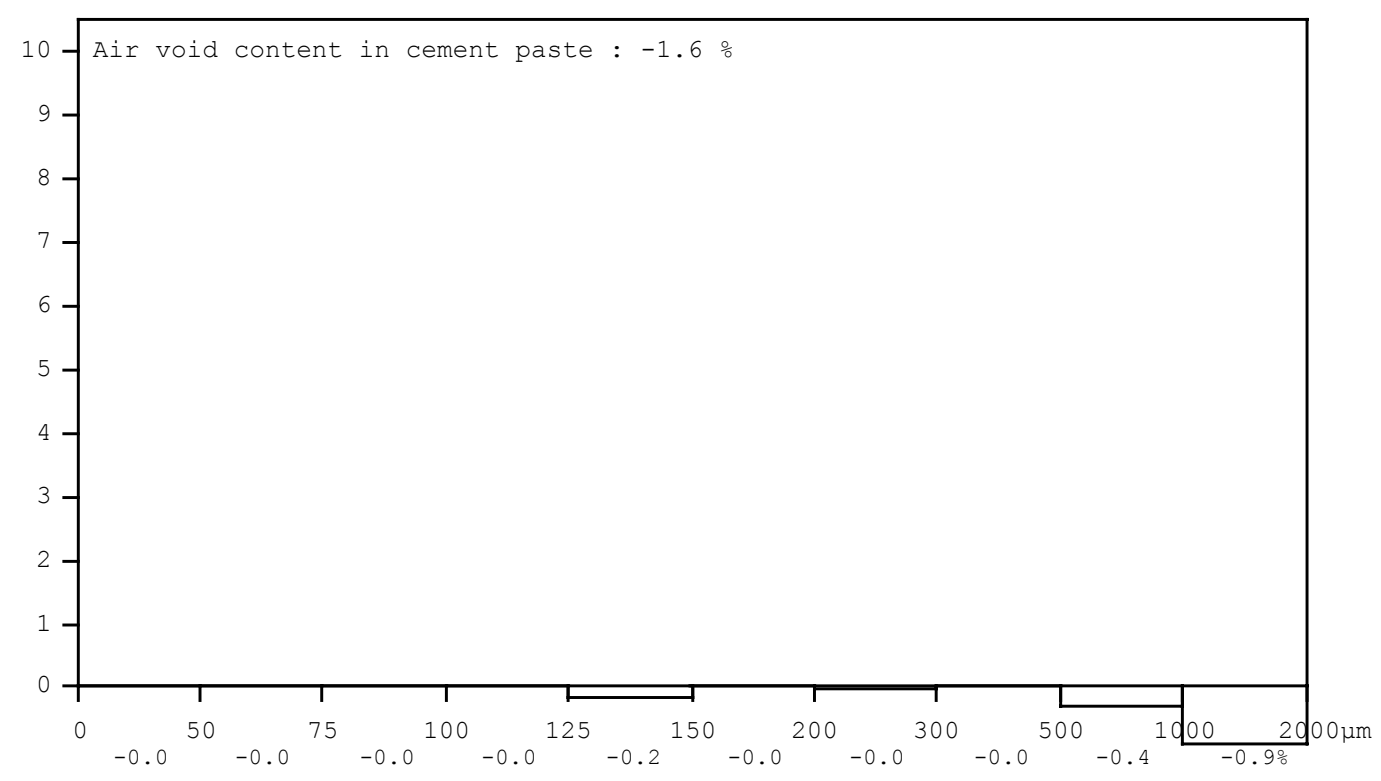


Air Void Analyzer AVA-3000

Type Company name

Measurement of Sep 18, $20082: 47$ PM

Sampler

Ordered by : davk

Sample location : U of L

Case number : Control $2 \mathrm{Cl}$

Sample number : 1

$\begin{array}{llrl}\text { Mortar<6mm } & : 57.51 \% \\ \text { Expected air } & : & 2.4 \div \\ \text { Paste } & : 22.52 \% \\ \text { Sample volume } & : 20.0 \mathrm{~cm} 3\end{array}$

Analysis

Start: $0.0 \mathrm{~g}$

+5 sec.: $0.19 \mathrm{~g}$

+30 sec.:

$0.34 \mathrm{~g}$

Temp: $\quad 23.5^{\circ} \mathrm{C}$

Diff/100

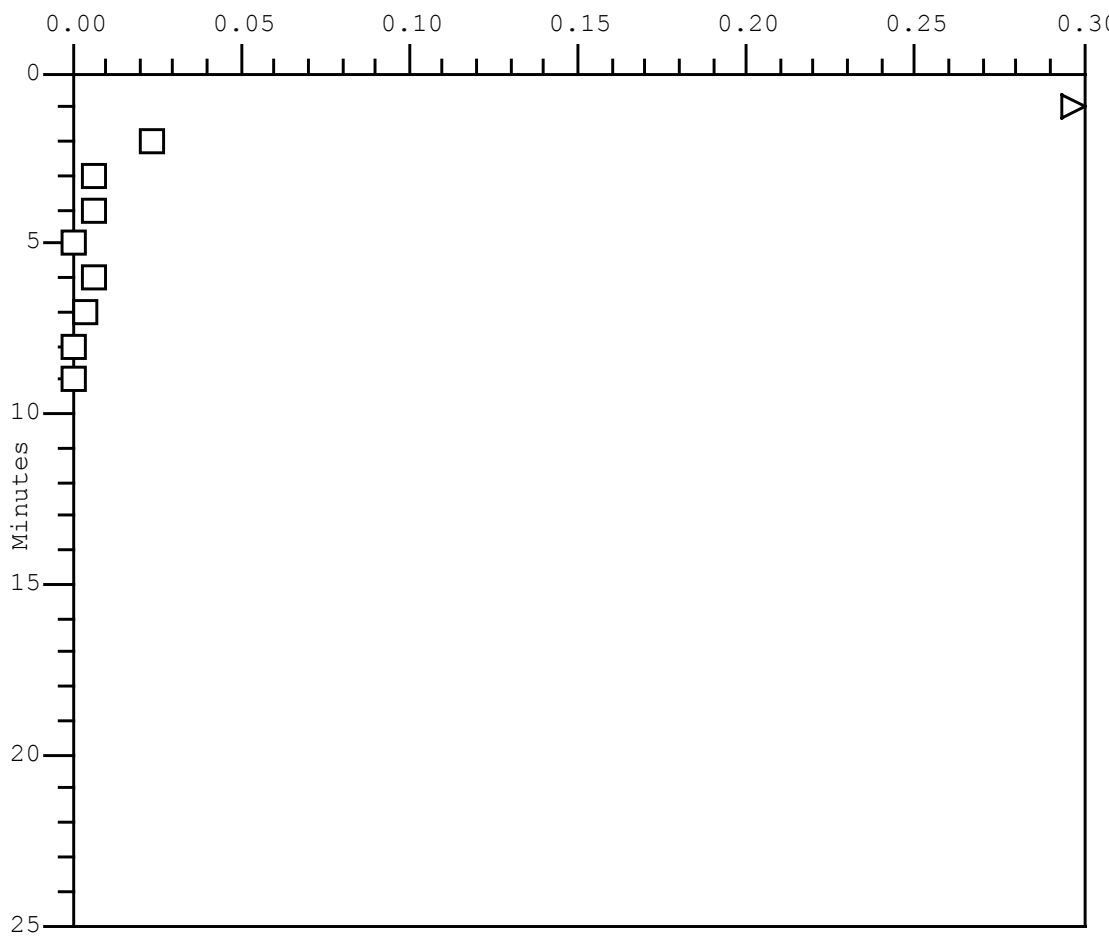

Diff -15 Min $+15 \mathrm{~T} /{ }^{\circ} \mathrm{C}$

$\begin{array}{llllll}37.3 & 0.37 & 0.37 & 0.38 & 23.9\end{array}$

$\begin{array}{llllll}2.3 & 0.39 & 0.40 & 0.40 & 23.9\end{array}$

$\begin{array}{llllll}0.7 & 0.40 & 0.40 & 0.41 & 23.9\end{array}$

$\begin{array}{lllll}0.7 & 0.41 & 0.41 & 0.41 & 23.9\end{array}$

$\begin{array}{llllll}0.0 & 0.41 & 0.41 & 0.41 & 23.9\end{array}$

$\begin{array}{lllll}0.7 & 0.41 & 0.42 & 0.42 & 23.9\end{array}$

$\begin{array}{lllll}0.3 & 0.42 & 0.42 & 0.42 & 23.9\end{array}$

$\begin{array}{lllll}0.0 & 0.42 & 0.42 & 0.42 & 24.1\end{array}$

$\begin{array}{lllll}0.0 & 0.42 & 0.42 & 0.42 & 23.9\end{array}$

Results (adjusted to correlate with ASTM C457)

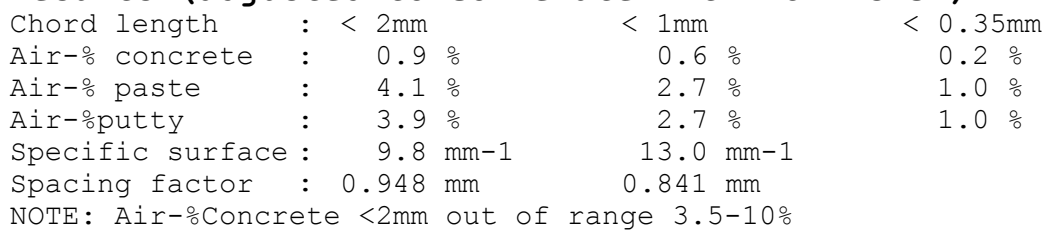

$0.00 .420 .42-0.4223 .9$

\section{Comments}

$>$ control $3 \mathrm{Cl}$
$>09 / 18 / 08 \quad 3: 47 \mathrm{pm}$
$>$

Sign.: 
Air Void Analyzer AVA-3000

Type Company name

\section{Measurement of Sep 18, $20082: 47$ PM}

Case number : Control $2 \mathrm{Cl}$

Sample number : 1

Distribution of air void content for voids $<2 \mathrm{~mm}$ (\%)

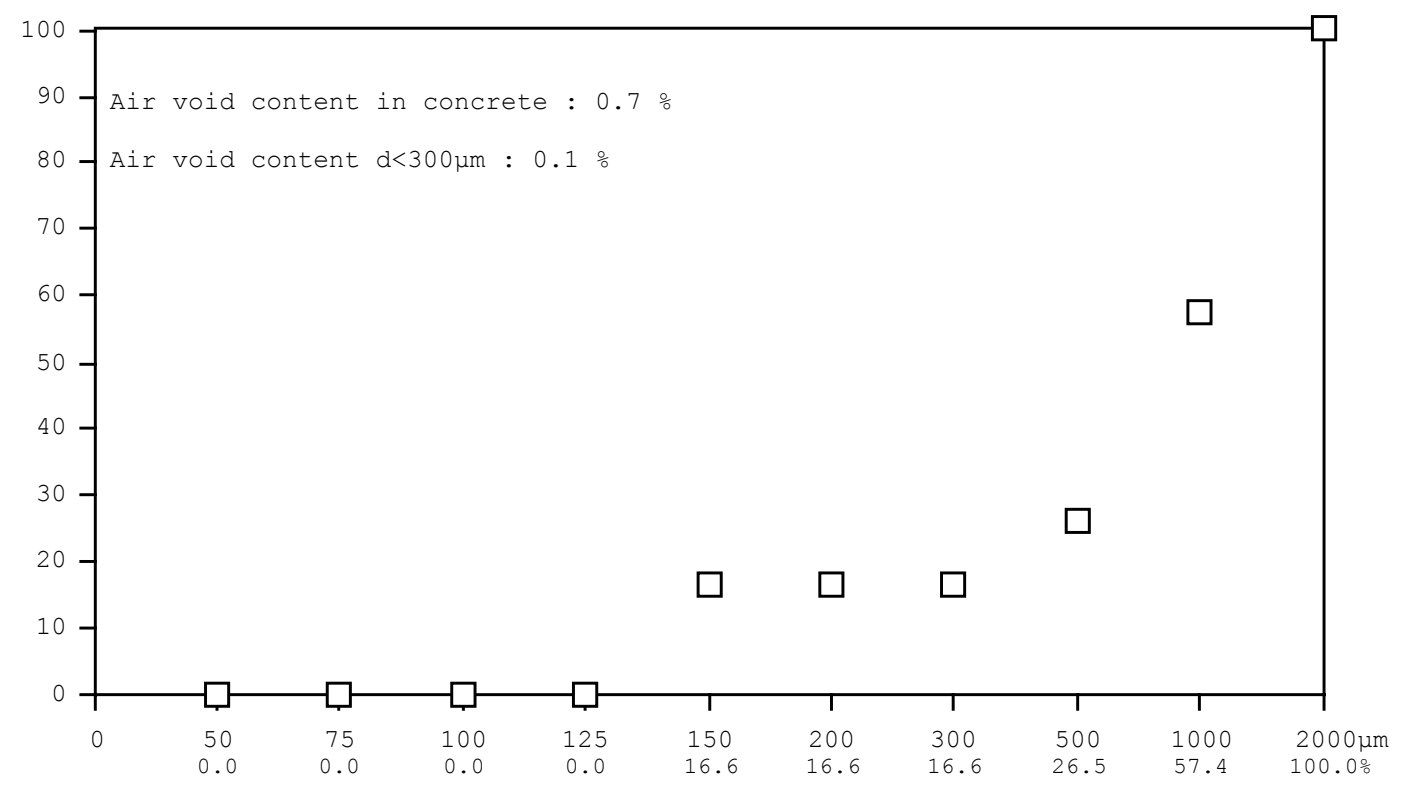

Distribution of air void content in cement paste for voids $2 \mathrm{~mm}$ ( $\%$ )

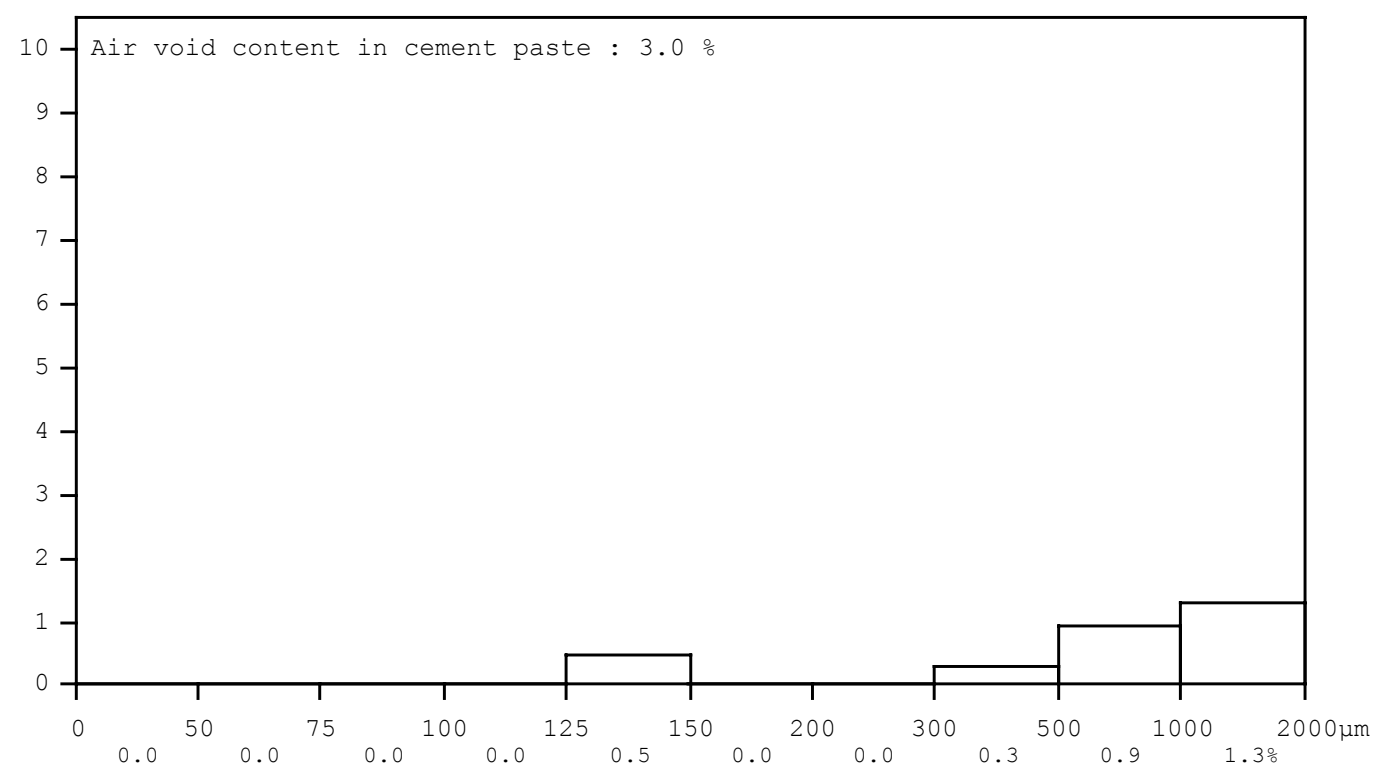


Air Void Analyzer AVA-3000

Type Company name

Measurement of Sep 18, 2008 3:12 PM

Sampler

Ordered by : davk

Sample location : U ofL K

Case number : Control 2 C2

Sample number : 2

$\begin{array}{llrl}\text { Mortar<6mm } & : 57.51 \% \\ \text { Expected air } & : & 2.4 \div \\ \text { Paste } & : 22.52 \% \\ \text { Sample volume } & : 20.0 \mathrm{~cm} 3\end{array}$

Analysis

Start: $0.0 \mathrm{~g}$

+5 sec.: $0.06 \mathrm{~g}$

$+30 \mathrm{sec} .:$

$0.45 \mathrm{~g}$

Temp:

$23.6^{\circ} \mathrm{C}$

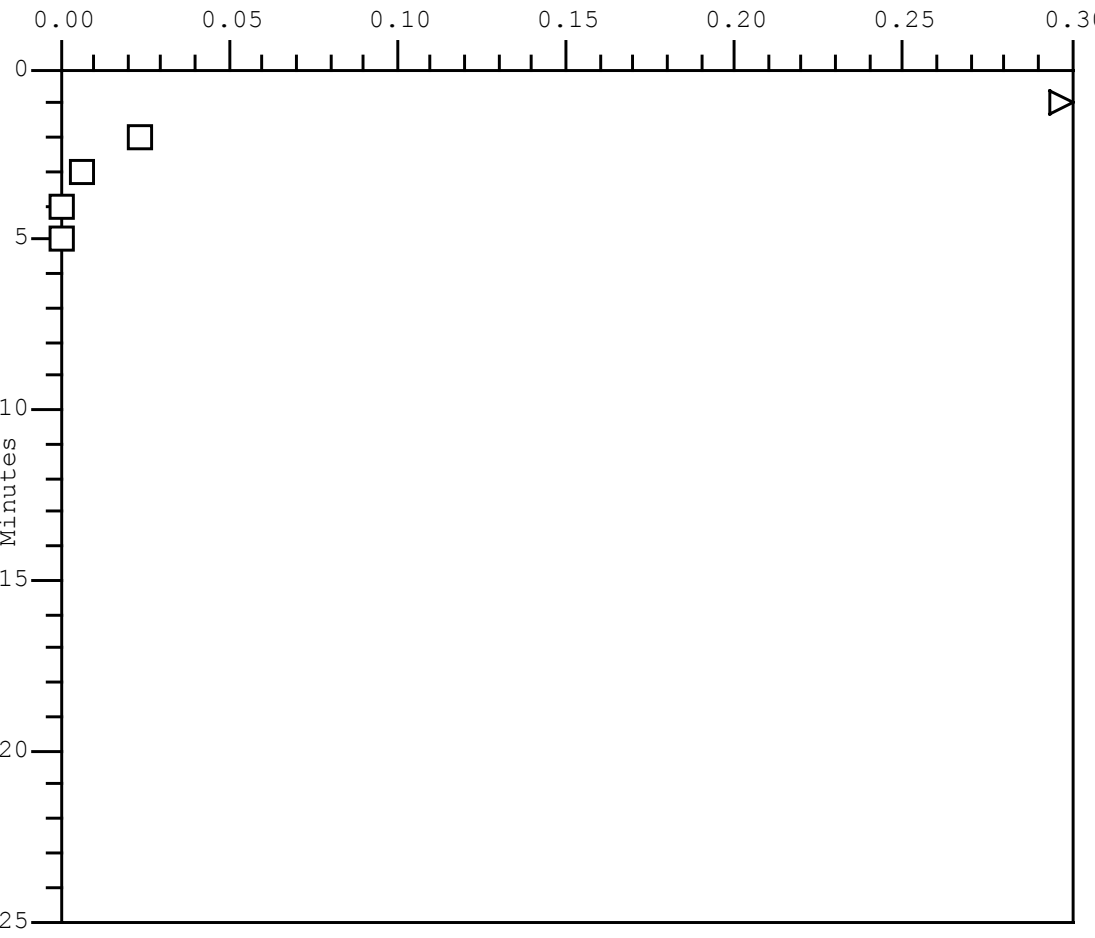

Diff $-15 \mathrm{Min}+15 \mathrm{~T} /{ }^{\circ} \mathrm{C}$

$\begin{array}{llllll}48.0 & 0.47 & 0.48 & 0.49 & 24.1\end{array}$

$\begin{array}{llllll}2.3 & 0.50 & 0.50 & 0.51 & 24.1\end{array}$

$\begin{array}{lllll}0.7 & 0.51 & 0.51 & 0.51 & 24.1\end{array}$

$\begin{array}{lllll}0.0 & 0.51 & 0.51 & 0.51 & 24.1\end{array}$

$\begin{array}{llllll}0.0 & 0.51 & 0.51 & 0.51 & 24.1\end{array}$

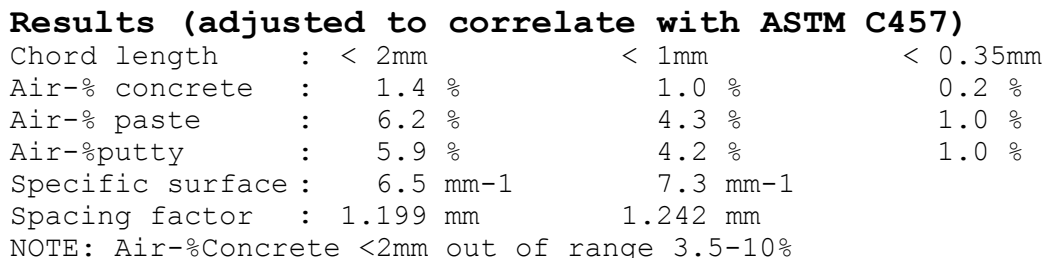

NOTE: Air-\%Concrete <2mm out of range 3.5-10\%

\section{Comments}

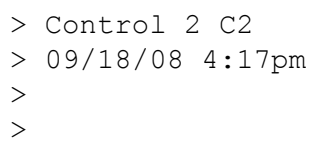

Sign. : 
Air Void Analyzer AVA-3000

Type Company name

\section{Measurement of Sep 18, 2008 3:12 PM}

Case number : Control $2 \mathrm{C} 2$

Sample number : 2

Distribution of air void content for voids $<2 \mathrm{~mm}$ ( $\left.\frac{\circ}{0}\right)$

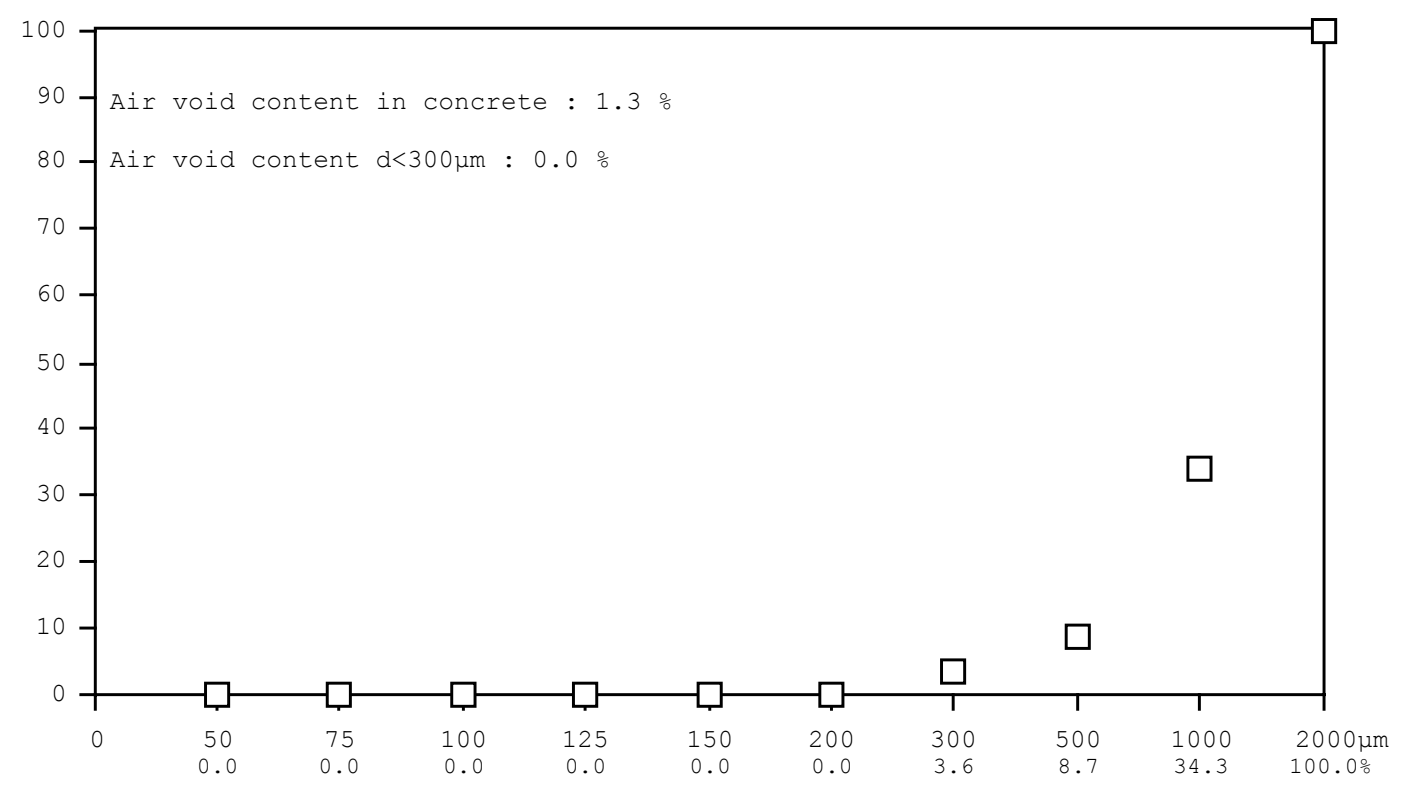

Distribution of air void content in cement paste for voids $<2 \mathrm{~mm}$ (\%)

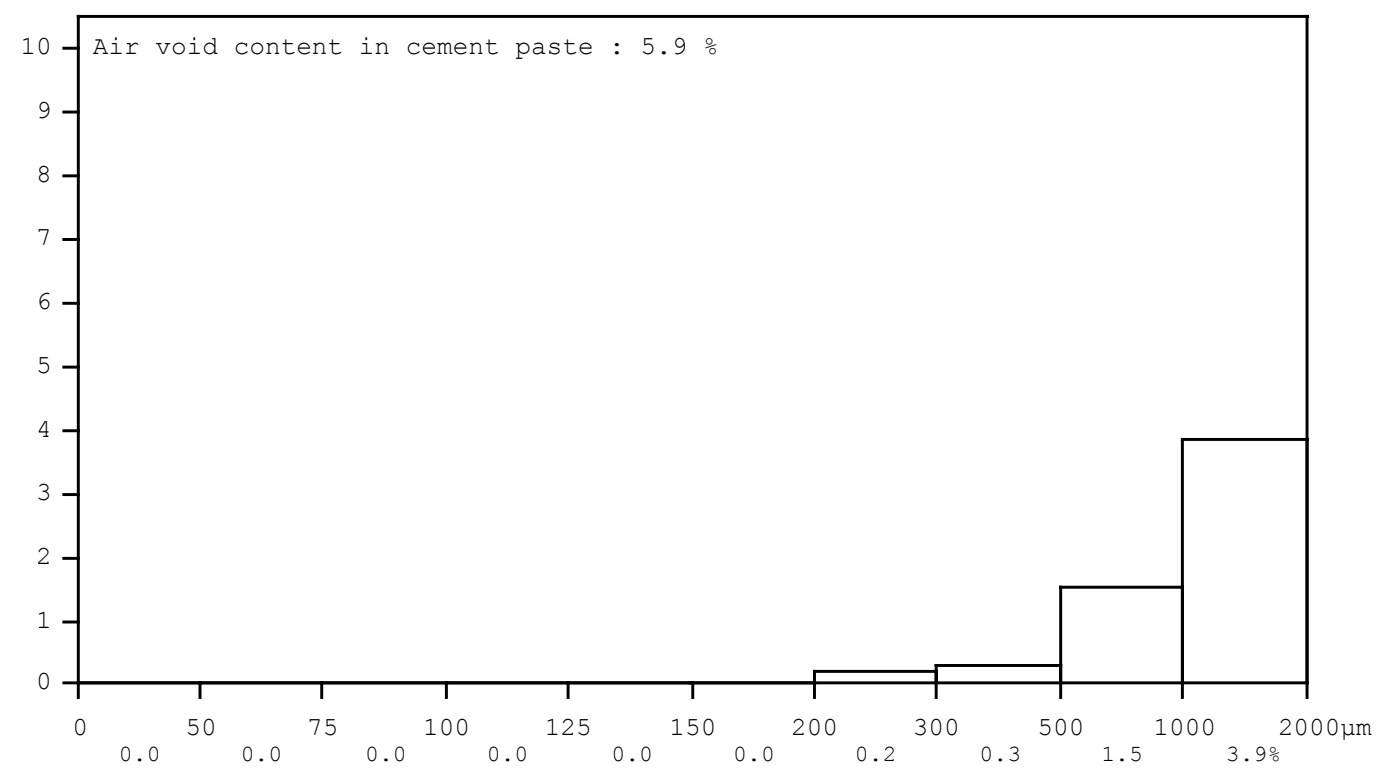


Air Void Analyzer AVA-3000

Type Company name

Measurement of Sep 18, 2008 3:47 PM

Sampler

Ordered by : davk

Sample location : U of L

Case number: Control 2 C3

Sample number : 3

Mortar<6mm : $57.51 \%$

Expected air : $2.4 \%$

Paste : $22.52 \%$

Sample volume : $20.0 \mathrm{~cm} 3$

\section{Analysis}$$
\text { Start: } 0.0 \mathrm{~g}
$$

$+5 \sec .: 0.1 \mathrm{~g}$

+30 sec. :

$0.5 \mathrm{~g}$

Temp:

$23.8^{\circ} \mathrm{C}$

Diff/100

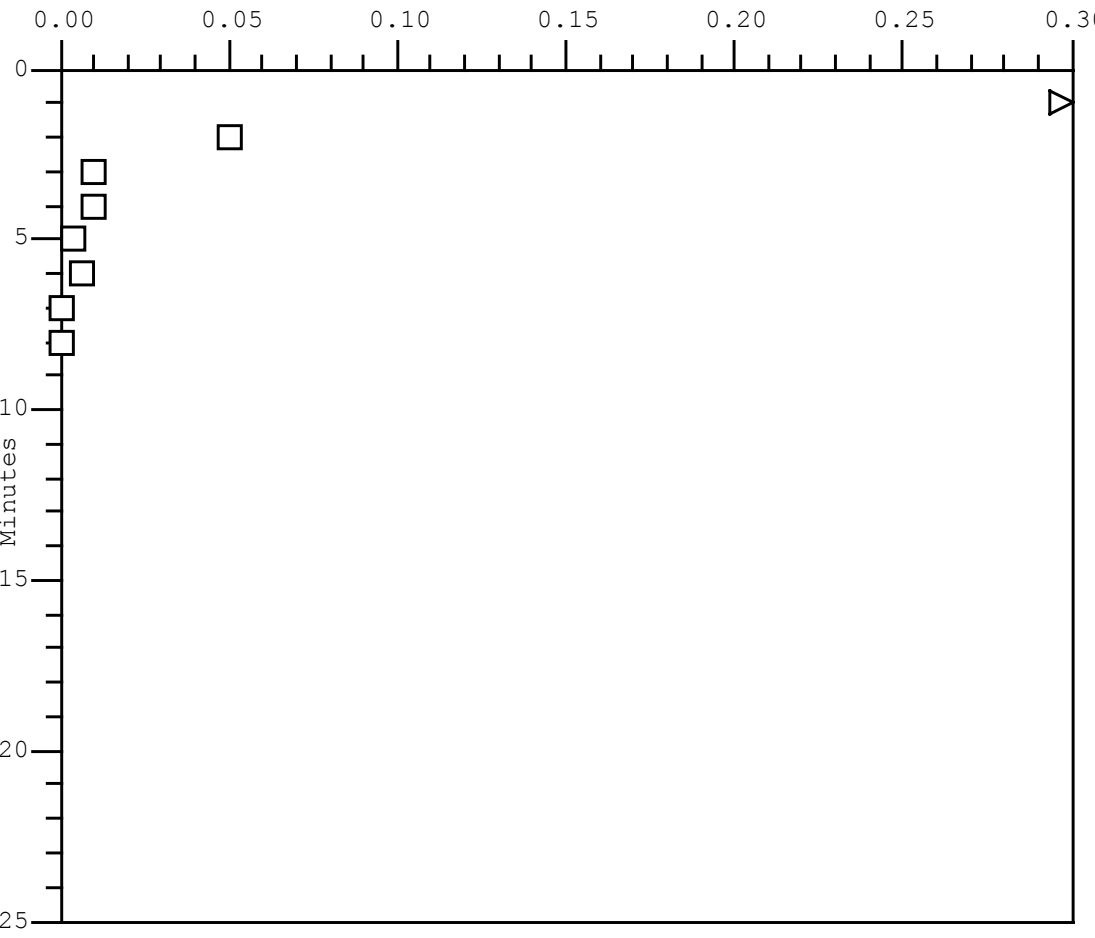

Diff $-15 \mathrm{Min}+15 \mathrm{~T} /{ }^{\circ} \mathrm{C}$

$\begin{array}{llllll}53.0 & 0.52 & 0.53 & 0.54 & 24.3\end{array}$

$\begin{array}{llllll}5.0 & 0.58 & 0.58 & 0.58 & 24.3\end{array}$

$\begin{array}{llllll}1.0 & 0.59 & 0.59 & 0.59 & 24.2\end{array}$

$\begin{array}{llllll}1.0 & 0.60 & 0.60 & 0.60 & 24.3\end{array}$

$\begin{array}{llllll}0.3 & 0.60 & 0.60 & 0.61 & 24.3\end{array}$

$\begin{array}{lllll}0.7 & 0.61 & 0.61 & 0.61 & 24.3\end{array}$

$\begin{array}{lllll}0.0 & 0.61 & 0.61 & 0.61 & 24.3\end{array}$

$\begin{array}{lllll}0.0 & 0.61 & 0.61 & 0.61 & 24.3\end{array}$

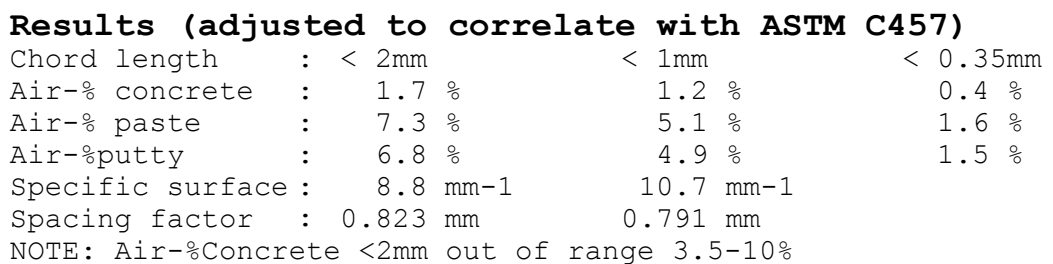

NOTE: Air-\%Concrete $<2 \mathrm{~mm}$ out of range $3.5-10 \%$

\section{Comments}

$>$ Control 2 C3
$>09 / 18 / 08 \quad 4: 47 \mathrm{pm}$
$>$
$>$

Sign. : 
Air Void Analyzer AVA-3000

Type Company name

\section{Measurement of Sep 18, $20083: 47$ PM}

Case number : Control $2 \mathrm{C3}$

Sample number : 3

Distribution of air void content for voids $<2 \mathrm{~mm}$ (\%)

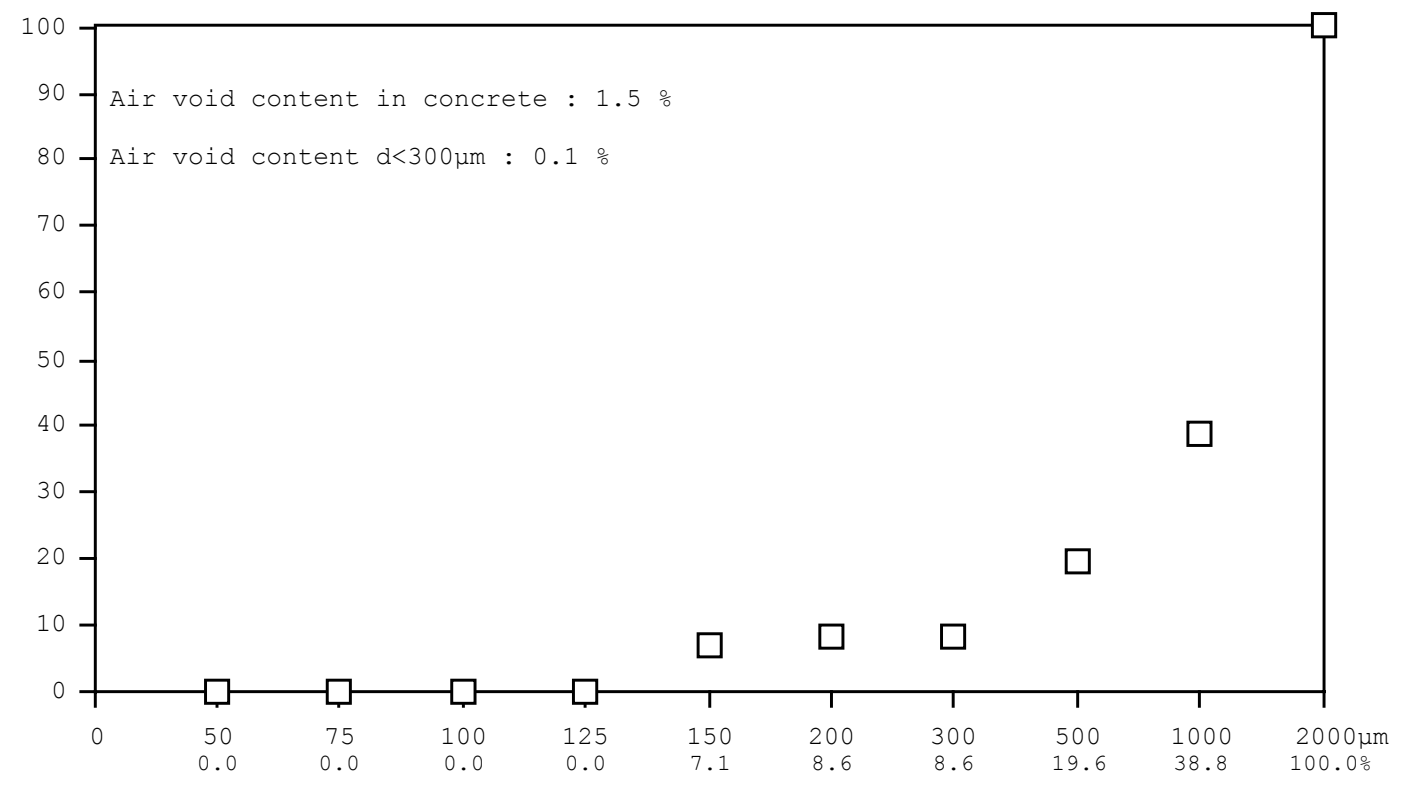

Distribution of air void content in cement paste for voids $<2 \mathrm{~mm}$ (\%)

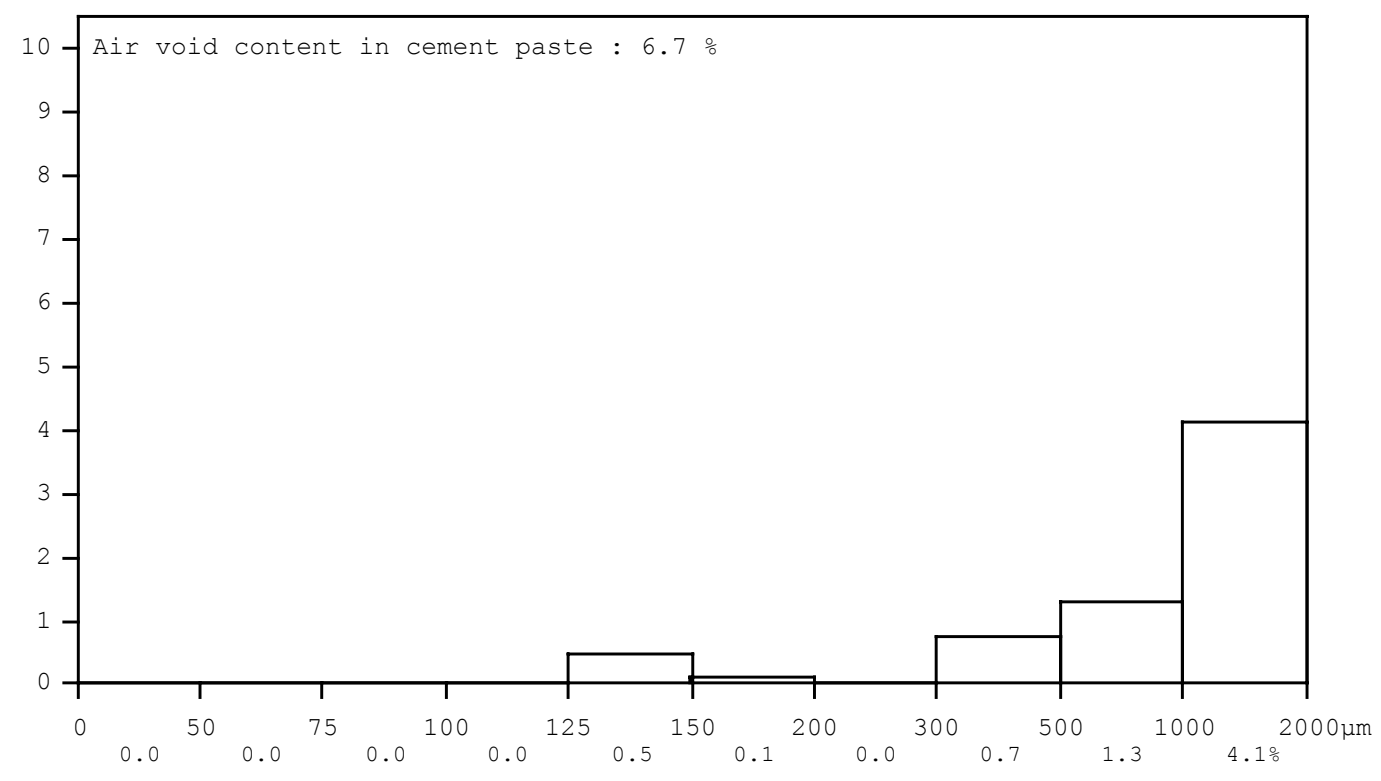


Air Void Analyzer AVA-3000

Type Company name

Measurement of Jul 25, 2008 12:30 PM

$\begin{array}{ll}\text { Sampler } & \text { : RSA } 10 \text { A1 } \\ \text { Ordered by } & \text { : davk } \\ \text { Sample location } & \text { : U of L } \\ \text { Case number } & : \text { RSA } 10 \text { A1 } \\ \text { Sample number } & : 1\end{array}$

Mortar<6mm : $55.01 \%$

Expected air : 4.9 응

Paste : $22.52 \%$

Sample number :

Sample volume : $20.0 \mathrm{~cm} 3$

\section{Analysis}

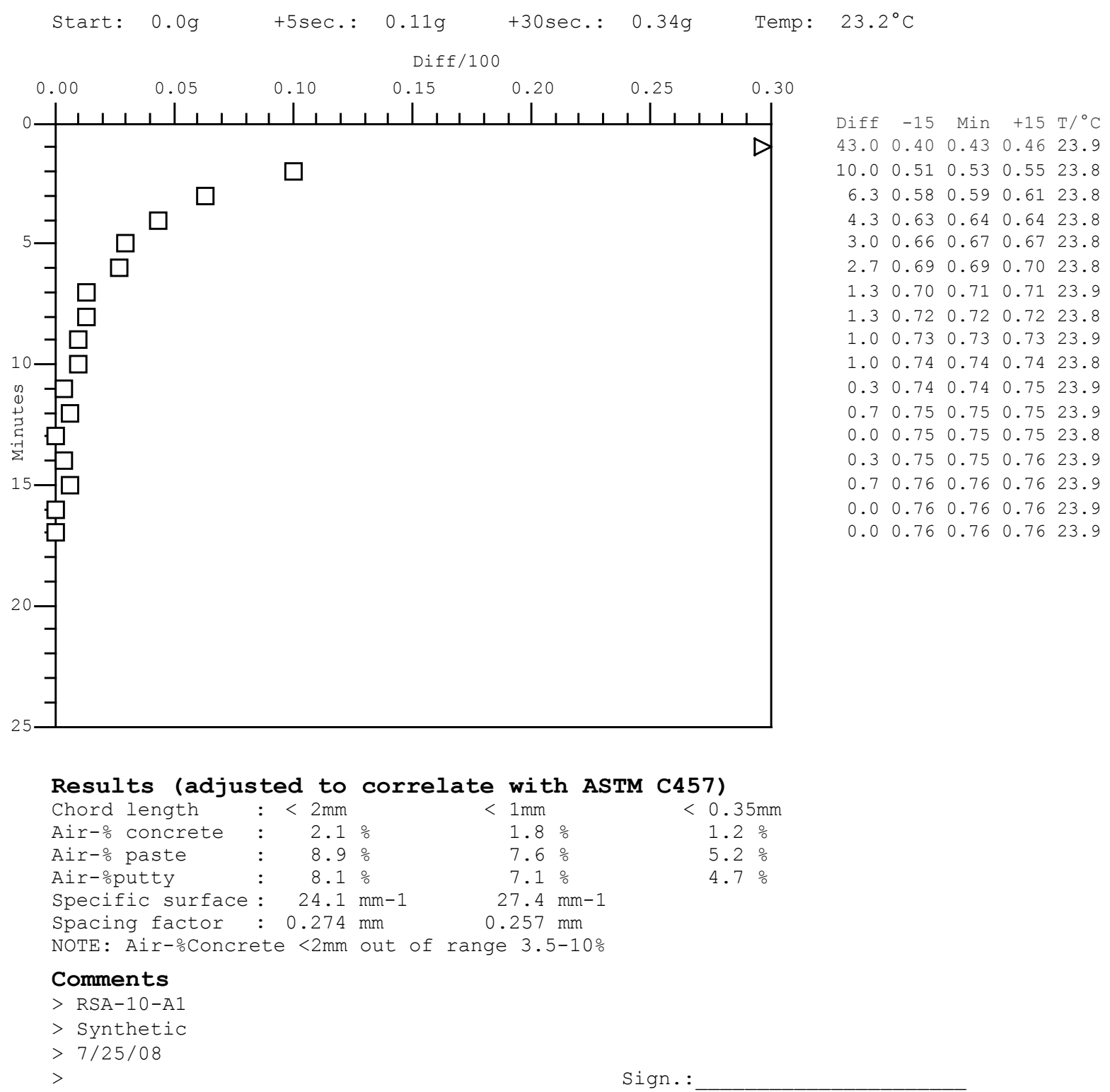


Air Void Analyzer AVA-3000

Type Company name

\section{Measurement of Jul 25, 2008 12:30 PM}

Case number : RSA 10 A1

Sample number : 1

Distribution of air void content for voids $<2 \mathrm{~mm}$ (\%)

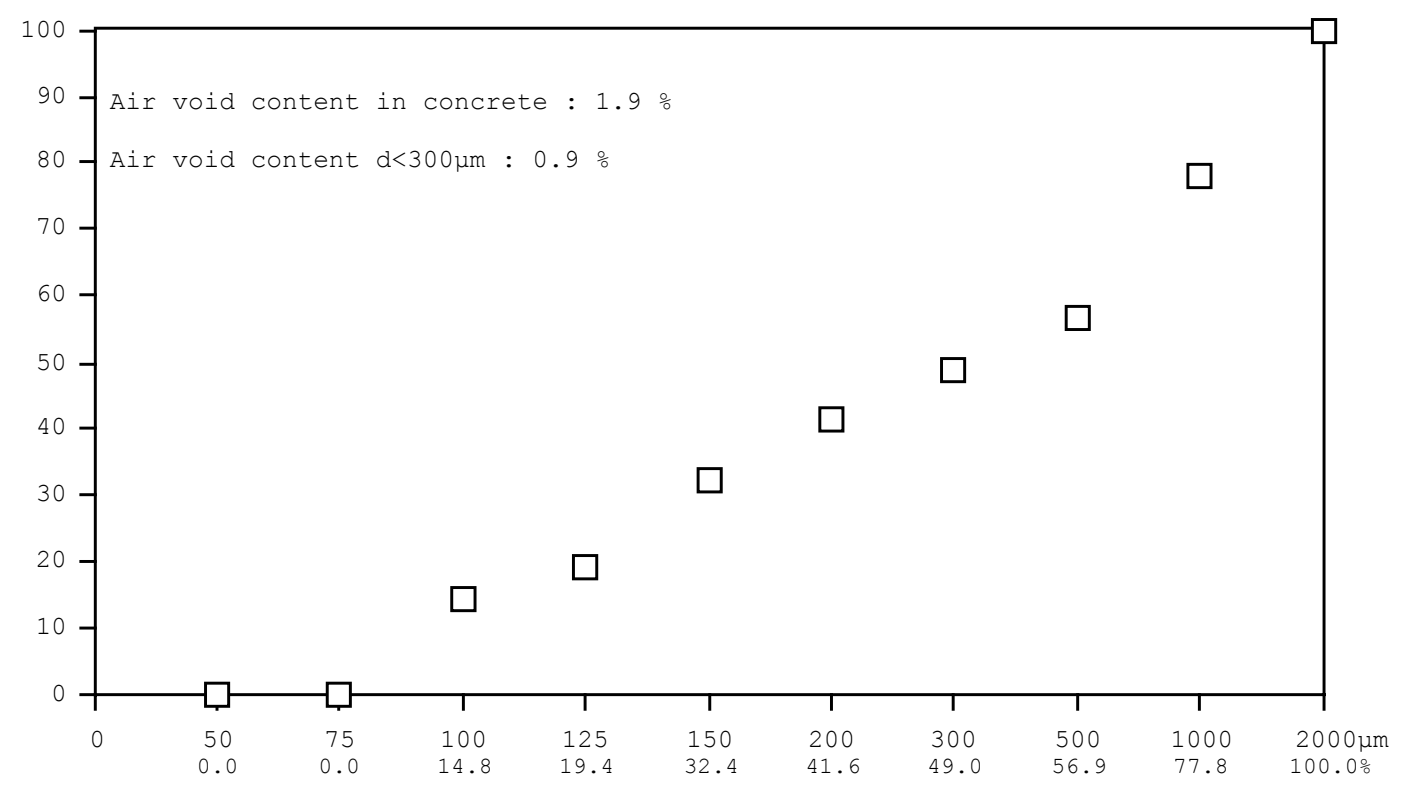

Distribution of air void content in cement paste for voids $<2 \mathrm{~mm}$ (\%)

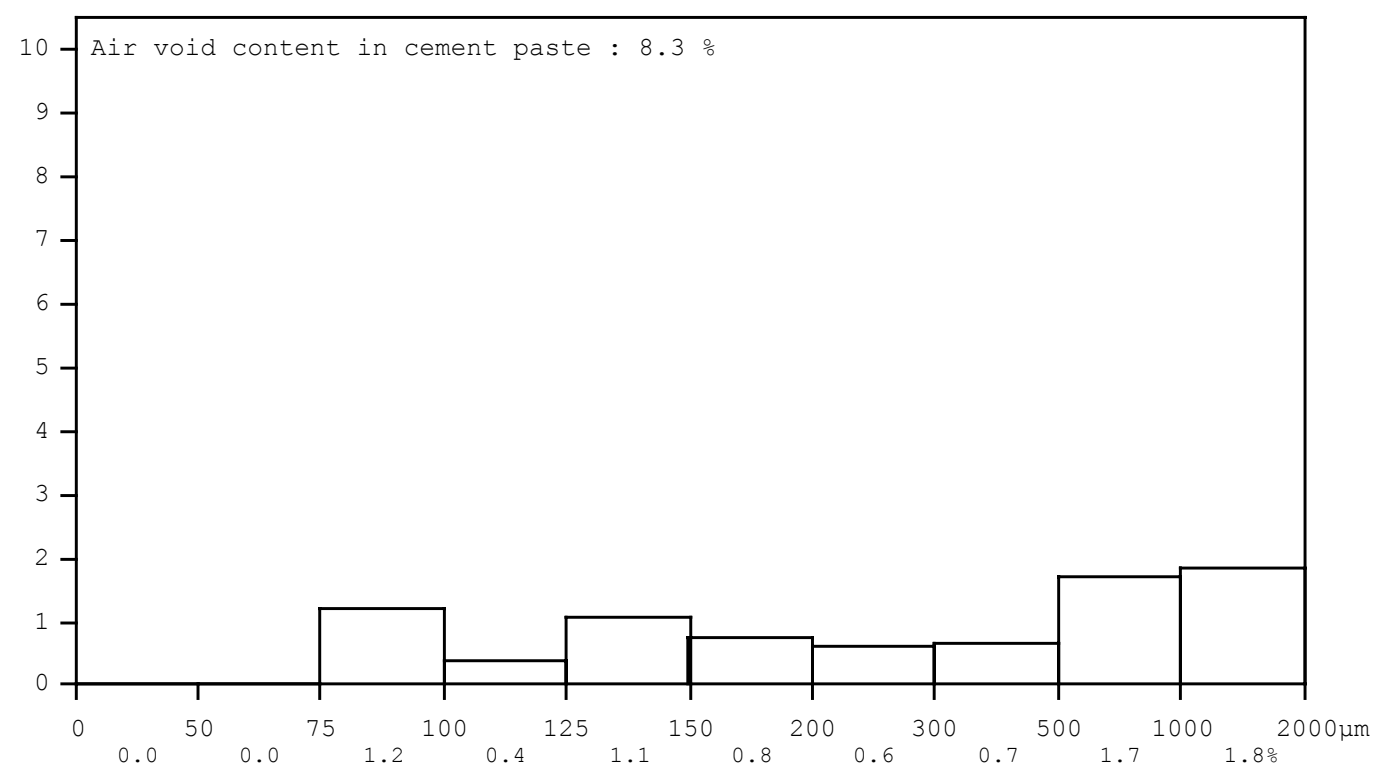


Air Void Analyzer AVA-3000

Type Company name

Measurement of Jul 25, 2008 1:01 PM

$\begin{array}{ll}\text { Sampler } & \text { : RSA } 10 \text { A2 } \\ \text { Ordered by } & \text { : davk } \\ \text { Sample location } & : \text { U of L } \\ \text { Case number } & : \text { RSA } 10 \text { A2 } \\ \text { Sample number } & : 2\end{array}$

$\begin{array}{llrl}\text { Mortar<6mm } & : 55.01 \% \\ \text { Expected air } & : & 4.9 \% \\ \text { Paste } & : & 22.52 \% \\ \text { Sample volume } & : & 20.0 \mathrm{~cm} 3\end{array}$

Analysis

start: $0.0 \mathrm{~g}$

+5sec.: $0.34 \mathrm{~g} \quad+30 \mathrm{sec}: 0.53 \mathrm{~g}$

Temp: $\quad 23.2^{\circ} \mathrm{C}$

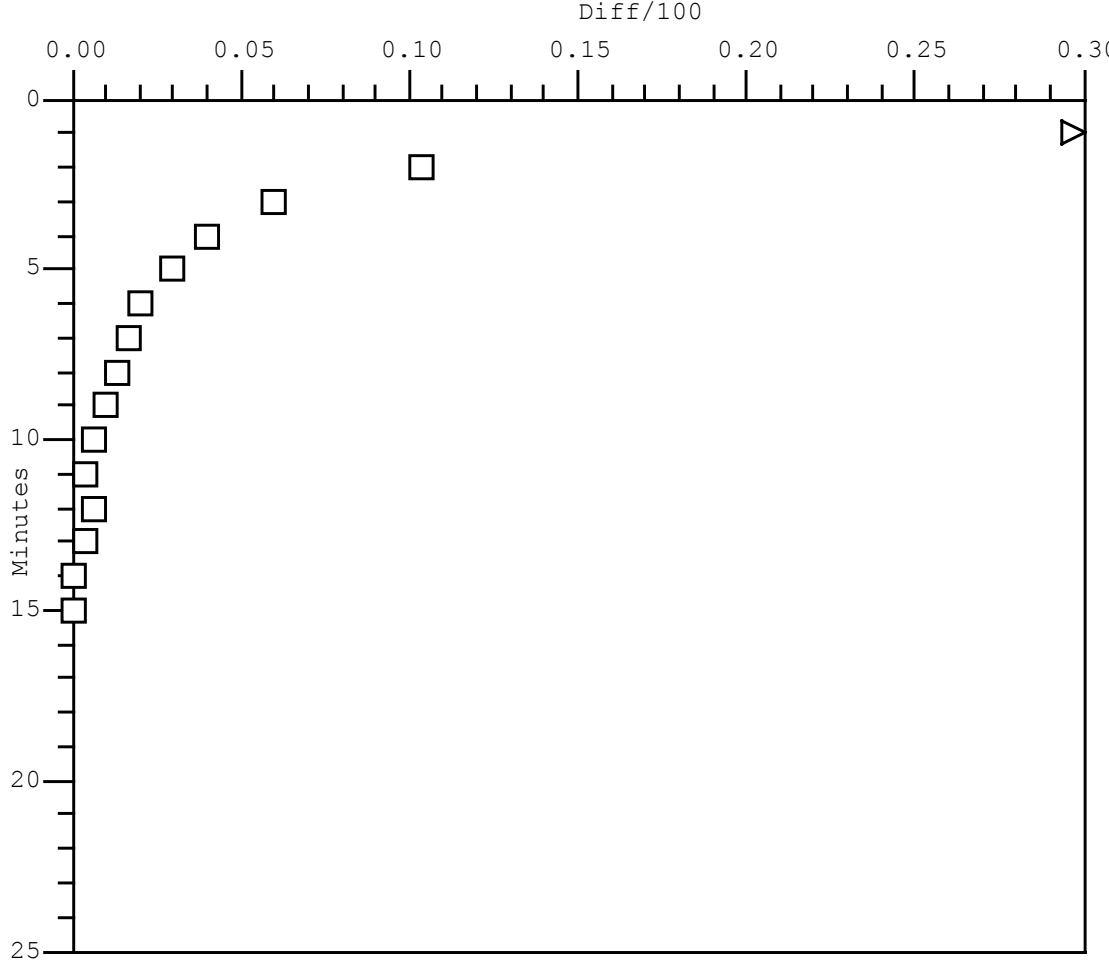

Diff $-15 \mathrm{Min}+15 \mathrm{~T} /{ }^{\circ} \mathrm{C}$

$\begin{array}{llllll}61.7 & 0.58 & 0.62 & 0.65 & 23.6\end{array}$

$\begin{array}{llllll}10.3 & 0.70 & 0.72 & 0.74 & 23.7\end{array}$

$\begin{array}{llllll}6.0 & 0.77 & 0.78 & 0.79 & 23.7\end{array}$

$\begin{array}{lllll}4.0 & 0.81 & 0.82 & 0.83 & 23.8\end{array}$

$\begin{array}{llllll}3.0 & 0.84 & 0.85 & 0.86 & 23.8\end{array}$

$\begin{array}{lllll}2.0 & 0.86 & 0.87 & 0.88 & 23.8\end{array}$

$\begin{array}{llllll}1.7 & 0.88 & 0.89 & 0.89 & 23.8\end{array}$

$\begin{array}{lllll}1.3 & 0.90 & 0.90 & 0.90 & 23.8\end{array}$

$\begin{array}{lllll}1.0 & 0.91 & 0.91 & 0.91 & 23.8\end{array}$

$\begin{array}{lllll}0.7 & 0.91 & 0.92 & 0.92 & 23.7\end{array}$

$\begin{array}{lllll}0.3 & 0.92 & 0.92 & 0.92 & 23.8\end{array}$

$\begin{array}{llllll}0.7 & 0.92 & 0.93 & 0.93 & 23.8\end{array}$

$\begin{array}{lllll}0.3 & 0.93 & 0.93 & 0.93 & 23.8\end{array}$

$\begin{array}{llllll}0.0 & 0.93 & 0.93 & 0.93 & 23.8\end{array}$

$\begin{array}{lllll}0.0 & 0.93 & 0.93 & 0.93 & 23.8\end{array}$

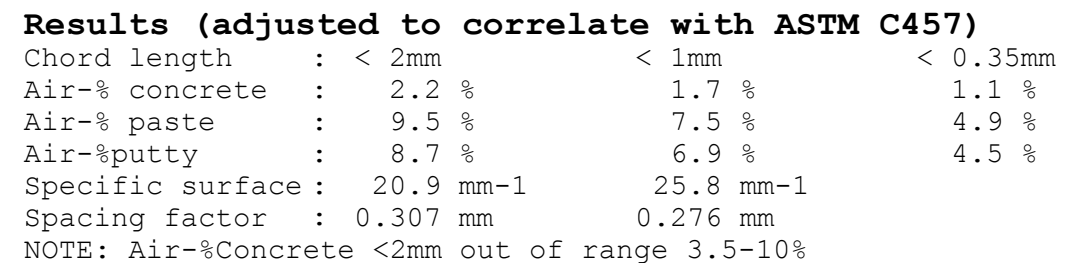

NOTE: Air-\%Concrete $<2 \mathrm{~mm}$ out of range $3.5-10 \%$

\section{Comments}

$>$ RSA10-A2
$>$
$>7 / 25 / 08$
$>$

Sign. : 
Air Void Analyzer AVA-3000

Type Company name

\section{Measurement of Jul 25, 2008 1:01 PM}

Case number : RSA 10 A2

Sample number : 2

Distribution of air void content for voids $<2 \mathrm{~mm}$ (\%)

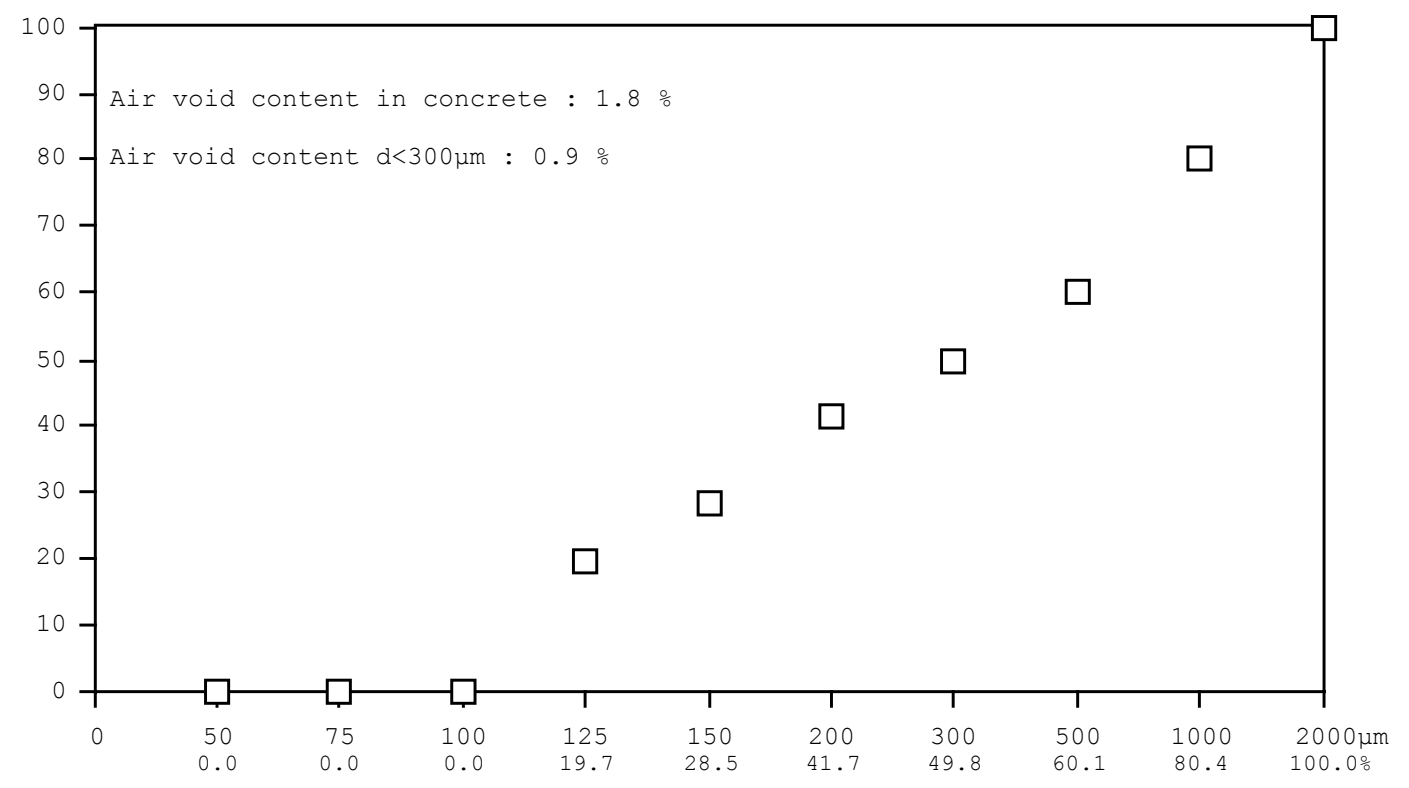

Distribution of air void content in cement paste for voids $<2 \mathrm{~mm}$ (\%)

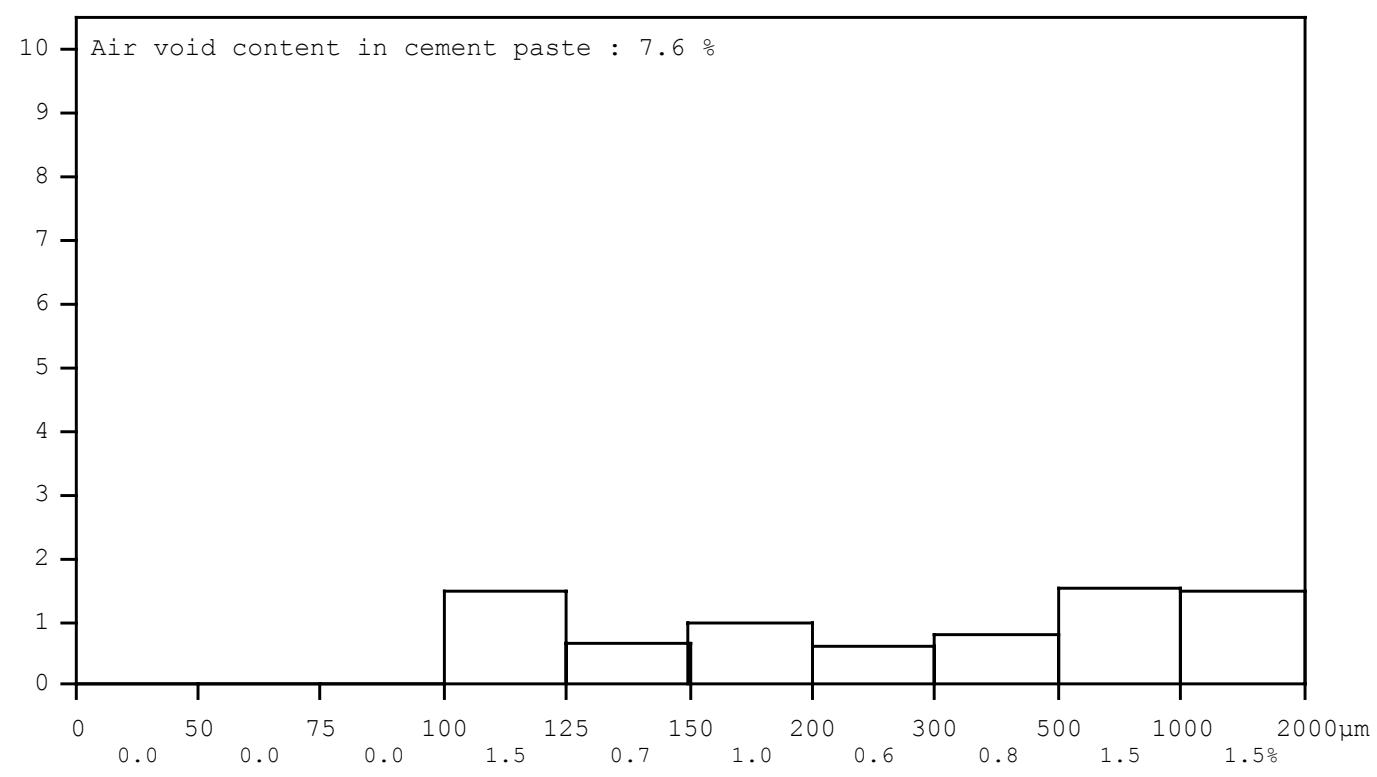


Air Void Analyzer AVA-3000

Type Company name

Measurement of Jul 25, $20081: 36$ PM

Sampler

: RSA 10 A3

Ordered by : davk

Sample location : U of L

Case number : RSA 10 A3

Sample number : 3

$\begin{array}{llrl}\text { Mortar<6mm } & : 55.01 \% \\ \text { Expected air } & : & 4.9 \% \\ \text { Paste } & : 22.52 \% \\ \text { Sample volume } & : & 20.0 \mathrm{~cm} 3\end{array}$

Analysis

Start: $0.0 \mathrm{~g}$

$+5 \sec .: 2.86 \mathrm{~g}$

$+30 \mathrm{sec} .: 2.85 \mathrm{~g}$

Temp: $\quad 23.0^{\circ} \mathrm{C}$

Diff/100

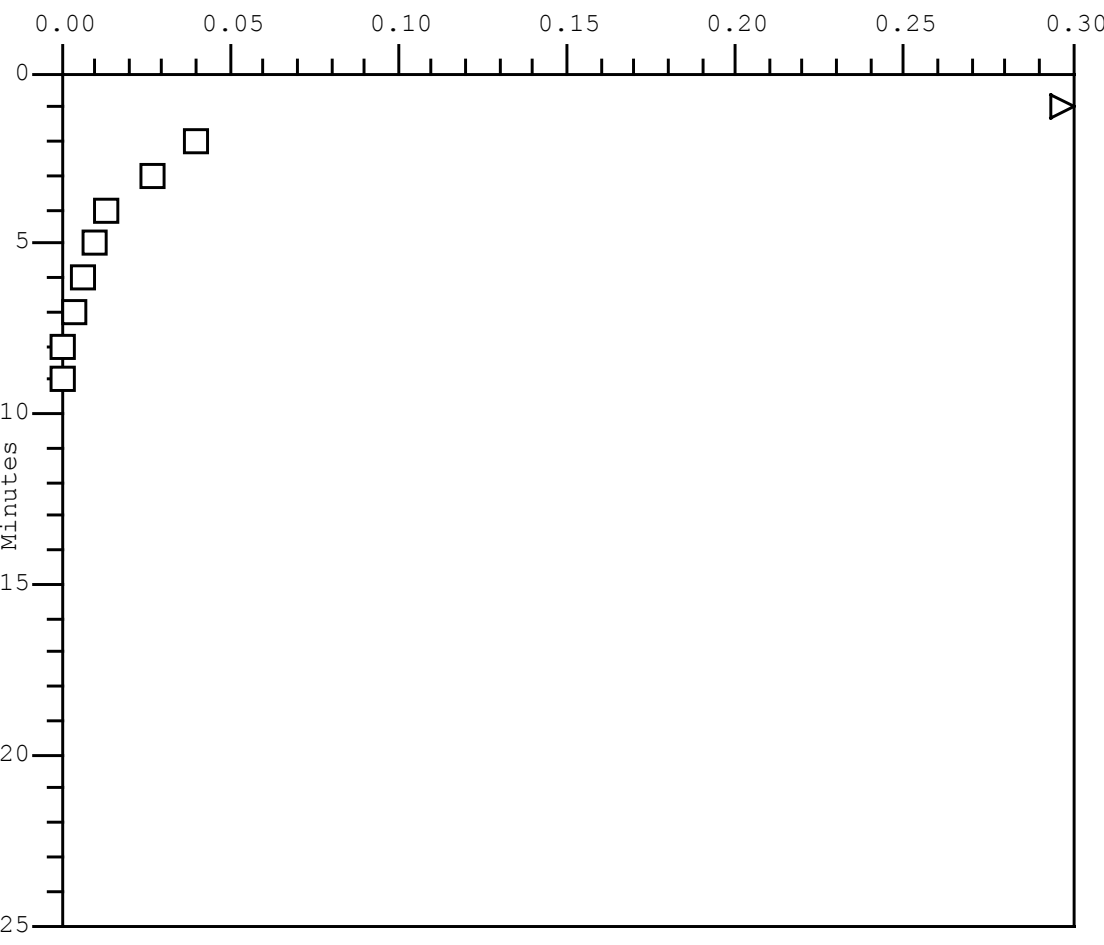

Diff -15 Min $+15 \mathrm{~T} /{ }^{\circ} \mathrm{C}$

$\begin{array}{llllll}288.0 & 2.87 & 2.88 & 2.89 & 23.5\end{array}$

$\begin{array}{lllll}4.0 & 2.91 & 2.92 & 2.93 & 23.5\end{array}$

$\begin{array}{llllll}2.7 & 2.94 & 2.95 & 2.95 & 23.6\end{array}$

$\begin{array}{lllll}1.3 & 2.96 & 2.96 & 2.96 & 23.6\end{array}$

$\begin{array}{llllll}1.0 & 2.97 & 2.97 & 2.97 & 23.6\end{array}$

$\begin{array}{lllll}0.7 & 2.97 & 2.98 & 2.98 & 23.6\end{array}$

$\begin{array}{lllll}0.3 & 2.98 & 2.98 & 2.98 & 23.6\end{array}$

$\begin{array}{lllll}0.0 & 2.98 & 2.98 & 2.98 & 23.6\end{array}$

$\begin{array}{llllll}0.0 & 2.98 & 2.98 & 2.98 & 23.6\end{array}$

Results (adjusted to correlate with ASTM C457)

$\begin{array}{llrrr}\text { Chord length } & : & <\mathrm{mm} & <1 \mathrm{~mm} & <0.35 \mathrm{~mm} \\ \text { Air-\% concrete } & : & 4.5 \% & 1.6 \% & 0.4 \% \\ \text { Air-\% paste } & : & 19.8 \% & 6.8 \% & 1.7 \% \\ \text { Air-\%putty } & : & 16.5 \% & 6.3 \% & 1.4 \% \\ \text { Specific surface }: & 4.7 \mathrm{~mm}-1 & 9.9 \mathrm{~mm}-1 & \\ \text { Spacing factor }: & 0.990 \mathrm{~mm} & 0.748 \mathrm{~mm} & \end{array}$

\footnotetext{
Comments

$>$ RAS10-A3

$>$

$>7 / 25 / 08$
}

Sign.: 
Air Void Analyzer AVA-3000

Type Company name

\section{Measurement of Jul 25, $20081: 36$ PM}

Case number : RSA 10 A3

Sample number : 3

Distribution of air void content for voids $<2 \mathrm{~mm}$ (\%)

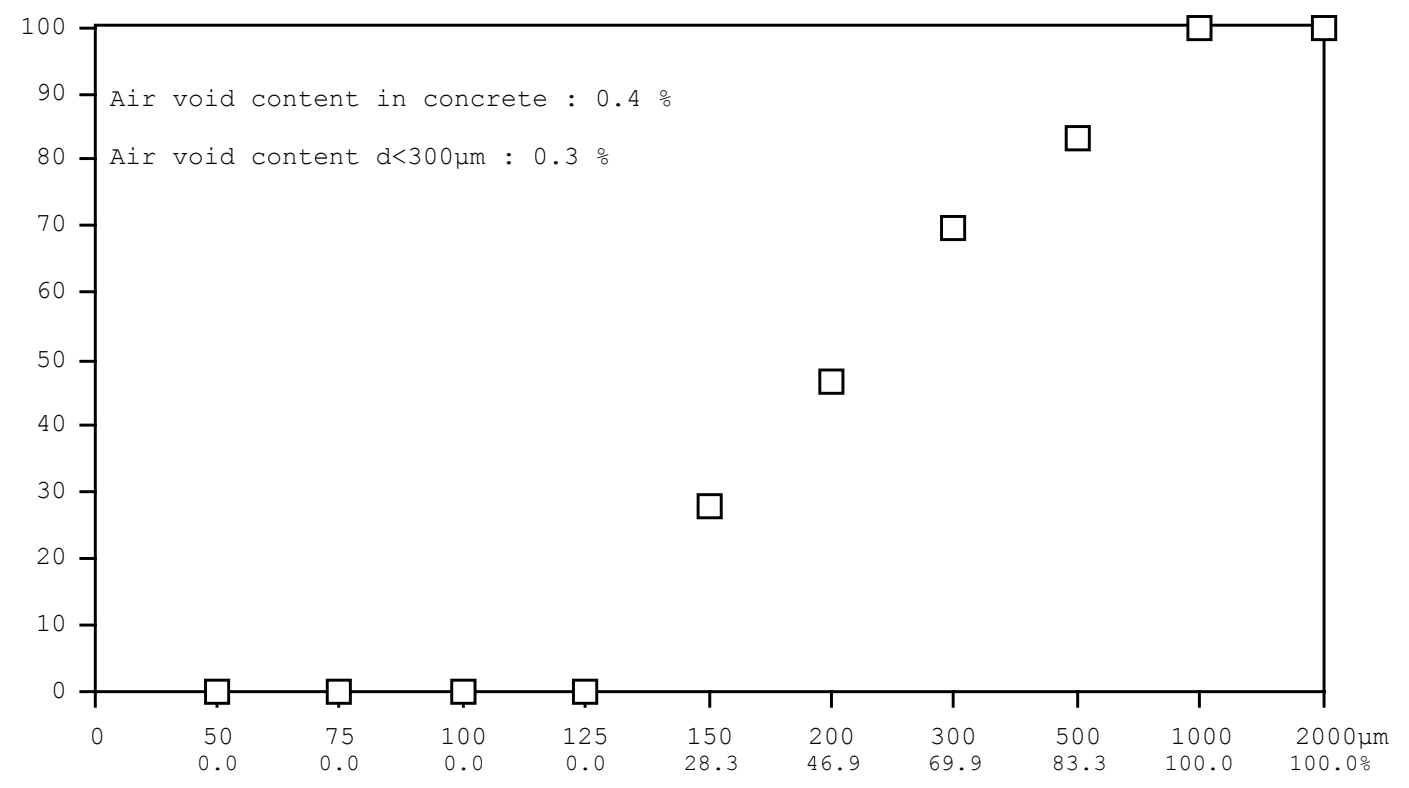

Distribution of air void content in cement paste for voids $2 \mathrm{~mm}$ ( $\%$ )

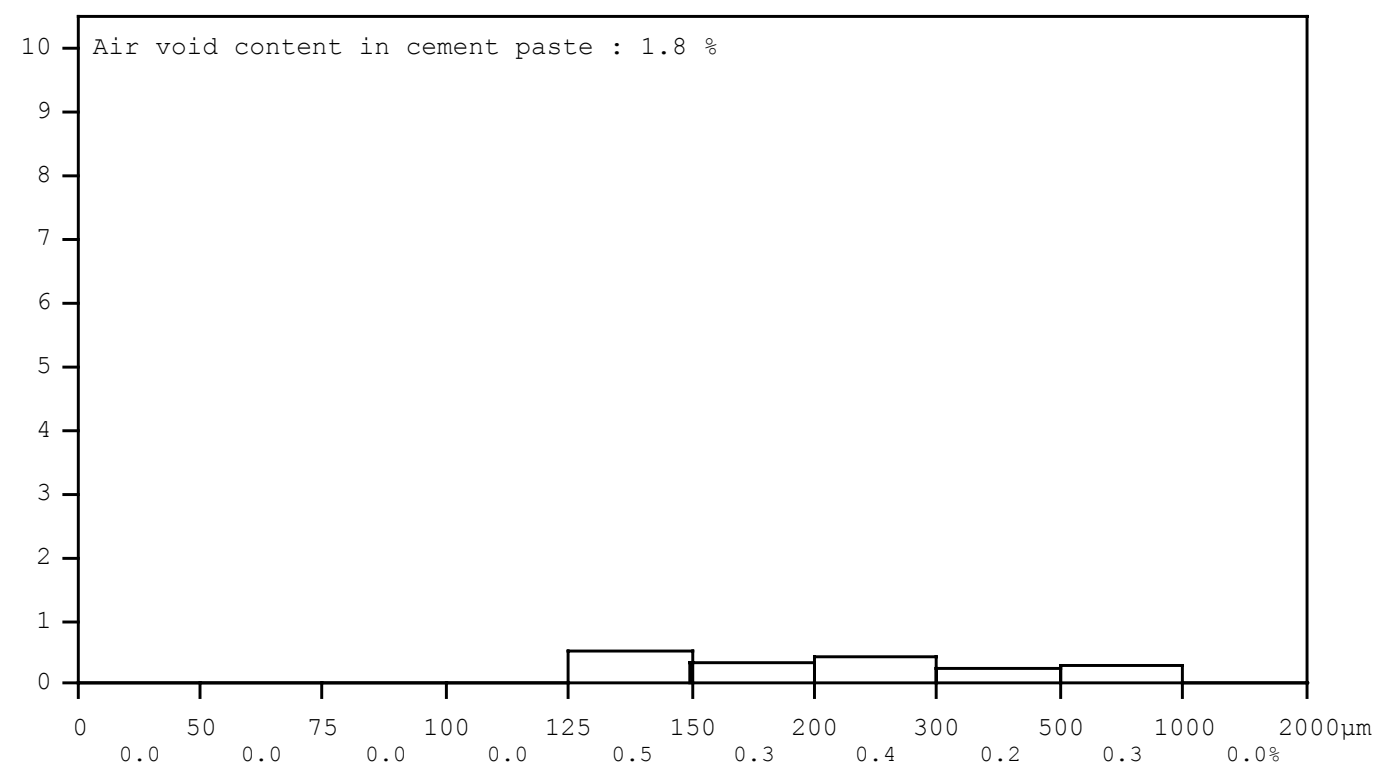


Air Void Analyzer AVA-3000

Type Company name

Measurement of Jul 25, 2008 2:09 PM

$\begin{array}{lll}\text { Sampler } & \text { : RSA } 10 \text { B1 } \\ \text { Ordered by } & \text { : davk } & \\ \text { Sample location } & \text { : U of L } & \\ \text { Case number } & : \text { RSA } 10 \text { B1 } \\ \text { Sample number } & : 1\end{array}$

Mortar $<6 \mathrm{~mm}$

Expected air

Paste

Sample volume $\begin{array}{rr}: 55.41 \% \\ : & 4.5 \% \\ : & 22.52 \% \\ : & 20.0 \mathrm{~cm} 3\end{array}$

\section{Analysis}

start: $0.0 \mathrm{~g}$

+5 sec.: $0.02 g$

+30 sec. :

$0.3 g$

Diff/100

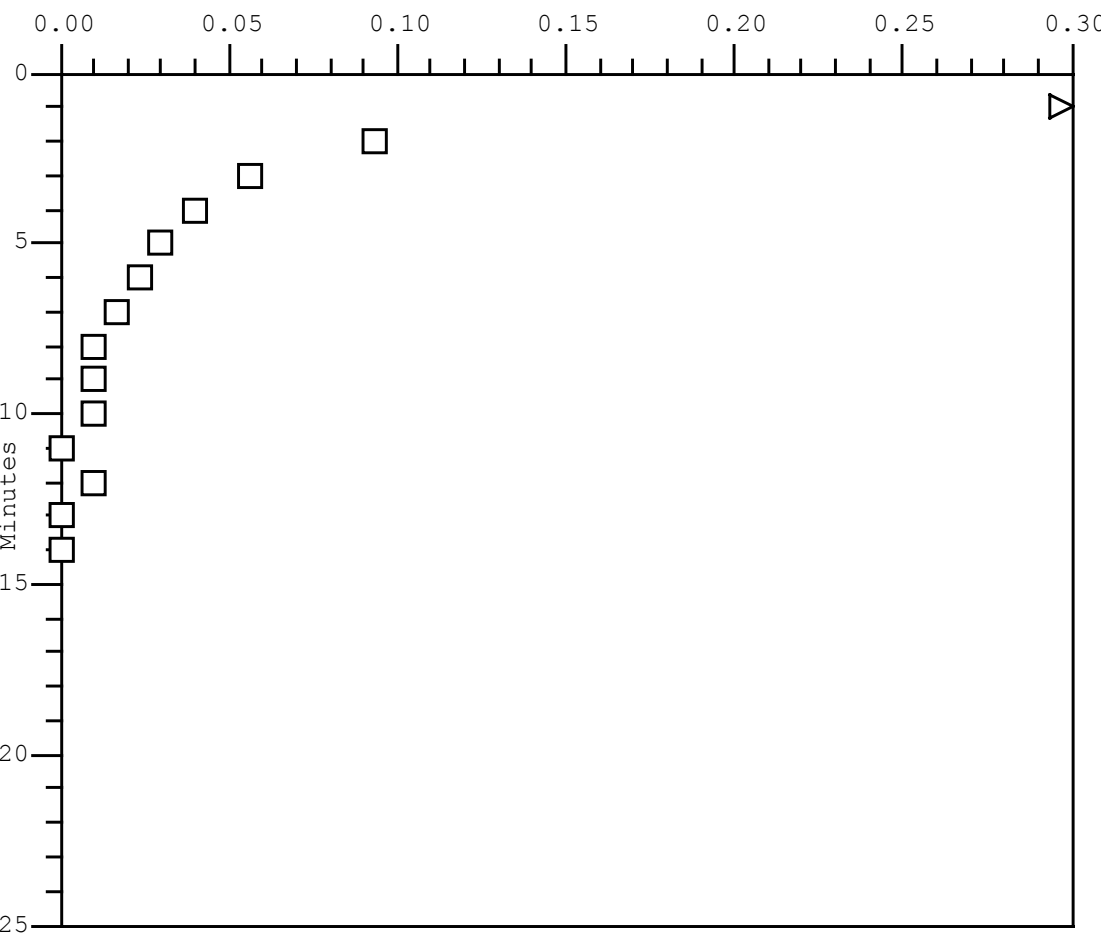

Results (adjusted to correlate with ASTM C457)

$\begin{array}{llrrr}\text { Chord length } & <2 \mathrm{~mm} & <1 \mathrm{~mm} & 0.35 \mathrm{~mm} \\ \text { Air-\% concrete }: & 1.9 \% & 1.6 \% & 1.1 \% \\ \text { Air-\% paste } & : & 8.3 \% & 7.1 \% & 4.6 \% \\ \text { Air-oputty } & : & 7.6 \% & 6.6 \% & 4.2 \% \\ \text { Specific surface : } & 23.1 \mathrm{~mm} \% & 26.2 \mathrm{~mm}-1 & \\ \text { Spacing factor : } 0.295 \mathrm{~mm} & 0.279 \mathrm{~mm} & \\ \text { NOTE: Air-oConcrete }<2 \mathrm{~mm} \text { out of range } 3.5-10 \%\end{array}$

\section{Comments}

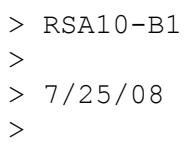

Sign. :
Diff $-15 \mathrm{Min}+15 \mathrm{~T} /{ }^{\circ} \mathrm{C}$ $\begin{array}{lllll}36.0 & 0.33 & 0.36 & 0.39 & 23.5\end{array}$ $9.3 \quad 0.440 .45 \quad 0.47 \quad 23.6$ $\begin{array}{llllll}5.7 & 0.50 & 0.51 & 0.52 & 23.5\end{array}$ $\begin{array}{lllll}4.0 & 0.54 & 0.55 & 0.56 & 23.6\end{array}$ $\begin{array}{llllll}3.0 & 0.57 & 0.58 & 0.59 & 23.5\end{array}$ $\begin{array}{llllll}2.3 & 0.60 & 0.60 & 0.61 & 23.6\end{array}$ $\begin{array}{llllll}1.7 & 0.62 & 0.62 & 0.62 & 23.6\end{array}$ $\begin{array}{llllll}1.0 & 0.63 & 0.63 & 0.63 & 23.6\end{array}$ $\begin{array}{llllll}1.0 & 0.64 & 0.64 & 0.64 & 23.6\end{array}$ $\begin{array}{llllll}1.0 & 0.65 & 0.65 & 0.65 & 23.6\end{array}$ $\begin{array}{llllll}0.0 & 0.65 & 0.65 & 0.65 & 23.6\end{array}$ $\begin{array}{llllll}1.0 & 0.66 & 0.66 & 0.66 & 23.6\end{array}$ $\begin{array}{llllll}0.0 & 0.66 & 0.66 & 0.66 & 23.7\end{array}$ $\begin{array}{llllll}0.0 & 0.66 & 0.66 & 0.66 & 23.7\end{array}$ 
Air Void Analyzer AVA-3000

Type Company name

\section{Measurement of Jul 25, 2008 2:09 PM}

Case number : RSA 10 B1

Sample number : 1

Distribution of air void content for voids $<2 \mathrm{~mm}$ (\%)

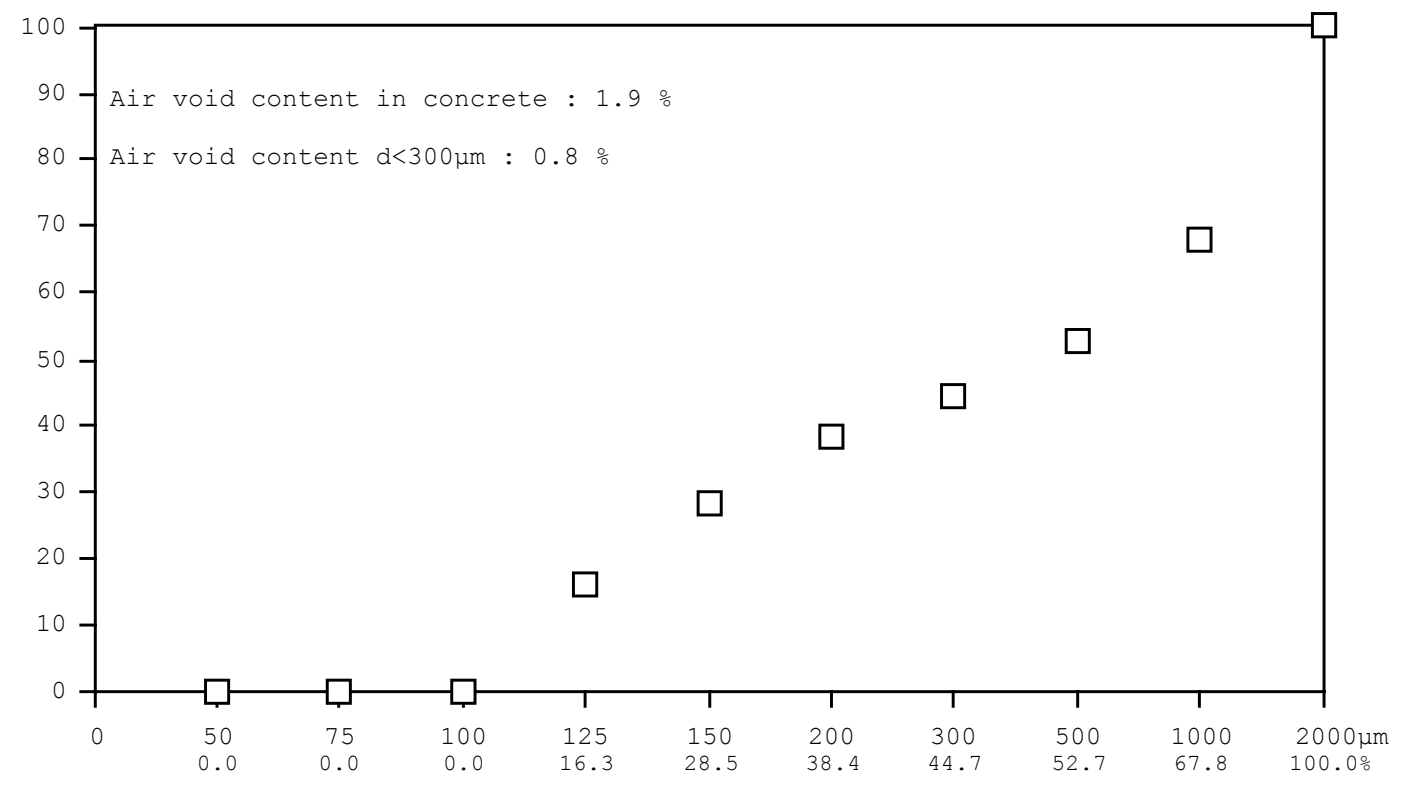

Distribution of air void content in cement paste for voids $2 \mathrm{~mm}$ ( $\%$ )

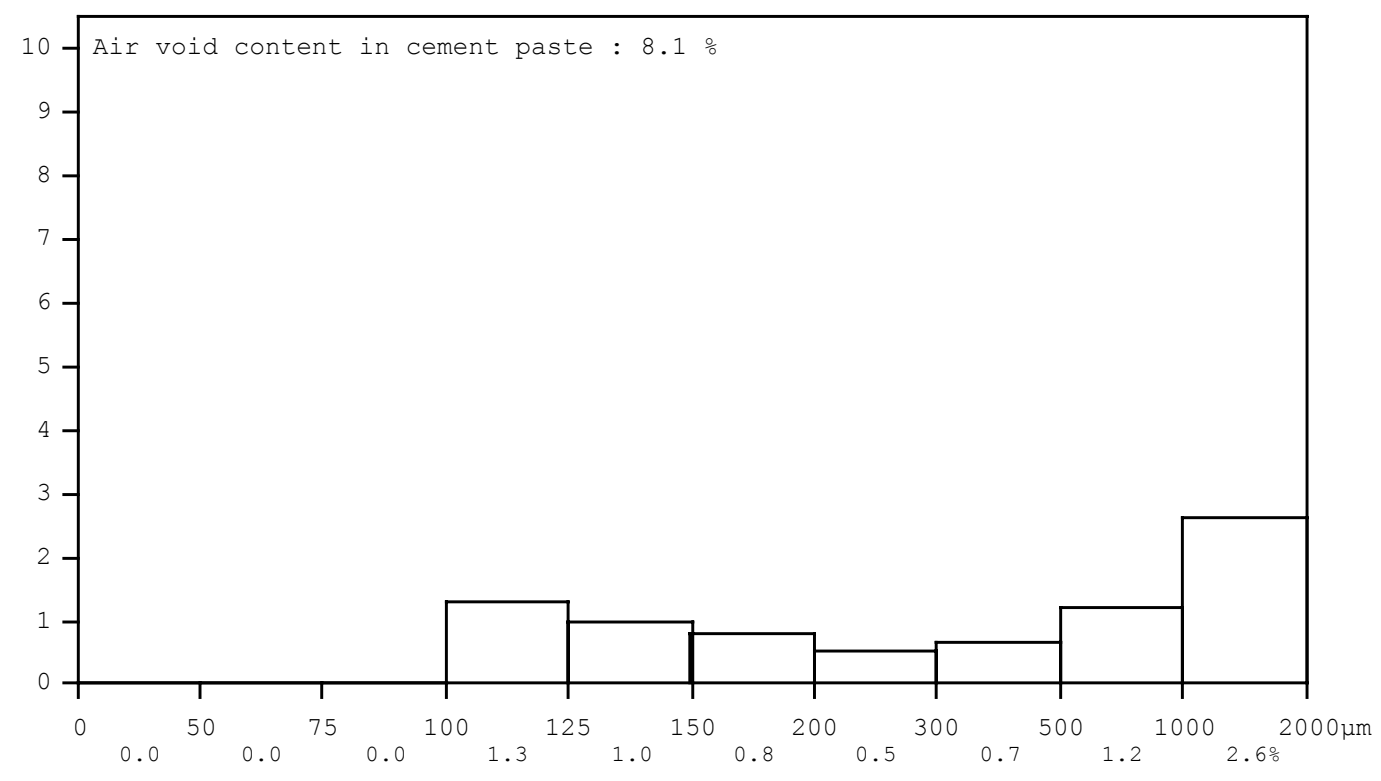


Air Void Analyzer AVA-3000

Type Company name

Measurement of Jul 25, 2008 2:39 PM

$\begin{array}{lll}\text { Sampler } & \text { RSA } 10 \text { B2 } \\ \text { Ordered by } & \text { : davk } & \\ \text { Sample location } & : \text { U of L } & \\ \text { Case number } & : \text { RSA } 10 \text { B2 } \\ \text { Sample number } & : 2 & \end{array}$

Mortar $<6 \mathrm{~mm}$

Expected air

Paste

Sample volume $\begin{array}{rrl}: & 55.41 \% \\ : & 4.5 \% \\ : & 22.52 \% \\ : & 20.0 & \mathrm{~cm} 3\end{array}$

\section{Analysis}

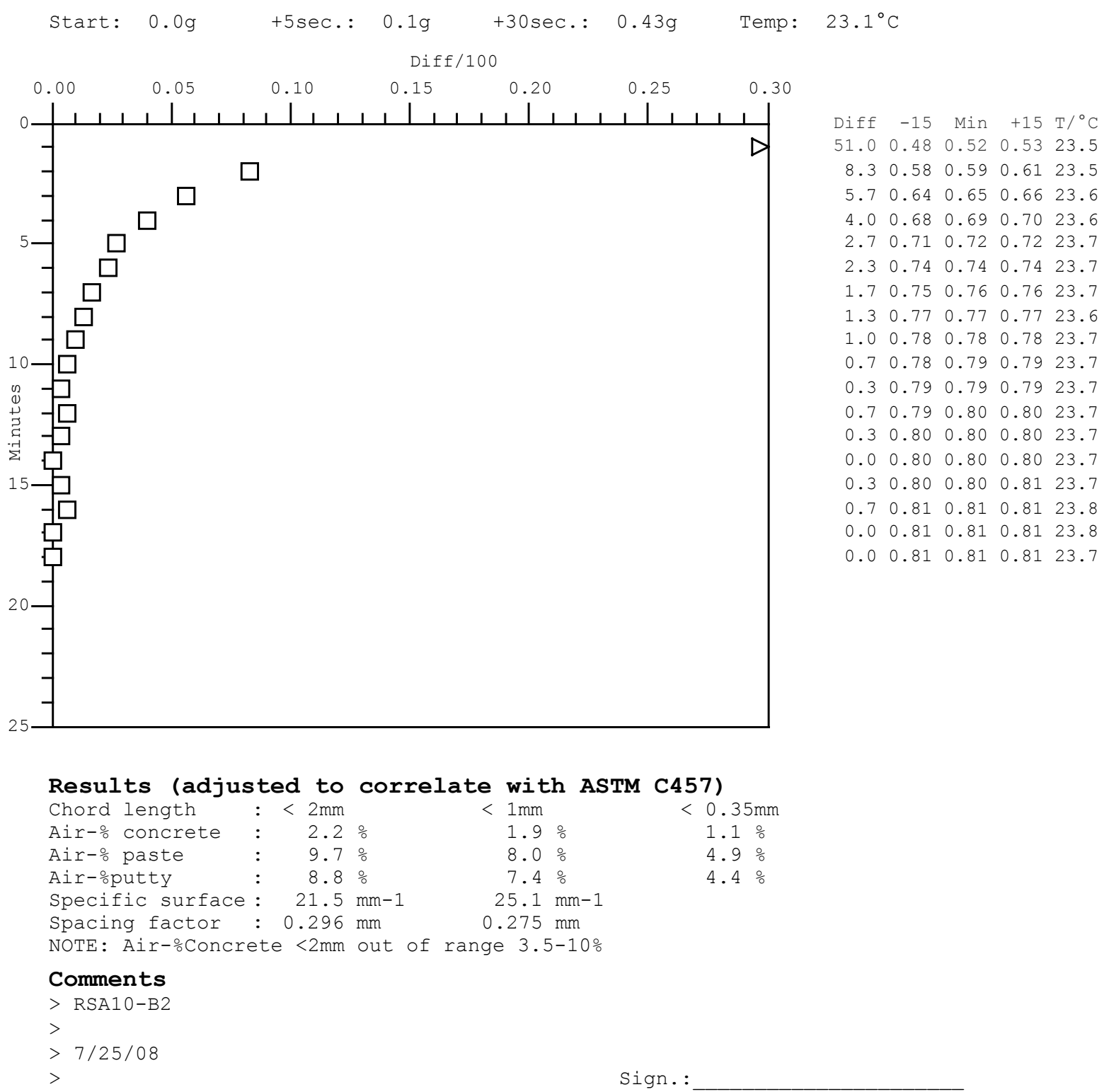


Air Void Analyzer AVA-3000

Type Company name

\section{Measurement of Jul 25, $20082: 39$ PM}

Case number : RSA 10 B2

Sample number : 2

Distribution of air void content for voids $<2 \mathrm{~mm}$ (\%)

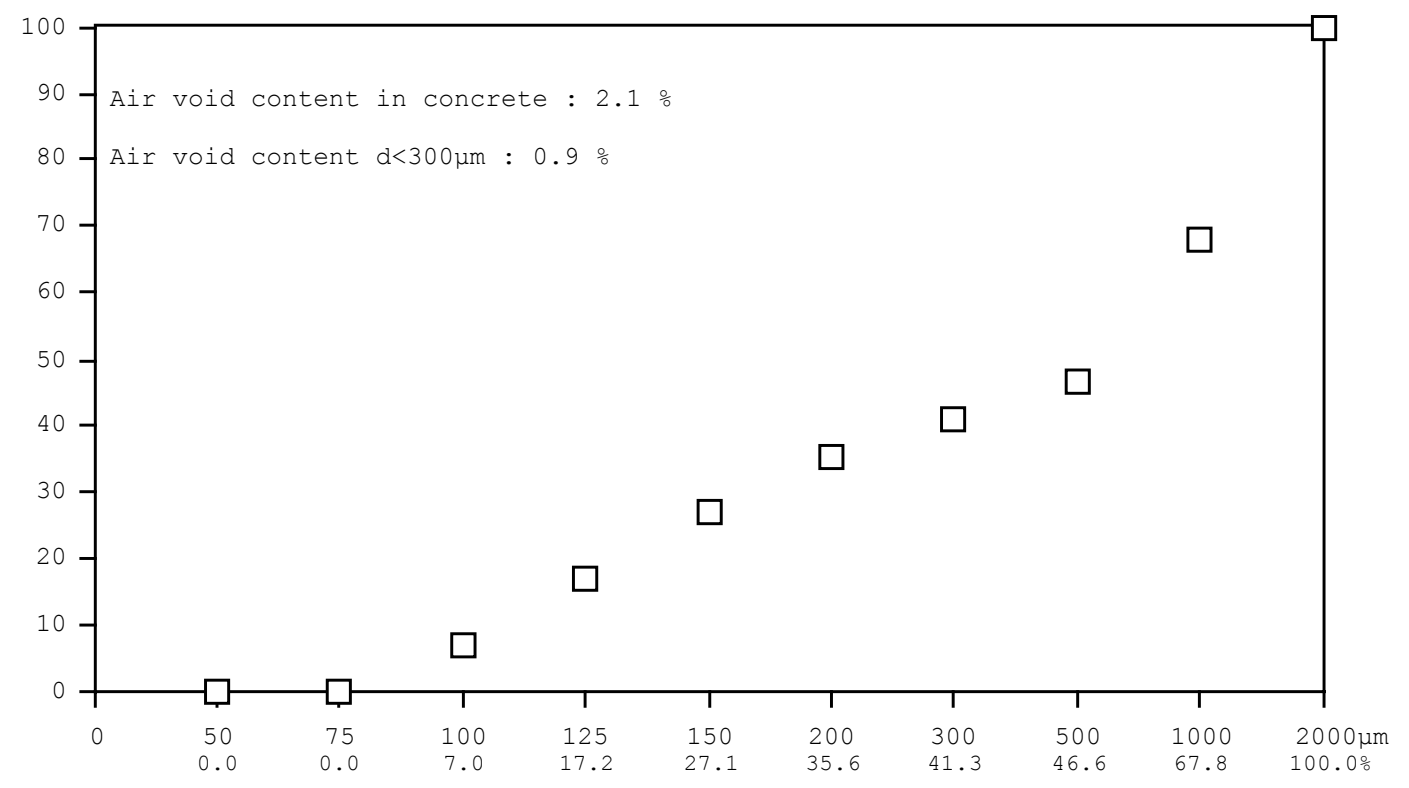

Distribution of air void content in cement paste for voids $<2 \mathrm{~mm}$ (\%)

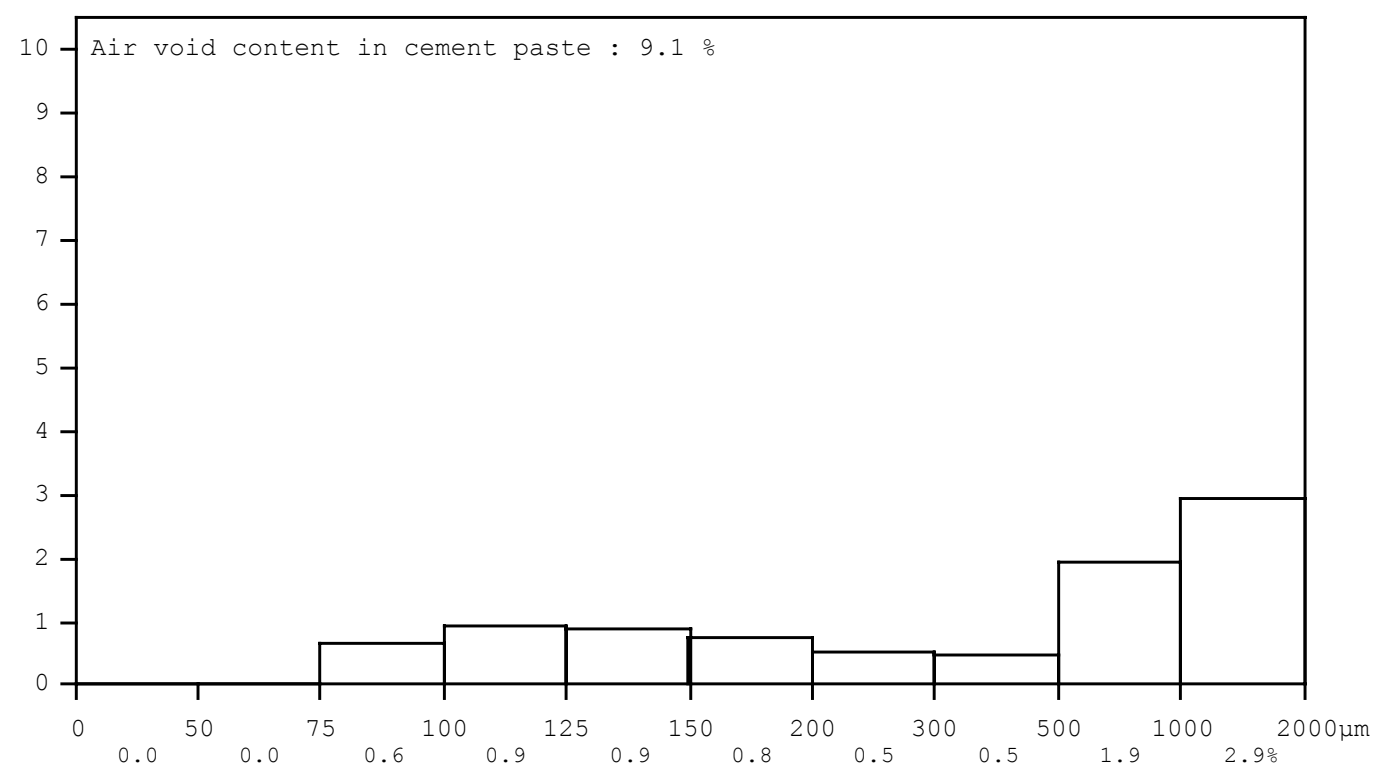


Air Void Analyzer AVA-3000

Type Company name

Measurement of Jul 25, 2008 3:09 PM

$\begin{array}{ll}\text { Sampler } & \text { : RSA } 10 \text { B3 } \\ \text { Ordered by } & \text { : davk } \\ \text { Sample location } & : \text { U of L } \\ \text { Case number } & : \text { RSA } 10 \text { B3 } \\ \text { Sample number } & : 3\end{array}$

$\begin{array}{llrl}\text { Mortar<6mm } & : 55.41 \% \\ \text { Expected air } & : & 4.5 \% \\ \text { Paste } & : & 22.52 \% \\ \text { Sample volume } & : & 20.0 \mathrm{~cm} 3\end{array}$

Analysis

start: $0.0 \mathrm{~g}$

+5sec.: $0.08 \mathrm{~g} \quad+30 \mathrm{sec}: 0.62 \mathrm{~g}$

Temp: $\quad 23.0^{\circ} \mathrm{C}$

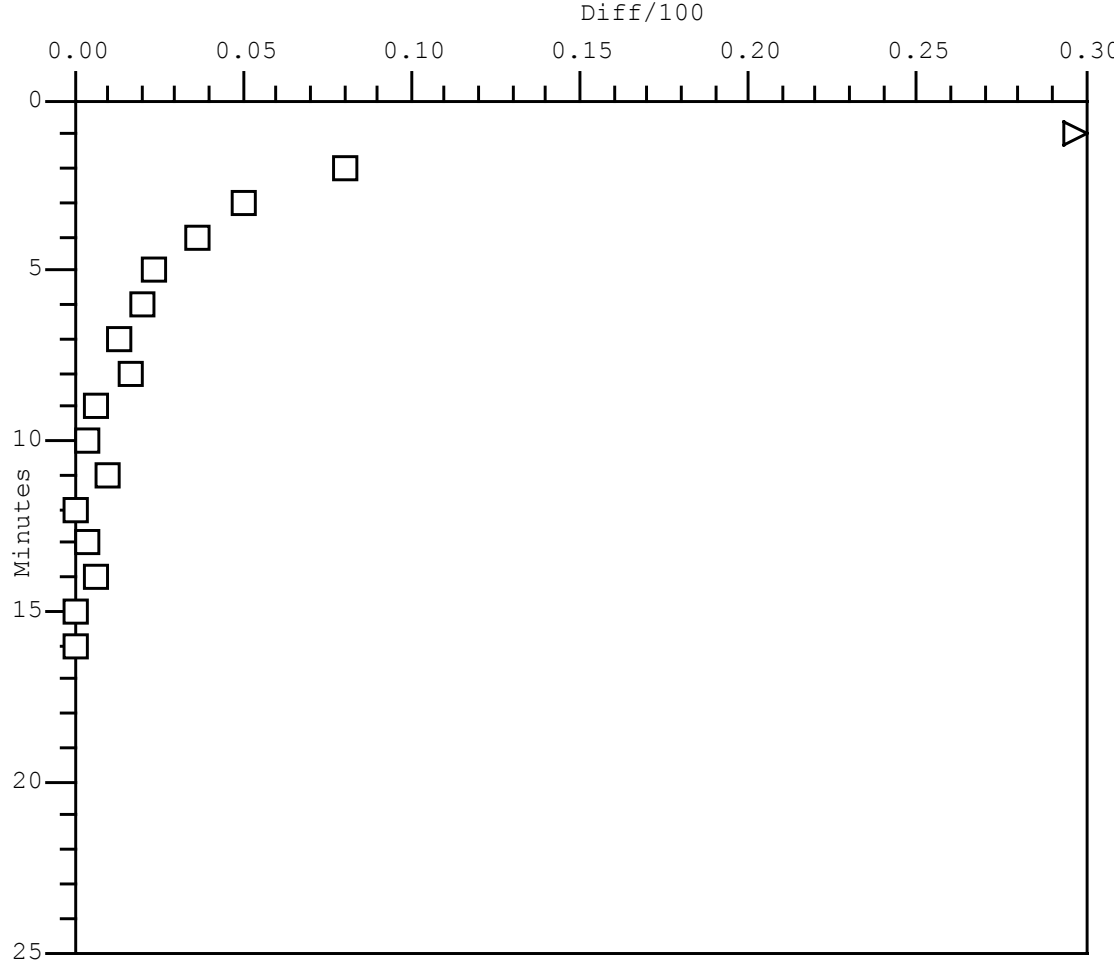

Diff $-15 \mathrm{Min}+15 \mathrm{~T} /{ }^{\circ} \mathrm{C}$

$\begin{array}{llllll}68.0 & 0.65 & 0.68 & 0.71 & 23.3\end{array}$

$\begin{array}{llllll}8.0 & 0.75 & 0.76 & 0.77 & 23.6\end{array}$

$\begin{array}{llllll}5.0 & 0.80 & 0.81 & 0.82 & 23.5\end{array}$

$\begin{array}{llllll}3.7 & 0.84 & 0.85 & 0.85 & 23.6\end{array}$

$\begin{array}{llllll}2.3 & 0.86 & 0.87 & 0.88 & 23.6\end{array}$

$\begin{array}{llllll}2.0 & 0.89 & 0.89 & 0.89 & 23.6\end{array}$

$\begin{array}{llllll}1.3 & 0.90 & 0.90 & 0.91 & 23.6\end{array}$

$\begin{array}{llllll}1.7 & 0.92 & 0.92 & 0.92 & 23.7\end{array}$

$\begin{array}{llllll}0.7 & 0.92 & 0.93 & 0.93 & 23.7\end{array}$

$\begin{array}{llllll}0.3 & 0.93 & 0.93 & 0.93 & 23.6\end{array}$

$\begin{array}{llllll}1.0 & 0.94 & 0.94 & 0.94 & 23.7\end{array}$

$\begin{array}{llllll}0.0 & 0.94 & 0.94 & 0.94 & 23.6\end{array}$

$\begin{array}{llllll}0.3 & 0.94 & 0.94 & 0.95 & 23.6\end{array}$

$\begin{array}{llllll}0.7 & 0.95 & 0.95 & 0.95 & 23.7\end{array}$

$\begin{array}{llllll}0.0 & 0.95 & 0.95 & 0.95 & 23.7\end{array}$

$\begin{array}{llllll}0.0 & 0.95 & 0.95 & 0.95 & 23.7\end{array}$

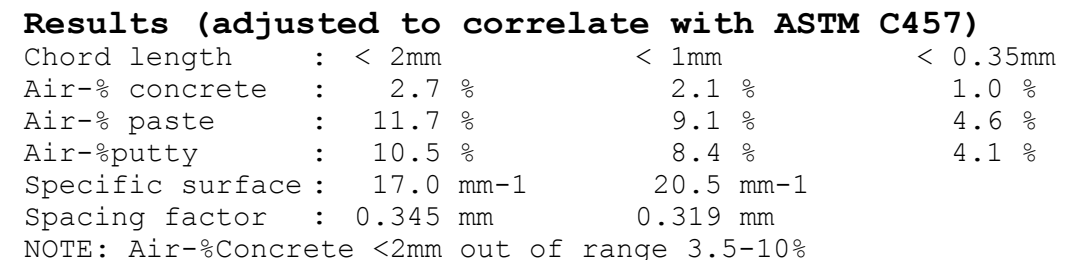

NOTE: Air-\%Concrete $<2 \mathrm{~mm}$ out of range $3.5-10 \%$

\section{Comments}

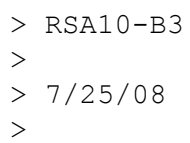

Sign. : 
Air Void Analyzer AVA-3000

Type Company name

\section{Measurement of Jul 25, 2008 3:09 PM}

Case number : RSA 10 B3

Sample number : 3

Distribution of air void content for voids $<2 \mathrm{~mm}$ (\%)

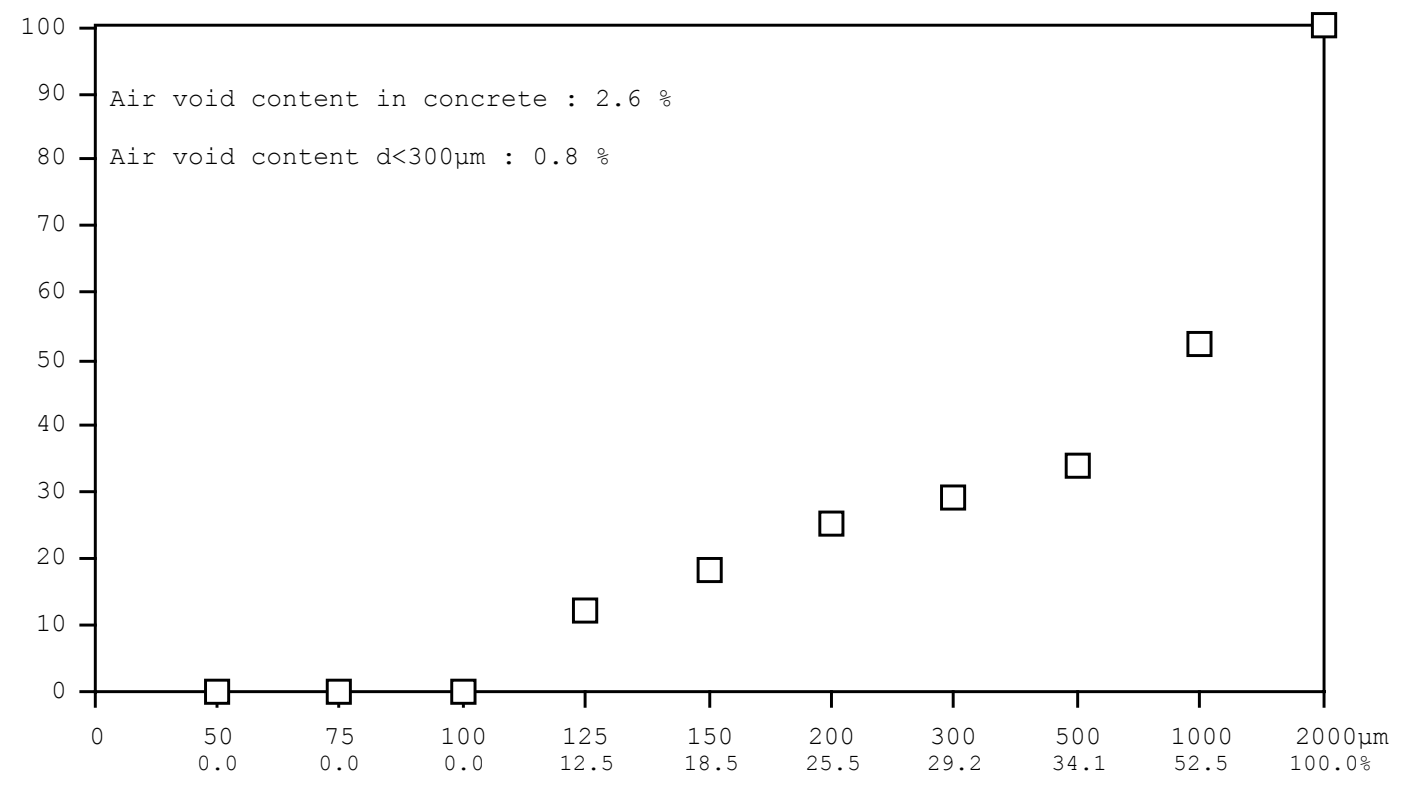

Distribution of air void content in cement paste for voids $2 \mathrm{~mm}$ ( $\%$ )

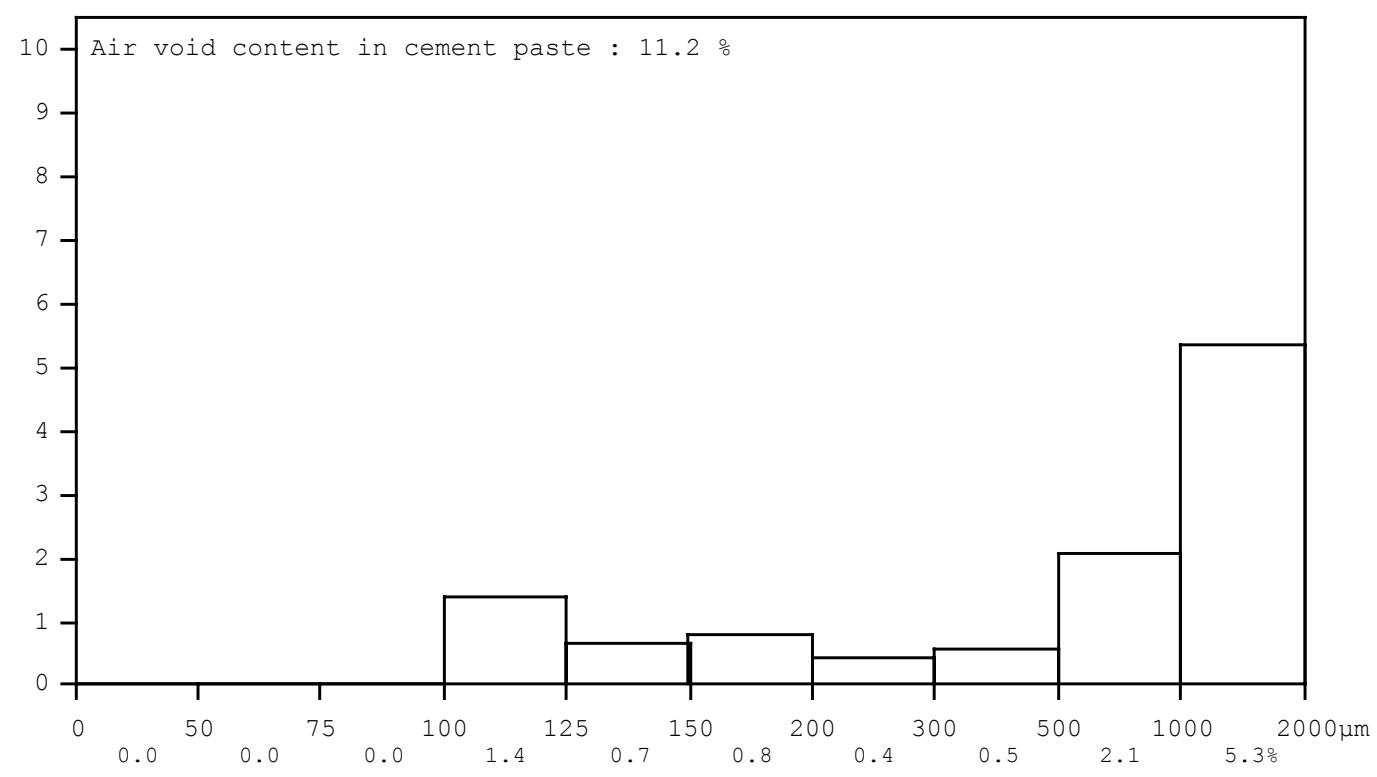


Air Void Analyzer AVA-3000

Type Company name

Measurement of Sep 11, 2008 5:07 PM

$\begin{array}{ll}\text { Sampler } & \text { : RSA } 10 \text { C1 } \\ \text { Ordered by } & \text { : davk } \\ \text { Sample location } & \text { : U of L } \\ \text { Case number } & : \text { RSA } 10 \text { C1 } \\ \text { Sample number } & : 1\end{array}$

$\begin{array}{lrr}\text { Mortar<6mm } & : 55.31 \% \\ \text { Expected air } & : & 4.6 \% \\ \text { Paste } & : & 22.52 \% \\ \text { Sample volume } & : & 20.0 \mathrm{~cm} 3\end{array}$

Analysis

start: $0.0 \mathrm{~g}$

+5 sec.: $0.16 \mathrm{~g}$

+30 sec.:

$0.11 \mathrm{~g}$

Temp: $\quad 23 \cdot 3^{\circ} \mathrm{C}$

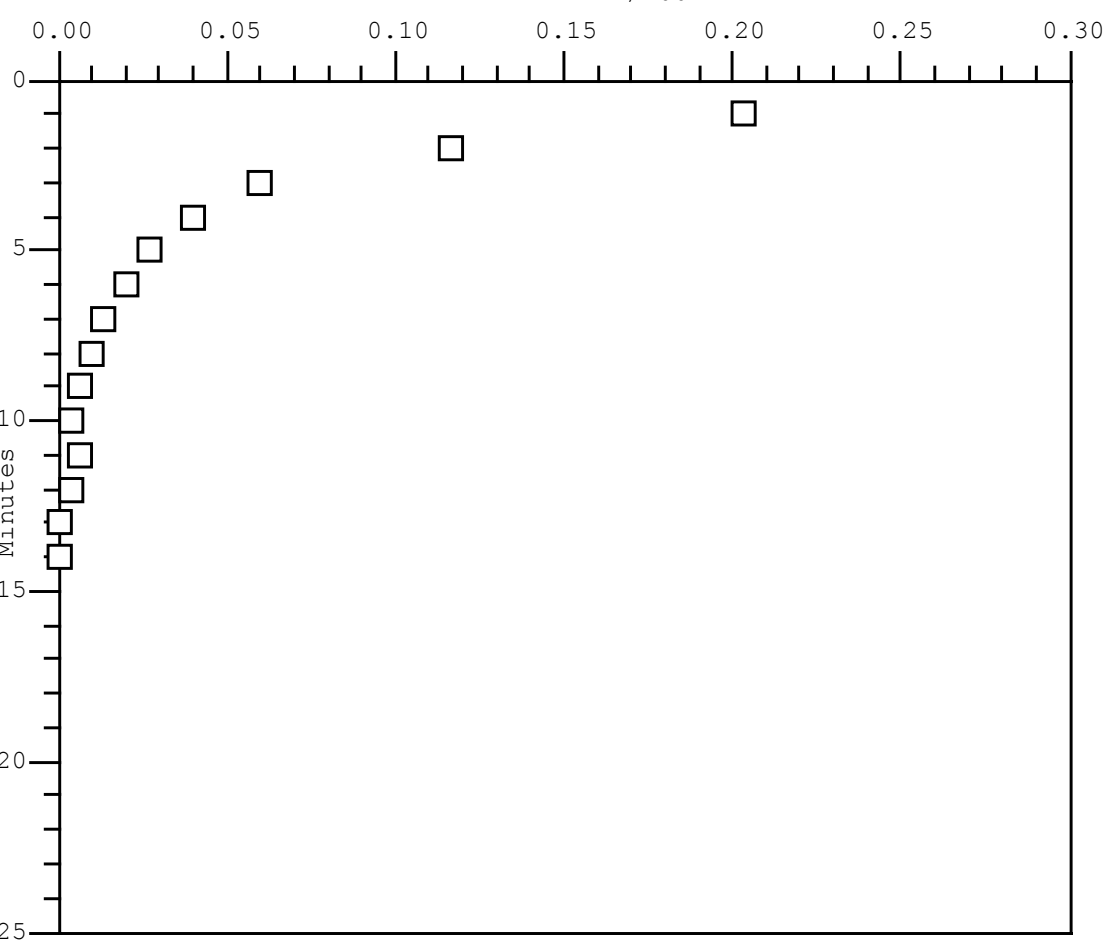

Diff $-15 \mathrm{Min}+15 \mathrm{~T} /{ }^{\circ} \mathrm{C}$

$20.3 \quad 0.16 \quad 0.21 \quad 0.24 \quad 23.8$

$\begin{array}{llllll}11.7 & 0.30 & 0.32 & 0.34 & 23.8\end{array}$

$\begin{array}{llllll}6.0 & 0.37 & 0.38 & 0.39 & 23.8\end{array}$

$\begin{array}{llllll}4.0 & 0.41 & 0.42 & 0.43 & 23.8\end{array}$

$\begin{array}{llllll}2.7 & 0.44 & 0.45 & 0.45 & 23.8\end{array}$

$\begin{array}{lllllll}2.0 & 0.46 & 0.47 & 0.47 & 23.8\end{array}$

$\begin{array}{llllll}1.3 & 0.48 & 0.48 & 0.48 & 23.8\end{array}$

$\begin{array}{llllll}1.0 & 0.49 & 0.49 & 0.49 & 23.8\end{array}$

$\begin{array}{lllllll}0.7 & 0.49 & 0.50 & 0.50 & 23.8\end{array}$

$\begin{array}{llllll}0.3 & 0.50 & 0.50 & 0.50 & 23.8\end{array}$

$\begin{array}{lllllll}0.7 & 0.50 & 0.51 & 0.51 & 23.8\end{array}$

$\begin{array}{llllll}0.3 & 0.51 & 0.51 & 0.51 & 23.8\end{array}$

$\begin{array}{llllll}0.0 & 0.51 & 0.51 & 0.51 & 23.8\end{array}$

$\begin{array}{llllll}0.0 & 0.51 & 0.51 & 0.51 & 23.8\end{array}$

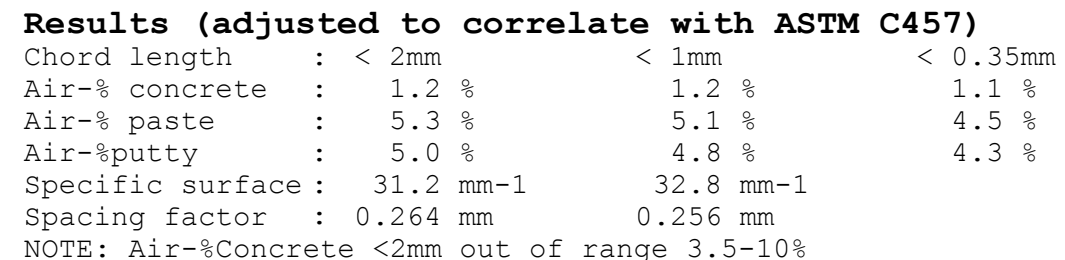

\section{Comments}

\footnotetext{
$>\mathrm{RSA}-10 \mathrm{C} 1$

$>$ 9-11-08

$>$ davk

$>$
}

Sign. : 
Air Void Analyzer AVA-3000

Type Company name

\section{Measurement of Sep 11, 2008 5:07 PM}

Case number : RSA $10 \mathrm{Cl}$

Sample number : 1

Distribution of air void content for voids $<2 \mathrm{~mm}$ (\%)

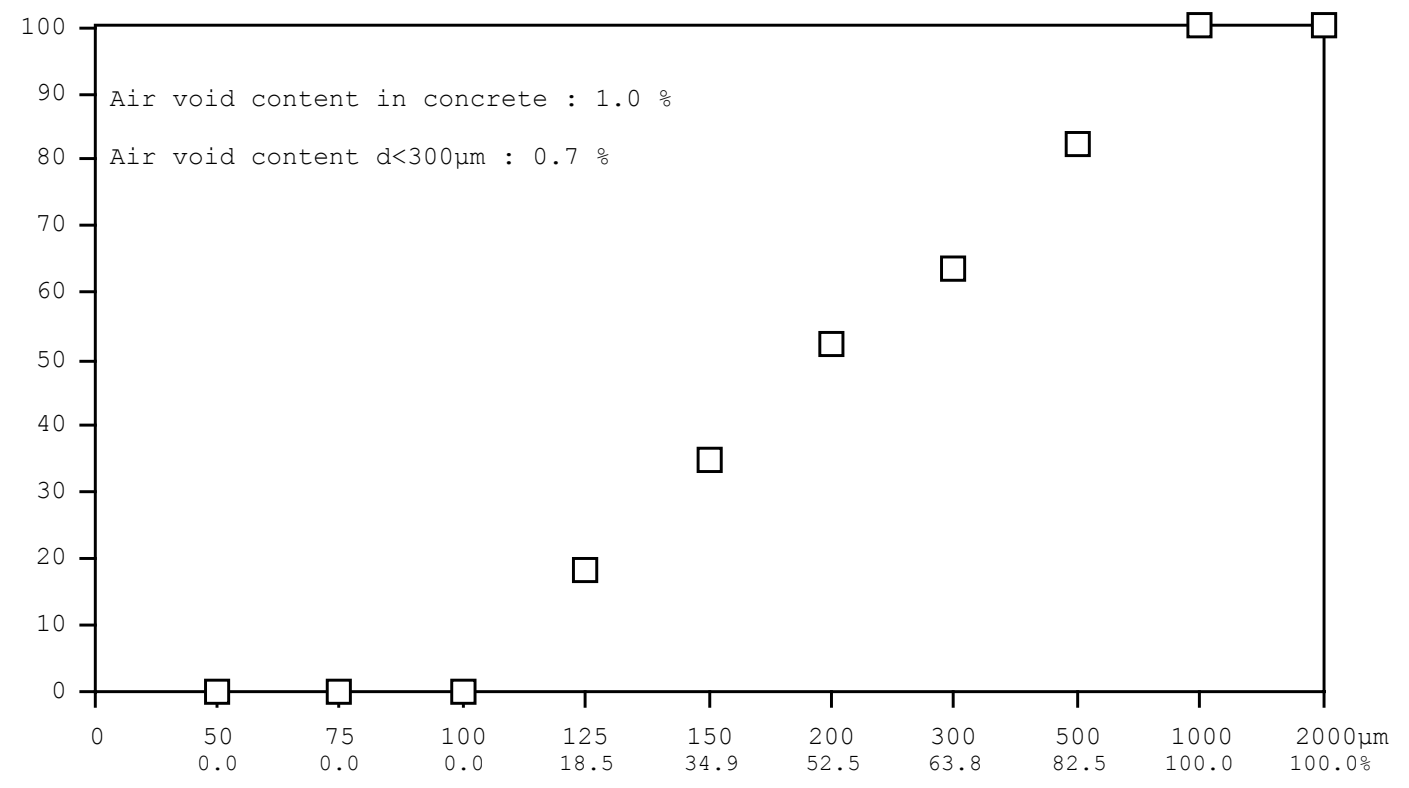

Distribution of air void content in cement paste for voids $2 \mathrm{~mm}$ ( $\%$ )

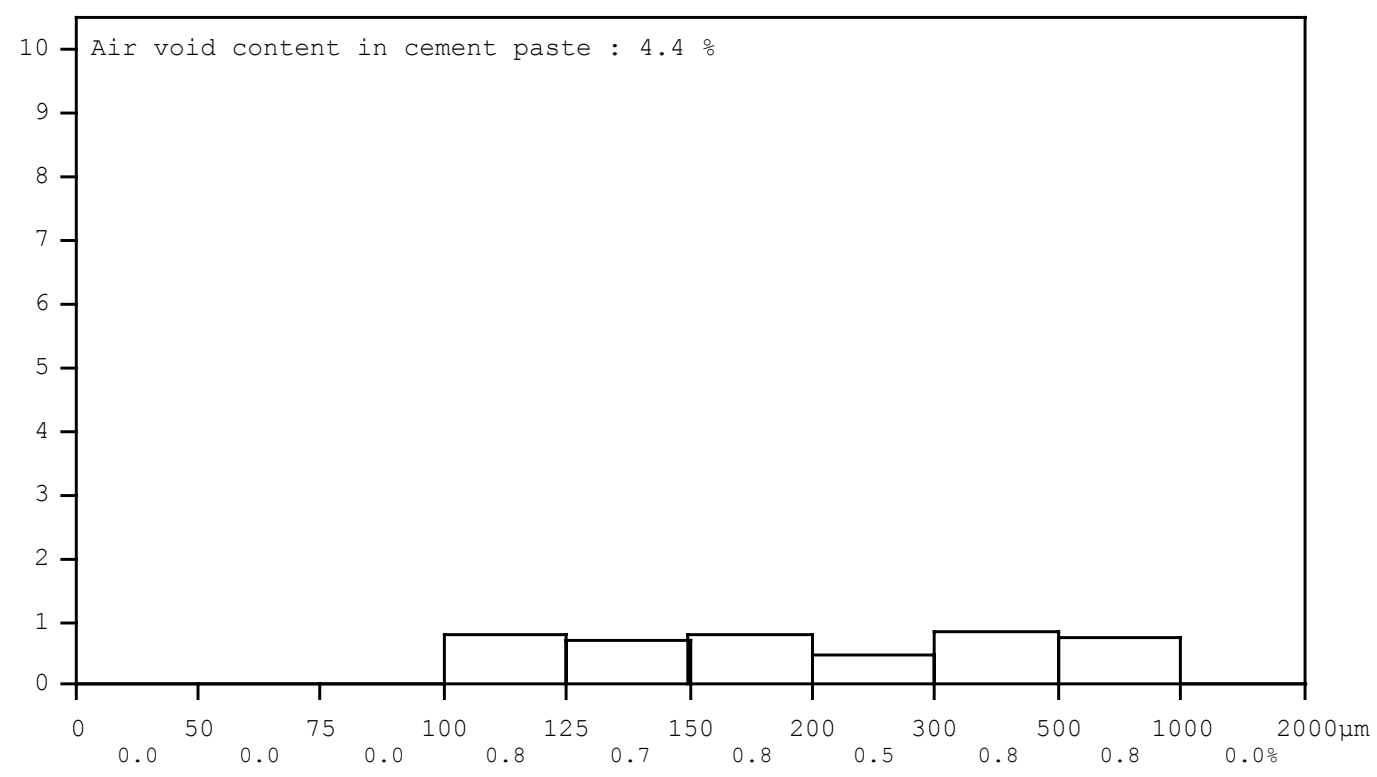


Air Void Analyzer AVA-3000

Type Company name

Measurement of Sep 11, 2008 5:36 PM

$\begin{array}{ll}\text { Sampler } & \text { : RSA } 10 \text { C2 } \\ \text { Ordered by } & \text { : davk } \\ \text { Sample location } & : \text { U of L } \\ \text { Case number } & : \text { RSA } 10 \text { C2 } \\ \text { Sample number } & : 2\end{array}$

Mortar<6mm : $55.31 \%$

Expected air : $4.6 \%$

Paste : $22.52 \%$

Sample number :

Sample volume : $20.0 \mathrm{~cm} 3$

\section{Analysis}

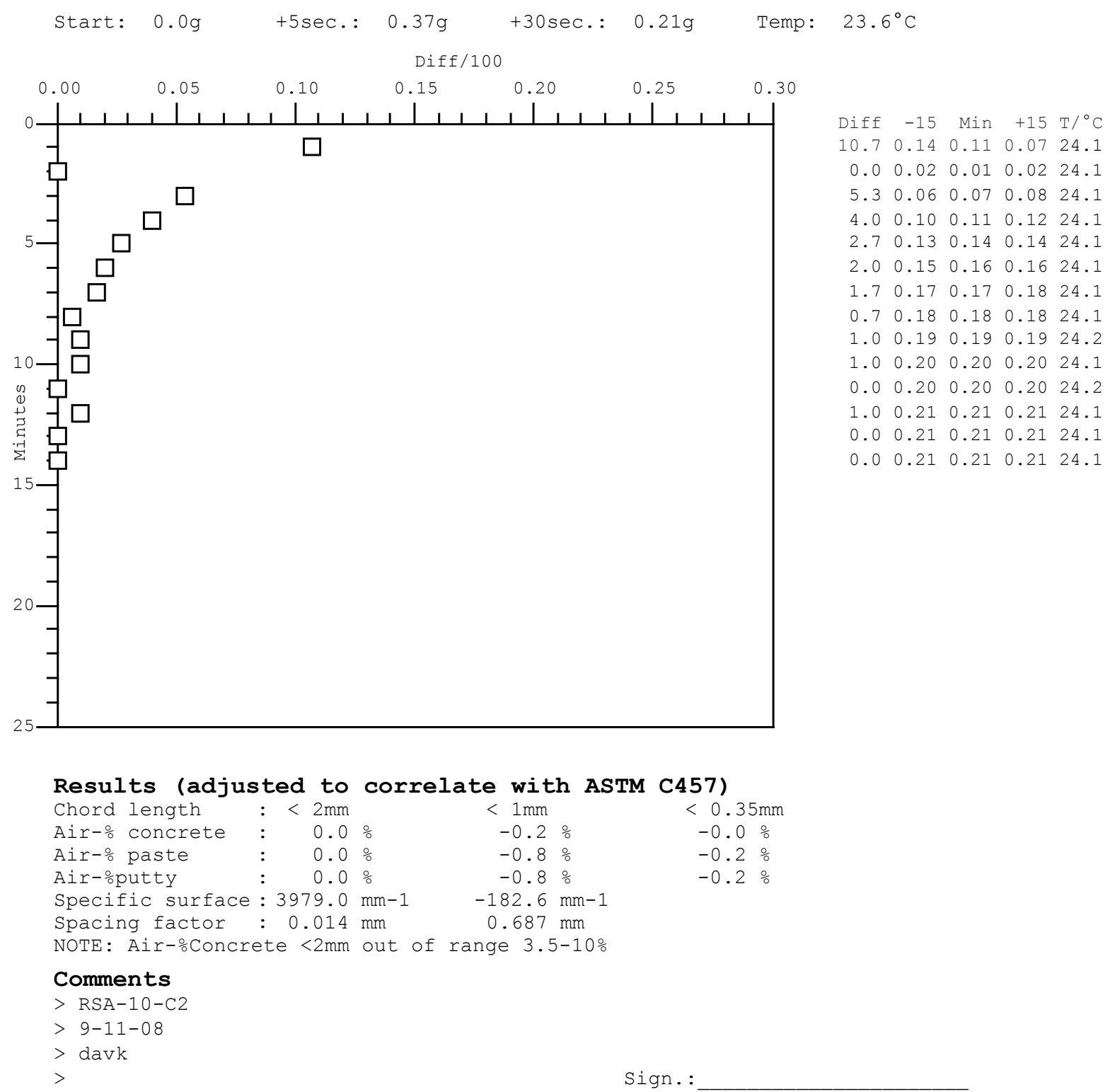


Air Void Analyzer AVA-3000

Type Company name

\section{Measurement of Sep 11, 2008 5:36 PM}

Case number : RSA $10 \mathrm{C} 2$

Sample number : 2

Distribution of air void content for voids $<2 \mathrm{~mm}$ (\%)

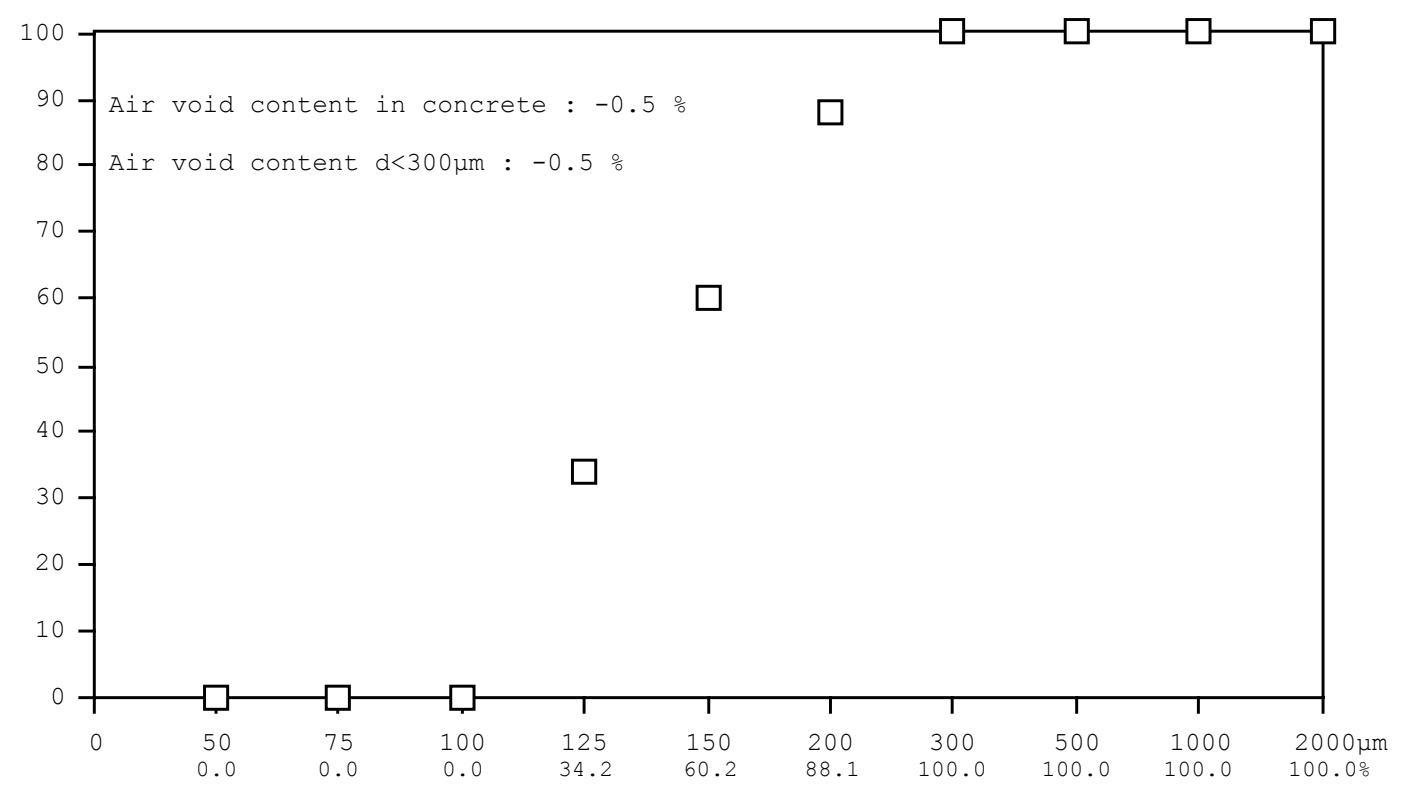

Distribution of air void content in cement paste for voids $2 \mathrm{~mm}$ ( $\%$ )

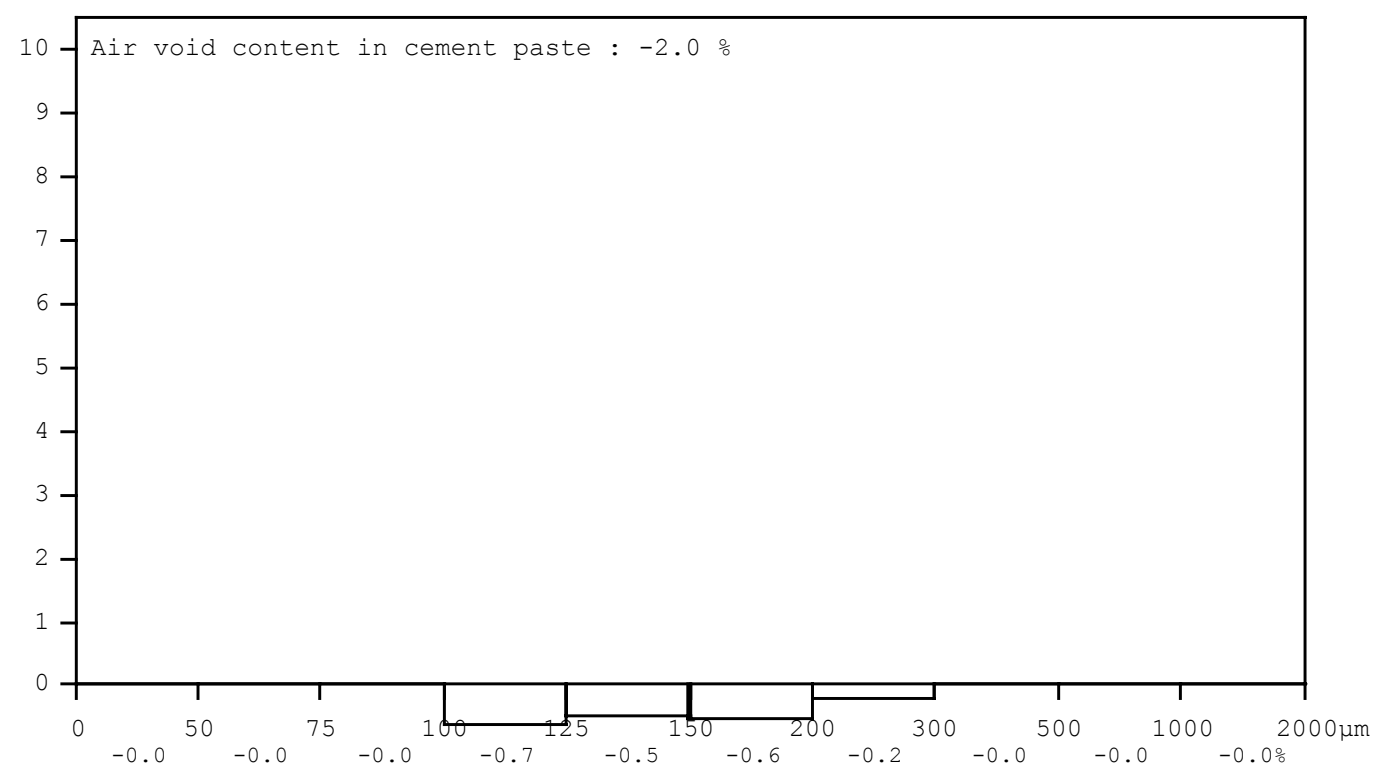


Air Void Analyzer AVA-3000

Type Company name

Measurement of Sep 11, 2008 6:06 PM

$\begin{array}{ll}\text { Sampler } & \text { : RSA } 10 \text { C3 } \\ \text { Ordered by } & \text { : davk } \\ \text { Sample location } & : \text { U of L } \\ \text { Case number } & : \text { RSA } 10 \text { C3 } \\ \text { Sample number } & : 3\end{array}$

$\begin{array}{lrr}\text { Mortar<6mm } & : 55.31 \% \\ \text { Expected air } & : & 4.6 \% \\ \text { Paste } & : & 22.52 \% \\ \text { Sample volume } & : & 20.0 \mathrm{~cm} 3\end{array}$

Analysis

start: $0.0 \mathrm{~g}$

+5sec.: $0.17 \mathrm{~g} \quad+30 \mathrm{sec}: 0.37 \mathrm{~g}$

Temp: $\quad 23.7^{\circ} \mathrm{C}$

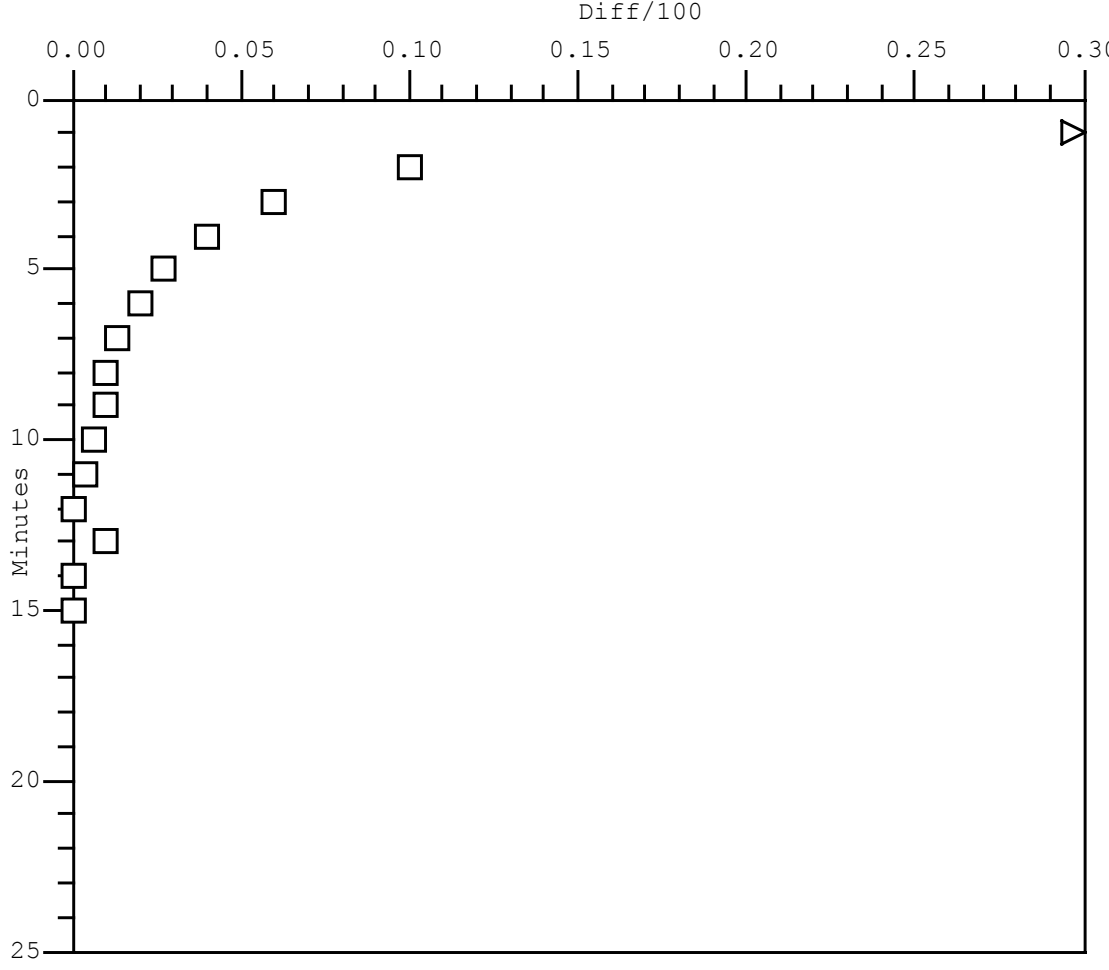

Diff $-15 \mathrm{Min}+15 \mathrm{~T} /{ }^{\circ} \mathrm{C}$

$\begin{array}{llllll}46.0 & 0.43 & 0.46 & 0.49 & 24.2\end{array}$

$\begin{array}{llllll}10.0 & 0.54 & 0.56 & 0.58 & 24.2\end{array}$

$\begin{array}{lllll}6.0 & 0.61 & 0.62 & 0.63 & 24.2\end{array}$

$\begin{array}{llllll}4.0 & 0.65 & 0.66 & 0.67 & 24.3\end{array}$

$\begin{array}{llllll}2.7 & 0.68 & 0.69 & 0.69 & 24.2\end{array}$

$\begin{array}{llllll}2.0 & 0.70 & 0.71 & 0.71 & 24.3\end{array}$

$\begin{array}{llllll}1.3 & 0.72 & 0.72 & 0.72 & 24.3\end{array}$

$\begin{array}{lllll}1.0 & 0.73 & 0.73 & 0.73 & 24.2\end{array}$

$\begin{array}{llllll}1.0 & 0.74 & 0.74 & 0.74 & 24.3\end{array}$

$\begin{array}{llllll}0.7 & 0.74 & 0.75 & 0.75 & 24.3\end{array}$

$\begin{array}{llllll}0.3 & 0.75 & 0.75 & 0.75 & 24.3\end{array}$

$\begin{array}{llllll}0.0 & 0.75 & 0.75 & 0.75 & 24.3\end{array}$

$\begin{array}{llllll}1.0 & 0.76 & 0.76 & 0.76 & 24.3\end{array}$

$\begin{array}{llllll}0.0 & 0.76 & 0.76 & 0.76 & 24.3\end{array}$

$\begin{array}{lllll}0.0 & 0.76 & 0.76 & 0.76 & 24.3\end{array}$

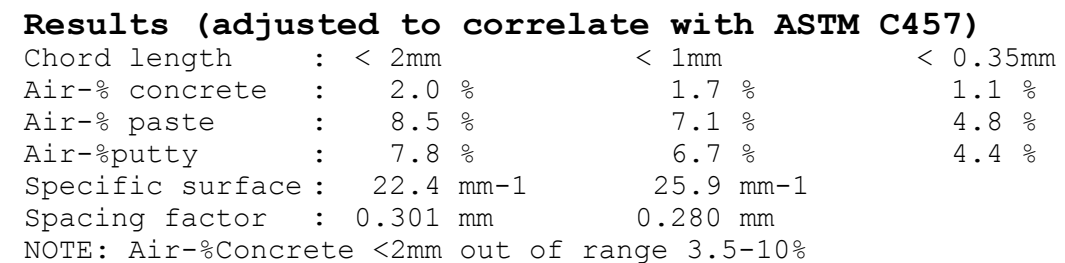

NOTE: Air-\%Concrete $<2 \mathrm{~mm}$ out of range $3.5-10 \%$

\section{Comments}

\footnotetext{
$>$ RSA10-C3

$>$ 9-11-08

$>$ davk

$>$
}

Sign.: 
Air Void Analyzer AVA-3000

Type Company name

\section{Measurement of Sep 11, 2008 6:06 PM}

Case number : RSA $10 \mathrm{C3}$

Sample number : 3

Distribution of air void content for voids $<2 \mathrm{~mm}$ (\%)

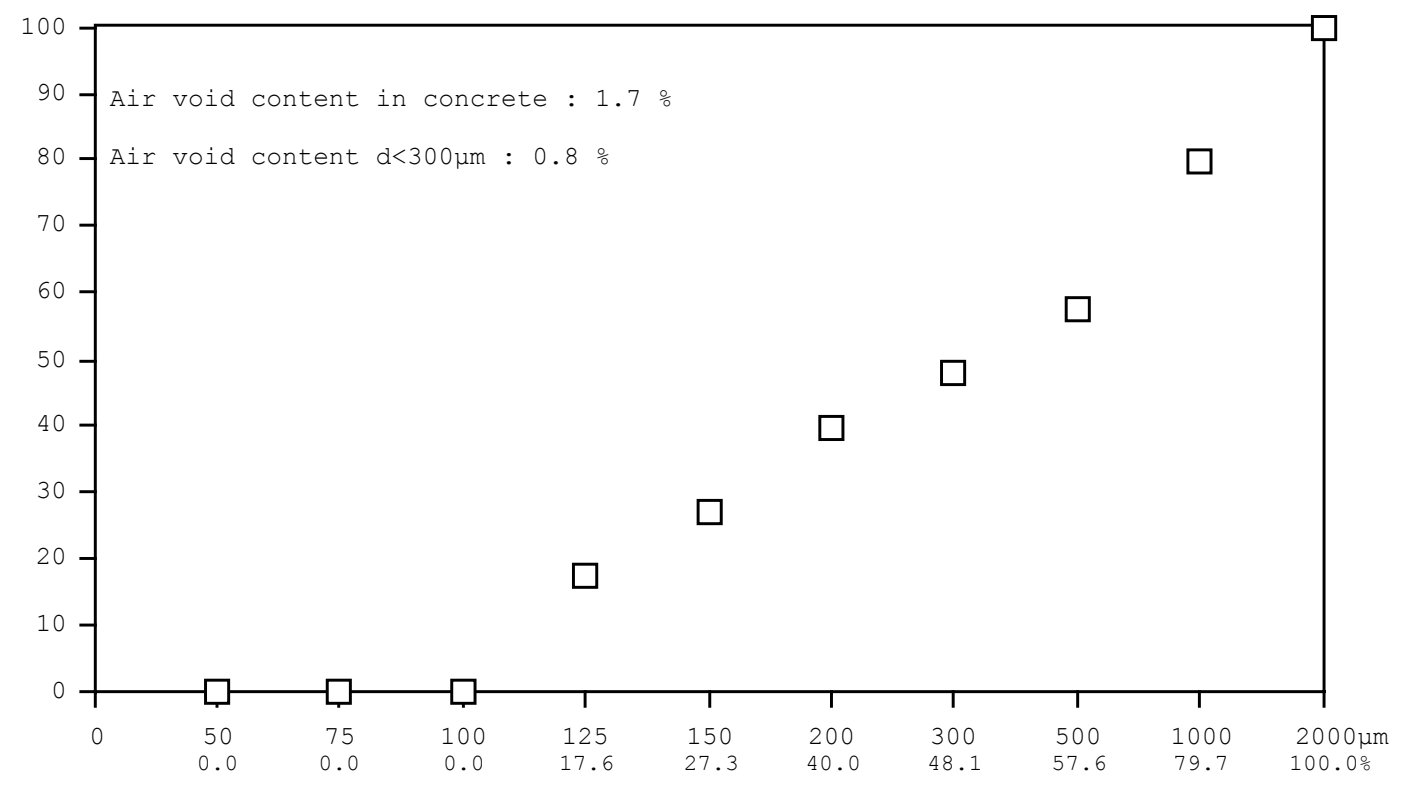

Distribution of air void content in cement paste for voids $<2 \mathrm{~mm}$ (\%)

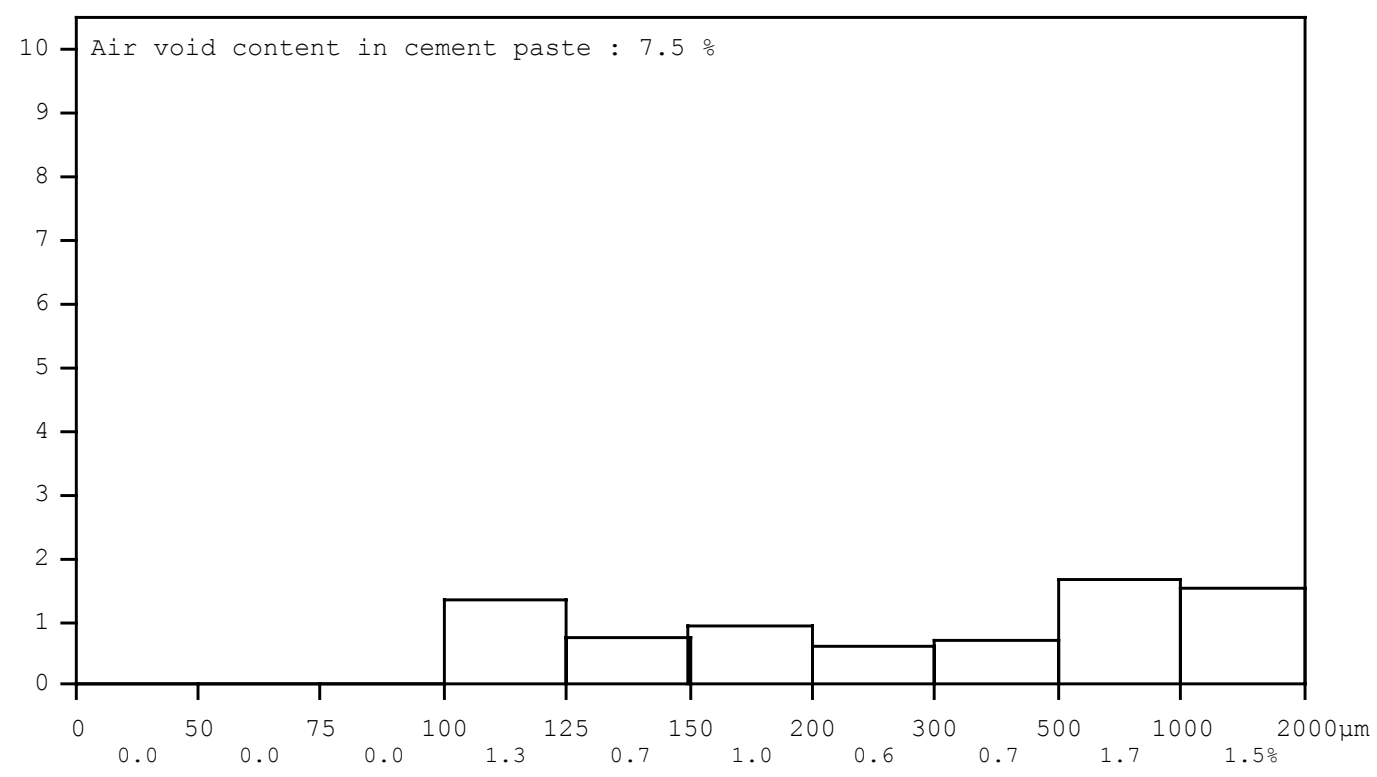


Air Void Analyzer AVA-3000

Type Company name

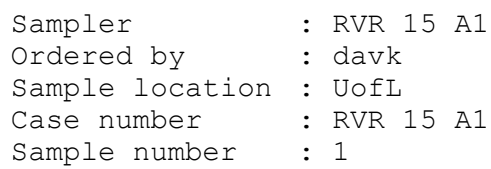

Sampler

Ordered by : davk

Sample location : UofI

Case number : RVR 15 A1

Sample number : 1

$\begin{array}{llr}\text { Mortar }<6 \mathrm{~mm} & : 52.51 \% \\ \text { Expected air } & : & 7.4 \% \\ \text { Paste } & : 22.52 \% \\ \text { Sample volume } & : \quad 20.0 \mathrm{~cm} 3\end{array}$

\section{Analysis}

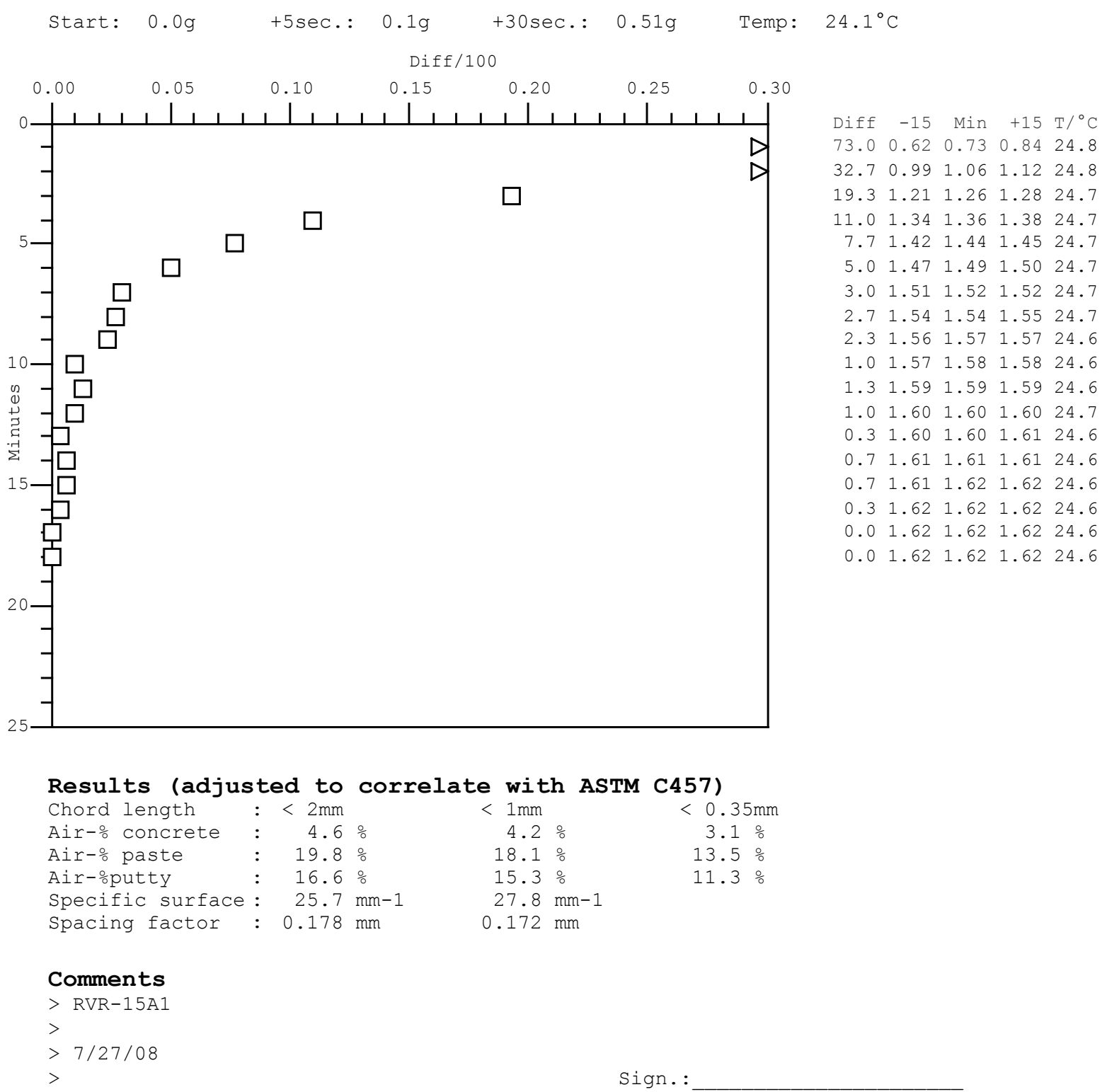


Air Void Analyzer AVA-3000

Type Company name

Measurement of Jul 27, 2008 8:00 AM

Case number : RVR 15 A1

Sample number : 1

Distribution of air void content for voids $<2 \mathrm{~mm}$ (\%)

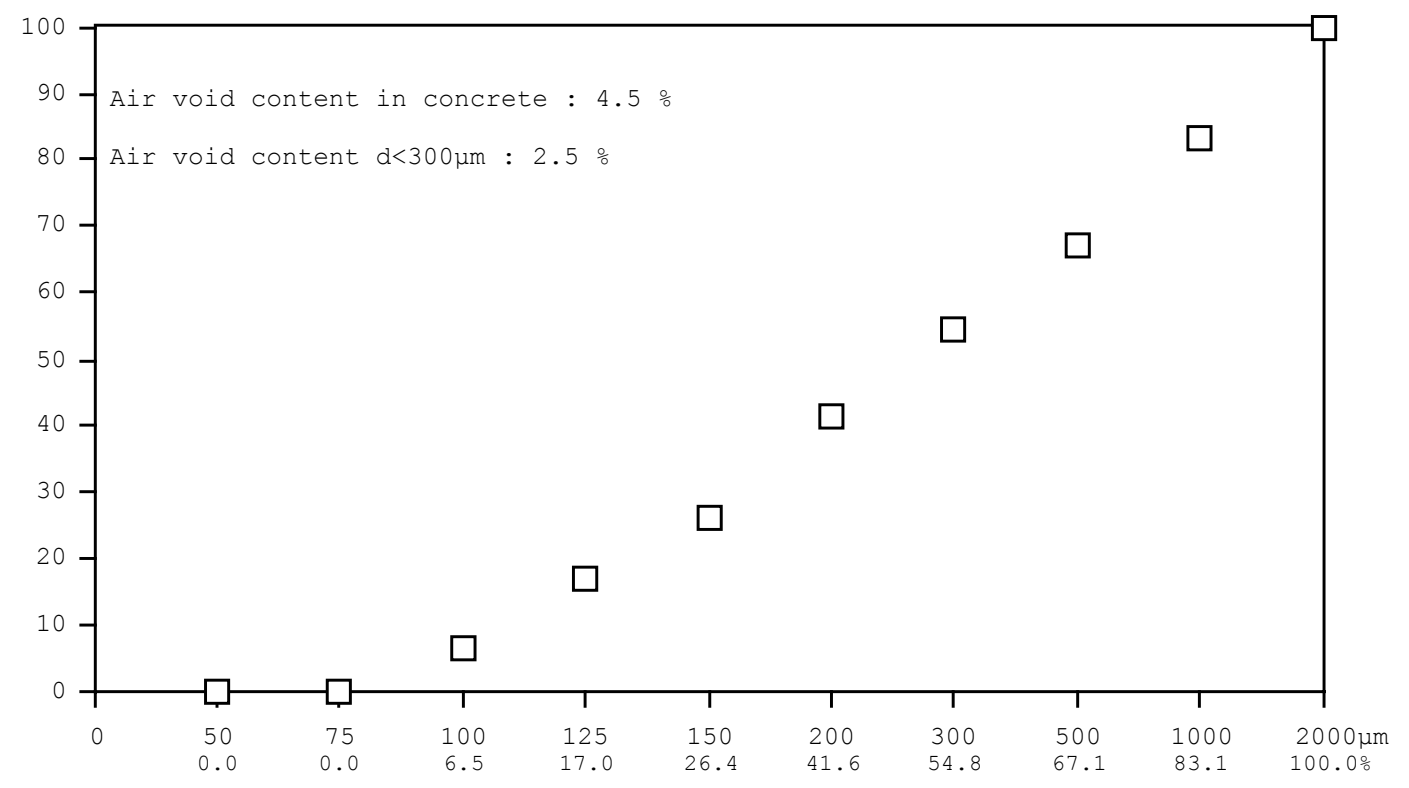

Distribution of air void content in cement paste for voids $<2 \mathrm{~mm}$ (\%)

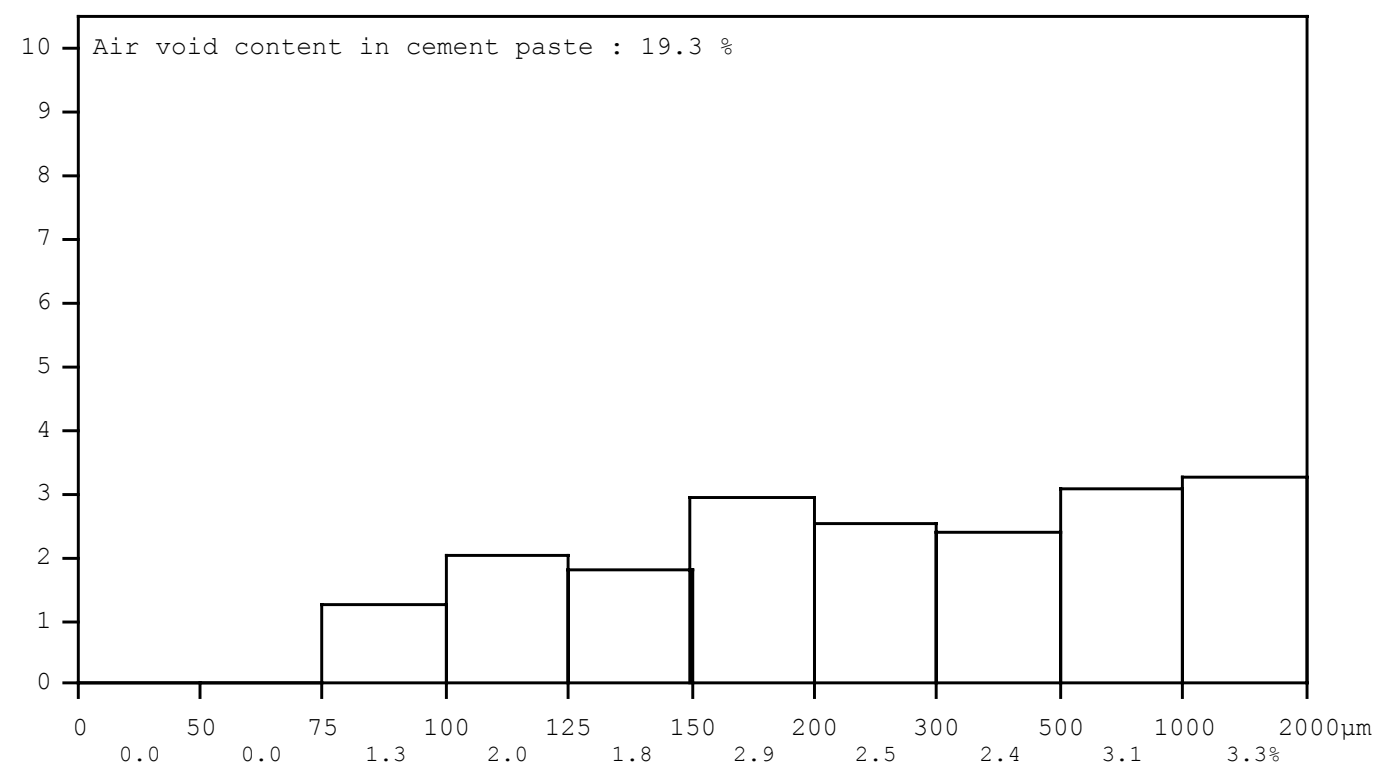


Air Void Analyzer AVA-3000

Type Company name

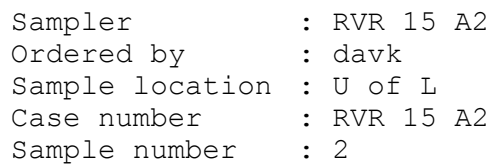

Sampler

Ordered by : davk

Sample location : U of L

Case number : RVR 15 A2

Sample number : 2

$\begin{array}{llr}\text { Mortar }<6 \mathrm{~mm} & : 52.51 \% \\ \text { Expected air } & : & 7.4 \% \\ \text { Paste } & : 22.52 \% \\ \text { Sample volume } & : \quad 20.0 \mathrm{~cm} 3\end{array}$

\section{Analysis}

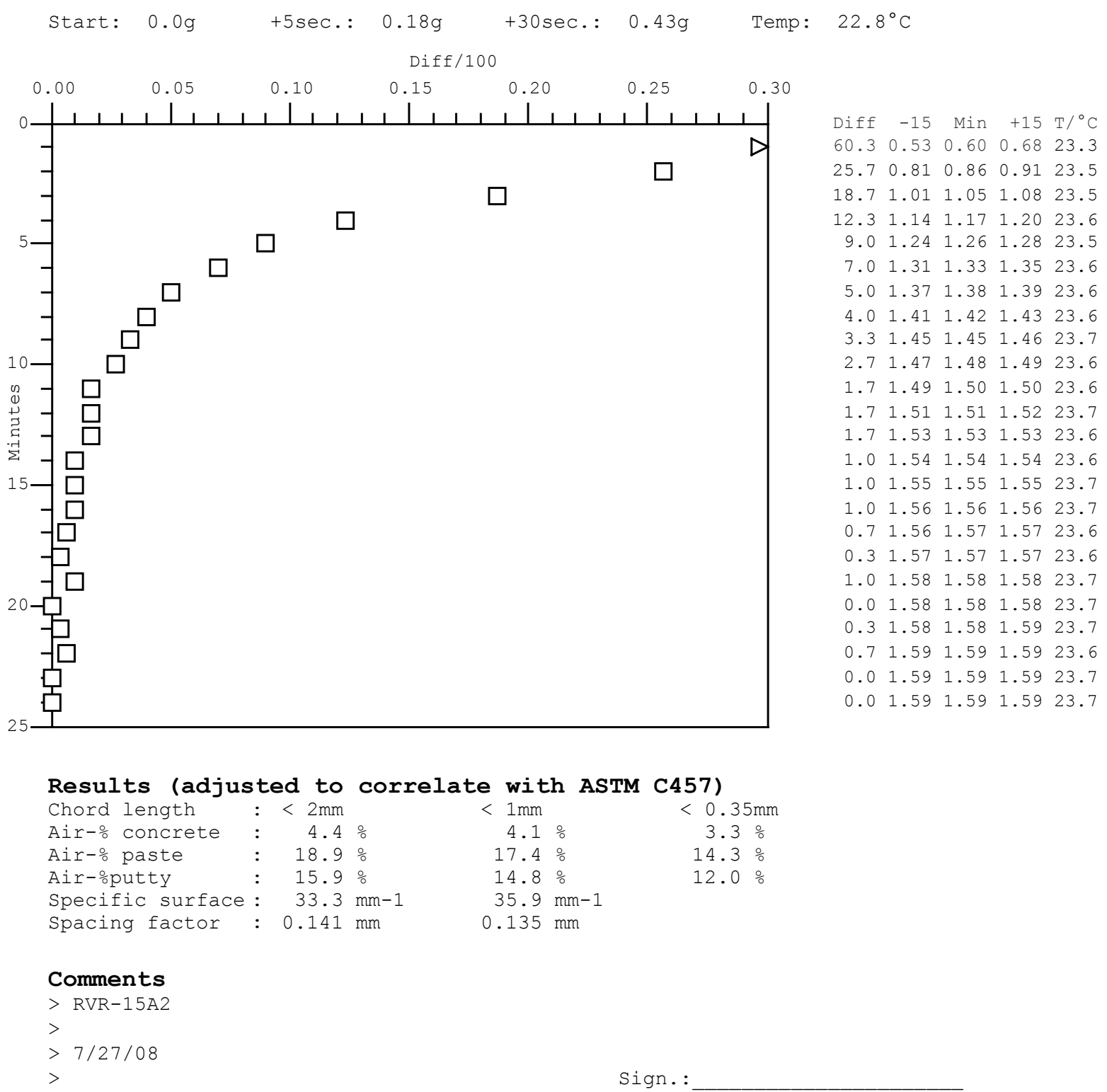


Air Void Analyzer AVA-3000

Type Company name

Measurement of Jul 27, 2008 8:30 AM

Case number : RVR 15 A2

Sample number : 2

Distribution of air void content for voids $<2 \mathrm{~mm}$ (\%)

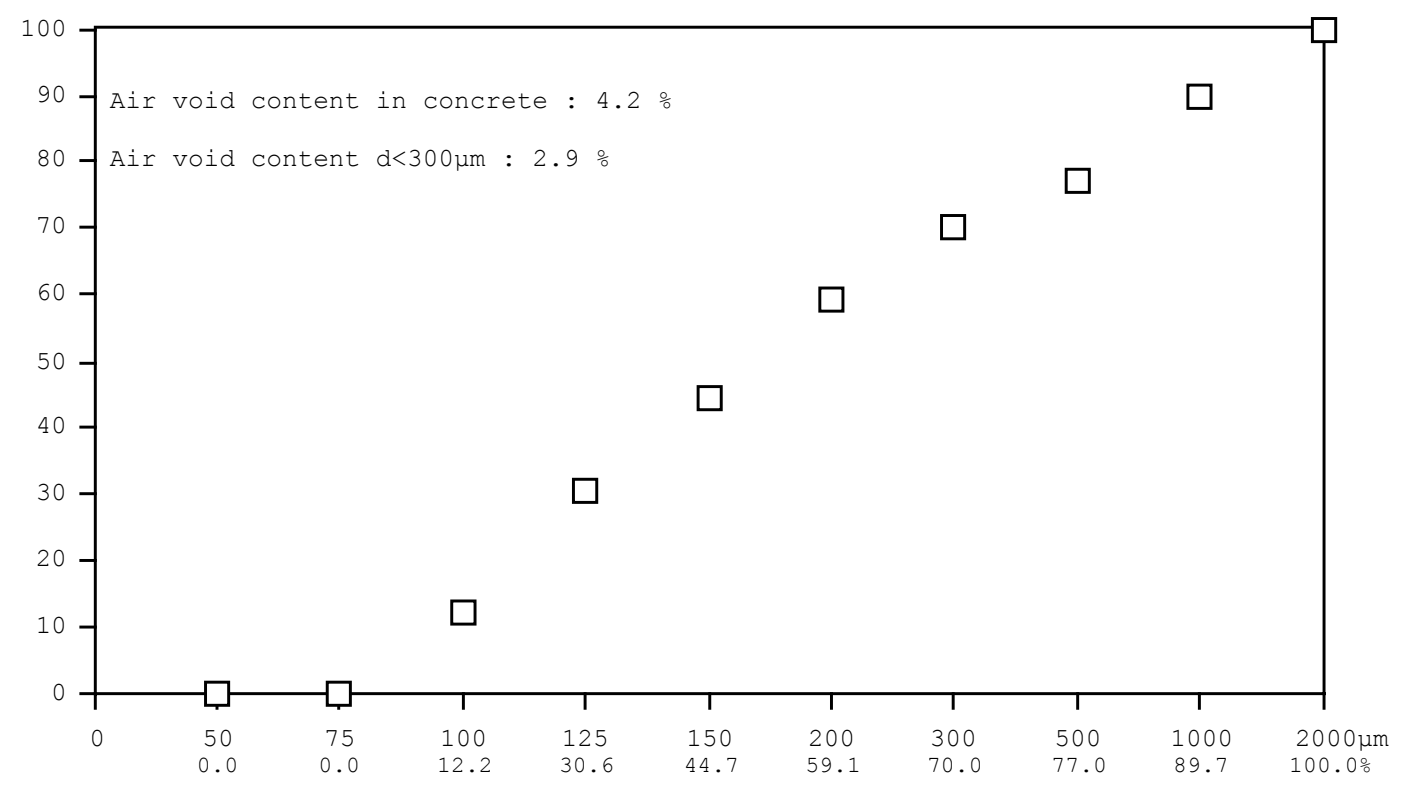

Distribution of air void content in cement paste for voids $<2 \mathrm{~mm}$ (\%)

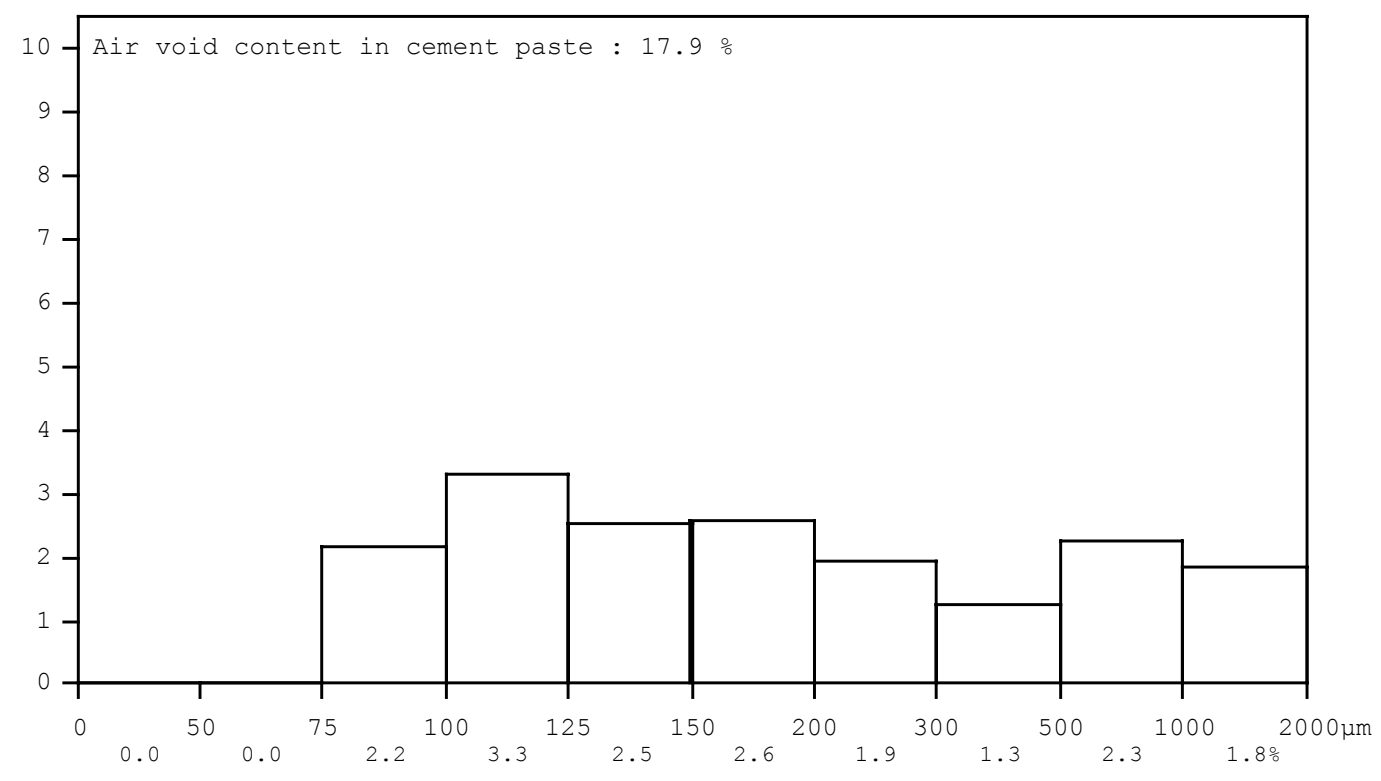


Air Void Analyzer AVA-3000

Type Company name
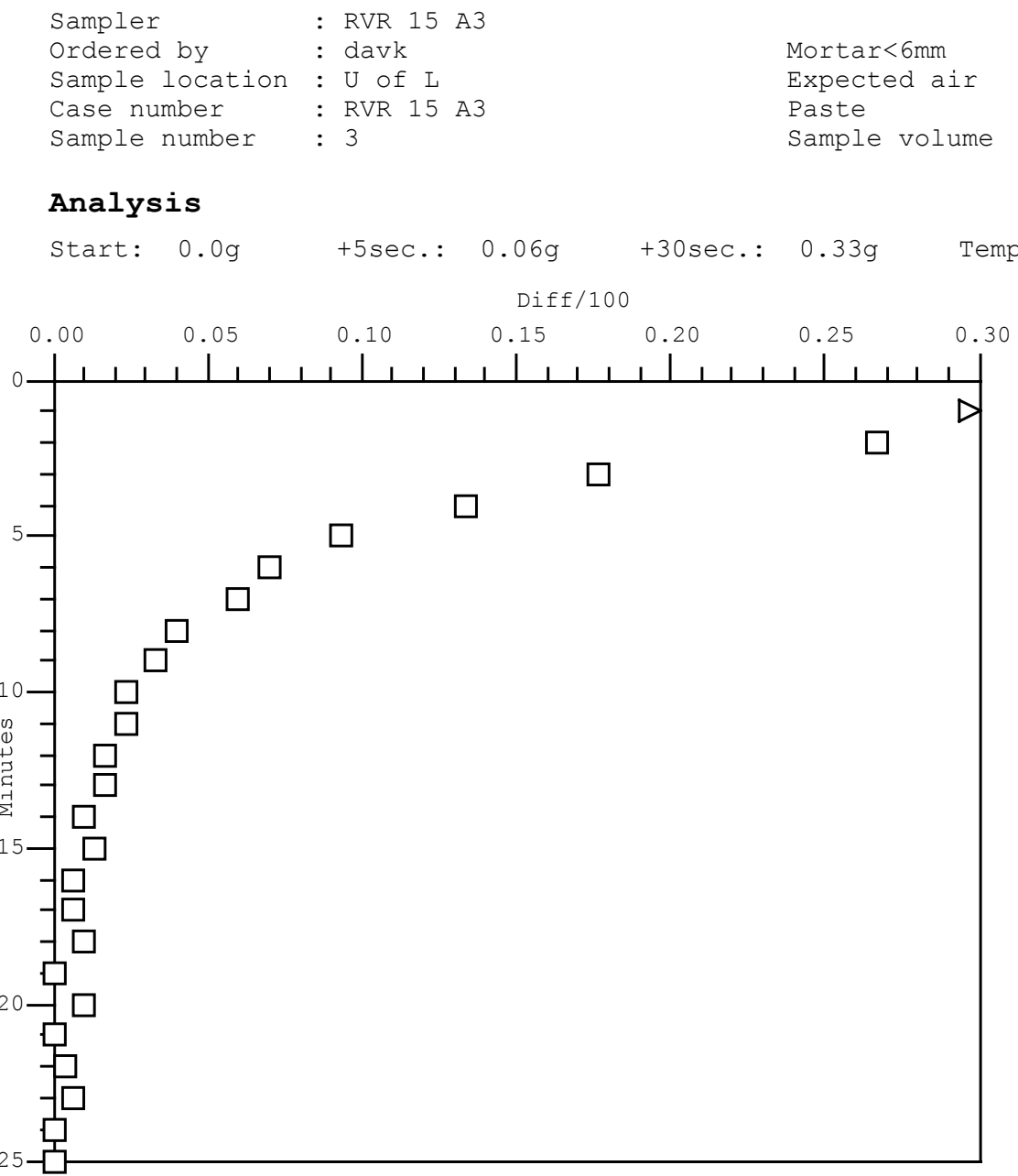

Diff -15 Min $+15 \mathrm{~T} /{ }^{\circ} \mathrm{C}$ $\begin{array}{llllll}51.0 & 0.43 & 0.52 & 0.58 & 23.1\end{array}$ $\begin{array}{llllll}26.7 & 0.73 & 0.77 & 0.83 & 23.2\end{array}$ $\begin{array}{llllll}17.7 & 0.92 & 0.95 & 0.99 & 23.3\end{array}$ $\begin{array}{llllll}13.3 & 1.06 & 1.09 & 1.11 & 23.3\end{array}$ $\begin{array}{llllll}9.3 & 1.16 & 1.18 & 1.20 & 23.3\end{array}$ $\begin{array}{llllll}7.0 & 1.24 & 1.25 & 1.26 & 23.3\end{array}$ $\begin{array}{lllll}6.0 & 1.30 & 1.31 & 1.32 & 23.3\end{array}$ $\begin{array}{lllll}4.0 & 1.34 & 1.35 & 1.36 & 23.3\end{array}$ $\begin{array}{lllll}3.3 & 1.38 & 1.38 & 1.39 & 23.3\end{array}$ $2.3 \quad 1.401 .41 \quad 1.4123 .3$ $\begin{array}{lllll}2.3 & 1.43 & 1.43 & 1.43 & 23.3\end{array}$ $\begin{array}{lllll}1.7 & 1.44 & 1.45 & 1.45 & 23.3\end{array}$ $\begin{array}{lllll}1.7 & 1.46 & 1.46 & 1.47 & 23.5\end{array}$ $\begin{array}{lllll}1.0 & 1.47 & 1.47 & 1.48 & 23.5\end{array}$ $\begin{array}{lllll}1.3 & 1.48 & 1.49 & 1.49 & 23.5\end{array}$ $\begin{array}{lllll}0.7 & 1.49 & 1.49 & 1.50 & 23.5\end{array}$ $\begin{array}{lllll}0.7 & 1.50 & 1.50 & 1.50 & 23.5\end{array}$ $\begin{array}{lllll}1.0 & 1.51 & 1.51 & 1.51 & 23.5\end{array}$ $\begin{array}{llllll}0.0 & 1.51 & 1.51 & 1.51 & 23.5\end{array}$ $\begin{array}{lllll}1.0 & 1.52 & 1.52 & 1.52 & 23.5\end{array}$ $\begin{array}{llllll}0.0 & 1.52 & 1.52 & 1.52 & 23.5\end{array}$ $\begin{array}{lllll}0.3 & 1.52 & 1.52 & 1.53 & 23.5\end{array}$ $\begin{array}{lllll}0.7 & 1.53 & 1.53 & 1.53 & 23.5\end{array}$ $\begin{array}{llllll}0.0 & 1.53 & 1.53 & 1.53 & 23.6\end{array}$ $\begin{array}{llllll}0.0 & 1.53 & 1.53 & 1.53 & 23.6\end{array}$

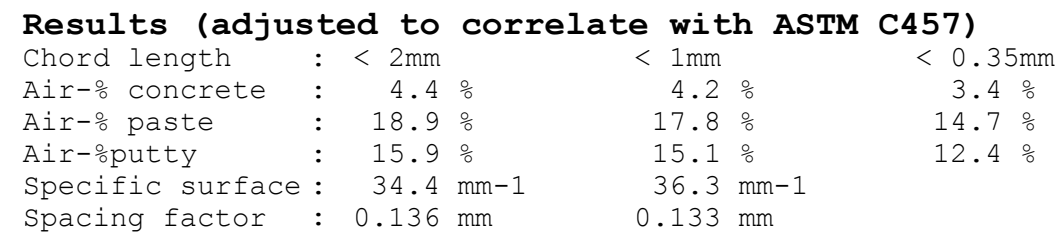

\title{
Comments
}

\author{
$>$ RVR-15A3
}

$>$

$>7 / 27 / 08$

Sign. : 
Air Void Analyzer AVA-3000

Type Company name

Measurement of Jul 27, 2008 9:03 AM

Case number : RVR 15 A3

Sample number : 3

Distribution of air void content for voids $<2 \mathrm{~mm}$ (\%)

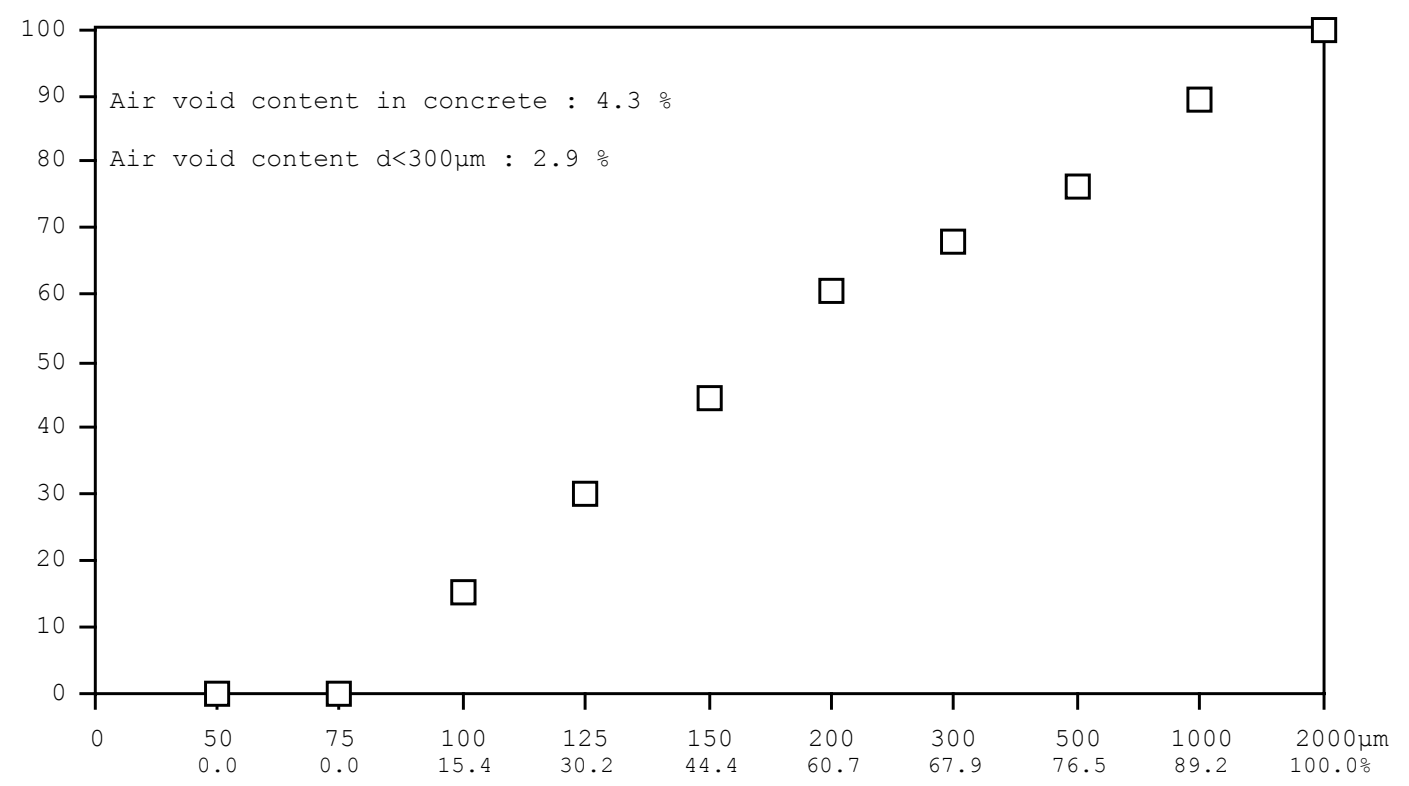

Distribution of air void content in cement paste for voids $<2 \mathrm{~mm}$ (\%)

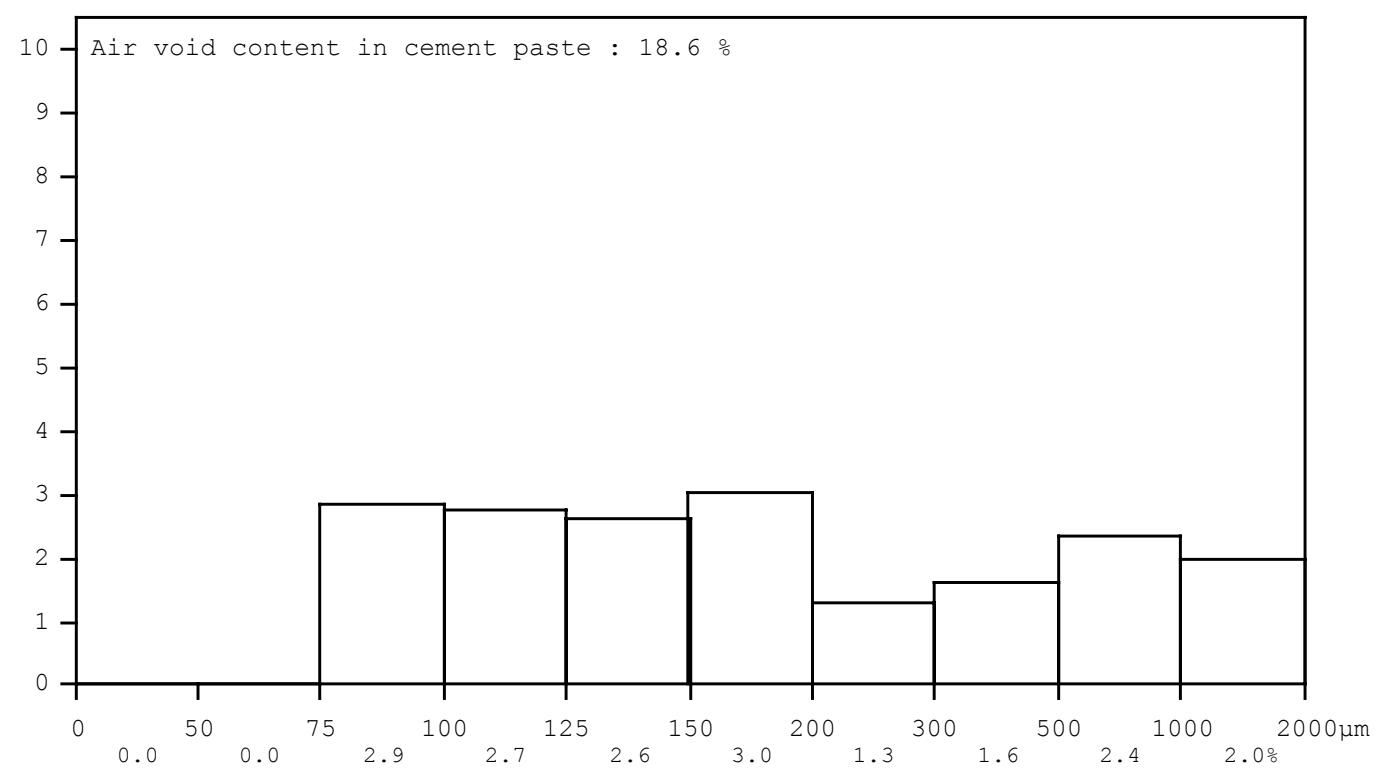


Air Void Analyzer AVA-3000

Type Company name

Measurement of Jul 27, 2008 9:36 AM

$\begin{array}{lll}\text { Sampler } & \text { : RVR } 15 \text { B1 } \\ \text { Ordered by } & \text { : davk } & \\ \text { Sample location } & \text { : U of L } & \\ \text { Case number } & \text { : RVR 15 B1 } \\ \text { Sample number } & : 1\end{array}$

Mortar $<6 \mathrm{~mm}$

Expected air

Paste

Sample volume $\begin{array}{rr}: & 53.9 \% \\ : & 6.0 \% \\ : & 22.52 \% \\ : & 20.0 \mathrm{~cm} 3\end{array}$

\section{Analysis}

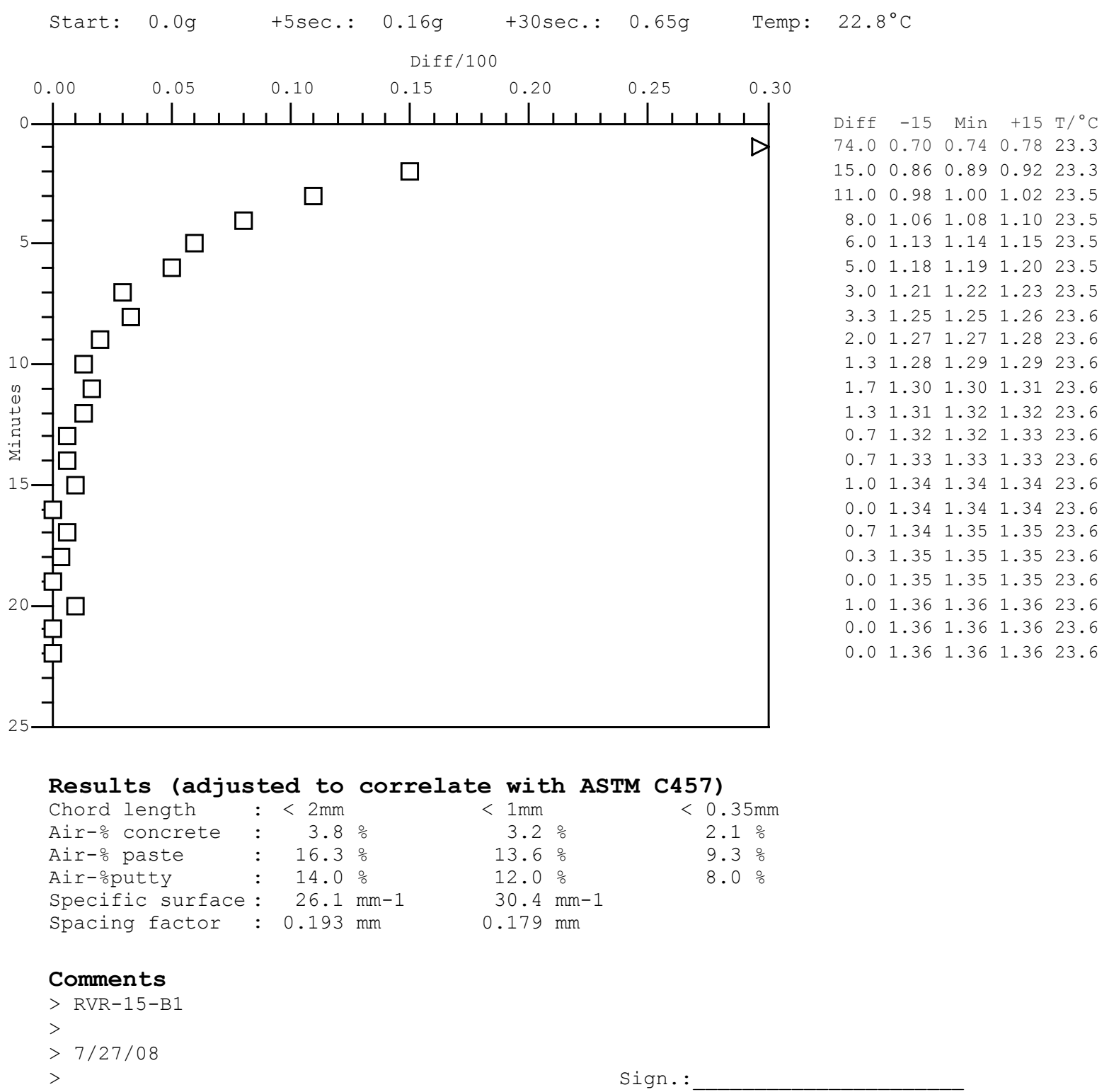


Air Void Analyzer AVA-3000

Type Company name

Measurement of Jul 27, $20089: 36 \mathrm{AM}$

Case number : RVR 15 B1

Sample number : 1

Distribution of air void content for voids $<2 \mathrm{~mm}$ (\%)

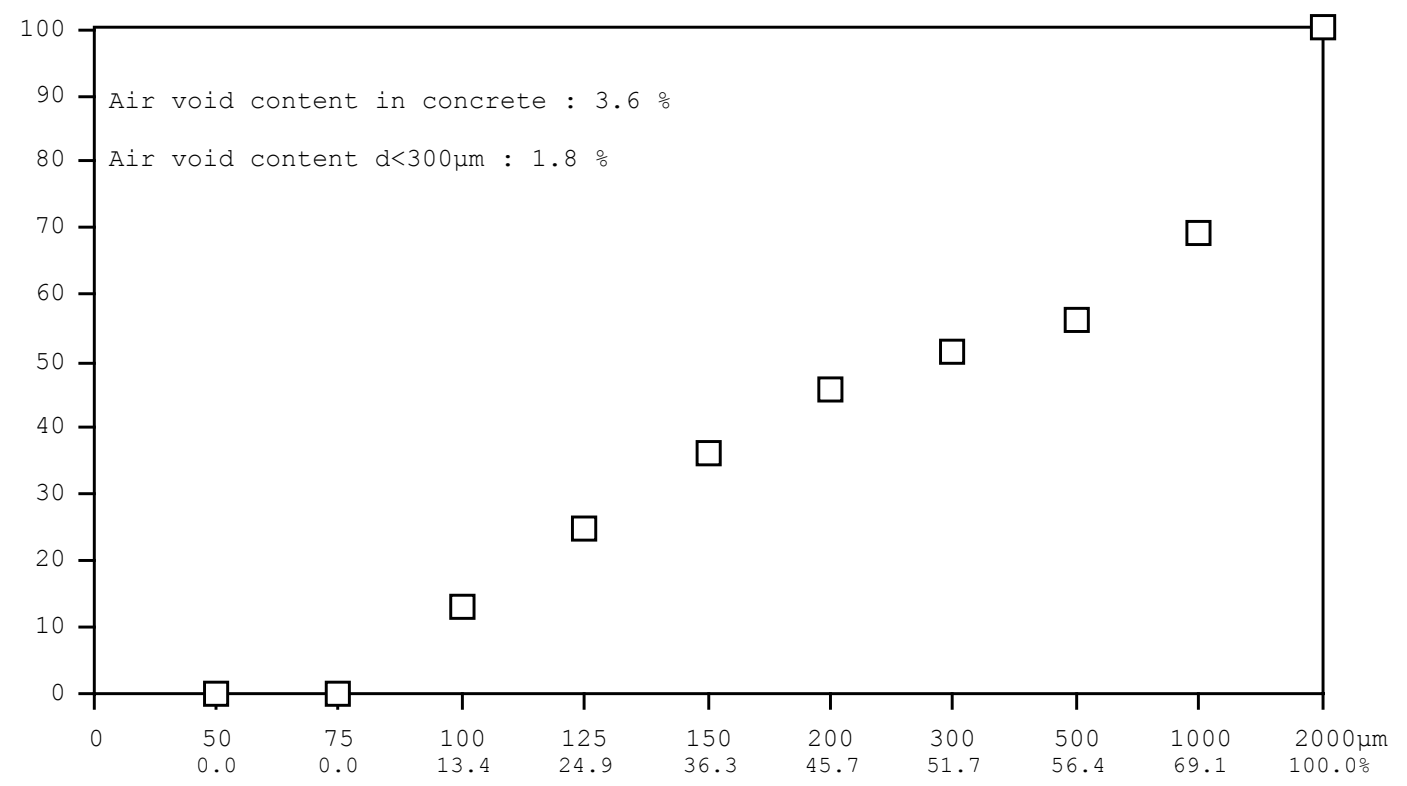

Distribution of air void content in cement paste for voids $<2 \mathrm{~mm}$ (\%)

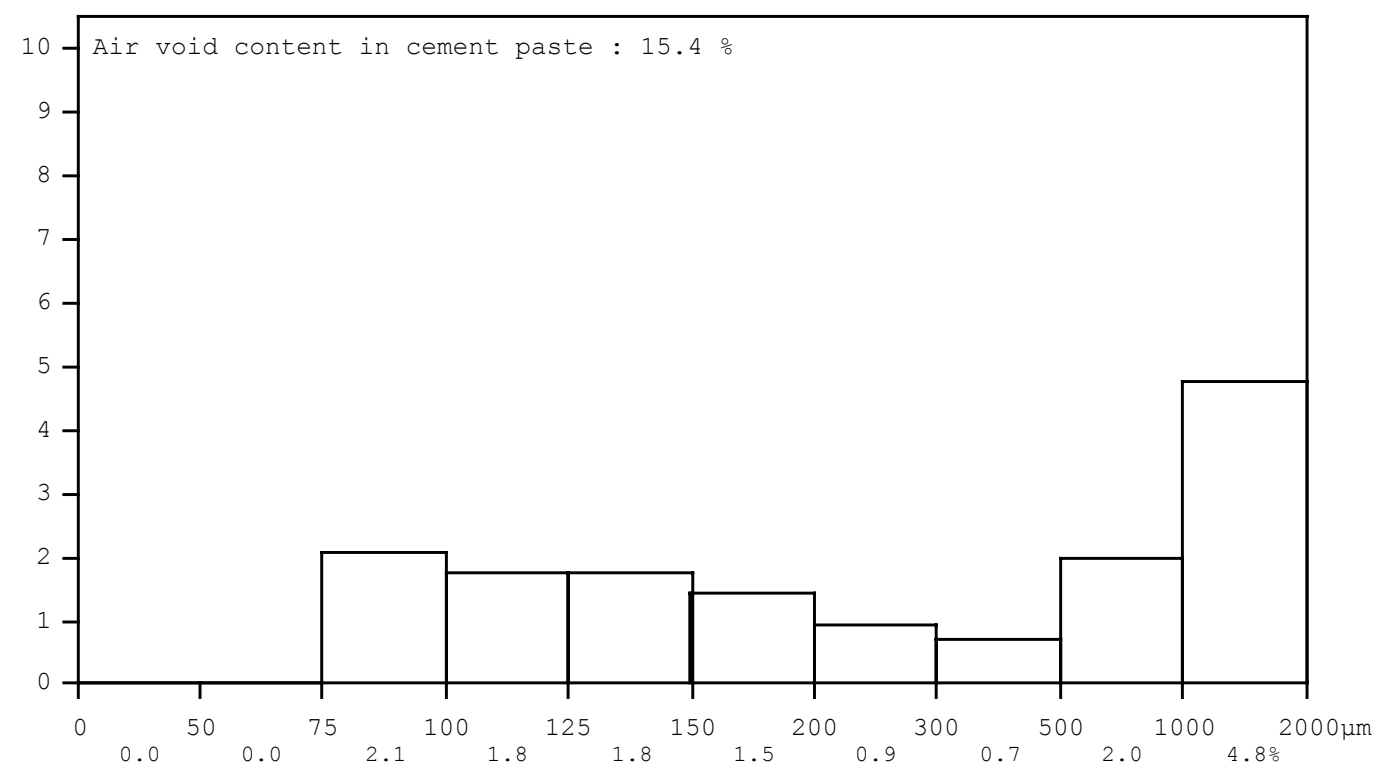


Air Void Analyzer AVA-3000

Type Company name

Measurement of Jul 27, 2008 10:08 AM

$\begin{array}{lll}\text { Sampler } & \text { : RVR 15 B2 } \\ \text { Ordered by } & \text { : davk } & \\ \text { Sample location } & \text { : U of L } & \\ \text { Case number } & \text { : RVR } 15 \text { B2 } \\ \text { Sample number } & : 2 & \end{array}$

Mortar<6mm : $53.9 \%$

Expected air : $6.0 \%$

Paste : $22.52 \%$

Sample volume : $20.0 \mathrm{~cm} 3$

\section{Analysis}

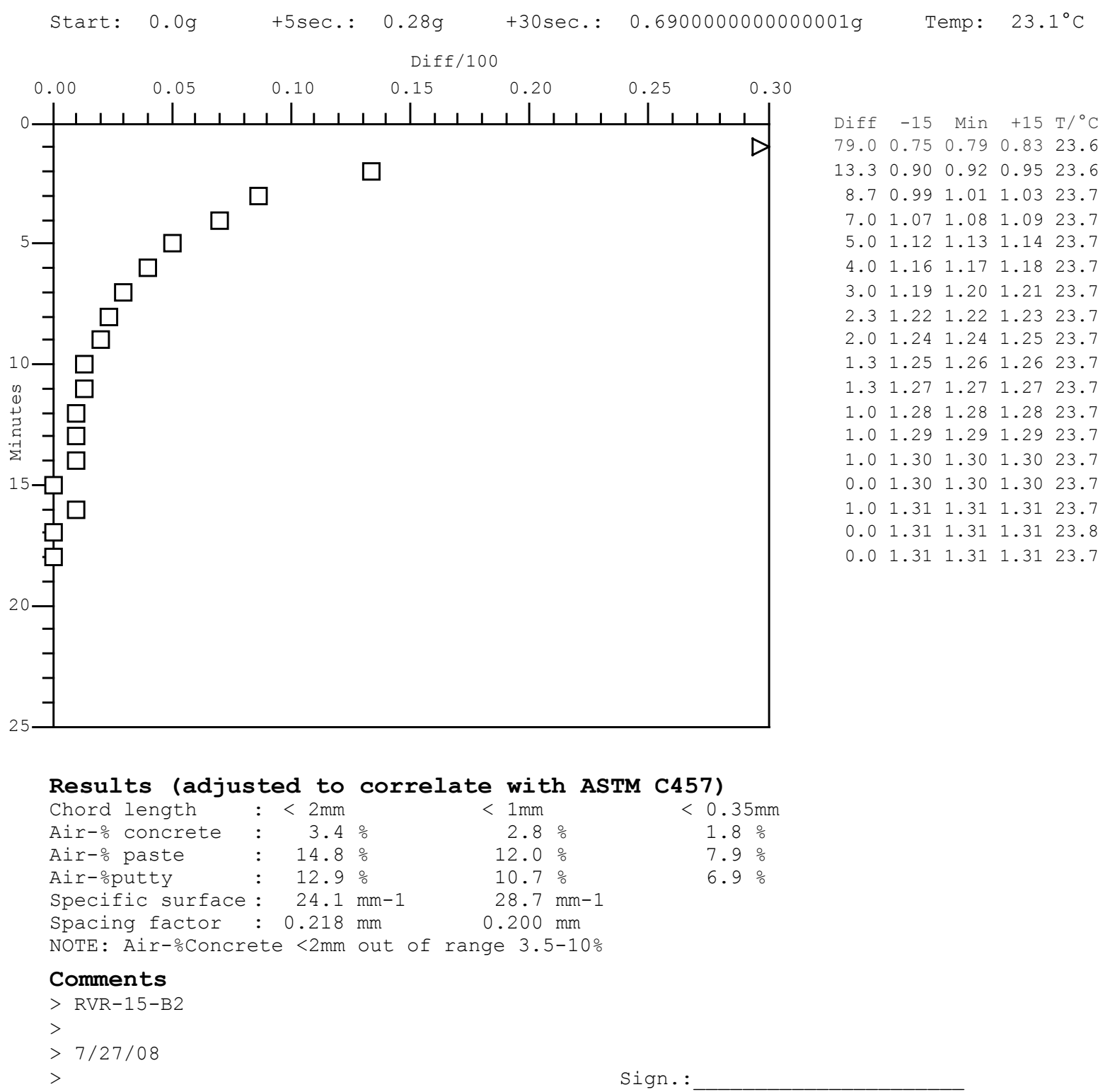


Air Void Analyzer AVA-3000

Type Company name

\section{Measurement of Jul 27, $200810: 08$ AM}

Case number : RVR 15 B2

Sample number : 2

Distribution of air void content for voids $<2 \mathrm{~mm}$ (\%)

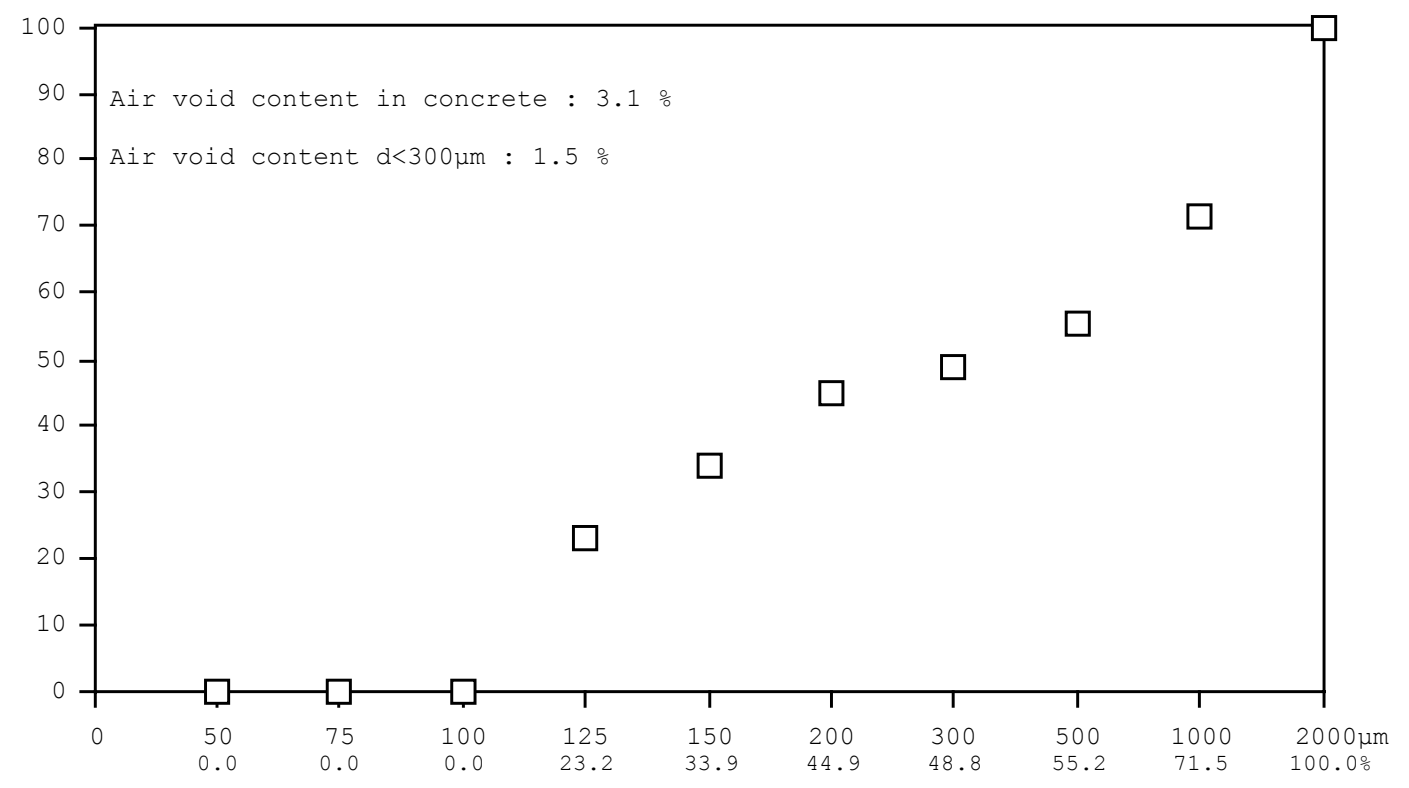

Distribution of air void content in cement paste for voids $<2 \mathrm{~mm}$ (\%)

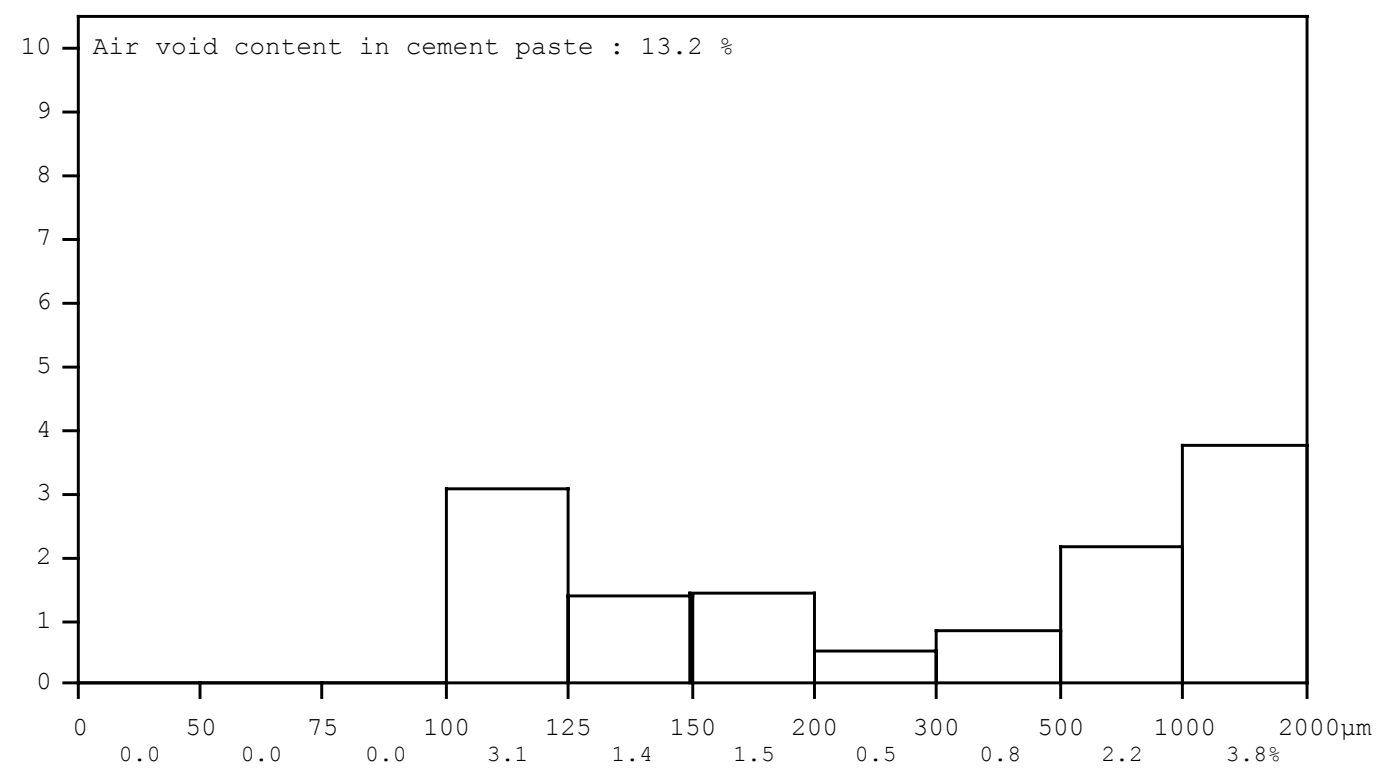


Air Void Analyzer AVA-3000

Type Company name

Measurement of Jul 27, 2008 10:36 AM

$\begin{array}{ll}\text { Sampler } & \text { : RVR 15 B3 } \\ \text { Ordered by } & \text { : davk } \\ \text { Sample location } & \text { : U of L } \\ \text { Case number } & \text { : RVR 15 B3 } \\ \text { Sample number } & : 3\end{array}$

Mortar $<6 \mathrm{~mm}$

Expected air

Paste

Sample volume

$\begin{array}{rr}: & 53.9 \% \\ : & 6.0 \% \\ : & 22.52 \% \\ : & 20.0 \mathrm{~cm} 3\end{array}$

$53.9 \%$

: $20.0 \mathrm{~cm} 3$

\section{Analysis}

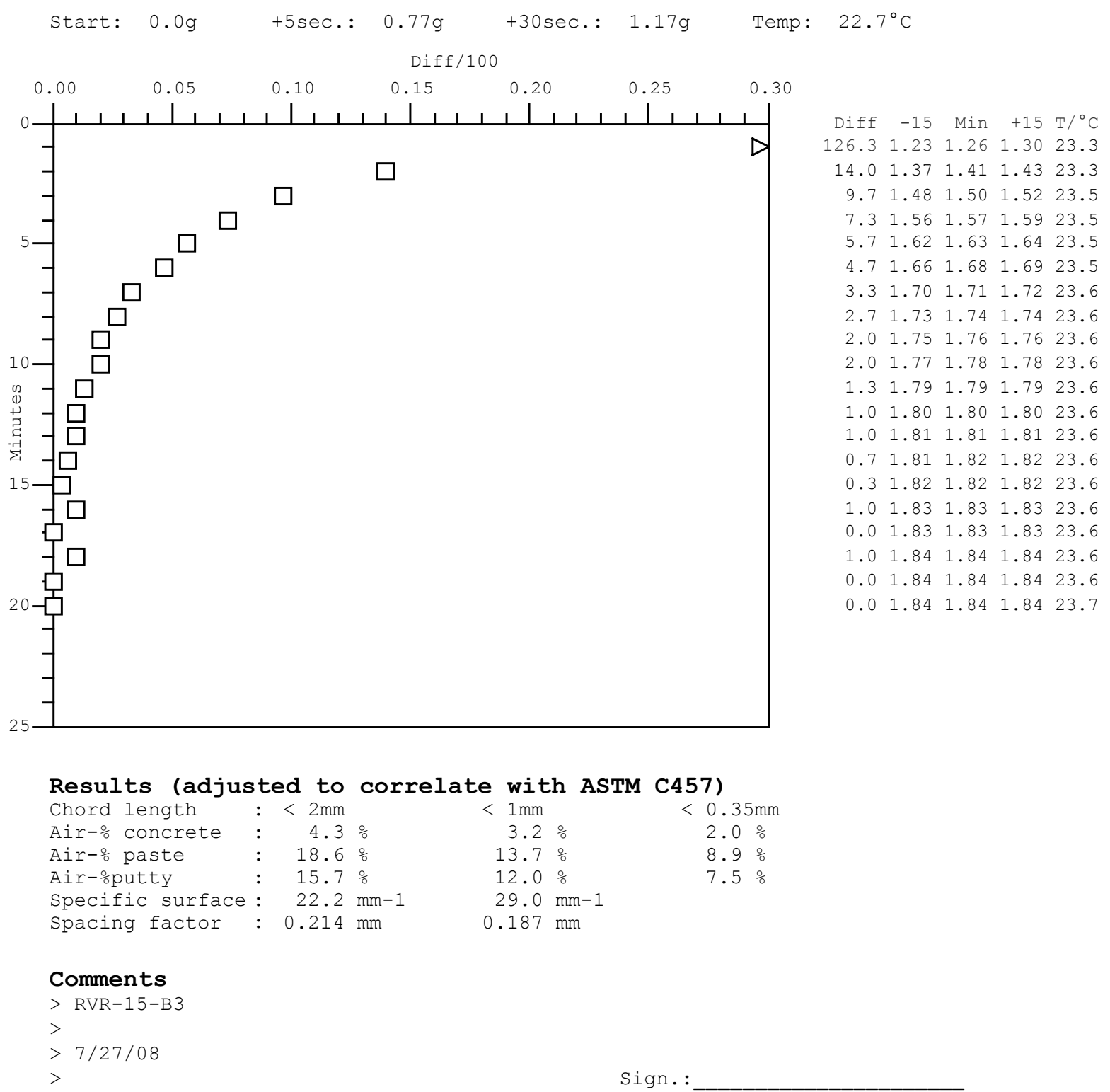


Air Void Analyzer AVA-3000

Type Company name

\section{Measurement of Jul 27, $200810: 36 \mathrm{AM}$}

Case number : RVR 15 B3

Sample number : 3

Distribution of air void content for voids $<2 \mathrm{~mm}$ (\%)

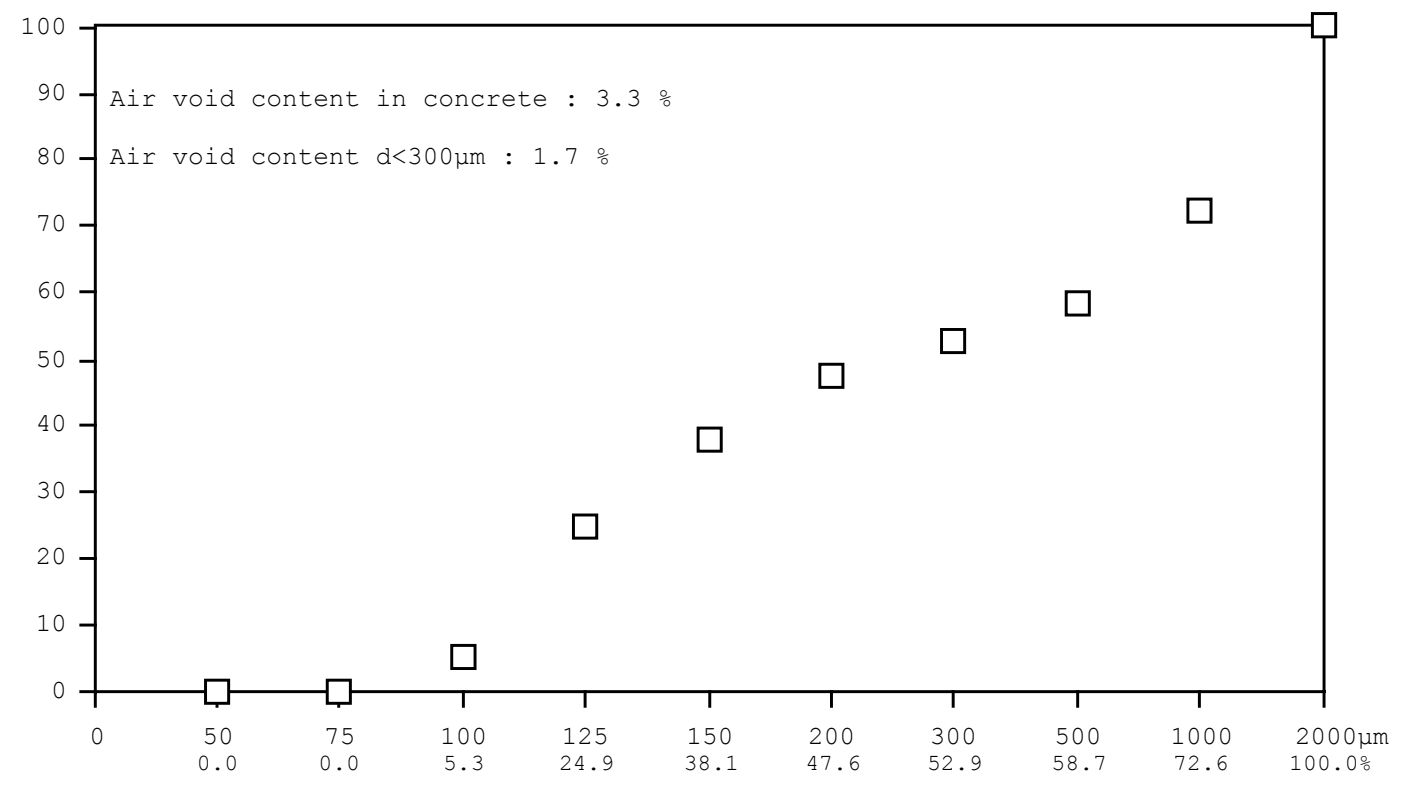

Distribution of air void content in cement paste for voids $2 \mathrm{~mm}$ ( $\%$ )

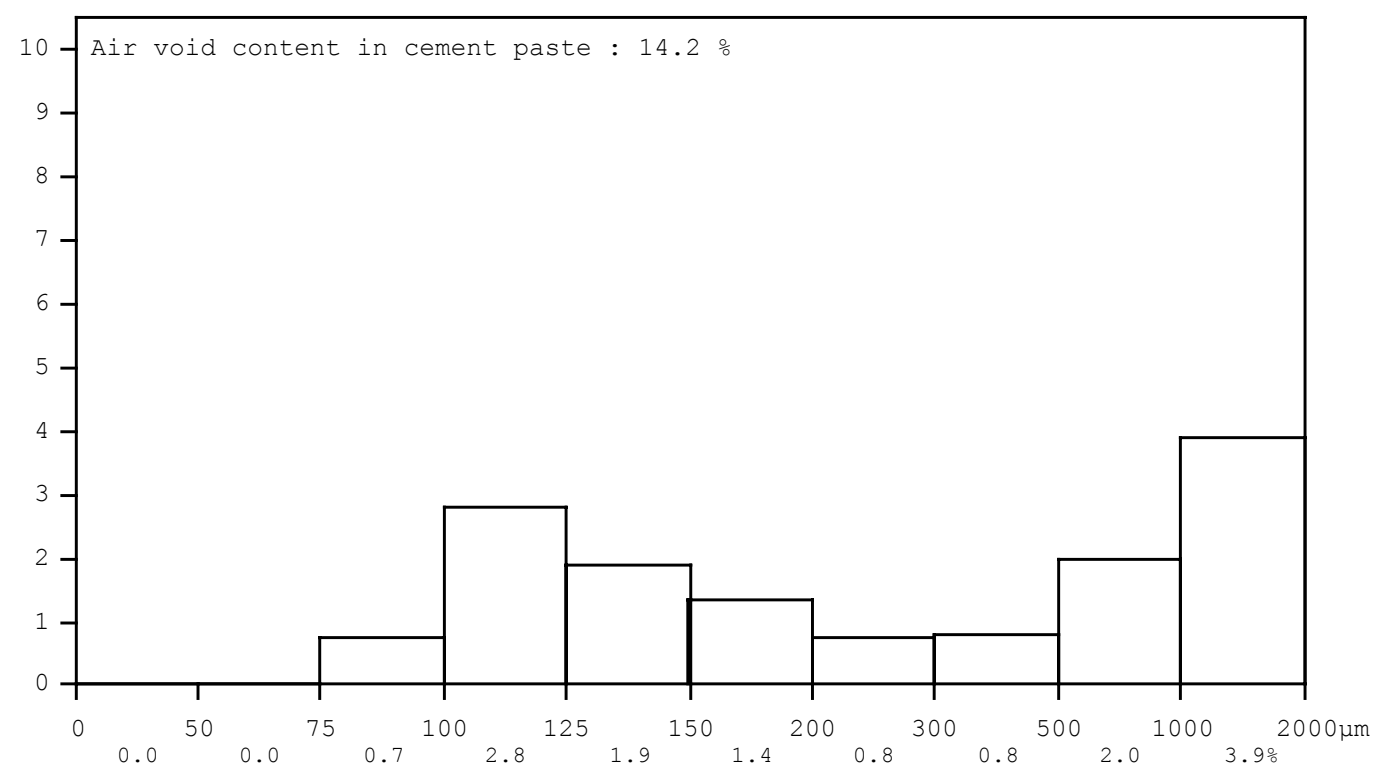


Air Void Analyzer AVA-3000

Type Company name

Measurement of Sep 18, 2008 4:16 PM

\begin{tabular}{|c|c|}
\hline Sampler & : RVR $15 \mathrm{C} 1$ \\
\hline Ordered by & : davk \\
\hline Sample location & : $\mathrm{U}$ of $\mathrm{L}$ \\
\hline se number & : RVR $15 \mathrm{C}$ \\
\hline number & $: 1$ \\
\hline
\end{tabular}

$\begin{array}{lrr}\text { Mortar<6mm } & : 53.61 \% \\ \text { Expected air } & : & 6.3 \% \\ \text { Paste } & : 22.52 \% \\ \text { Sample volume } & : & 20.0 \mathrm{~cm} 3\end{array}$

Analysis

start: $0.0 g$

+5 sec.: $0.04 \mathrm{~g} \quad+30 \mathrm{sec}: 0.46 \mathrm{~g}$

Temp: $\quad 23.6^{\circ} \mathrm{C}$

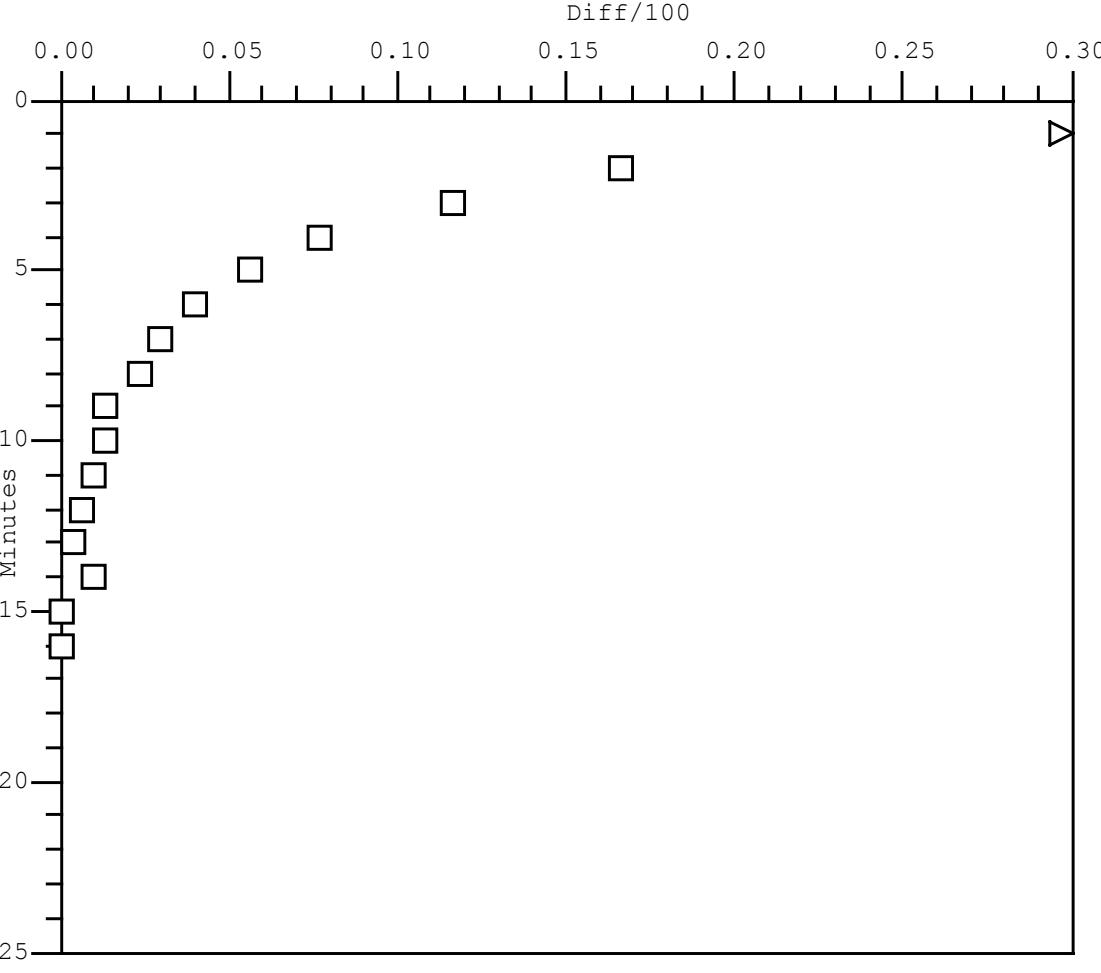

Diff $-15 \mathrm{Min}+15 \mathrm{~T} /{ }^{\circ} \mathrm{C}$

$\begin{array}{llllll}57.3 & 0.52 & 0.57 & 0.63 & 24.1\end{array}$

$\begin{array}{llllll}16.7 & 0.71 & 0.74 & 0.77 & 24.1\end{array}$

$\begin{array}{lllll}11.7 & 0.84 & 0.85 & 0.88 & 24.1\end{array}$

$\begin{array}{llllll}7.7 & 0.92 & 0.93 & 0.95 & 24.2\end{array}$

$\begin{array}{llllll}5.7 & 0.98 & 0.99 & 1.00 & 24.2\end{array}$

$\begin{array}{llllll}4.0 & 1.02 & 1.03 & 1.04 & 24.3\end{array}$

$3.0 \quad 1.05 \quad 1.06 \quad 1.07 \quad 24.2$

$2.3 \quad 1.08 \quad 1.08 \quad 1.09 \quad 24.3$

$\begin{array}{llllll}1.3 & 1.09 & 1.10 & 1.10 & 24.3\end{array}$

$\begin{array}{llllll}1.3 & 1.11 & 1.11 & 1.11 & 24.3\end{array}$

$\begin{array}{lllll}1.0 & 1.12 & 1.12 & 1.12 & 24.3\end{array}$

$\begin{array}{llllll}0.7 & 1.12 & 1.13 & 1.13 & 24.3\end{array}$

$\begin{array}{llllll}0.3 & 1.13 & 1.13 & 1.13 & 24.3\end{array}$

$\begin{array}{llllll}1.0 & 1.14 & 1.14 & 1.14 & 24.3\end{array}$

$\begin{array}{llllll}0.0 & 1.14 & 1.14 & 1.14 & 24.3\end{array}$

$\begin{array}{llllll}0.0 & 1.14 & 1.14 & 1.14 & 24.4\end{array}$

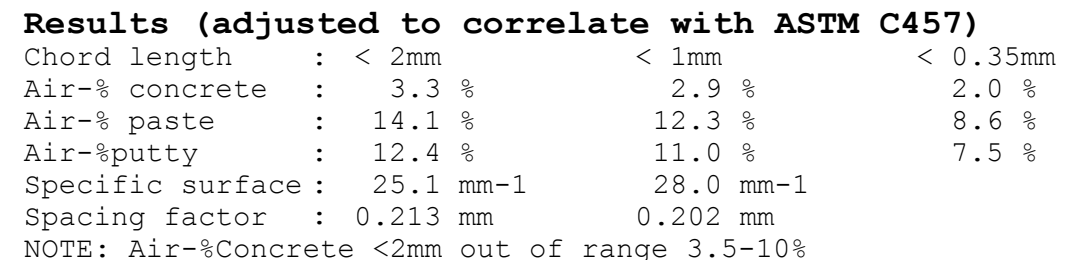

NOTE: Air-\%Concrete $<2 \mathrm{~mm}$ out of range $3.5-10 \%$

\section{Comments}

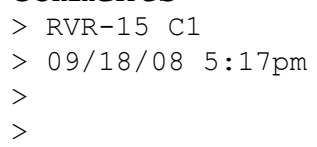

Sign. : 
Air Void Analyzer AVA-3000

Type Company name

\section{Measurement of Sep 18, 2008 4:16 PM}

Case number : RVR $15 \mathrm{C} 1$

Sample number : 1

Distribution of air void content for voids $<2 \mathrm{~mm}$ (\%)

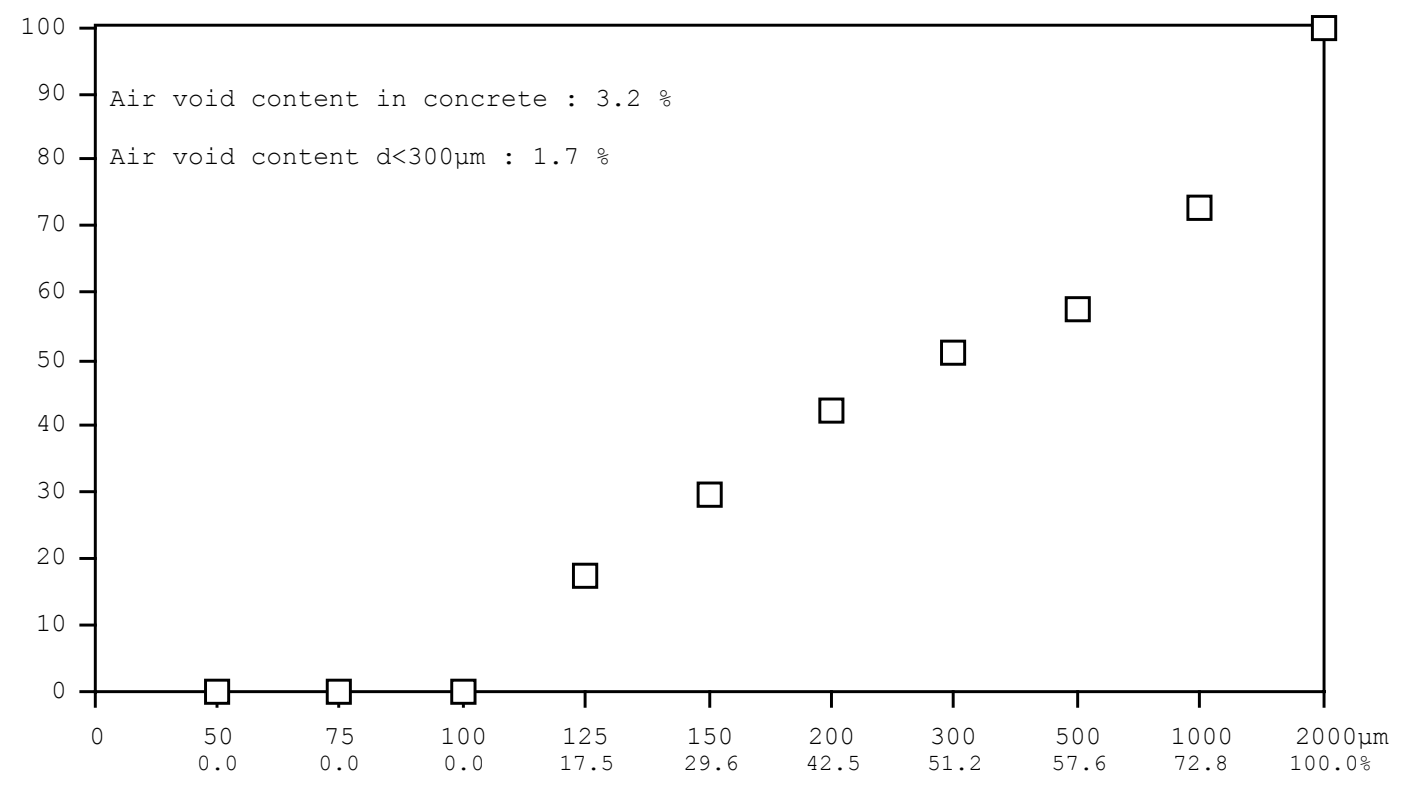

Distribution of air void content in cement paste for voids $<2 \mathrm{~mm}$ (\%)

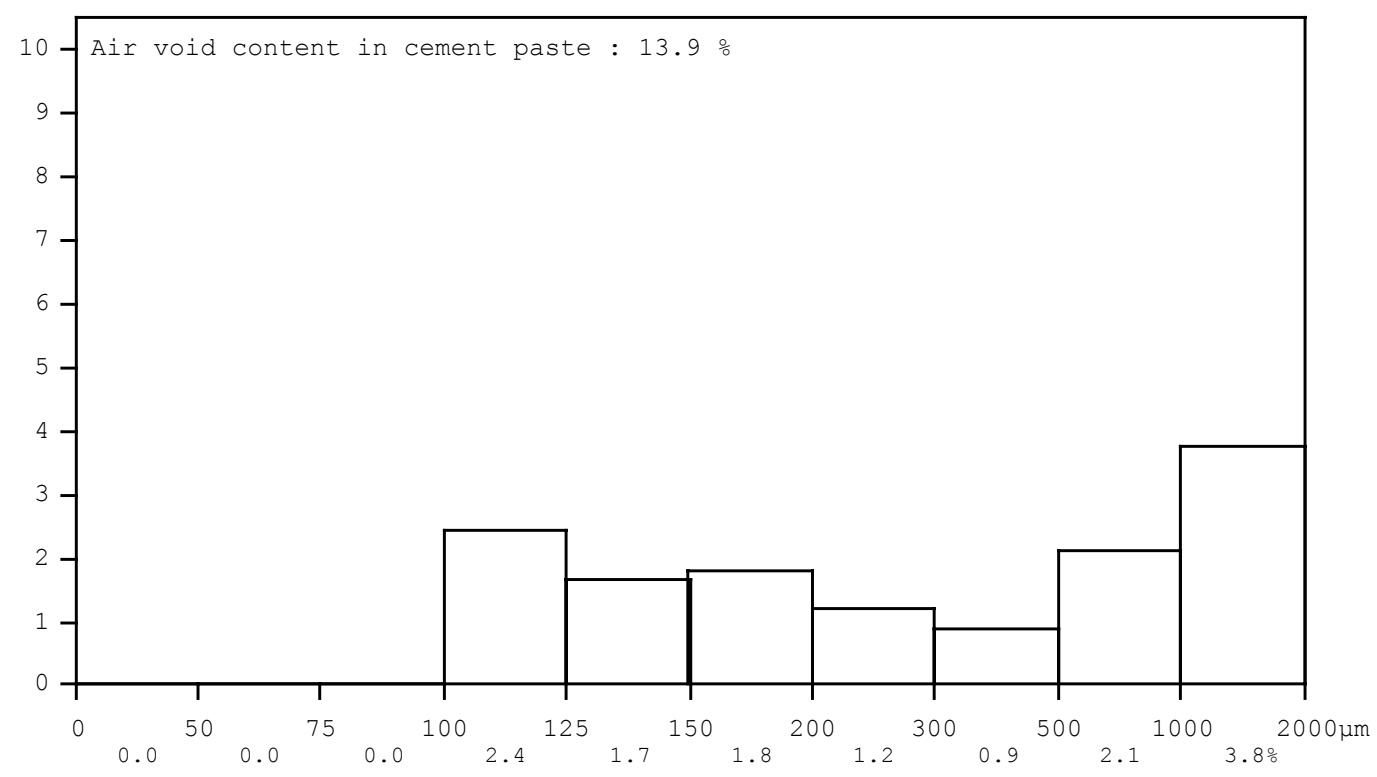


Air Void Analyzer AVA-3000

Type Company name

Measurement of Sep 18, 2008 4:46 PM

$\begin{array}{llll}\text { Sampler } & \text { : RVR } 15 \text { C2 } \\ \text { Ordered by } & \text { : davk } & \\ \text { Sample location } & \text { : U of L } & \\ \text { Case number } & : \text { RVR } 15 \text { C2 } \\ \text { Sample number } & : 2 & \end{array}$

Mortar<6mm : $53.61 \%$

Expected air : 6.3 응

Paste : $22.52 \%$

Sample volume : $20.0 \mathrm{~cm} 3$

\section{Analysis}

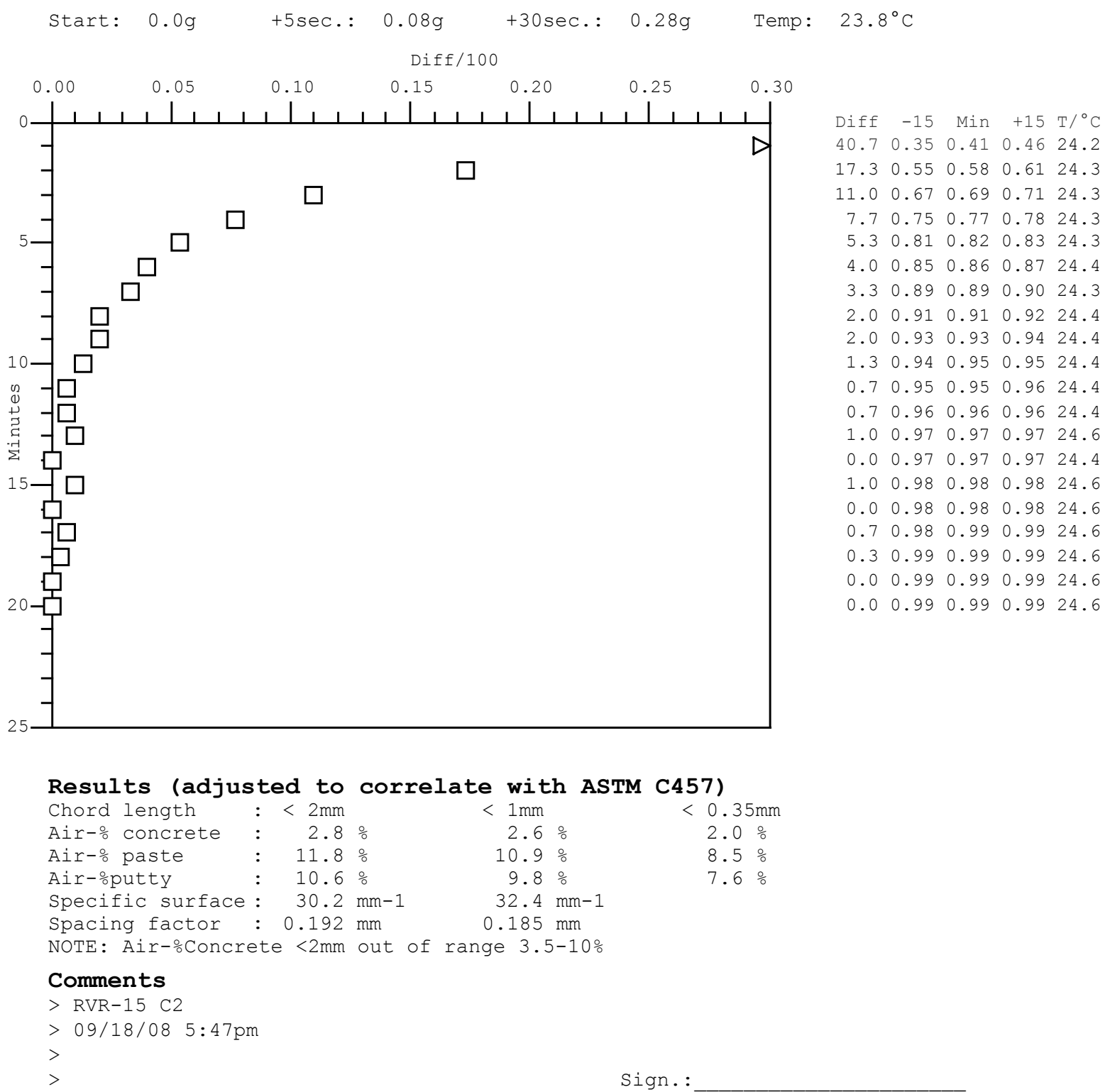


Air Void Analyzer AVA-3000

Type Company name

\section{Measurement of Sep 18, 2008 4:46 PM}

Case number : RVR 15 C2

Sample number : 2

Distribution of air void content for voids $<2 \mathrm{~mm}$ (\%)

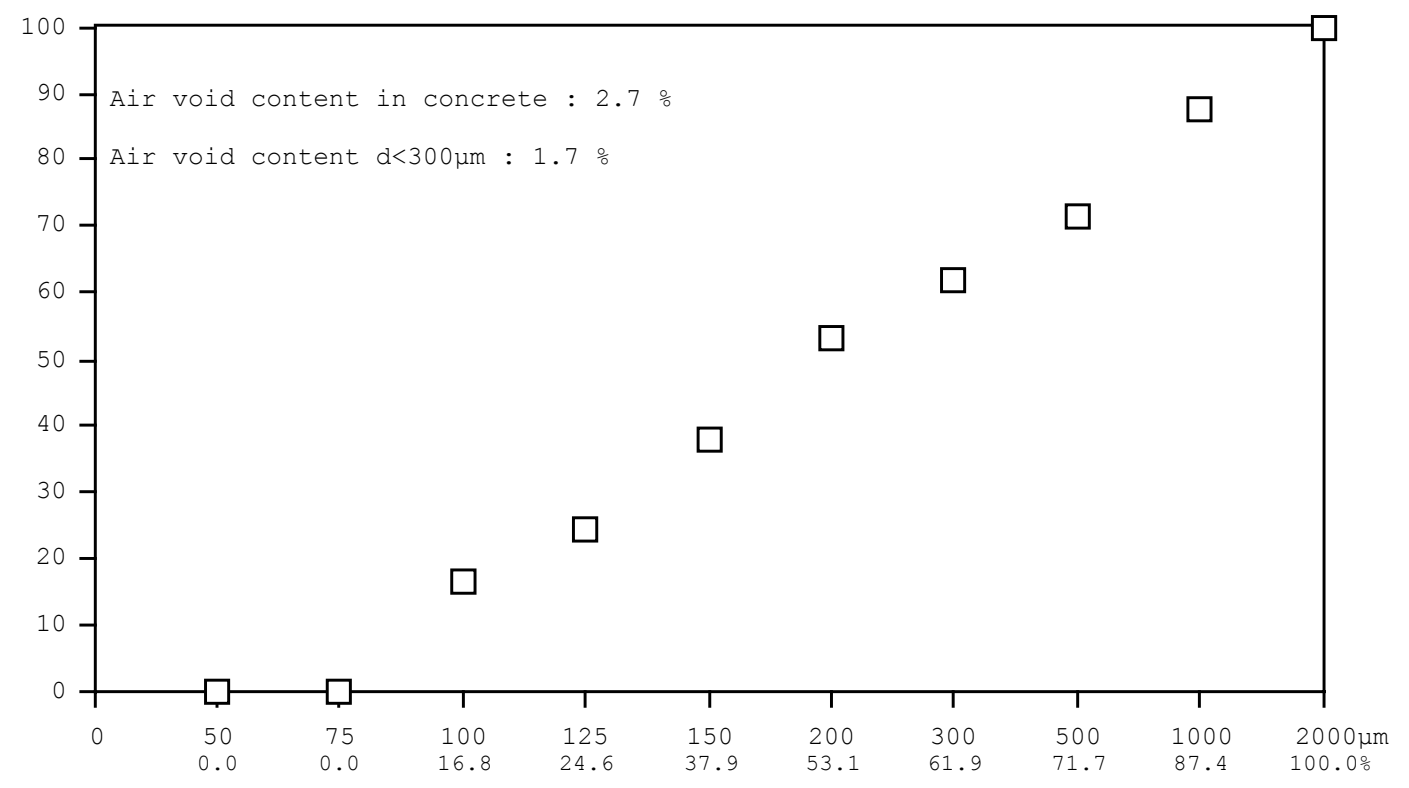

Distribution of air void content in cement paste for voids $<2 \mathrm{~mm}$ (\%)

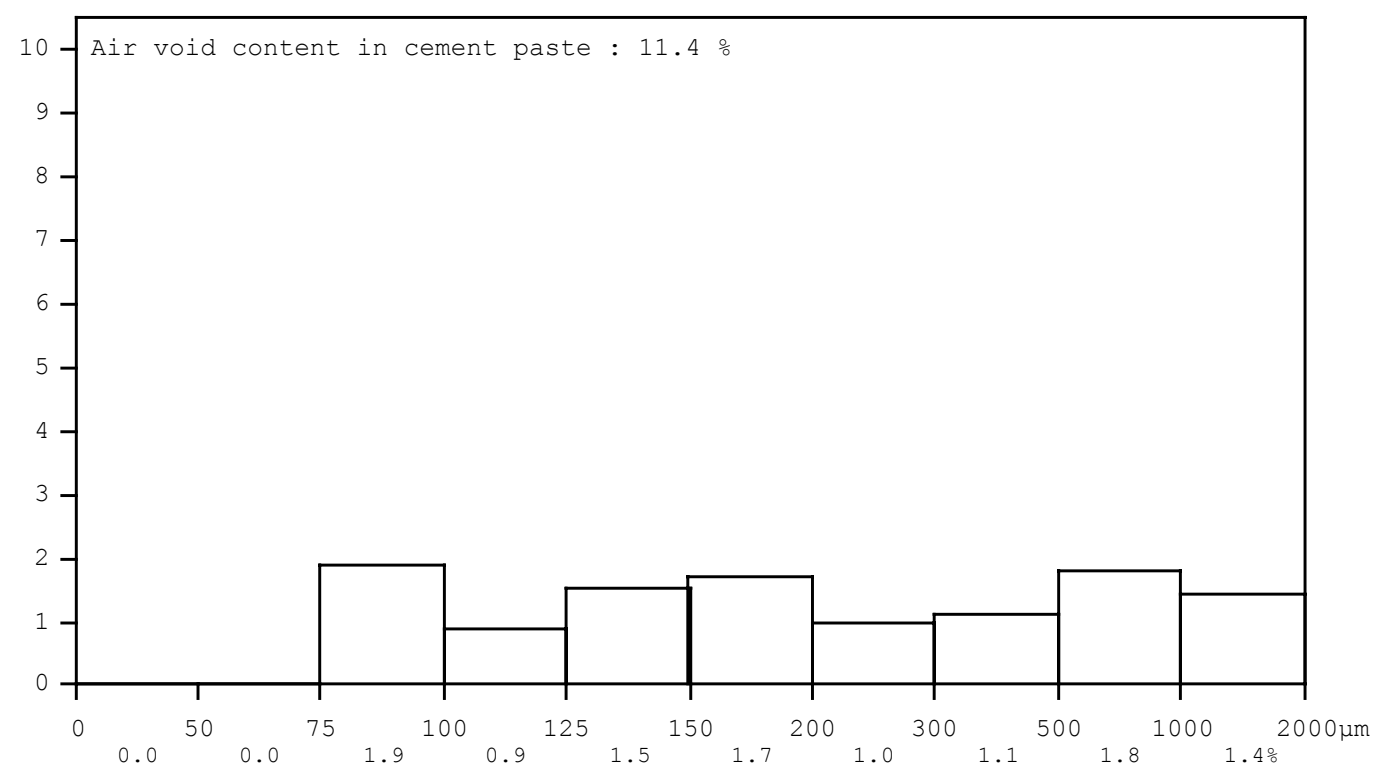


Air Void Analyzer AVA-3000

Type Company name

Measurement of Sep 18, 2008 5:09 PM

$\begin{array}{lll}\text { Sampler } & \text { : RVR } 15 \text { C3 } \\ \text { Ordered by } & \text { : davk } & \\ \text { Sample location } & \text { : U of L } & \\ \text { Case number } & : \text { RVR } 15 \text { C3 } \\ \text { Sample number } & : 3 & \end{array}$

$\begin{array}{lrr}\text { Mortar<6mm } & : 53.61 \% \\ \text { Expected air } & : & 6.3 \% \\ \text { Paste } & : 22.52 \% \\ \text { Sample volume } & : & 20.0 \mathrm{~cm} 3\end{array}$

Analysis

start: $0.0 g$

+5sec.: $0.04 \mathrm{~g} \quad+30 \mathrm{sec}: 0.31 \mathrm{~g}$

Temp: $\quad 23.7^{\circ} \mathrm{C}$

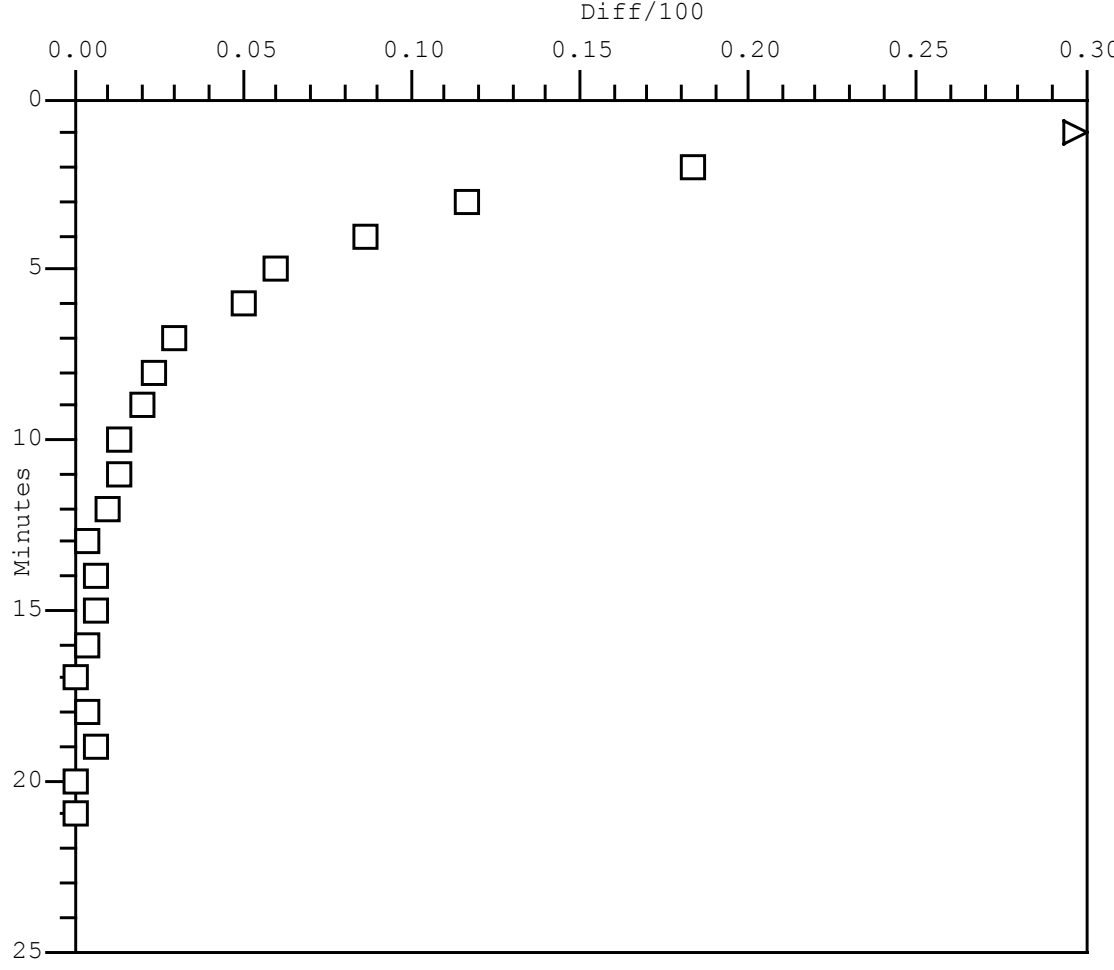

Diff -15 Min $+15 \mathrm{~T} /{ }^{\circ} \mathrm{C}$

$\begin{array}{llllll}45.3 & 0.39 & 0.46 & 0.51 & 24.2\end{array}$

$\begin{array}{llllll}18.3 & 0.60 & 0.64 & 0.67 & 24.3\end{array}$

$\begin{array}{llllll}11.7 & 0.73 & 0.75 & 0.78 & 24.3\end{array}$

$\begin{array}{llllll}8.7 & 0.82 & 0.84 & 0.86 & 24.4\end{array}$

$\begin{array}{llllll}6.0 & 0.89 & 0.90 & 0.91 & 24.4\end{array}$

$\begin{array}{llllll}5.0 & 0.94 & 0.95 & 0.96 & 24.6\end{array}$

$\begin{array}{llllll}3.0 & 0.97 & 0.98 & 0.99 & 24.6\end{array}$

$2.31 .00 \quad 1.00 \quad 1.01 \quad 24.4$

$2.01 .02 \quad 1.02 \quad 1.03 \quad 24.6$

$\begin{array}{lllll}1.3 & 1.03 & 1.04 & 1.04 & 24.6\end{array}$

$\begin{array}{lllll}1.3 & 1.05 & 1.05 & 1.05 & 24.4\end{array}$

$\begin{array}{lllll}1.0 & 1.06 & 1.06 & 1.06 & 24.4\end{array}$

$0.3 \quad 1.06 \quad 1.06 \quad 1.07 \quad 24.6$

$\begin{array}{llllll}0.7 & 1.07 & 1.07 & 1.07 & 24.4\end{array}$

$\begin{array}{llllll}0.7 & 1.07 & 1.08 & 1.08 & 24.6\end{array}$

$\begin{array}{llllll}0.3 & 1.08 & 1.08 & 1.08 & 24.6\end{array}$

$\begin{array}{lllll}0.0 & 1.08 & 1.08 & 1.08 & 24.6\end{array}$

$0.3 \quad 1.08 \quad 1.08 \quad 1.09 \quad 24.6$

$0.7 \quad 1.091 .09 \quad 1.0924 .6$

0.01 .091 .091 .0924 .6

$0.01 .091 .09 \quad 1.0924 .6$

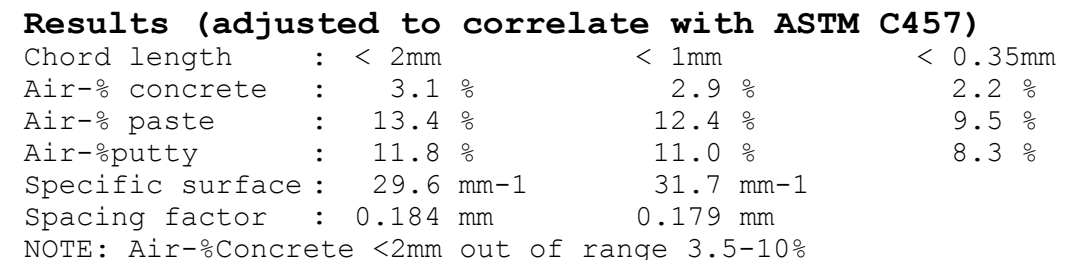

NOTE: Air-\%Concrete $<2 \mathrm{~mm}$ out of range $3.5-10 \%$

\section{Comments}

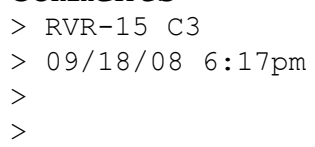

Sign. : 
Air Void Analyzer AVA-3000

Type Company name

\section{Measurement of Sep 18, 2008 5:09 PM}

Case number : RVR $15 \mathrm{C3}$

Sample number : 3

Distribution of air void content for voids $<2 \mathrm{~mm}$ (\%)

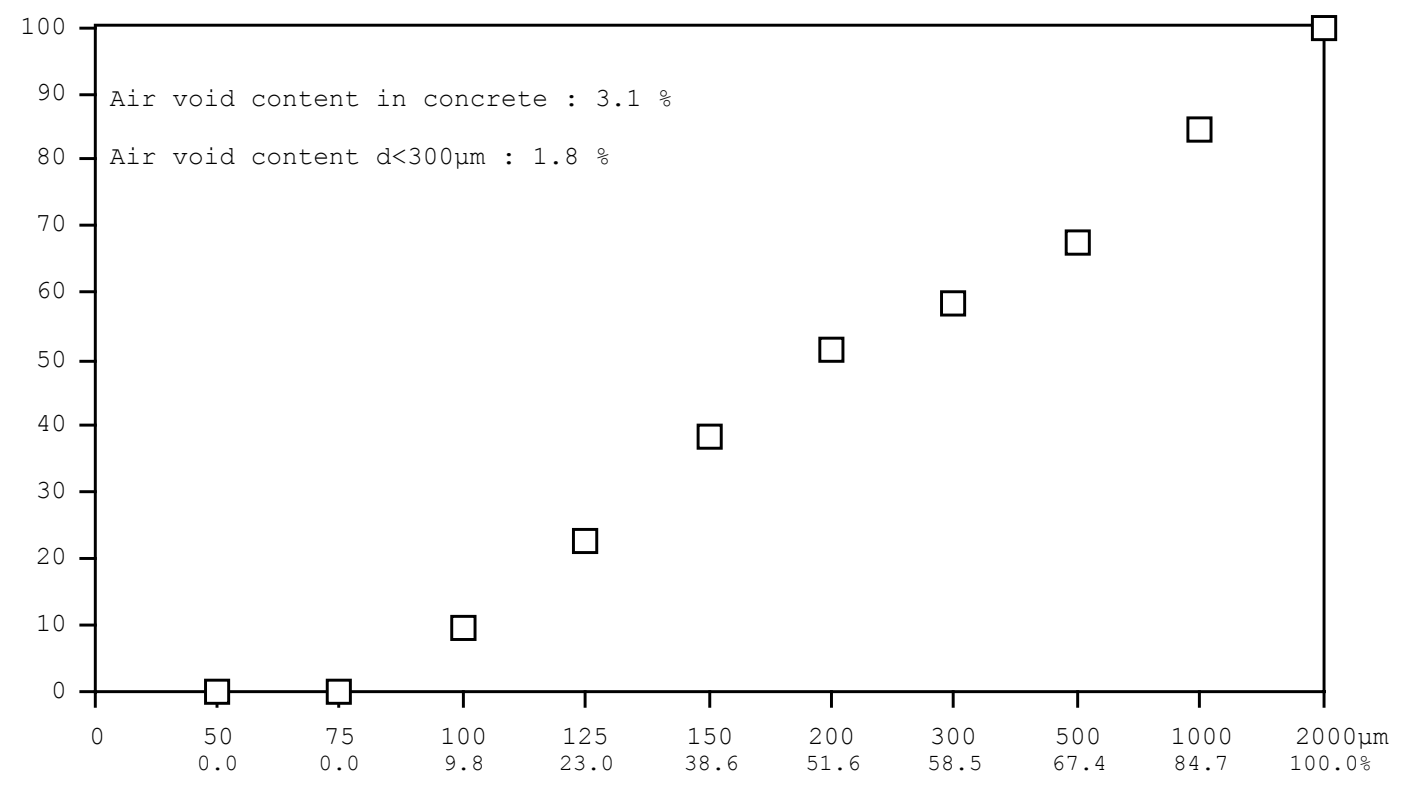

Distribution of air void content in cement paste for voids $<2 \mathrm{~mm}$ (\%)

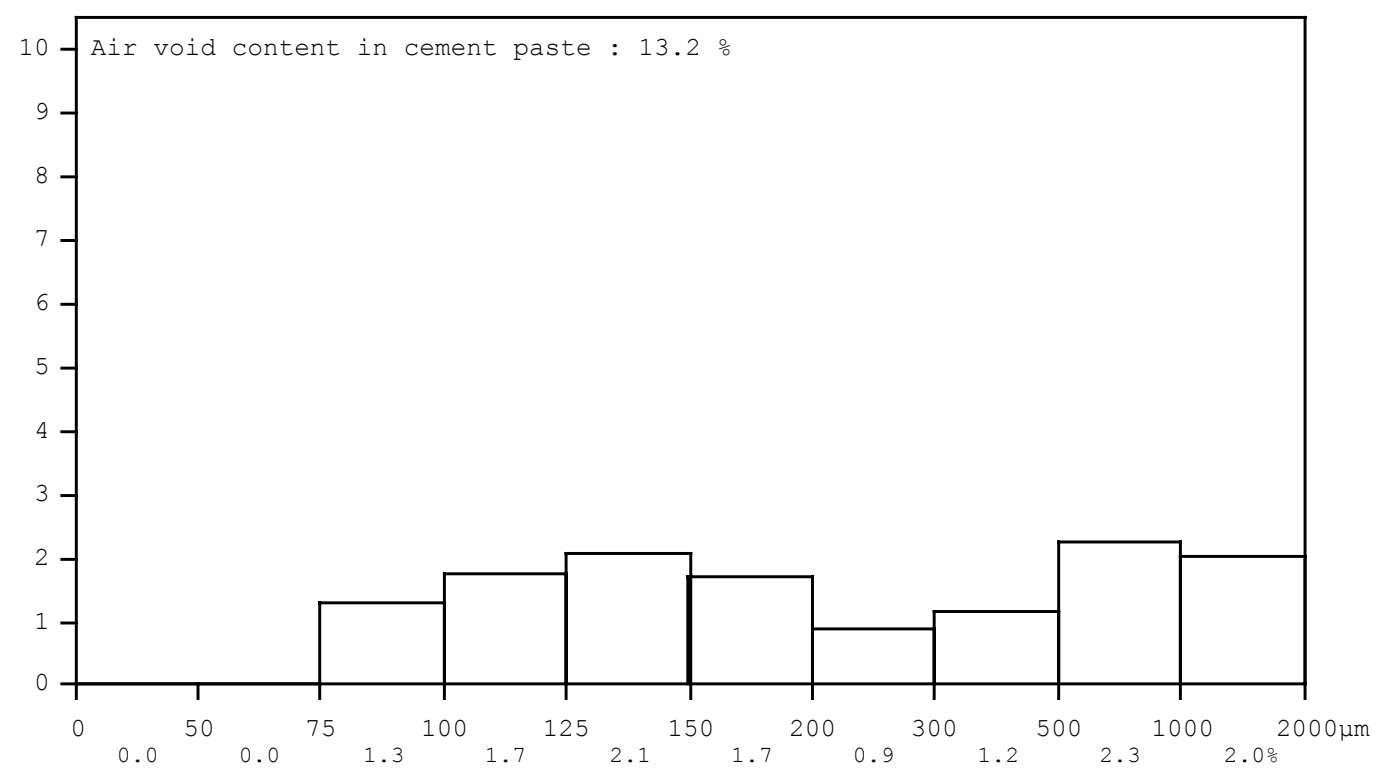


Air Void Analyzer AVA-3000

Type Company name

Measurement of Jul 24, 2008 5:54 AM

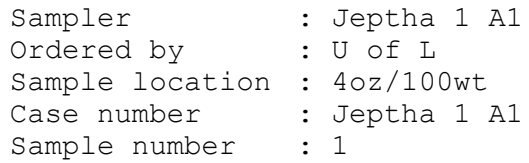

Analysis

Start: $0.0 \mathrm{~g}$

+5sec.: $0.04 \mathrm{~g} \quad+30 \mathrm{sec}: 0.17 \mathrm{~g}$

Temp: $\quad 21.1^{\circ} \mathrm{C}$

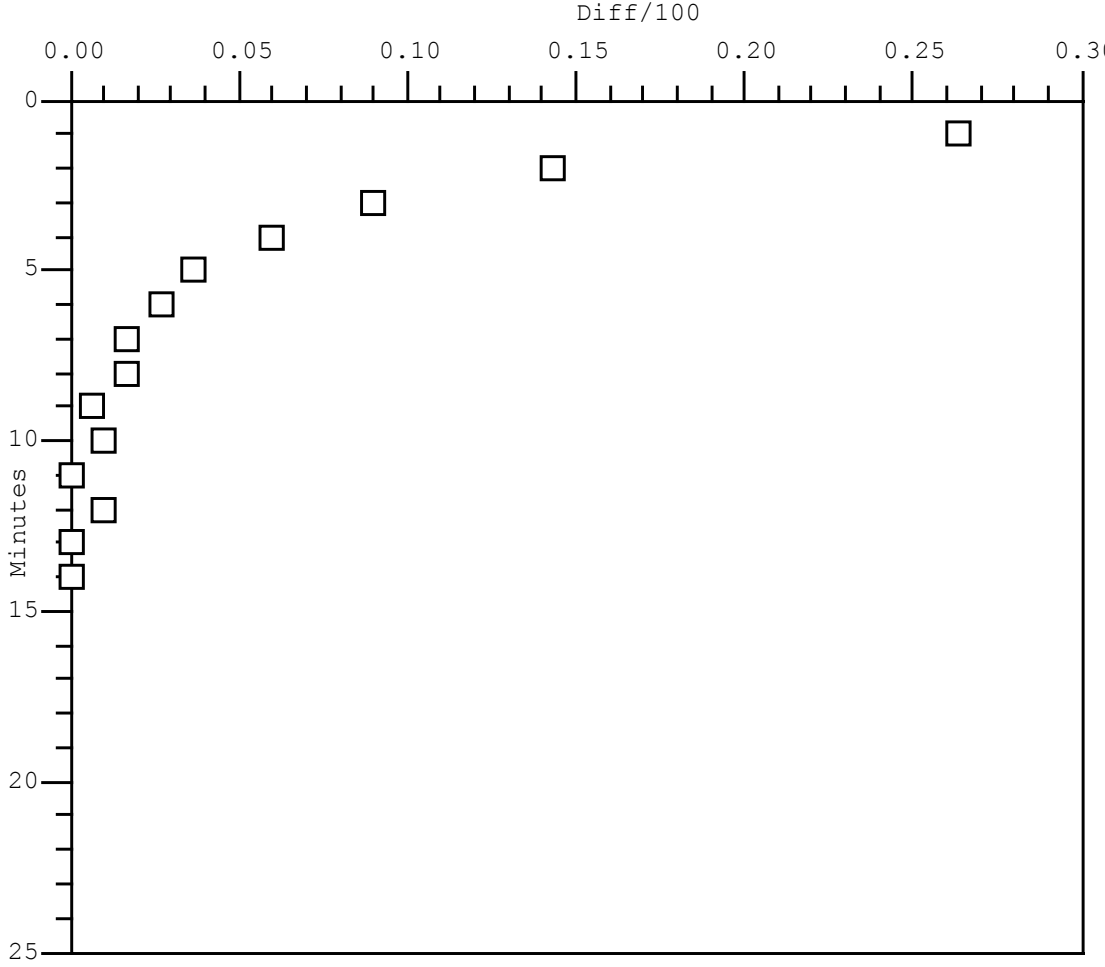

Diff -15 Min $+15 \mathrm{~T} /{ }^{\circ} \mathrm{C}$ $\begin{array}{lllllll}26.3 & 0.23 & 0.26 & 0.30 & 22.0\end{array}$ $\begin{array}{llllll}14.3 & 0.38 & 0.41 & 0.43 & 22.0\end{array}$ $\begin{array}{llllll}9.0 & 0.48 & 0.50 & 0.51 & 21.9\end{array}$ $\begin{array}{llllll}6.0 & 0.54 & 0.56 & 0.57 & 21.7\end{array}$ $\begin{array}{llllll}3.7 & 0.59 & 0.59 & 0.60 & 21.7\end{array}$ $\begin{array}{llllll}2.7 & 0.61 & 0.62 & 0.63 & 21.6\end{array}$ $\begin{array}{llllll}1.7 & 0.63 & 0.64 & 0.64 & 21.6\end{array}$ $\begin{array}{llllll}1.7 & 0.65 & 0.65 & 0.66 & 21.6\end{array}$ $\begin{array}{llllll}0.7 & 0.66 & 0.66 & 0.66 & 21.6\end{array}$ $\begin{array}{llllll}1.0 & 0.67 & 0.67 & 0.67 & 21.5\end{array}$ $\begin{array}{lllllll}0.0 & 0.67 & 0.67 & 0.67 & 21.5\end{array}$ $\begin{array}{llllll}1.0 & 0.68 & 0.68 & 0.68 & 21.4\end{array}$ $\begin{array}{llllll}0.0 & 0.68 & 0.68 & 0.68 & 21.4\end{array}$ $\begin{array}{llllll}0.0 & 0.68 & 0.68 & 0.68 & 21.4\end{array}$

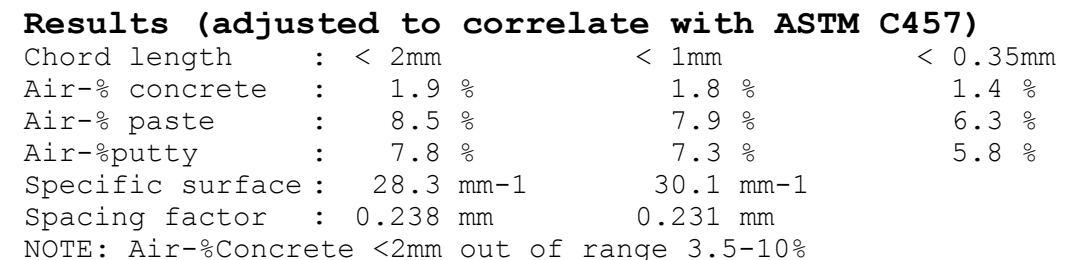

\section{Comments}

\footnotetext{
$>$ Jeptha1A1

$>40 z / 100 w t$

$>7 / 24 / 08$
}

Sign. : 
Air Void Analyzer AVA-3000

Type Company name

\section{Measurement of Jul 24, 2008 5:54 AM}

Case number : Jeptha 1 A1

Sample number : 1

Distribution of air void content for voids $<2 \mathrm{~mm}$ (\%)

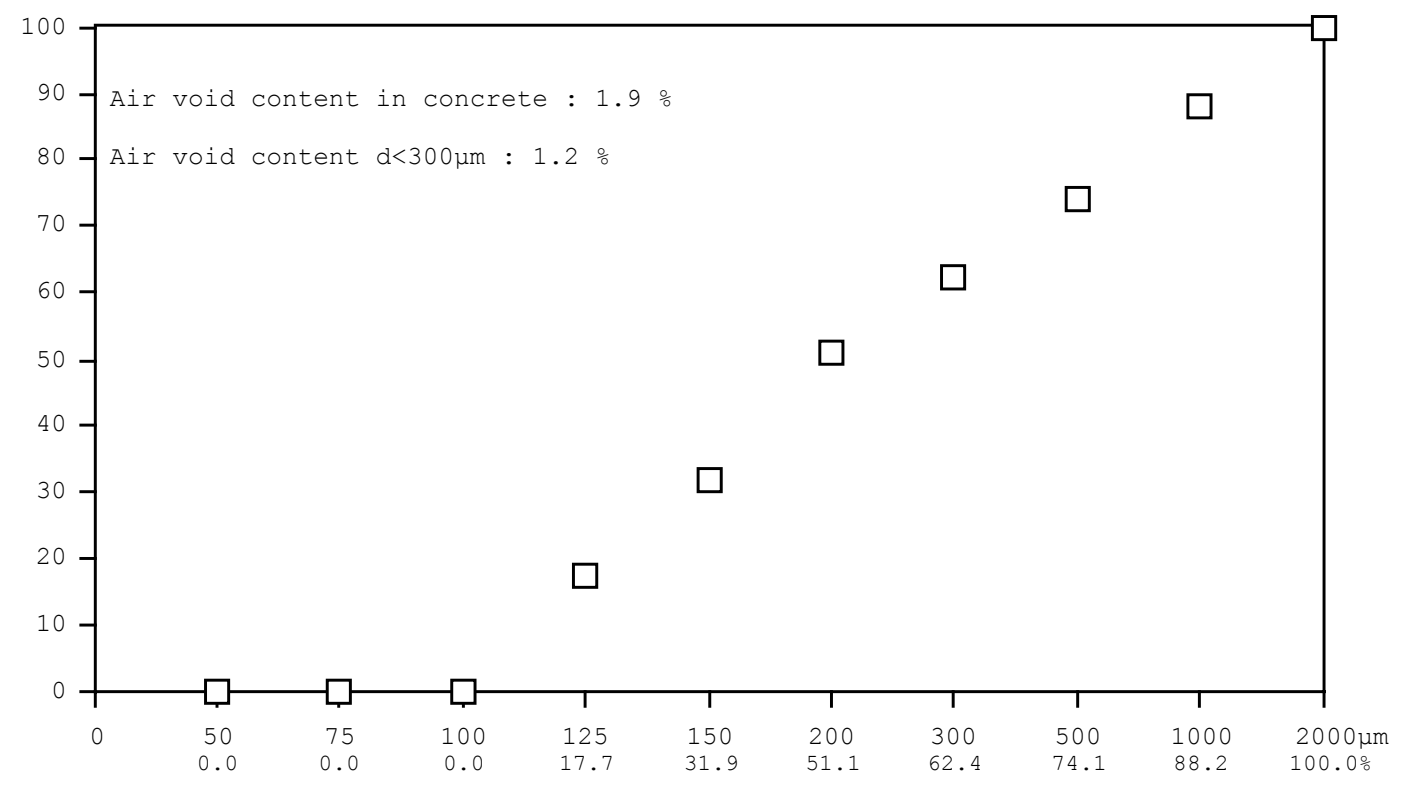

Distribution of air void content in cement paste for voids $<2 \mathrm{~mm}$ (\%)

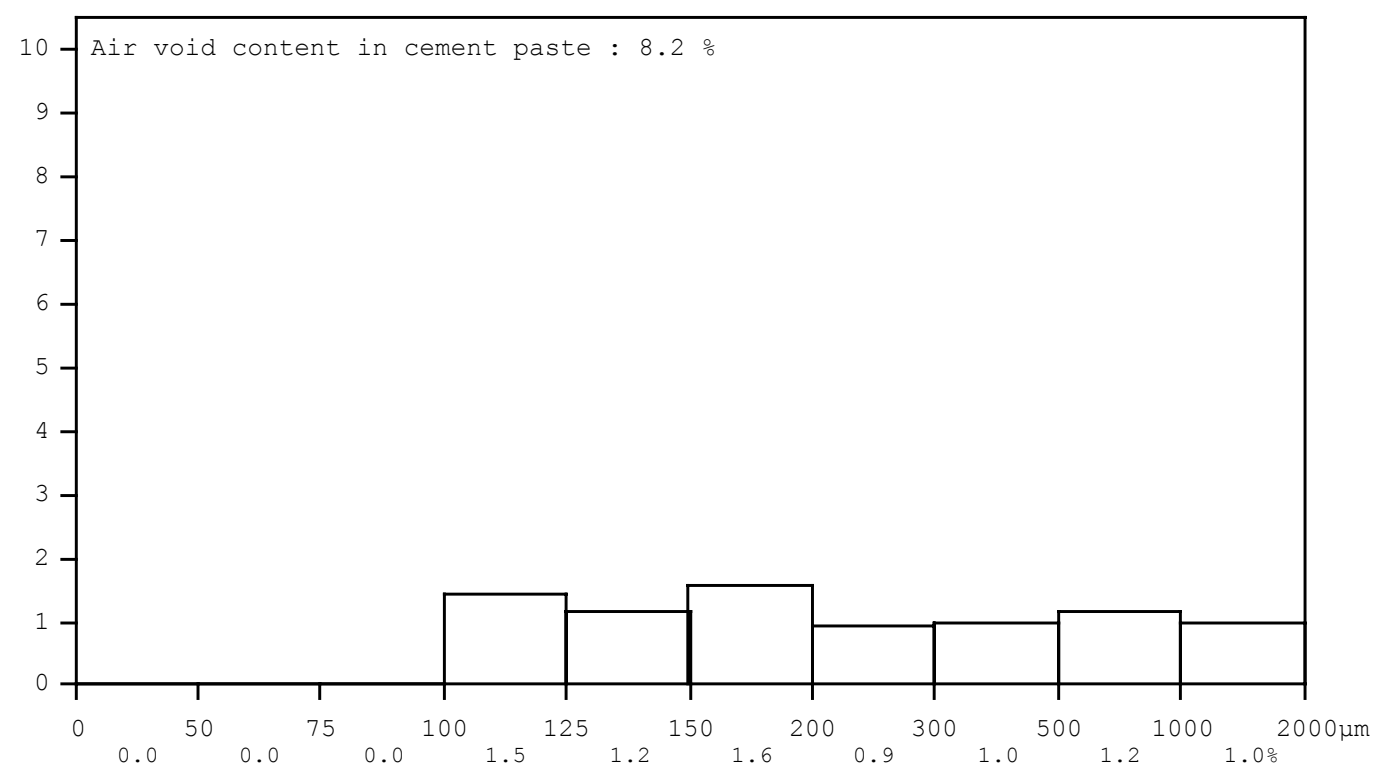


Air Void Analyzer AVA-3000

Type Company name

Measurement of Jul 24, $20086: 25 \mathrm{AM}$

Case number : Jeptha 1 A2

Sample number : 2

Distribution of air void content for voids $<2 \mathrm{~mm}$ (\%)

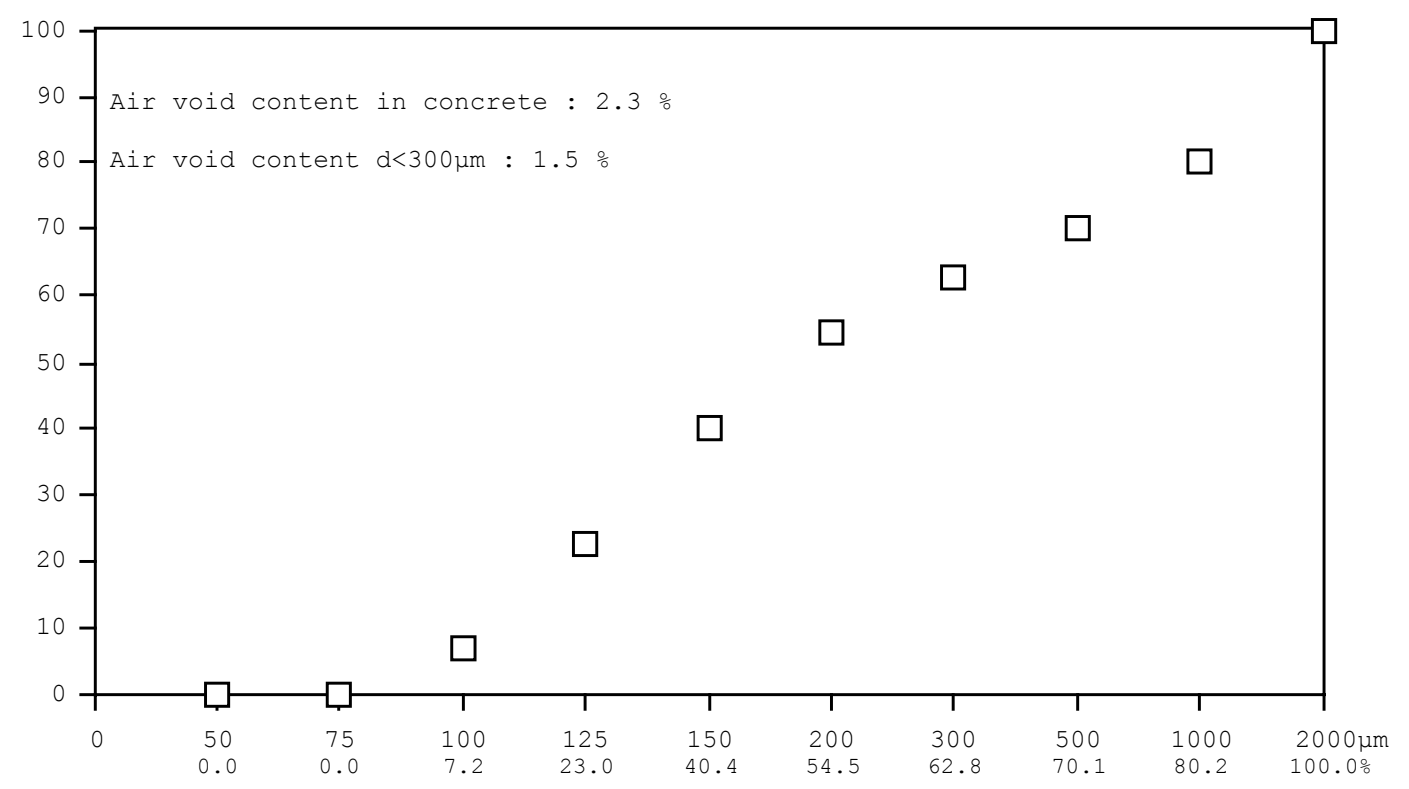

Distribution of air void content in cement paste for voids $<2 \mathrm{~mm}$ (\%)

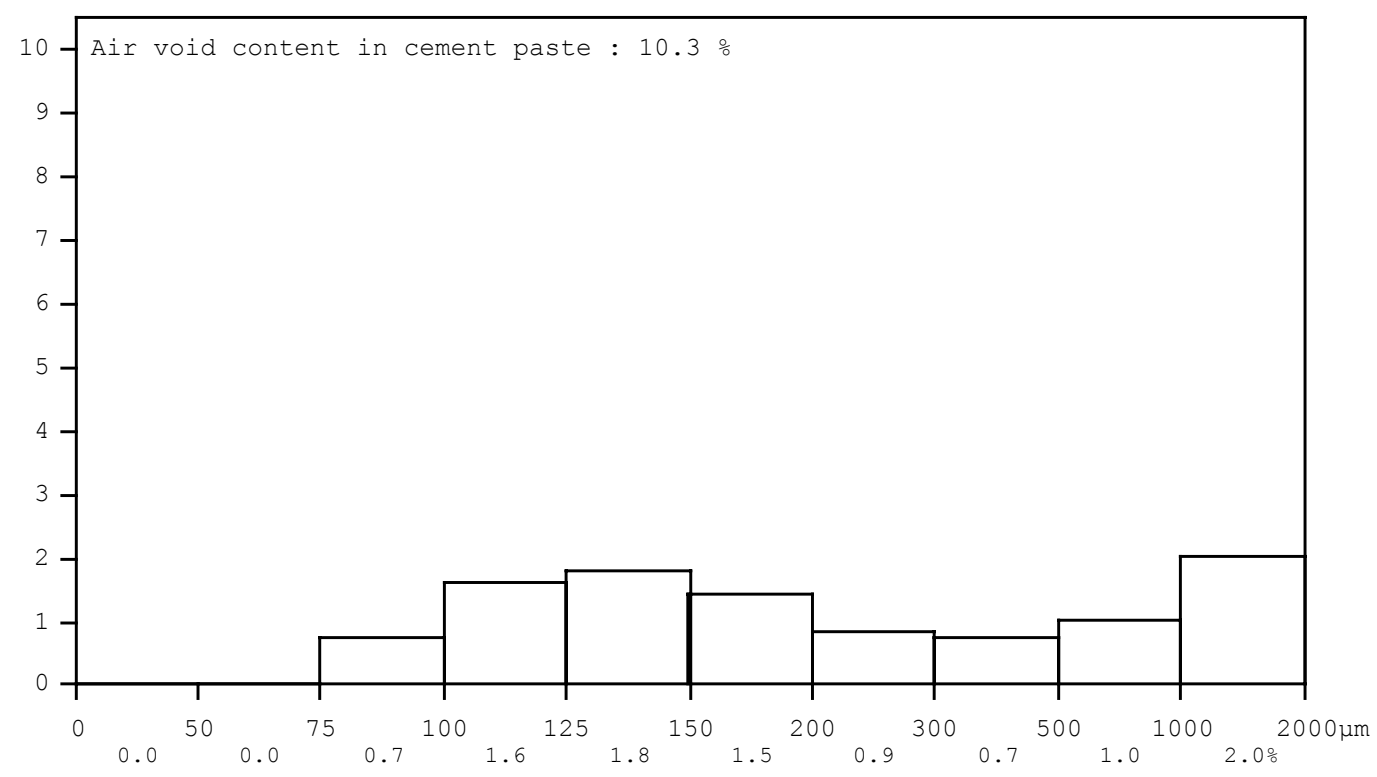


Air Void Analyzer AVA-3000

Type Company name

Measurement of Jul 24, 2008 6:57 AM

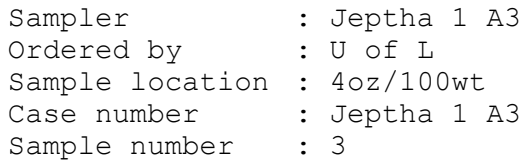

A3

Mortar $<6 \mathrm{~mm}$

Expected air

Paste

Sample volume

$$
\begin{array}{rr}
: & 55.54 \% \\
: & 4.2 \% \\
: & 22.35 \% \\
& 20.0 \mathrm{~cm} 3
\end{array}
$$

\section{Analysis}

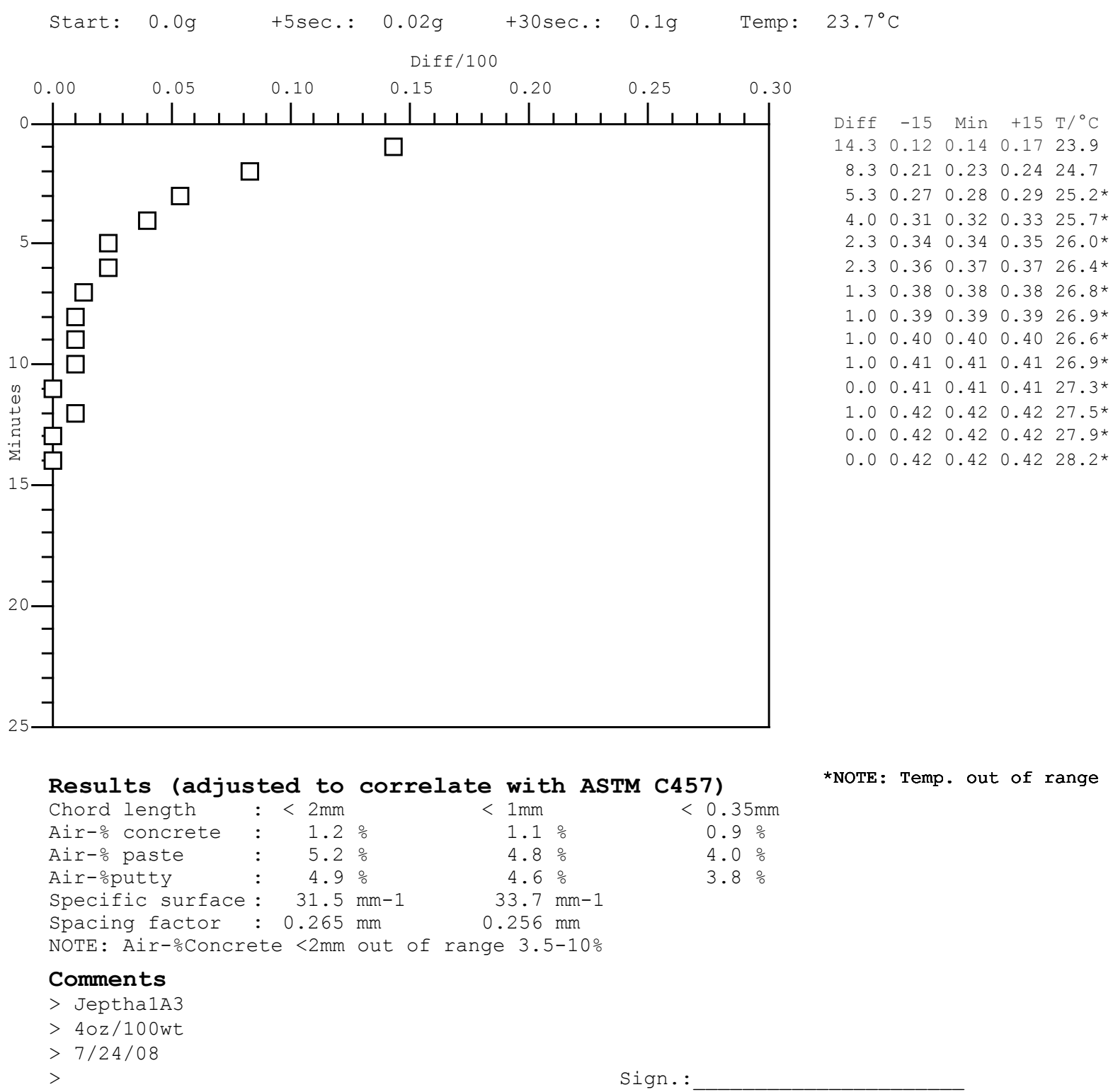


Air Void Analyzer AVA-3000

Type Company name

\section{Measurement of Jul 24, $20086: 57$ AM}

Case number : Jeptha 1 A3

Sample number : 3

Distribution of air void content for voids $<2 \mathrm{~mm}$ (\%)

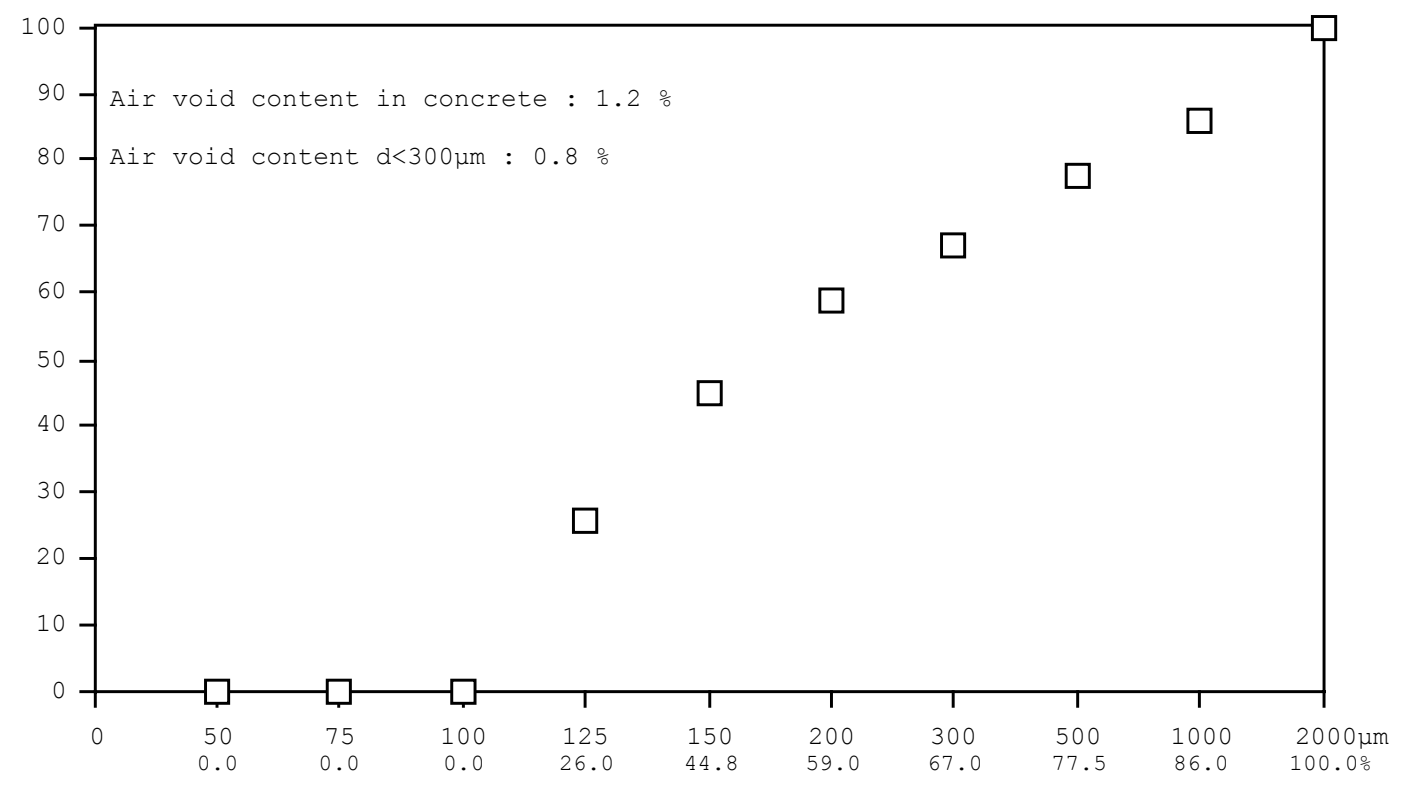

Distribution of air void content in cement paste for voids $<2 \mathrm{~mm}$ (\%)

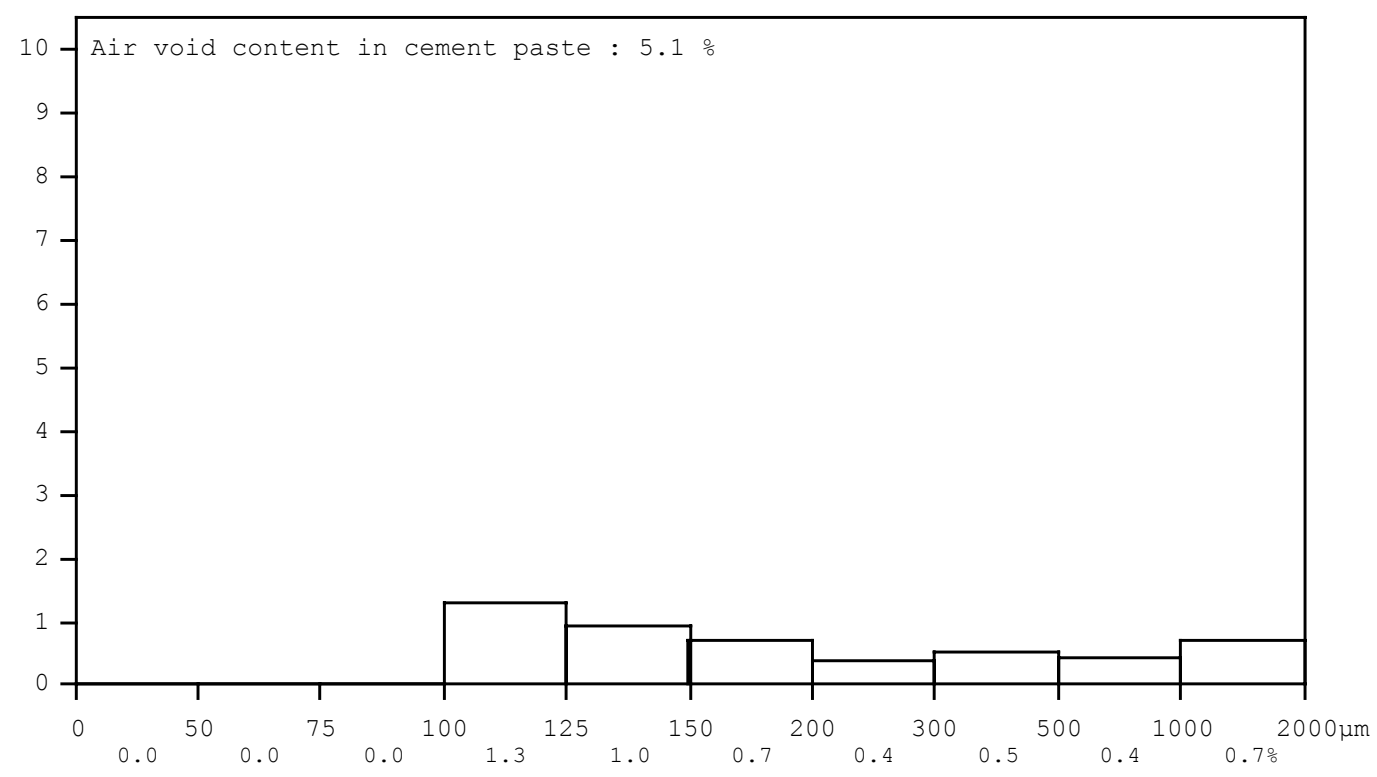


Air Void Analyzer AVA-3000

Type Company name

Measurement of Aug 1, 2008 1:08 AM

$\begin{array}{ll}\text { Sampler } & \text { R-R } 1 \text { A1 } \\ \text { Ordered by } & : \text { davk } \\ \text { Sample location } & : \text { R-R } 1 \text { A1 } \\ \text { Case number } & : 1 \\ \text { Sample number } & : 1\end{array}$

Mortar $<6 \mathrm{~mm} \quad: 52.54 \%$

Expected air : $7.2 \%$

Paste : $22.35 \%$

Sample number : 1

Sample volume : $20.0 \mathrm{~cm} 3$

\section{Analysis}

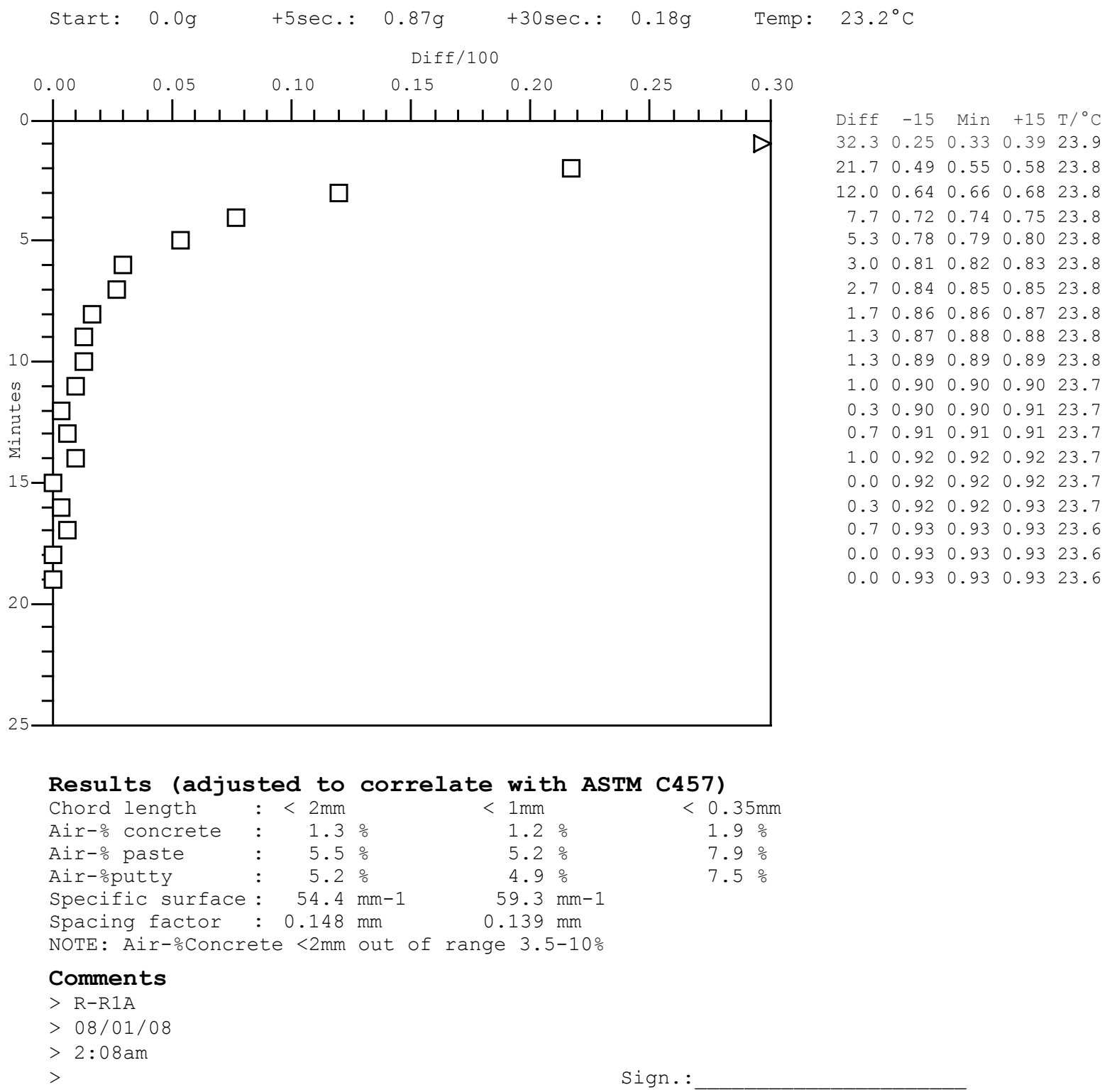


Air Void Analyzer AVA-3000

Type Company name

\section{Measurement of Aug 1, 2008 1:08 AM}

Case number : 1

Sample number : 1

Distribution of air void content for voids $<2 \mathrm{~mm}$ (\%)

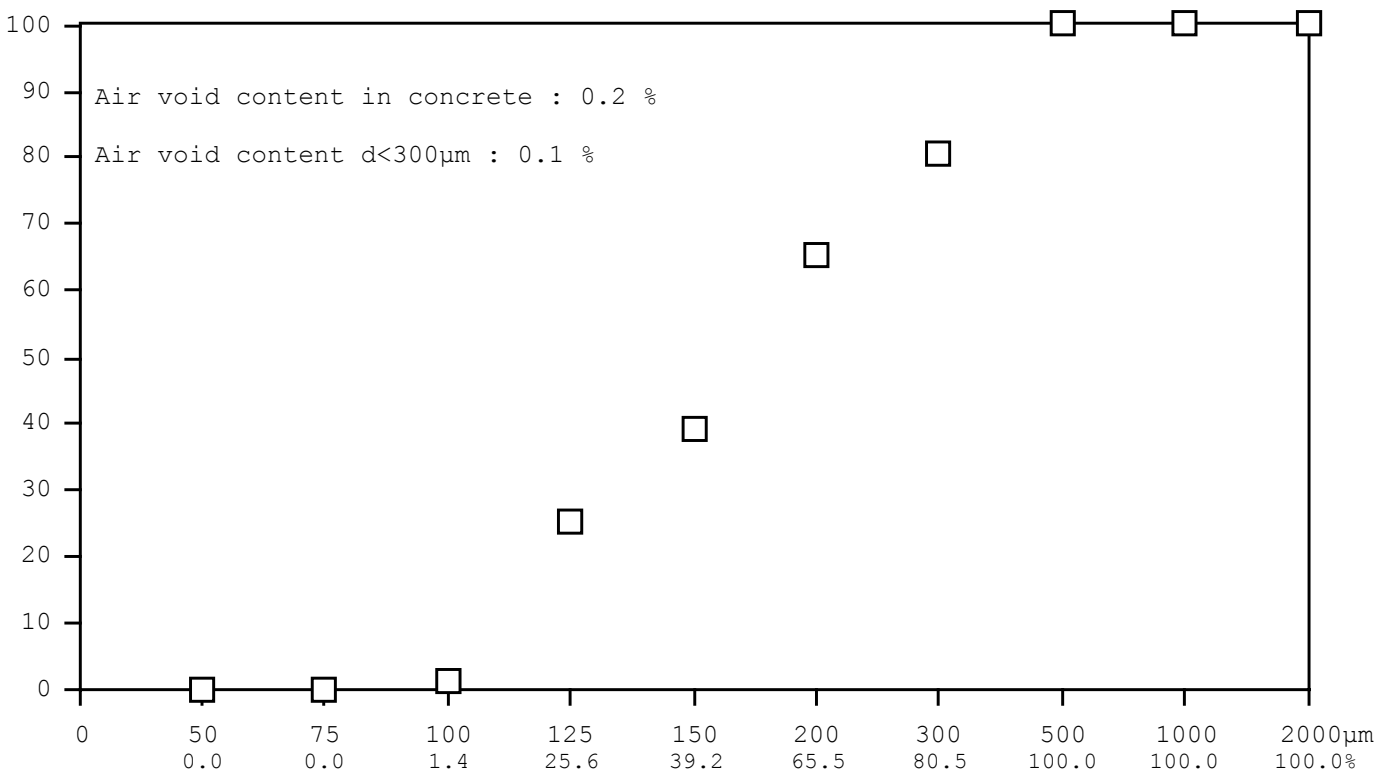

Distribution of air void content in cement paste for voids $2 \mathrm{~mm}$ ( $\%$ )

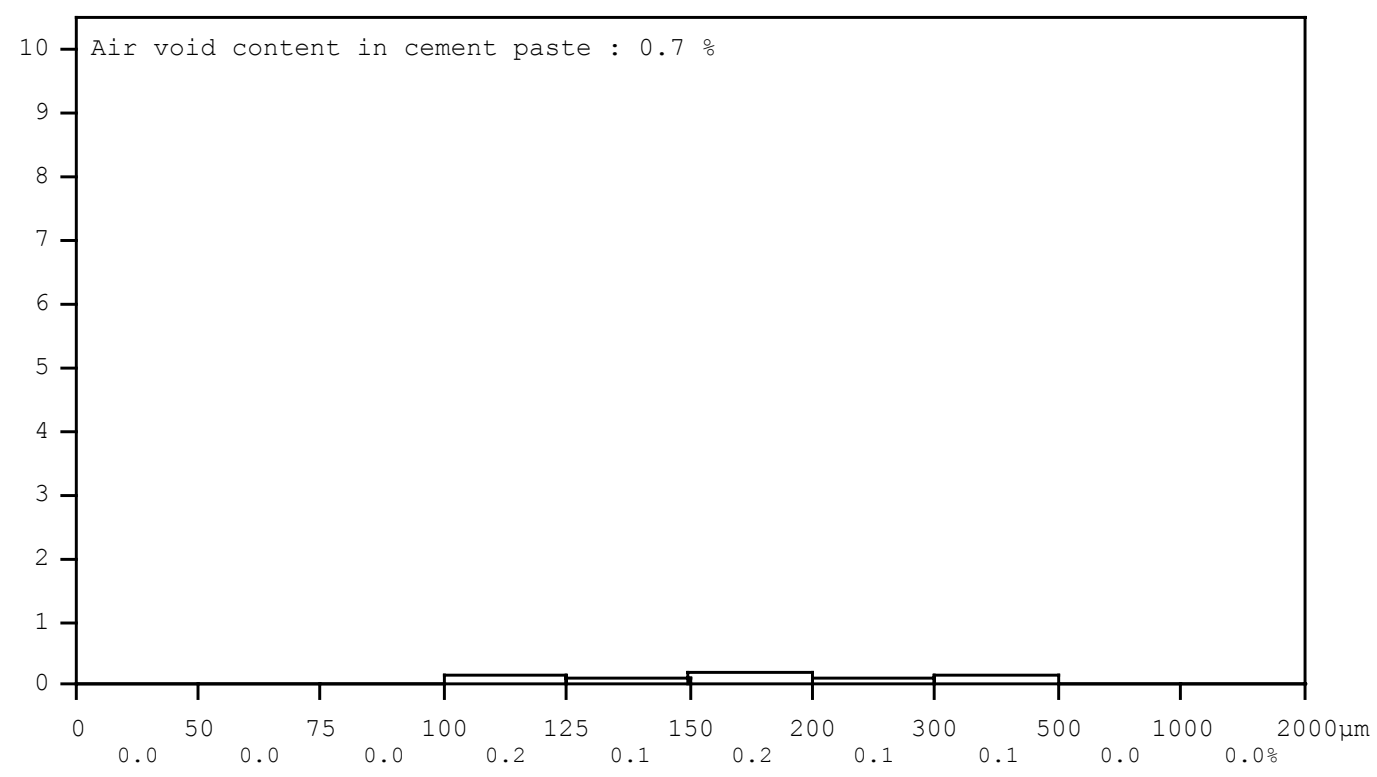


Air Void Analyzer AVA-3000

Type Company name

Measurement of Aug 1, 2008 1:41 AM

$\begin{array}{ll}\text { Sampler } & \text { R-R } 1 \text { A2 } \\ \text { Ordered by } & : \text { davk } \\ \text { Sample location } & : \text { R-R } 1 \text { A2 } \\ \text { Case number } & : 2 \\ \text { Sample number } & : 2\end{array}$

\section{Analysis}

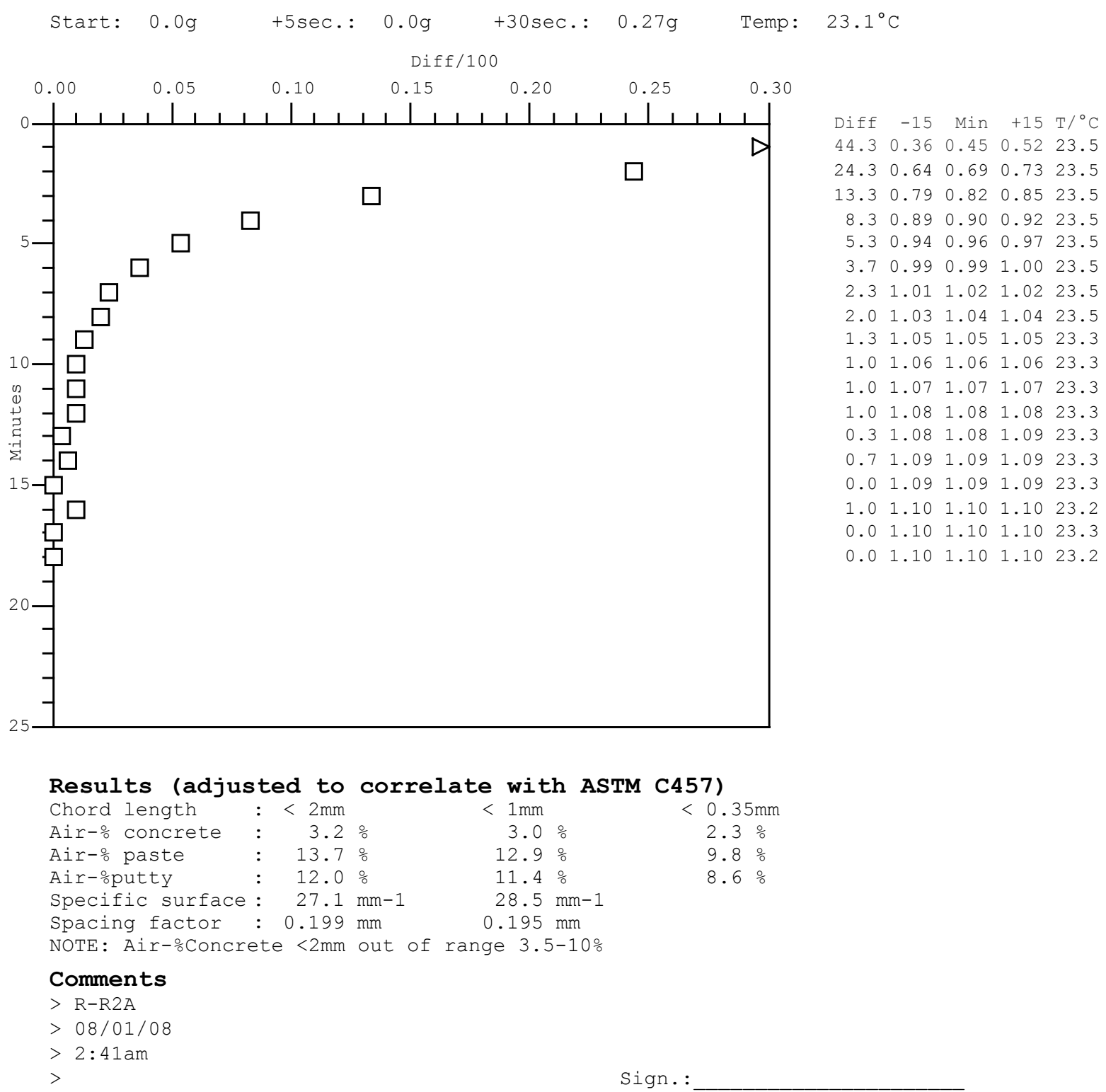


Air Void Analyzer AVA-3000

Type Company name

\section{Measurement of Aug 1, $20081: 41$ AM}

Case number : 2

Sample number : 2

Distribution of air void content for voids $<2 \mathrm{~mm}$ ( $\%$ )

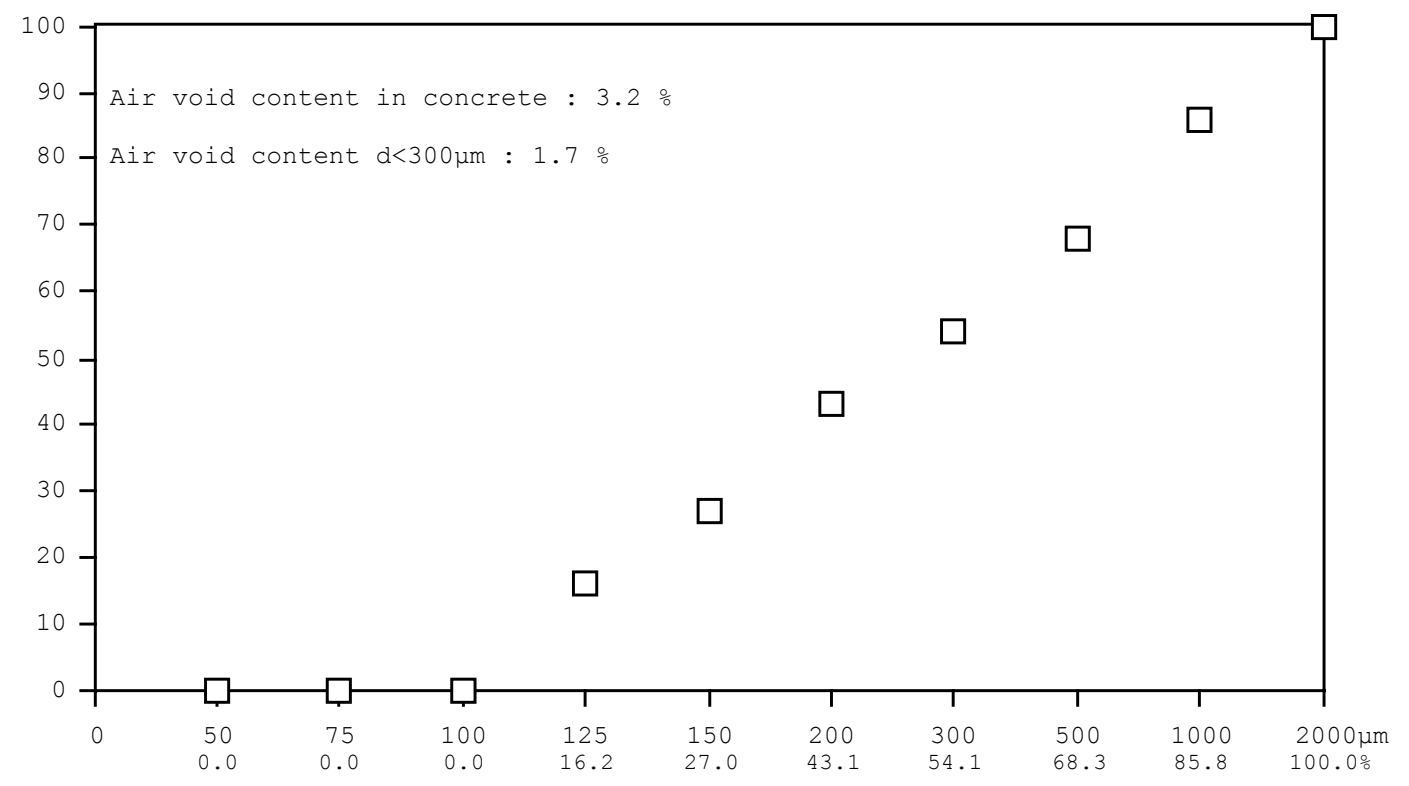

Distribution of air void content in cement paste for voids $<2 \mathrm{~mm}$ (\%)

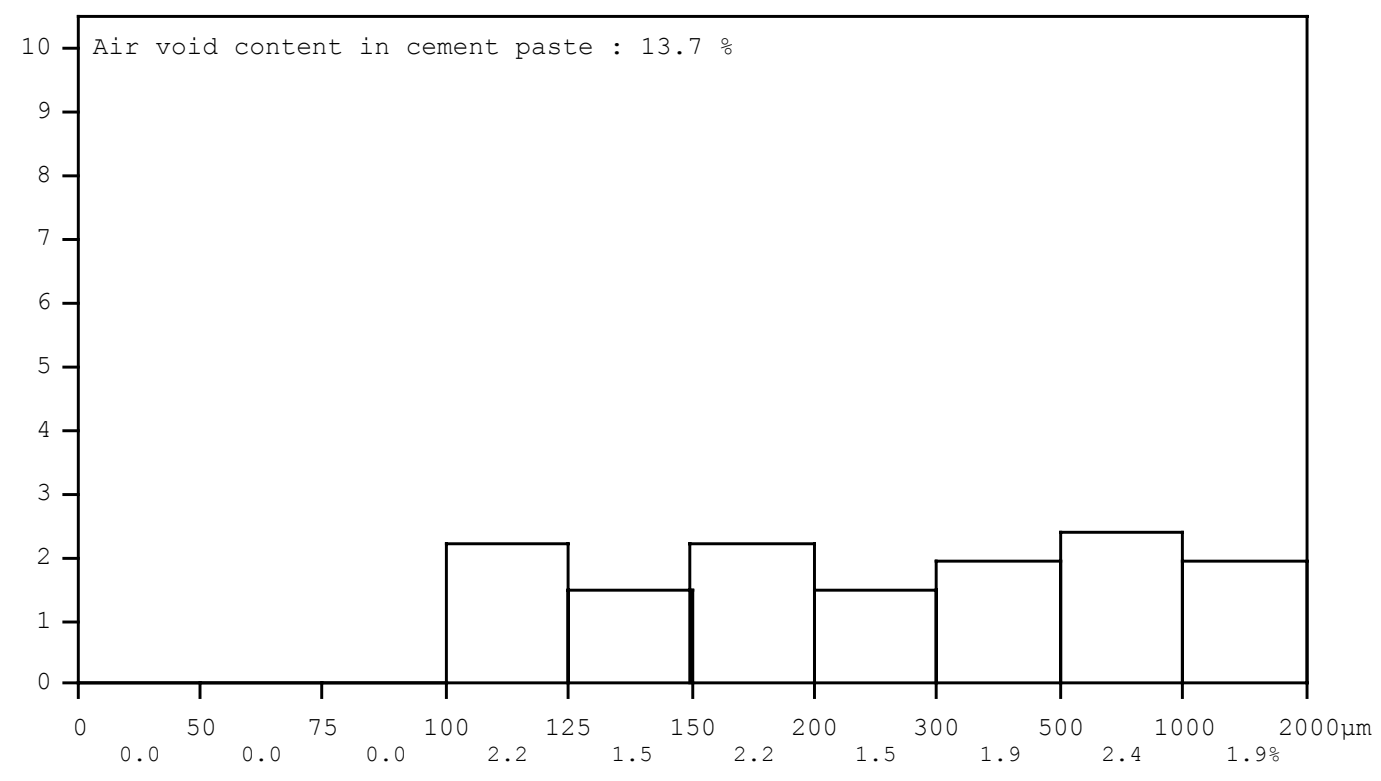


Air Void Analyzer AVA-3000

Type Company name

Measurement of Aug 1, 2008 2:09 AM

$\begin{array}{ll}\text { Sampler } & \text { R-R } 1 \text { A3 } \\ \text { Ordered by } & : \text { davk } \\ \text { Sample location } & : \text { R-R } 1 \text { A3 } \\ \text { Case number } & : 3 \\ \text { Sample number } & : 3\end{array}$

Mortar $<6 \mathrm{~mm} \quad: 52.54 \%$

Expected air : $7.2 \%$

Paste : $22.35 \%$

Sample number : 3

Sample volume : $20.0 \mathrm{~cm} 3$

\section{Analysis}

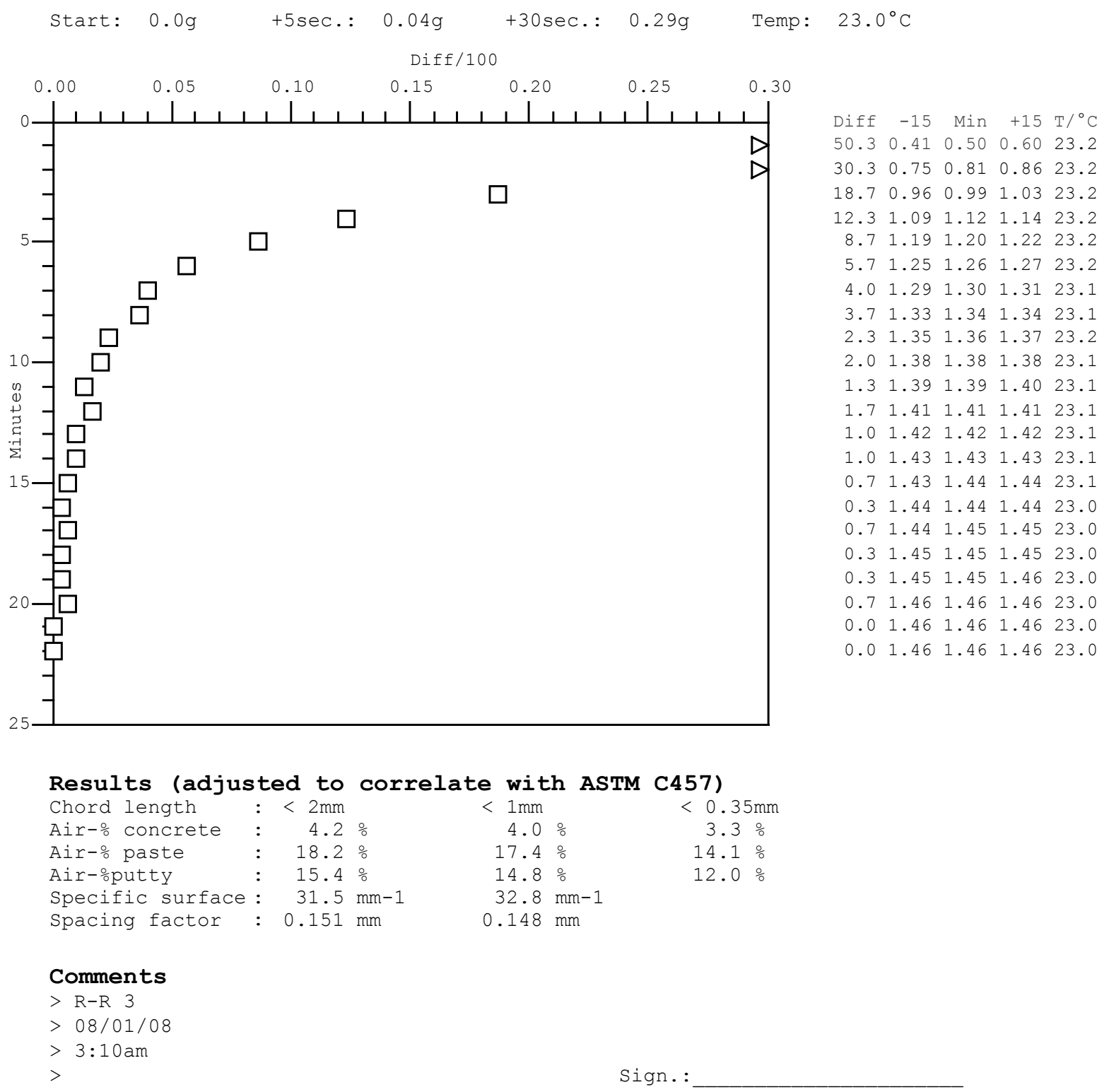


Air Void Analyzer AVA-3000

Type Company name

\section{Measurement of Aug 1, 2008 2:09 AM}

Case number : 3

Sample number : 3

Distribution of air void content for voids $<2 \mathrm{~mm}$ (\%)

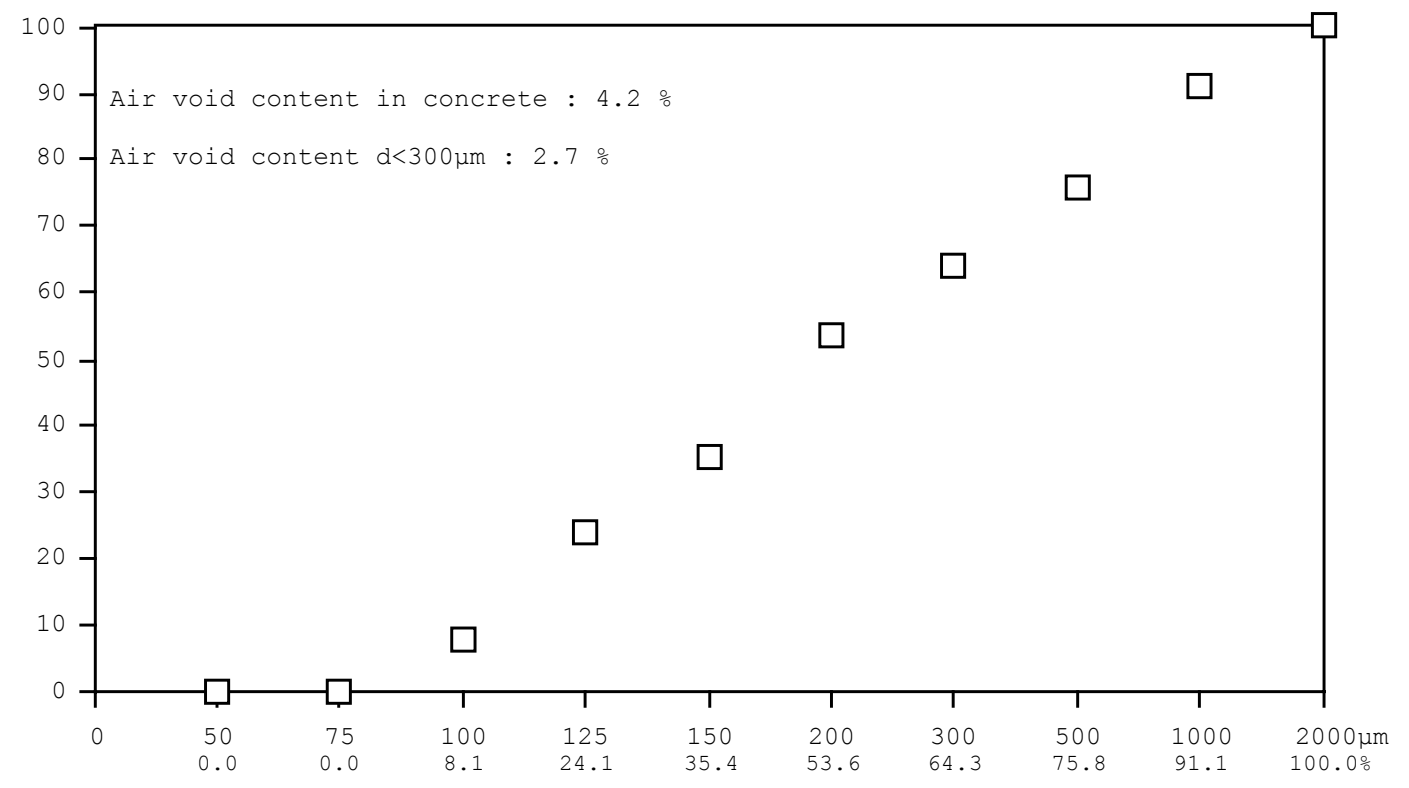

Distribution of air void content in cement paste for voids $<2 \mathrm{~mm}$ (\%)

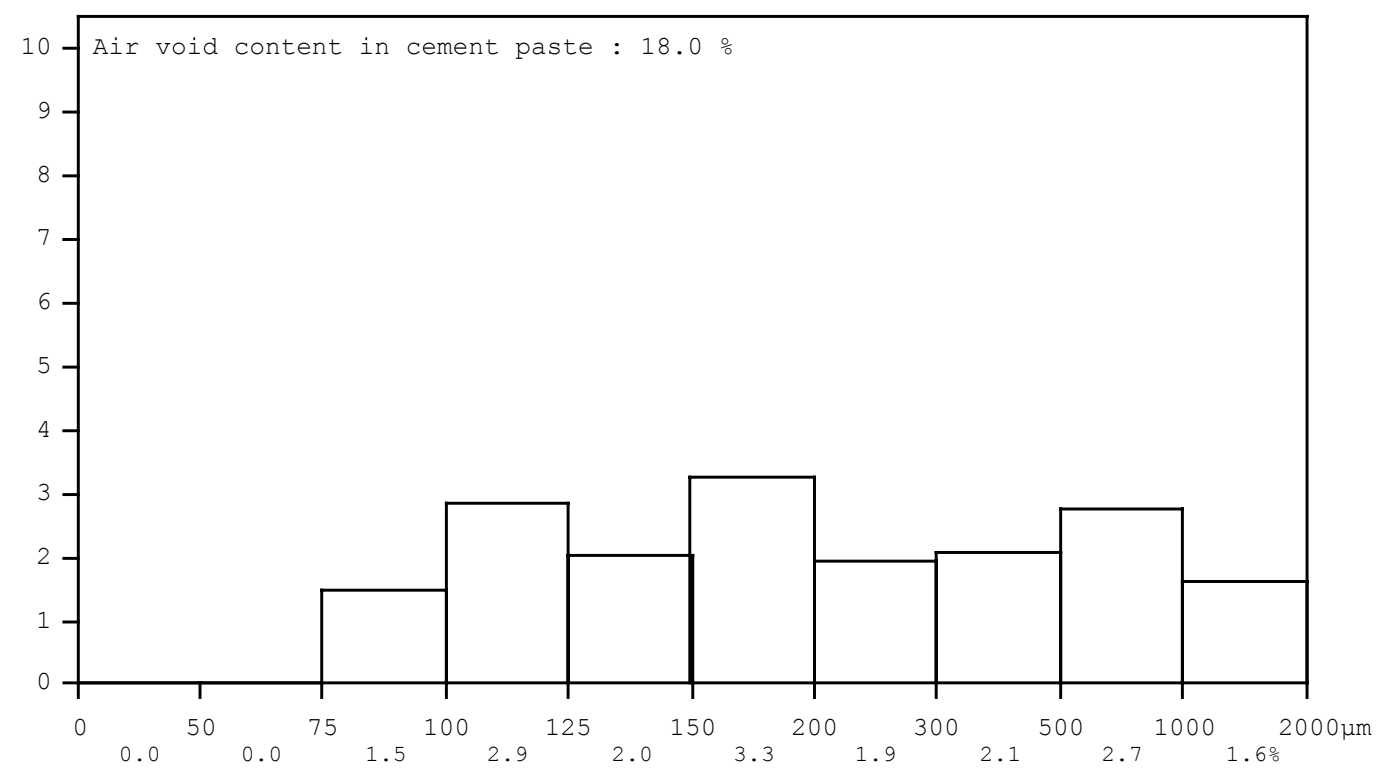


Air Void Analyzer AVA-3000

Type Company name

Measurement of Sep 17, 2008 12:15 AM

Sampler

: KY 395 A1

Sample location : KY 395 Al

Case number : 1

Sample number : 1

$\begin{array}{llrl}\text { Mortar<6mm } & : & 55.54 \% \\ \text { Expected air } & : & 4.2 \% \\ \text { Paste } & : & 22.35 \% \\ \text { Sample volume } & : & 20.0 \mathrm{~cm} 3\end{array}$

\section{Analysis}

Start: $0.0 \mathrm{~g}$

+5 sec.: $0.25 \mathrm{~g}$

+30 sec.:

0.39

Temp:

$21.6^{\circ} \mathrm{C}$

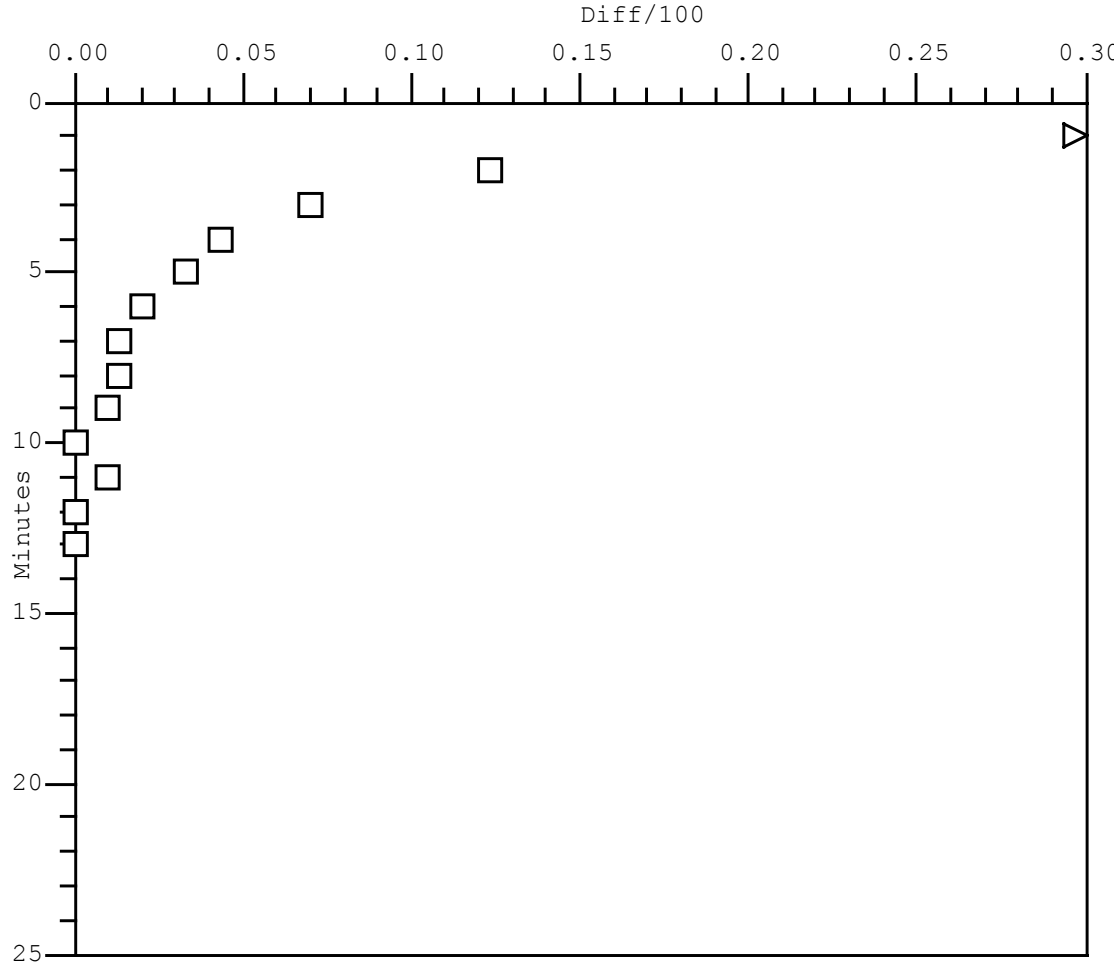

Diff -15 Min $+15 \mathrm{~T} /{ }^{\circ} \mathrm{C}$

$\begin{array}{llllll}38.3 & 0.34 & 0.39 & 0.42 & 22.4\end{array}$

$\begin{array}{llllll}12.3 & 0.49 & 0.50 & 0.53 & 22.2\end{array}$

$\begin{array}{llllll}7.0 & 0.56 & 0.58 & 0.59 & 22.1\end{array}$

$\begin{array}{llllll}4.3 & 0.61 & 0.62 & 0.63 & 22.0\end{array}$

$\begin{array}{llllll}3.3 & 0.65 & 0.65 & 0.66 & 22.0\end{array}$

$\begin{array}{lllll}2.0 & 0.67 & 0.67 & 0.68 & 21.9\end{array}$

$\begin{array}{llllll}1.3 & 0.68 & 0.69 & 0.69 & 21.9\end{array}$

$\begin{array}{llllll}1.3 & 0.70 & 0.70 & 0.70 & 21.9\end{array}$

$\begin{array}{llllll}1.0 & 0.71 & 0.71 & 0.71 & 21.7\end{array}$

$\begin{array}{lllll}0.0 & 0.71 & 0.71 & 0.71 & 21.6\end{array}$

$\begin{array}{llllll}1.0 & 0.72 & 0.72 & 0.72 & 21.6\end{array}$

$\begin{array}{lllll}0.0 & 0.72 & 0.72 & 0.72 & 21.5\end{array}$

$\begin{array}{llllll}0.0 & 0.72 & 0.72 & 0.72 & 21.5\end{array}$

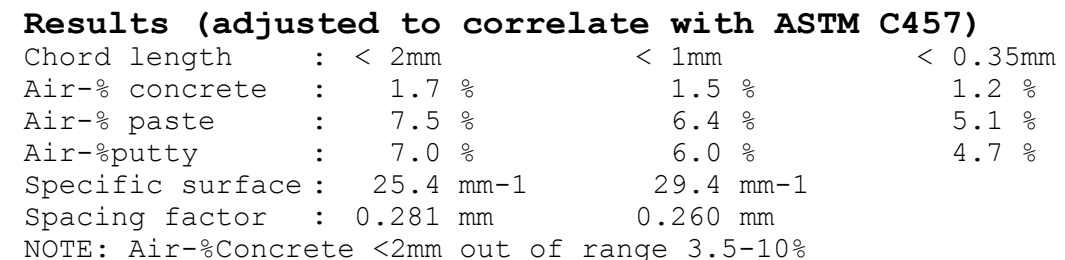

NOTE: Air-\%Concrete $<2 \mathrm{~mm}$ out of range $3.5-10 \%$

\section{Comments}

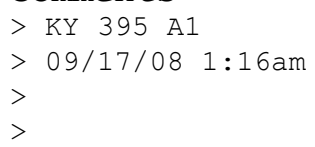

Sign. : 
Air Void Analyzer AVA-3000

Type Company name

\section{Measurement of Sep 17, 2008 12:15 AM}

Case number : 1

Sample number : 1

Distribution of air void content for voids $<2 \mathrm{~mm}$ (\%)

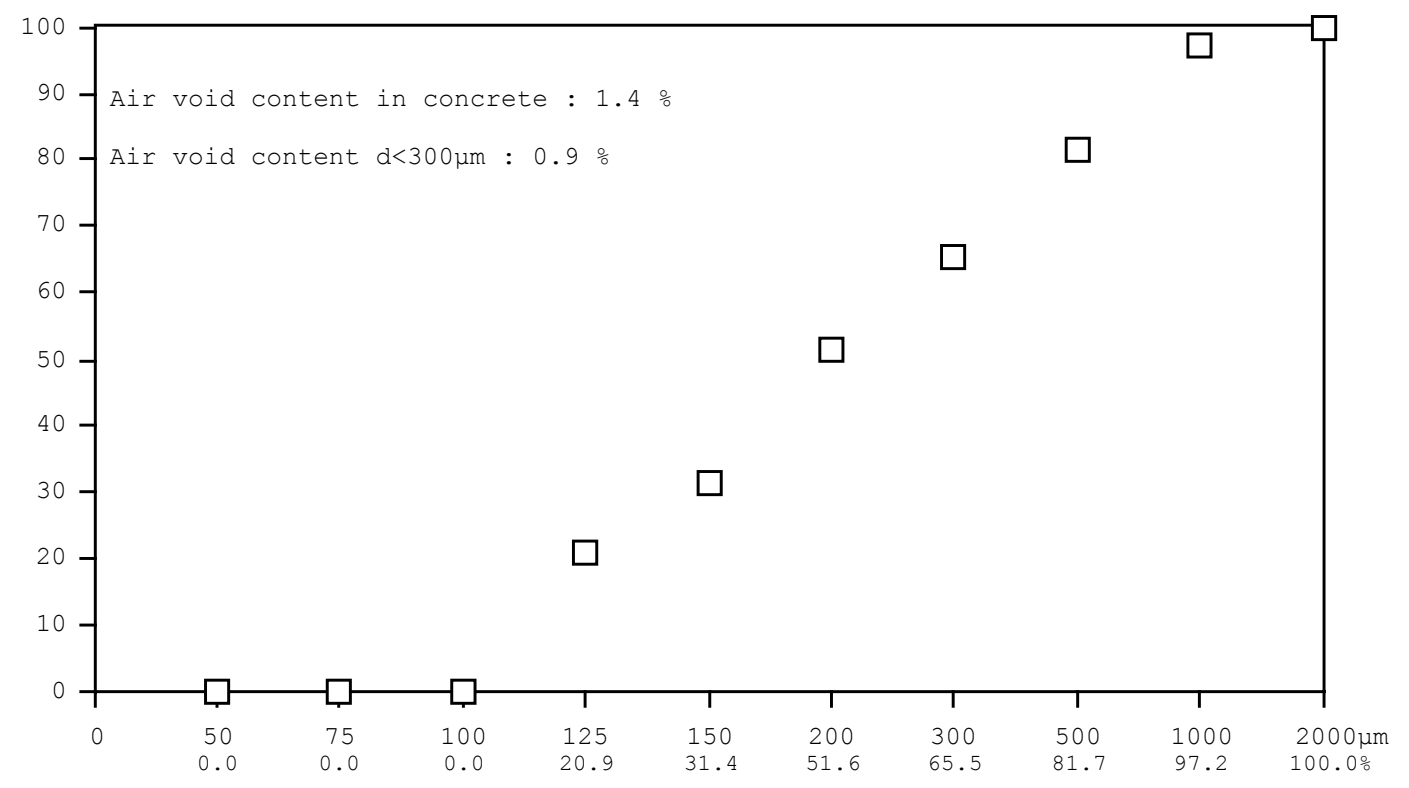

Distribution of air void content in cement paste for voids $2 \mathrm{~mm}$ ( $\%$ )

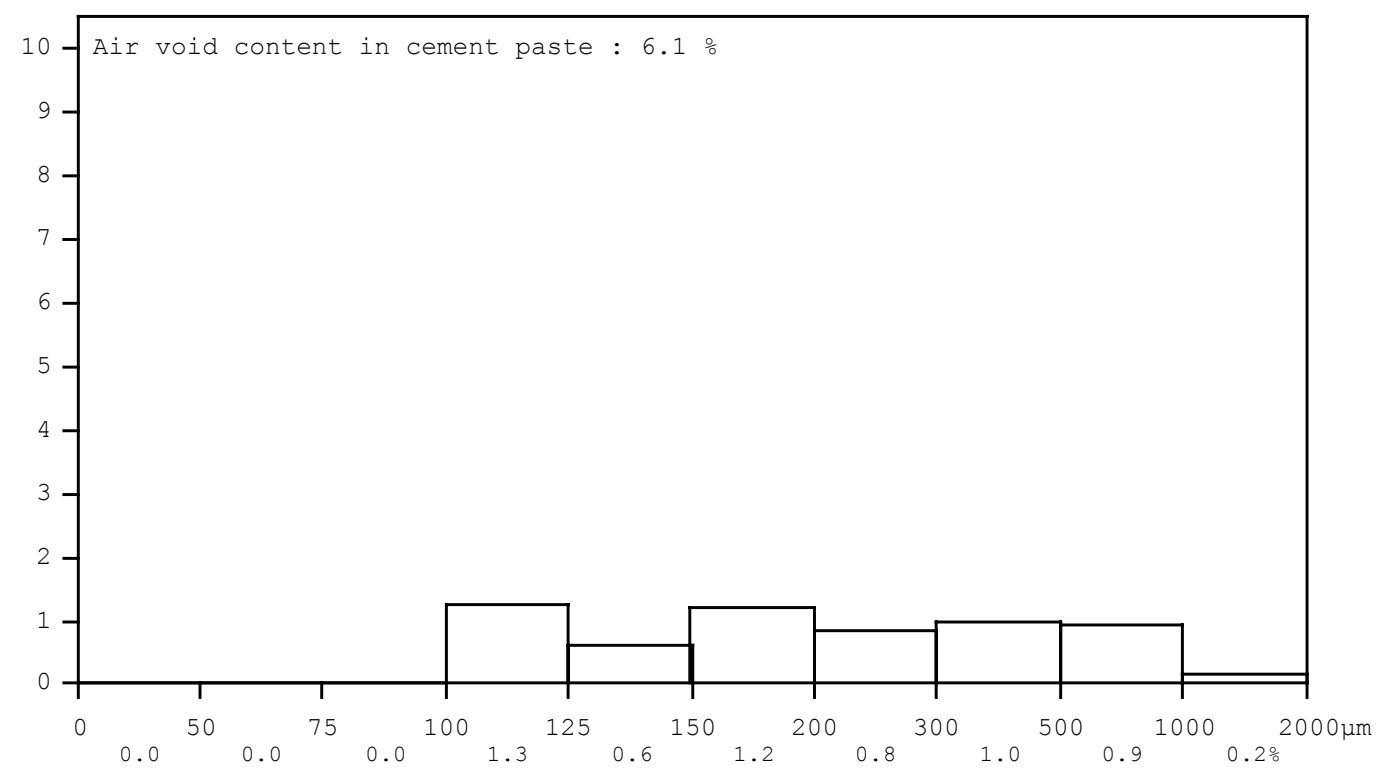


Air Void Analyzer AVA-3000

Type Company name

Measurement of Sep 17, 2008 12:52 AM

Sampler

: KY 395 A2

Sample location : KY 395 A2

Case number : 2

Sample number : 2

$\begin{array}{llr}\text { Mortar<6mm } & : 55.54 \% \\ \text { Expected air } & : & 4.2 \% \\ \text { Paste } & : 22.35 \% \\ \text { Sample volume } & : & 20.0 \mathrm{~cm} 3\end{array}$

Analysis

Start: $0.0 \mathrm{~g}$

+5 sec.: $0.0 \mathrm{~g} \quad+30 \mathrm{sec} .:$

$0.21 \mathrm{~g}$

Temp:

$21.0^{\circ} \mathrm{C}$

Diff/100

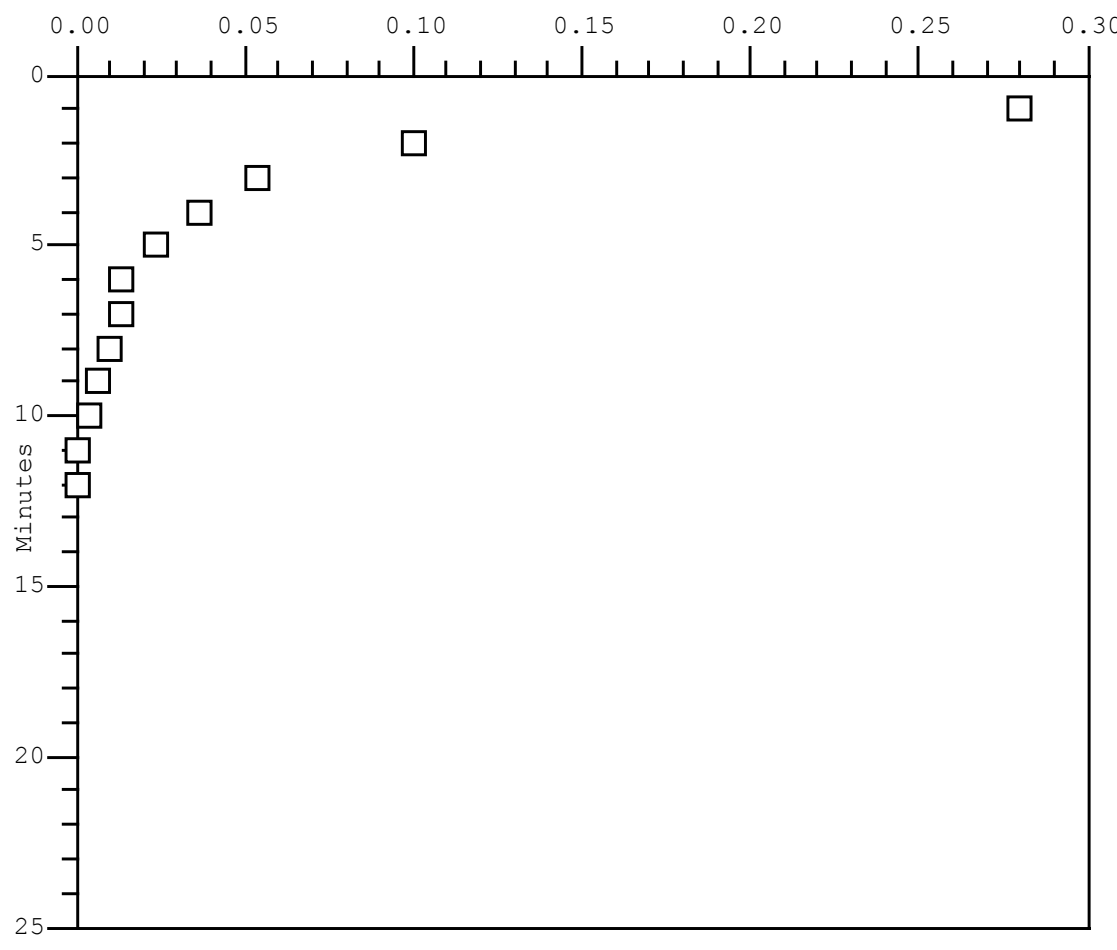

Diff $-15 \mathrm{Min}+15 \mathrm{~T} /{ }^{\circ} \mathrm{C}$

$\begin{array}{lllllll}28.0 & 0.25 & 0.28 & 0.31 & 21.0\end{array}$

$\begin{array}{llllll}10.0 & 0.36 & 0.38 & 0.40 & 21.1\end{array}$

$\begin{array}{llllll}5.3 & 0.42 & 0.44 & 0.44 & 21.5\end{array}$

$\begin{array}{llllll}3.7 & 0.46 & 0.47 & 0.48 & 21.4\end{array}$

$\begin{array}{llllll}2.3 & 0.49 & 0.49 & 0.50 & 21.2\end{array}$

$\begin{array}{lllll}1.3 & 0.50 & 0.51 & 0.51 & 21.7\end{array}$

$\begin{array}{lllll}1.3 & 0.52 & 0.52 & 0.52 & 21.6\end{array}$

$\begin{array}{lllll}1.0 & 0.53 & 0.53 & 0.53 & 21.5\end{array}$

$\begin{array}{llllll}0.7 & 0.53 & 0.54 & 0.54 & 21.4\end{array}$

$\begin{array}{llllll}0.3 & 0.54 & 0.54 & 0.54 & 21.2\end{array}$

$\begin{array}{llllll}0.0 & 0.54 & 0.54 & 0.54 & 21.4\end{array}$

$\begin{array}{llllll}0.0 & 0.54 & 0.54 & 0.54 & 22.2\end{array}$

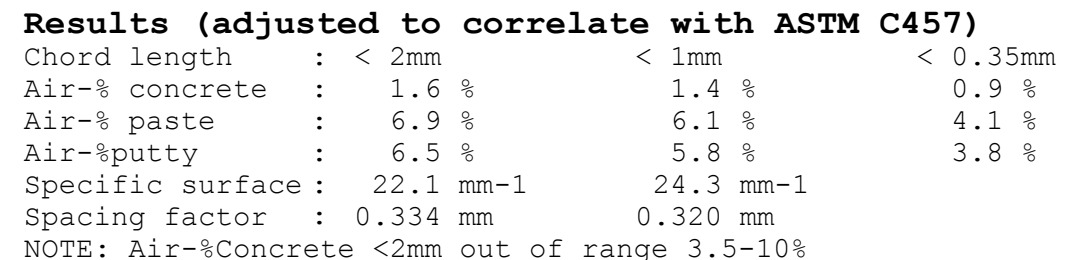

NOTE: Air-\%Concrete <2mm out of range 3.5-10\%

\section{Comments}

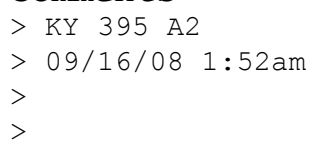

Sign. : 
Air Void Analyzer AVA-3000

Type Company name

\section{Measurement of Sep 17, 2008 12:52 AM}

Case number : 2

Sample number : 2

Distribution of air void content for voids $<2 \mathrm{~mm}$ (\%)

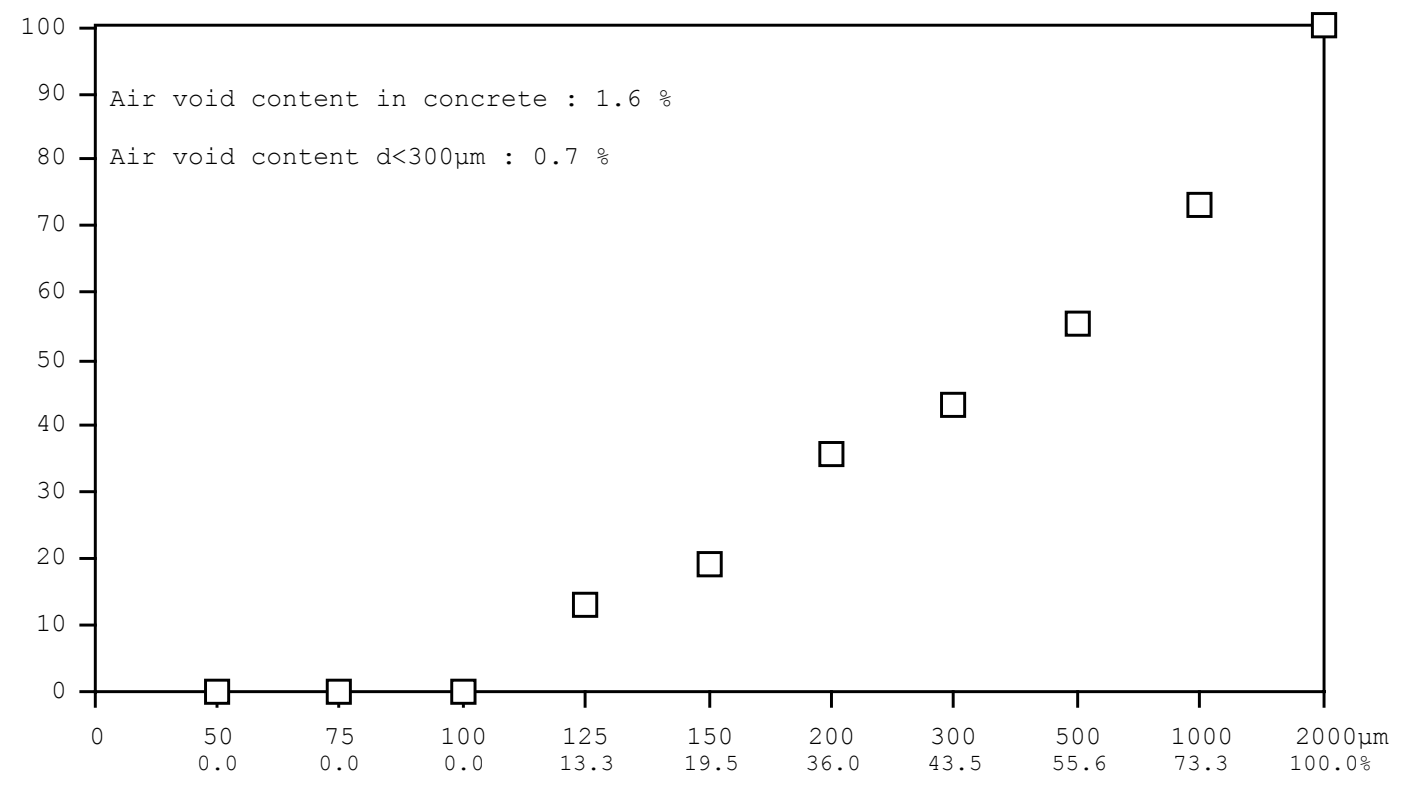

Distribution of air void content in cement paste for voids $2 \mathrm{~mm}$ ( $\%$ )

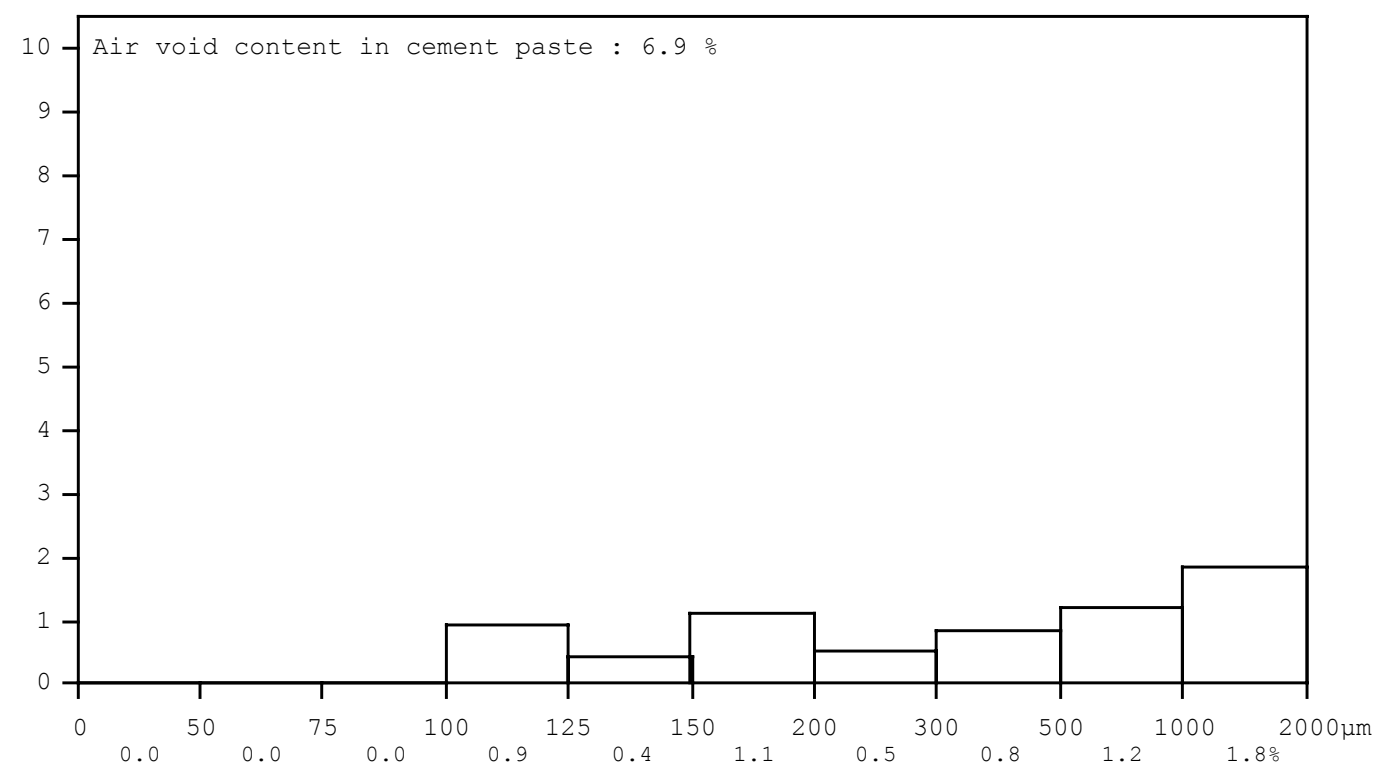


Air Void Analyzer AVA-3000

Type Company name

Measurement of Sep 17, 2008 1:15 AM

$\begin{array}{ll}\text { Sampler } & : \text { KY } 395 \text { A3 } \\ \text { Ordered by } & : \text { davk } \\ \text { Sample location } & : \text { KY } 395 \text { A3 } \\ \text { Case number } & : 3 \\ \text { Sample number } & : 3\end{array}$

Analysis

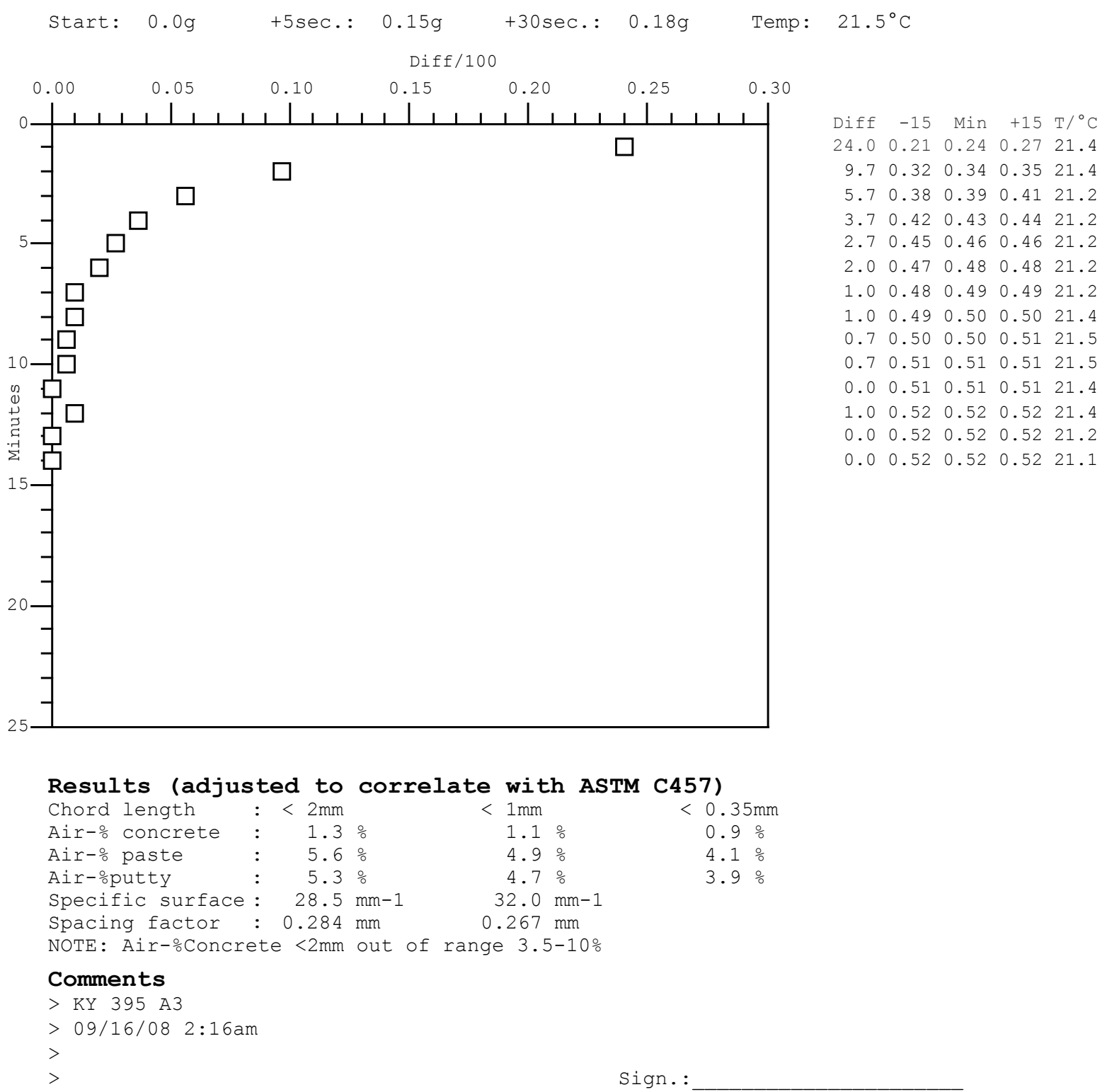


Air Void Analyzer AVA-3000

Type Company name

\section{Measurement of Sep 17, $20081: 15$ AM}

Case number : 3

Sample number : 3

Distribution of air void content for voids $<2 \mathrm{~mm}$ (\%)

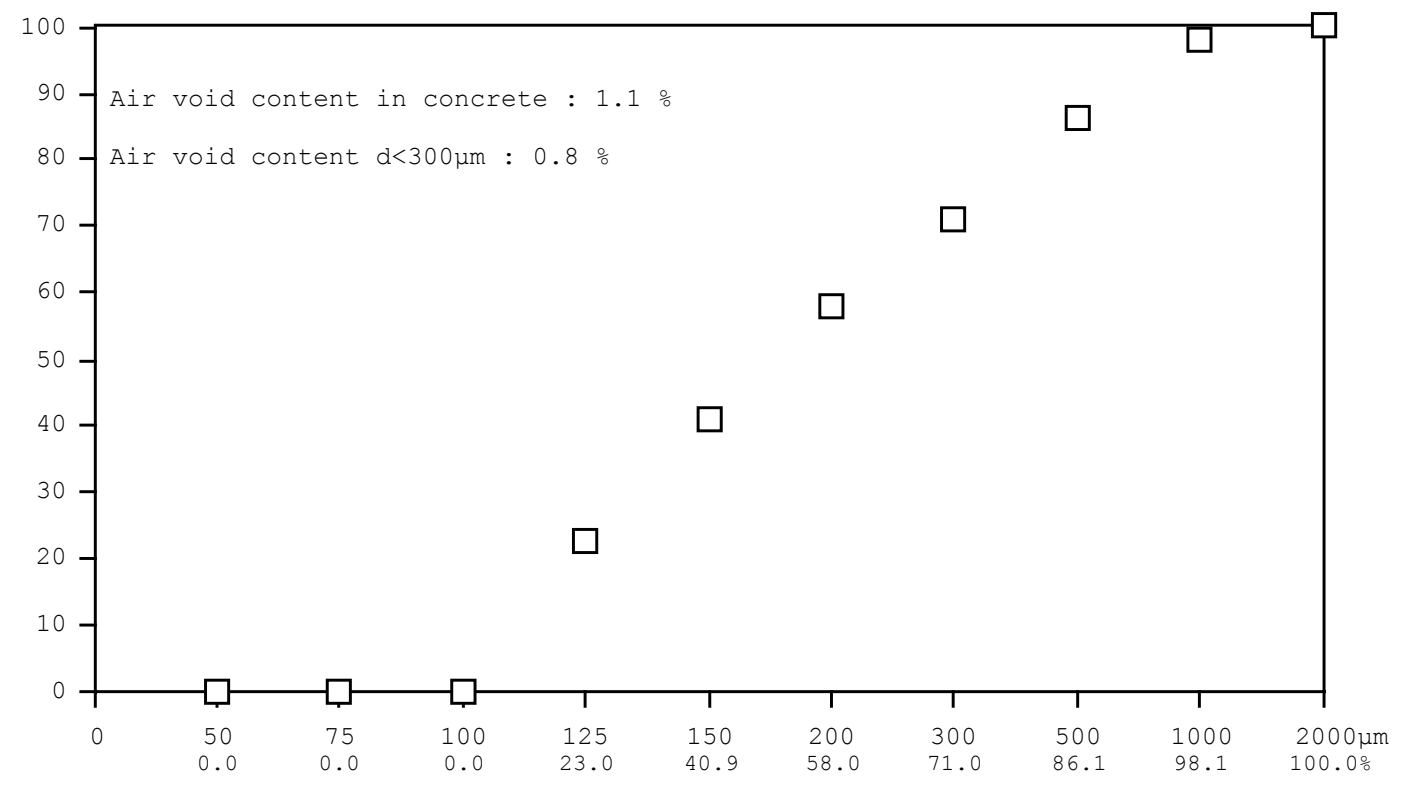

Distribution of air void content in cement paste for voids $2 \mathrm{~mm}$ ( $\%$ )

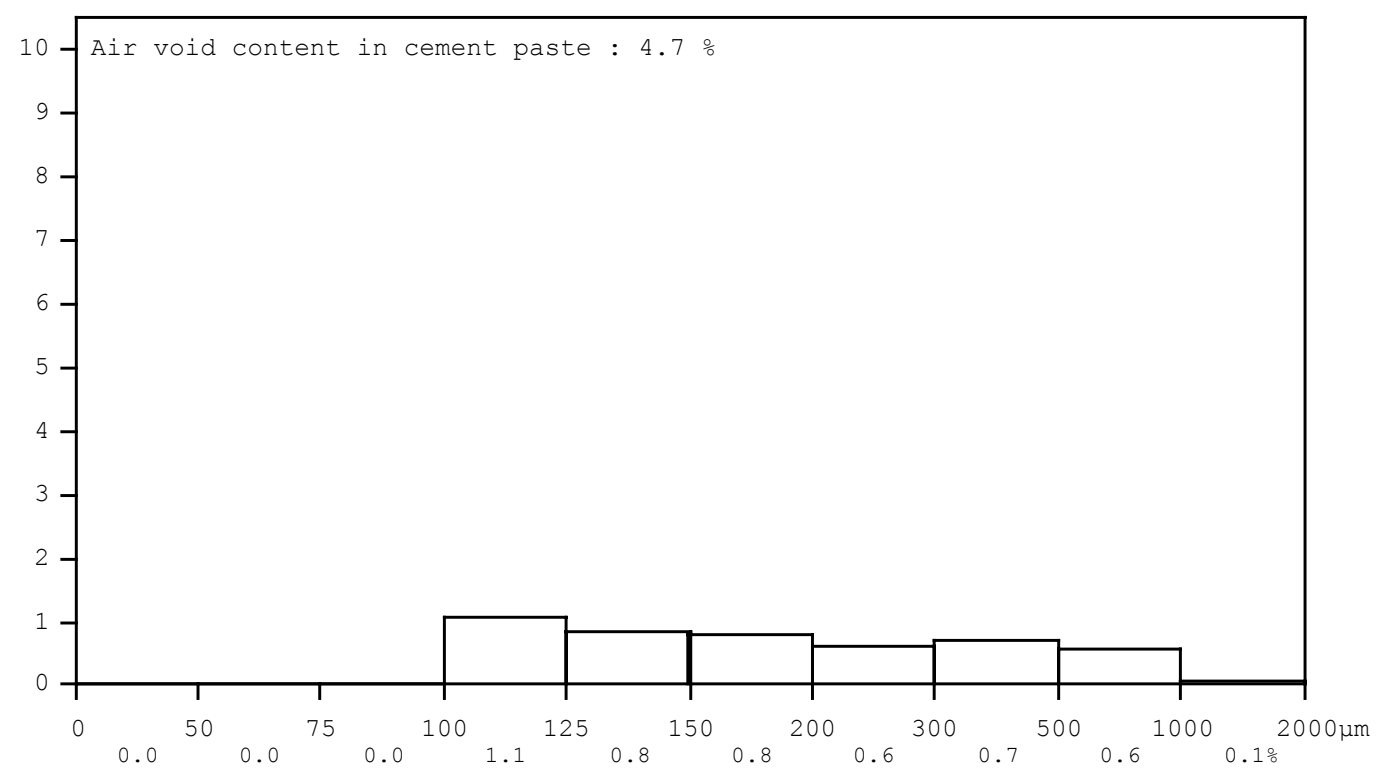


VITA

David (Dav) Todd Kessinger was born on November 18, 1971 in Louisville, Kentucky. He graduated from Bullitt Central High School in Shepherdsville, Kentucky in June of 1989. David entered Speed Scientific School in August of 2000. In May of 2007, he received a bachelor's degree in Civil Engineering. David has worked for the Kentucky Department of Transportation since 1992. Upon graduation he will continue to work for the Kentucky Department of Transportation with his office located in Louisville, Kentucky. 